\title{
A LABORATORY STUDY OF THE DEGRADATION OF AGGREGATES IN BITUMINOUS MIXES
}

JULY 1962
NO. 17
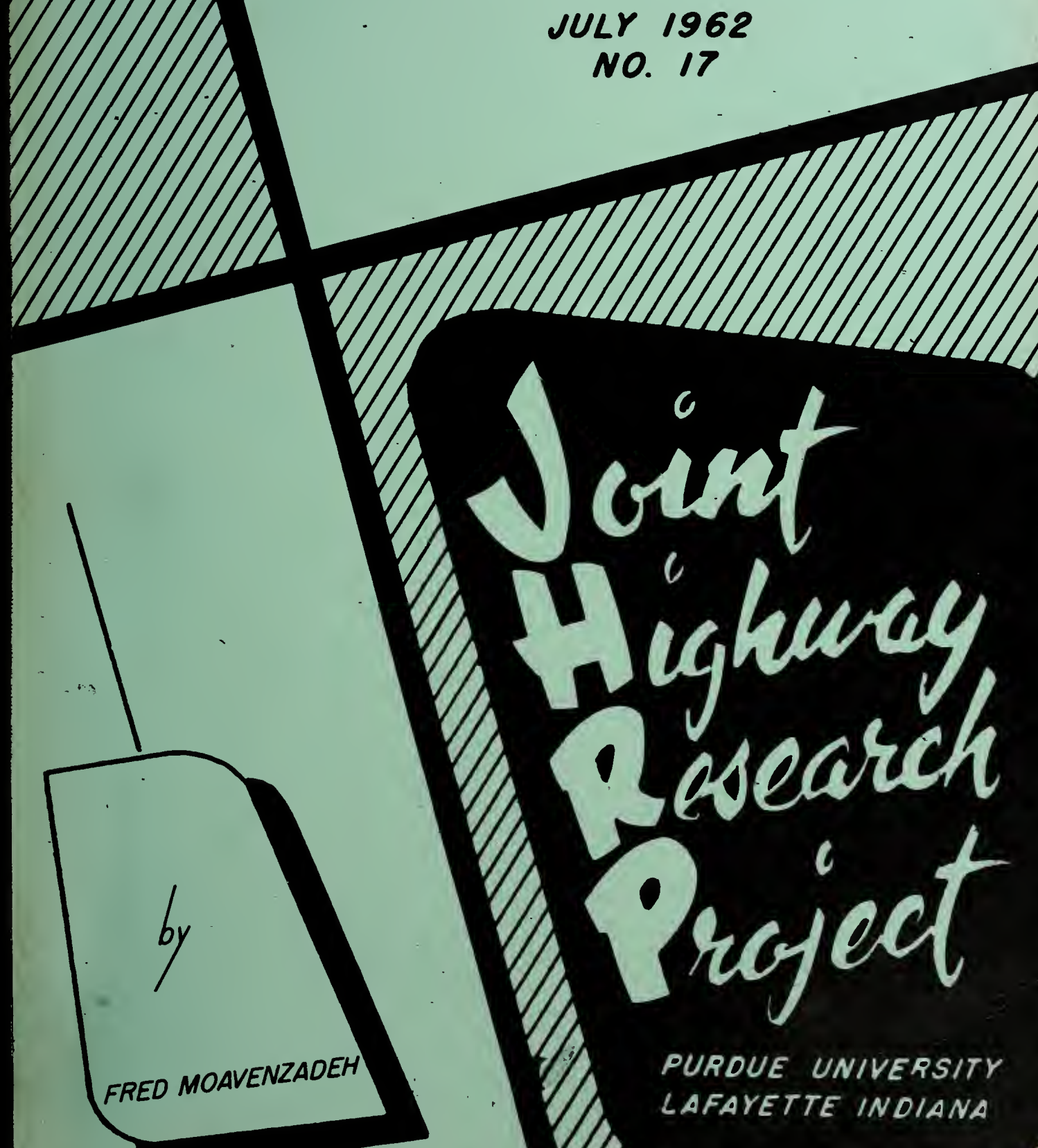



\section{Final. Report}

A LABORATORY STUOY OF THE DECRADATITON OF AGGREGAMTES

IN BTITIMTNOUS MIXTS

TO: K. B. Woods, Director

Joint Highway Reseerch Froject

July 13, 1962

FrROM: H. I. Michael, Associate Director

Joint Highwey Research Project

Fine: $2-8-3$

Project: C-36-27C

A final report entitled "A Ieboratory Study of the Degradation of Aggregates in Biturninous $\mathrm{Blilxes"} \mathrm{by} \mathrm{Mr.} \mathrm{Fred} \mathrm{Moevenzadel,} \mathrm{graduate}$ assistant on our stafy, is attached. The rescarch reported was pexformed by Ir. Moavenzadeh as his thesis for the Ph.D. degree.

The research utslized the gyratory testing mabine to investigate the effect of leind of aggregates, gradation of aggregates compactive effort and amount of asphalt in the degradation characteristics of bituminous mixtures. It wes found that the pattern of degradation is independent of these factors, but that amount of degradation relas rela to all of ther. This relationship was a consistent one for all but the asphalt fretor in which case no direct relationship between degradation and asphalt content ins found. Wine most important factor affecting degradation was found to be the gradation of the orlginul mix.

The report is presented to the Boara for the record.

Respectiully subritted,

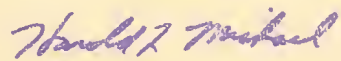

Farold I. Hichael, Secretary

EIM:lme

A:tachment

\section{Copy:}

F. I. Asbbeucher

J. R. Cooper

W. I. Dolch

J. F. Mclaughtin

W. H. Coetz

R. D. Miles

F. F. Havey

R. E. Mills

N. B. Scott

F. S. $\mathrm{HIII]}$

J. V. Surythe

G. A. Ireonards

J. I. Waling

E. J. Yoder 
Digitized by the Internet Archive in 2011 with funding from

LYRASIS members and Sloan Foundation; Indiana Department of Transportation 


\title{
Final Report
}

\section{A IABORATORY STUDY OF THE DEGRADATION OF AGGREGATYS}

II BITUMTINOUS MIXXFS

\author{
by
}

Fred Moavenzadeh

Graduate Assistant

Joint Highway Research Project

File No: 2-8-3

Project No: C-36-22C

Purdue University

Lafayette, Indiana

JuIy 13, 1962 


\section{ACKONOWLEDGMENTS}

The author is grateful to the Joint Highway Research Project of Purdue University, Professor K. B. Woods, Director, for its sponsorship of this investigation.

The most special thanks go to the author's Major Professor and advisor, W. H. Coetz, for the time, support, and encouragement that he continually provided.

Dr. M. E. Harr, Dr. R. B. Johnson, and Dr. J. F. Mclaughlin were most helpful in technical assistance and reviewing those sections of the report connected with their major fields of interest and indicating suggestions for improvement.

Finally, the author wishes to express his thanks to his wife, whose encouragement made the successful conclusion of this study a reality. 
TABLE OF CONTENTS

LIST OF TABLES .................... v LIST OF FIGURES .................. v vii ABSTRACT ................................

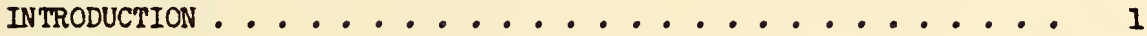
REVIEW OF LITERATURE ................... 4

Tests ....................... 6

Tests on Individual Particles ............. 7

Tests on Aggregates ................ 8

Controlling Factors ................ 13

Type of Aggregate .................. 14

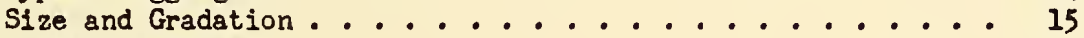

Aggregate Shape ................. 16

Effect of Asphalt ............... 17

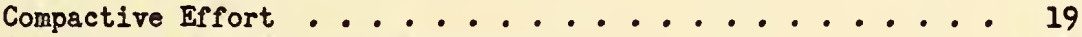

Other Factors Affecting Degradation .......... 20

ANALYSIS OF MECHANISM OF DEGRADATION ............ 21

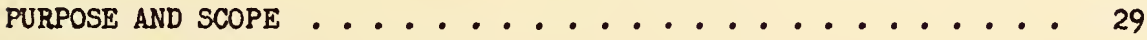

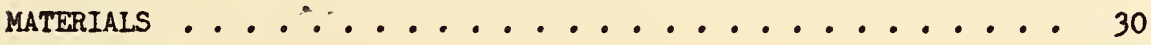

Aggregates . . . . . . . . . . . 30

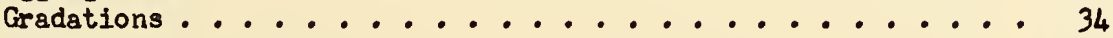

Asphalt ........................... 40

PROCEDURES AND EQUIPMENT ................ 43

Batching and Mixing .............. 43

Compaction ................... . . 44

Gyratory Testing Machine................. 46

Production of Rounded Aggregate ............. 51

Dyeing Process ................ 53

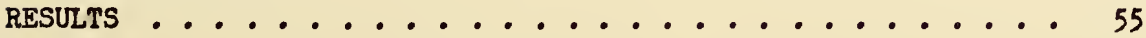


TABLE OF CONTENTS (continued)

Page

Single-Sized Aggregate . . . . . . . . . . 59

Dyed Aggregates . . . . . . . . . . . . 79

Detailed study . . . . . . . . . . . . . . 121

Asphalt Content ................ . 146

Aggregate Shape ................... 150

Degradation vs Los Angeles Value .............. 157

Petrographic Analysis ............... 167

Relation Between Theory and Experiment........... 174

SUMMARY OF RESULTS . . . . . . . . . . . . . . 179

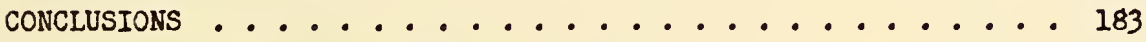

SUGGESTIONS FOR FURTHER RESEARCH . . . . . . . . . 186

LIST OF REFERENCES . . . . . . . . . . . . 188

APPENDIX . . . . . . . . . . . . . 193

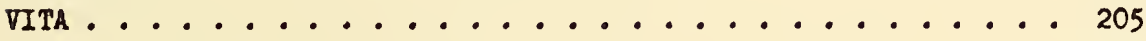




\section{LIST OF TABLES}

Table

1. Results of Ios Angeles Abrasion and Compressive Strength Tests................. . . 33

2. Sieve-Size Fractions Used in Gradation Analyses . . . . . 38

3. Original Gradations ............... 39

4. Regults of Tests on Asphalt Cement . . . . . . . . . . 42

5. Surface-Area Factors . . . . . . . . . . . 56

6. Results of Gyratory Tests of Various One-Sized Aggregates - 200 psi, 100 Revolutions ...........

7. Results of Static Load and Kneading Compactor Tests of One-Sized Aggregates .. . . . . . . . . . . 67

8. Results of Gyratory Tests of One-Sized Aggregates $100 \mathrm{psi}$......................

9. Results of Sieve Analysís of Colored Aggregates Grading 0, 0\% Asphalt ..................

10. Results of Sieve Analysis of Colored Aggregates Grading 0, 4\% Asphalt ..................

11. Results of Sieve Analysis of Colored Aggregates Grading B, 0\% Asphalt ...................

12. Results of Sieve Analysis of Colored Aggregatea Grading B, 4\% Asphalt ............... 105

13. Results of Sieve Analysis of Colored Aggregates Grading F, O\% Asphalt ................. 110

14. Results of Sieve Analysis of Colored Aggregates Grading F, 4\% Asphalt ................ 115

15. Percent Increase in Surface Area - Dolomite . . . . . . 123 16. Percent Increase in Surface Area - Limestone . . . . . . . 123 


\section{LIST OF TABLFS (continued)}

Table

17. Percent Increase in Surface Area - Quartz1te . . . . . 125

18. Percent Increase in Surface Area - Rounded Quartz1te . . . 151

19. Petrographic Analysis of H \& R Dolomite . . . . . . 168

20. Petrographic Analysis of Bloomington Limestone . . . . 169

21. Petrographic Analysis of Baraboo Quartzite ........ 170

22. Total Weight of Specimens - Dolomite . . . . . . . 193

23. Final Surface Area $\mathrm{cm}^{2} / \mathrm{gr}$ - Dolomite.......... 194

24. Increase in Surface Area $\mathrm{cm}^{2} / \mathrm{gr}$ - Dolomite . . . . . . 195

25. Total Weight of Specimens - Limestone . . . . . . 196

26. Final Surface Area $\mathrm{cm}^{2} / \mathrm{gr}$ - Limestone . . . . . . 197

27. Increase in Surface Area $\mathrm{cm}^{2} / \mathrm{gr}$ - Limestone ....... 198

28. Total Weight of Specimens - Quartzite . . . . . . 199

29. Final Surface Area $\mathrm{cm}^{2} / \mathrm{gr}$ - Quartzite ......... 200

30. Increase in Surface Area $\mathrm{cm}^{2} / \mathrm{gr}$ - Quartzite ....... 201

31. Total Weight of Specimens - Rounded Quartzite ...... 202

32. Final Surface Area $\mathrm{cm}^{2} / \mathrm{gr}$ - Rounded Quartzite . . . . 203

33. Increase in Surface Area $\mathrm{cm}^{2} / \mathrm{gr}$ - Rounded Quartzite . . . 204 


\section{LIST OF FIGURES}

\section{Figure}

1-A. H \& R Dolomite ............... 35

1-B. Bloomington Limestone ............ 36

1-C. Baraboo Quartzite............. 37

2. Gradation Curves for Original Gradations ........ 41

3. Gyratory Testing Machine ........... 47

4. Schematic Side View of Section Through Gyrating Mechanism ........... 48

5. Crushed and Rounded Quartzite .......... 52

6. Dyed and Natural Color of Top Four Sizes of Limestone ................... 54

7. Sieve Analysis of One-Sized Dolomite Aggregates after Cyratory Compaction ............. 60

8. Sive Analysis of One-Sized Limestone Aggregates after Gyratory Compaction............... 61

9. Sieve Analysis of One-Sized Quartzite Aggregates after Gyratory Compaction ............. 62

10. Degradation vs Aggregate Size - Gyratory Compaction, One-Sized Aggregates ............

11. Degradation vs Los Angeles Value - Cyratory Compaction, One-Sized Aggregates

12. Sieve Analysis of Compacted $1 / 2 "$ - 3/8" Aggregates Kneading Compaction.................... 68

13. Sieve Analysis of Compacted $1 / 2^{\prime \prime}-3 / 8^{\prime \prime}$ Aggregates Static Compaction ...............

14. Sieve Analysis of Compacted 3/8" - \#3 Aggregates Static Compaction ............... 
LIST OF FIGURES (continued)

Figure

15. Degradation vs Los Angeles Value - Static and Kneading Compaction - OnemSized Aggregates ......

16. Sieve Analysis of One-Sized Dolomite Aggregates -

Varying Number of Revolutions of Gyratory Compactor . . .

17. Sieve Analysis of One-Sized Limestone Aggregates -

Tarying Number of Revolutions of Gyratory Compactor . . . 76

18. Sieve Analysis of One-Sized Quartzite Aggregates -

Varying Number of Revolutions of Gyratory Compactor . . . 77

19. Degradation vs Number of Revolutions for One-Sized

Aggregates .............. 78

20. Sieve Analysis of Compacted Colored Aggregate -

Crading 0 , 0\% Asphalt, 100 psi, 30 Rev. ....... 84

21. Sieve Analysis of Compacted Colored Aggregate -

Grading 0, 0\% Asphalt, 100 psi, 100 Rev. ....... 85

22. Sieve Analysis of Compacted Colored Aggregate -

Crading 0, 0\% Asphalt, 200 psi, 30 Rev. ....... 86

23. Sieve Analysis of Compacted Colored Aggregate -

Grading 0, 0\% Asphalt, 200 psi, 100 Rev. ....... 87

24. Sieve Analysis of $1 / 2^{\prime \prime}$ - 3/8" Colored Aggregate -

Grading 0, 0\% Asphalt, Variable Compactive Effort . . . 88

25. Sieve Analysis of $3 / 8 "$ - \#3 Colored Aggregate -

Grading 0 , $0 \%$ Asphalt, Variable Compactive Effort . . . . 9

26. Sieve Analysis of \#3 - \#4 Colored Aggregate -

Grading 0 , $0 \%$ Asphalt, Variable Compactive Effort . . . i 0

27. Sieve Analysis of \#4 - \#6 Colored Aggregate -

Crading 0 , 0\% Asphalt, Variable Compactive Effort .... 71

28. Sieve Analysis of Compacted Colored Aggregate -

Grading 0 , 4\% Asphalt, 100 psi, 30 Rev. ....... 94

29. Sieve Analysis of Compacted Colored Aggregate -

Crading 0, 4\% Asphalt, 100 psi, 100 Rev. ....... 95 
30. Sieve Analysis of Compacted Colored Aggregate Grading 0, 4\% Asphalt, 200 psi, 30 Rev......... 96

31. Sieve Analysis of Compacted Colored Aggregate Grading 0, 4\% Asphalt, 200 psi, 100 Rev. ........ 97

32. Sieve Analysis of Compacted Colored Aggregate Crading B, 0\% Asphalt, 100 psi, 30 Rev......... 100

33. Sieve Analysis of Compacted Colored Aggregate Grading B, 0\% Asphalt, 100 psi, 100 Rev. ....... 101

34. Sieve Analysis of Compacted Colored Aggregate Grading B, 0\% Asphalt, 200 psi, 30 Rev. . . . . . . . 102

35. Sieve Analysis of Conpacted Colored Aggregate Grading B, 0\% Asphalt, 200 psi, 100 Rev. ....... 103

36. Sieve Analysis of Compacted Colored Aggregate Grading B, 4\% Asphalt, 100 psi, 30 Rev. . . . . . 106

37. Sieve Analysis of Compacted Colored Aggregate Crading B, 4\% Asphalt, 100 psi, 100 Rev. . . . . . 107

38. Sieve Analysis of Compacted Colored Aggregate Grading B, 4\% Asphalt, 200 psi, 30 Rev......... 108

39. Sieve Analysis of Compacted Colored Aggregate Grading B, $4 \%$ Asphalt, 200 psi, 100 Rev. ....... 109

40. Sieve Analysis of Compacted Colored Aggregate Grading F, 0\% Asphalt, 100 psi, 30 Rev......... 111

41. Sieve Analysis of Compacted Colored Aggregate Grading F, 0\% Asphalt, 100 psi, 100 Rev. . . . . . . 112

42. Sieve Analysis of Compacted Colored Aggregate Grading F, 0\% Asphalt, 200 psi, 30 Fiev. ....... 113

43. Sieve Analysis of Compacted Colored Aggregate Grading F, 0\% Asphalt, 200 psi, 100 Rev. ........ 114

44. Sieve Analysis of Compacted Colored Aggregate Grading F, 4\% Asphalt, 100 psi, 30 Rev. . . . . . . 116 
IIST OF FIGURES (continued)

Figure

45. Sieve Analysis of Conpacted Colored Aggregate Grading F, 4\% Asphalt, 100 psi, 100 Rev. . . . . . . 117

46. Sieve Analysis of Compacted Colored Aggregate Grading F, $4 \%$ Asphalt, 200 psi, 30 Rev......... 118

47. Sieve Analysis of Compacted Colored Aggregate Grading F, $4:$ Asphalt, 200 psi, 100 Rev. ....... 11 ?

48. Degradation vs Number of Revolutions -

Variable Ram Pressure . . . . . . . . . 126

49. Degradation vs Ram Pressure for Dolomite -

O\% Asphalt ................. 128

50. Degradation vs Ram Pressure for Iimestone -

$0 \%$ Asphalt . . . . . . . . . . . 129

51. Degradation vs Ram Pressure for Quartzite -

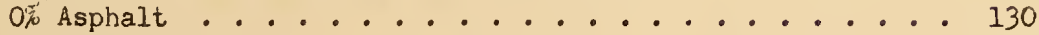

52. Degradation vs Ram Pressure for Dolomite -

$2 \%$ Asphalt .................. 131

53. Degradation vs Ram Pressure for Limestone -

$2 \%$ Asphalt ................... 132

54. Degradation vs Ram Pressure for Quartzite -

$2 \%$ Asphalt . . . . . . . . . . . 133

55. Degradation vs Ram Pressure for Dolomite -

$4 \%$ Asphalt ....................... 134

56. Degradation vs Ram Pressure for Limestone -

$4 \%$ Asphalt ..................... 135

57. Degradation vs Ram Pressure for Quartzite -

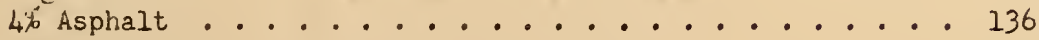

58. Degradation vs Ram Pressure for Dolomite -

$6 \%$ Asphalt ................. 137

59. Legradation vs Ram Pressure For Limestone -

$6 \%$ Asphalt ....................... 138 


\section{LIST OF FIGURES (continued)}

Figure

Page

60. Legradation vs Ram Pressure for Quartzite -

6\% Asphalt

61. Degradation vs Number of Revolutions - O\% Asphalt . . . . 141

62. Degradation vs Number of Revolutions - 2\% Asphalt . . . . 142

63. Derradation vs Number of Revolutions - $4 \%$ Asphalt . . . . 143

64. Degradation vs Number of Revolutions - 6\% Asphalt. . . . . 144

65. Defradation vs Asphalt Content - Dolomite . . . . . . . 147

66. Deqradation vs Asphalt Content - Iimestone . . . . . . 148

67. Degradation vs Aspralt Content - Vuartzite ....... . 149

68. Degradation vs Ram Pressure for Rounded Quartzite -

Of Asphalt . . . . . . . . . . . . . . . 153

69. Degradation vs Ram Pressure for Rounded Quartzite -

$4 \%$ Asphalt . . . . . . . . . . . . . . . . 154

70. Degradation vs lumber of Revolutions -

Angular and Rounded Zuartzite, O* Asphalt . . . . . . 155

71. Degradation vs Number of Revolutions -

Ancular and Rounded Euartzite, $4 \%$ Asphalt ......... 156

72. Legradation vs Los Angeles Value -

Grading 0, 100 psi .............. 159

73. Degradation vs Los Angeles Value -

Grading 0, 200 psi ............... . . 160

74. Degradation vs Los Angeles Value -

Grading 0, $250 \mathrm{psi}$............... 162

75. Degradation vs Los Angeles Value -

Grading $\mathrm{B}, 100 \mathrm{psi}$................ 163

76. Degradation vs Los Angeles Value -

Grading B, 200 psi ............... 164

77. Legradation vs Los Angeles value -

Grading F, $100 \mathrm{psi}$.............. 165 


\section{LIST OF FICURES (continued)}

Figure

78. Degradation vs Los Angeles Value -

Grading F, 200 psi ............. 166

79. Thin Section of $H \&$ Dolorite, Ordinary light . . . . I7I

80. Thin Section of Bloomington Limestone, Ordinary Ifght . . 172

8I. Thin Section of Baraboo Guartzite, Crossed Nicols . . . . 173

62. Sieve hnaysis of Compacted One-Sizfd Dolonite AgEregate - Log Log Flot . . . . . . . . 176

83. Sieve Analysis of Compacted One-Sized Limestone Aggregate - Log Log Plot . . . . . . . . . 177

84. Sieve Anaiysis of Compacted Ont-Sized Guartzito AgEregate - Iog Iog Plot ........... 178 


\section{ABSTRACT}

Moavenzadeh, Faramarz, Ph. D., Purdue University, August, 1962. A Laboratory Study of the Degradation of Aggregates in Bituminous Mixtures. Major Professor: William H. Goetz.

A laboratory study was performed on bituminous mixtures using a gyratory testing machine in order to determine the factors affecting degradation of aggregate in bituminous mixtures.

The study was subdivided into three parts. In the first part tests were performed on one-sized aggregate; in the second part, a dyeing process was utilized to 1dentify the separate fractions of each size in the grading in order to determine the influence of the presence of other sizes in the degradation of each size; and in the third part a detalled study of factors affecting degradation of aggregate was made.

Three kinds of aggregates with different Los Angeles values were used. The aggregates were blended according to three different gradations ranging from an open gradation to a Fuller maximum density gradation. Four different asphalt contents ranging from zero to 6 percent were used for most of the gradations. Use of a eyratory testing machine made it possible to produce specimens having densities and structure similar to field pavement. The mechanism of the machine also made it possible to change the compactive efforts in two different ways: change in magnitude of load, and change in repetition of load. In order to study the effect of shape of particles on degradation, artificlally rounded pleces were produced by subjecting angular pleces to a few thousand revolutions in the Los Angeles machine. 
INTRODUCTION

Bituminous mixtures are essentially a three-phase system consisting of bitumen, aggregate and air. In order for such a mixture to serve its purpose, the mixture is compacted to a certain degree before being subjected to traffic. During its life, the mixture is subjected to further compaction due to the action of traffic. This further densification of a bituminous mixture under traffic may produce progressive deterioration of the parement, either by reduction of voids to the point where a plastic mixture results, or by producing ravelling. In either case, degradation of the aggregate may play an important role.

Compaction is an energy-consuming process, which results from the application of forces to the mixture. The mixture withstands these forces in many ways, such as by 1nterlock, by frictional resistance, and by viscous or flow resistance. When the applied forces have a component in ang direction greater than the resistance of the mat, the material will move and shift around until a more stable position is attalned. This rearrangement of the material, especially the aggregate phase, causes a closer packing of particles, a new internal arrangement or structure, and a higher unit weight.

The enerey required for the relocation or rearrangement of particles is provided by contact pressure, and the particles while adjusting to their new locations are subjected to forces which cause breakage and wear at the points of contact. This phenomenon, called degradation, reduces 
the size of particles and changes the gradation of aggregate which in turn causes the reduction in void volume and increase in density. Degradation of aggregate in bituminous mixtures is greatest in channelized traffic areas under heavy loads. Any change in the gradation of the aggregate in a $\mathrm{mix}$ is associated with a change in basic properties of the bituminous mixture, namely stability and durability. In some mixtures the change of gradation due to degradation of aggregate causes the asphalt present in the voids to be pushed out and an unstable mix to result, while in other mixtures the amount of asphalt present is not enough to coat all the newly produced surfaces and disintegration of the mat results. Degradation may reduce the angularity of aggregate particles, and thus decrease the interlocking which in turn results in a loss in stability of the mixtures with resulting shoving, distorting, and corrugating.

The only protective measure against degradation of aggregate adopted by most highway authorities is through a test which measures such qualities of rocks as hardness and toughness. The most widely used test for this purpose is the Los Angeles Abrasion Test which subjects a certain amount of aggregate pieces of certain sizes, along with a certain number of standard steel balls, to five hundred revolutions in a steel drum. The result of the test is expressed as a weight percentage of broken material as compared to the original amount. Most highway authorities have selected a certain value of this percentage as a dividing point between acceptable and rejected material (1). Some investigators have expressed their doubts with regard to the validity of the test for aggregate, especially in bituminous mixtures, due to the facts that the test is not being performed on a gradation similar to that of the mixture and the degradation in the field is not as severe as that in the test. 
One of the most important problems facing many highway engineers is the shortage of good quality aggregate within hauling distance from the job site. Often the highway engineer is faced with the question of what to do with aggregates with Los Angeles values close to the rejecting point. It is obvious that savings could be made if some protective measures could be taken that would make possible the use of such aggregates.

It was these thoughts and the problem outlined that led to the present investigation, in which factors affecting the degradation characteristics of aggregates in bituminous mixtures are evaluated. The current status of knowledge of the degradation characteristics of aggregates is established by a review of the available literature. The material and equipment used for the study are presented. The tests and results of these tests are discussed. Suggestions for further research that would provide a logical continuation of this study are presented. It is hoped that the results found in the present investigation will add to the understanding of the factors affecting degradation and will indicate protective measures which can be taken to reduce degradation of aggregate in bituminous mixtures. 
REVIEW OF IITERATURE

One of the most important objects of highway engineering is to predict the performance of highway materials during construction and the life of the highway. Aggregate is one of the most commonly used road-building materials. A review of the literature concerning aggregate qualities shows that numerous methods heve been used to determine the suitability of aggregates for road-building purposes. This can be tracked back to as early as 1819 when John MacAdam stated that the workmen determined the proper size of stone by measuring them with their fists (50).

Testing of road materials, including aggregates, started in the United States about $1890(42)$ and has developed steadily since that time. Much work was done to relate the results of mechanical tests on road stones to the life and performance of the roads in which they were used as aggregates (52).

In bituminous roads, forces due to traffic tend to cause degradation. Macnaughton (32) states that one of the features which has to be considered in the design of bituminous mixtures is the matter of degradation of aggregates during the process of compaction. He further states that this degradation 18 due to considerable pressure developed at points of contact between particles and to continual shifting and rearrangement of particles as they gradually attempt to occupy the least possible space. Workers in the Road Research Laboratory of England ( 8 ) have substantiated the orlentation of particles in bituminous roads by stating, "The orientation of the aggregate 
In a section of road carpet is largely determined by the boundaries. In the carpet most of the aggregate particles are arranged with their long axis horizontal." Increase of pressure and reorientation of particles produce a grinding effect which tends to round off corners and odges, thus permitting the particles to fit more closely together. This process may proceed to such an extent that aggregate vold space is materially reduced, and the stability of the mixture is impaired on account of the presence of an excess of liquid (32).

Smith (55) states: "- - some mixes of adequate internal friction and cohesion at the time of construction became over-lubricated due to densification under traffic. As the result of this densification, the stability properties (internal friction in particular) of the mix as measured by the triaxial test were greatly reduced." Pauls and Carpenter (43) have concluded that the principal cause of degradation is the rolling operation, and excessive degradation of the aggregate in bituminous concrete under the roller may cause ravelling, excessive absorption of water, and progressive deterioration. Benson (3) considers that the relocation of particles occurs as soon as the friction between the particles is overcome, and bituminous materials assist in the action by acting as a priction reducer. He states "within a bitumen-aggregate structure, one of the main roles of bitumen is that it permits a re-establishment of the original resistance to deformation when the bitumen-aggregate structure is deformed by excessive stress and is then compacted by further action of traffic."

The northwestern states of the United States have experienced considerable trouble in new roads with distressed pavements resulting from aggregate breakdown. Minor reports (39) that failure of bituminous mats caused 
by inferior mineral aggregate is manifested first by softening of the mixture followed soon afterward by actual disintegration of the mat. $H . L$. Day of the Idaho Department of Highways reports (10) that construction records in that state indicate a pavement built with a shale aggregate failed before construction was completed and had to be reconstructed before being put into service.

\section{Tests}

The most important object of testing is to provide reliable criteria for accepting or rejecting aggregates. Aughenbaugh et al. (2) states, "Tests for aggregate degradation whether conducted in the laboratory or in the field should serve a definite purpose. They should give results which can be used to evaluate those properties of a material which are affected in the field by the conditions or actions that one is concerned with. They should also approximate or imitate the actual field conditions."

A. S. Faust et al. (16) divided the properties of solids into two classes; those belonging to the individual piece and those belonging to the aggregation of pieces. It is obvious that the properties of the second group depend upon the properties of the first. Determination of the relationship between properties of the two classes may not be so difficult when the pleces are all identical, but it is a very difficult problem when the pieces exist in a range of sizes, a variety of shapes, and sometimes even have different compositions. This is why many investigators agree that the so-called "standard tests" are not satisfactory (11) (39) (46) (52). Minor (39) states, "- - none of the conventional laboratory tests will positively detect aggregates which are prone to harmful degradation." 
Shergold ( 52 ) believes that the closest correlation between the results of different tests on road aggregate is obtained between tests carried out on the aggregation of pleces rather than individual pleces. This is largely due to the better reproducibility of these tests.

\section{Tests on Individual Particles}

The most 1mportant tests on individual particles are those concerned with petrographic analysis and with impact and crushing strength.

In petrographic analysis the nature of the rock is determined by Identifying the type of minerals present, percent of bulk minerals, average grain s1ze, rock structure, interlocking of individual crystals, etc. (11). Rhodes and Mielenz (47) state, "Petrographic and mineralogic composition and internal texture and structure of the particles control the physical and chemical properties of the aggregates. Consequently, the suitability of aggregates for proposed uses can be evaluated by petrographic methods." In relation to the use of petrographic analysis as a routine test for aggregate quality, investigators are of different opinions. Those in South Africa (9) (30) consider it very practical, simple, and absolutely necessary for correct interpretation of aggregate behavior in service, while those in the northwestern states (39) (57) consider it as too time-consuming and not practical as a laboratory test to be used in routine acceptance or rejection of materials. Shergold of the Road Research Laboratory in England (52) states that "Roadstone should not be classified as good or bad merely according to rock type, but each should be judged on its individual merits as revealed by petrological examination and mechanical test." 
In the bituminous field, petrographic analysis has been used mostly in studying the adhesion of bituminous films to aggregates (12) (58). The crushing test is often regarded as the only mechanical test on road material that provides a true physical constant for a particular rock (52). Sweet (56) states that the resistance to degradation in non-rigid road surfaces is undoubtedly affected by the actual strength of the aggregate substance. Shergold (52) in a review of available information on the significance of roadstone tests found that very little work has been done to correlate crushing strength with service behavior. He believes that the poor reproducibility of these tests on individually prepared specimens makes correlation with service behavior difficult. He further suggests that impact and crushing strength tests that can be applied to the aggregates as used in the road will considerably improve both reproducibility and correlation with service behavior.

\section{Tests on Aggregates}

Numerous tests are cited in the literature for measuring different properties of aggregates (56) (65). Of these, abrasion tests, compression tests, and field and laboratory roller tests are pertinent to the degradation of aggregates, especially in bituminous mixtures.

The American Society for Testing and Materials lists three methods of test for abrasion of coarse aggregates, one with the Los Angeles machine and two using the Deval machine. The Deval test was developed for determining the suitability of stone for road metal in macadam construction in France in the $1870^{\prime}$ s (56). Numerous modifications have been recommended and the test procedure has changed substantially (65), but at present most investigators are of the opinion that the test is lengthy, unrealistic, 
and without relationship between its results and field performance (14) (15). Lang (31) pointed out that "The Deval abrasion test does not necessarily show the strength of the aggregates."

The Los Angeles abrasion test was developed in 1916 and has been adopted widely since that time as a quality test for aggregates. Goldbeck (20) enumerates the following advantages of the Los Angeles test as a test for the quality of aggregates for use in bituminous construction:

1) The sample is made up of aggregate as it is supplied commercially; that is, the test, unlike the Deval test, is made on a sample which truly represents the material which is supplied for the work.

2) The test requires only 16 minutes for the actual run as against 5 hours for the Deval test.

3) The results of the test seem to agree very well with the behavior of aggregates in particular forms of service, especially aggregate used as cover material for bituminous surface treatment work.

4) The concordance of results on materials from the same source, tested in different laboratories is remarkably good.

Adequacy of the Los Angeles test to measure resistance to degradation is a matter of controversy among investigators even though several direct investigations have been made on the correlation between service behavior and the results of the test. Shelburne (50) determined the amount of degradation produced by 5- and I0-ton rollers on different aggregates and found that "The Los Angeles abrasion machine at 100 revolutions gives a good indication of the amount of degradation under road rolling - - .." Although there was considerably more degradation from 500 revolutions in the machine, the relative resistance of the aggregates in the abrasion test was in accord with their resistance under rolling. Goldbeck (18) in comparing the results obtained from the Los Angeles, Deval, and toughness tests with those of a laboratory roller test concluded: "In view of the 
fact that the roller test is really a service test, it is clear that neither the toughness test nor the Deval abrasion test can be relied upon to indicate service behavior, but on the other hand, the Los Angeles rattler test does agree exceptionally well with service behavior." Sweet (56) states that the results of the Los Angeles test are of value as indications of aggregate breakdown under rollers and wheel loads in traffic-bound or lowtype bituminous road surfacings. The validity of the Los Angeles test as a measure of the degradation of aggregates used for surface treatment work has been demonstrated by many other investigators (9) (19) (53).

Unsatisfactory results obtained by the use of the Los Angeles test are reported mostly by investigators in the northwestern states of the United States where the production of fine materials due to degradation of a special kind of basalt has been recognized as the major cause of many pavement failures ( 7 ) (11) (39). Minor (39) states, "The Los Angeles rattler and Deval machine, for example, both measure the resistance of aggregate to abrasion or impact under highly synthetic conditions. They undoubtedly serve as a partial measure of quality for aggregates intended strictly for surface treatments, but the abrasive action to which these machines subject the aggregate is hardly similar to the action of pneumatictired vehicles on modern highways."

Some investigators, in an attempt to predict the amount of breakage of aggregates in the field by a simple laboratory test, have used different methods of compaction. These include direct compression, high-frequency power tamping, repetitive loading, kneading compaction, and gratory compaction. The most important disadvantage of most of these methods is the confinement of the material in a mold. Such confinement does not allow 
for relocation of particles due to horizontal forces such as exist in the field. Macnaughton (32) concluded that "Direct compression is not a suitable method for forming specimens of paving mixtures in the laboratory, as high densities, comparable to those obtained in actual service, can not be obtained without serious crushing of aggregate particles." Miller (38) stated, "If an aggregate is placed under pressure in a confined space, it will grind itself into that particular grading which is best for that particular aggregate, and which will provide the greatest inherent stability."

Phillppi (44), in an attempt to develop a laboratory compaction method for bituminous mixtures which would produce specimens having both a density approximately equal to that obtained in a pavement and an aggregate degram dation of field order, used nine different machines. With regard to direct compression, he concluded that the amount of degradation increased with the compressive Ioad, and in order to obtain a density ralue close to the field density excessive degradation is unavoidable. He further stated that molding rate has no effect in reduction of degradation in a direct compression test.

With regard to vibratory methods of compaction, Macnaughton (32) concluded that high-frequency pneumatic compaction is a more satisfactory laboratory method of compaction than direct compression. On the other hand, Philippi, (44) using the P.R.A, vibratory method, could not obtain densities close to fleld density without excessive degradation.

The California kneading compactor has been used by the northwestern states in an attempt to obtain aggregate degradation in the laboratory similar to that which occurs in the field (14) (15) (27) (57), Minor (39), by rarying the number of tamps and thus increasing the degradation, tried 
to measure the effect of progressive degradation on the stability value of the material (measured by Hreem Stabilometer). He coneluded that the results were not comparable to the field condition because the increased tamping served merely to densify and further stabilize the mass rather than to produce plastic fines as was the case in highways in which of a special kind of basalt was used. Havers and Yoder (24), using a repeated loading device, found that the method of application of repeated load influences degradation. "Single-acting" tests (piston remains in contact with sample) resulted in less breakage than "double-acting" tests (piston returns to zero position after each loading).

Philippi (44) came to the conclusion that in order to obtain a specimen of the same density and order of degradation of the field mix, considerations must be given to the relocation and rearrangement of particles during the compaction of specimens in the laboratory. To achieve this purpose he suggested the use of a machine which imparts a gyratory motion to the molding cylinder during the compaction. With the use of such a machine he found that the density and degradation of laboratory-compacted specimens corresponded very closely to the field conditions. The gyratory compactor later was motorized and modified by the Corps of Engineers (59) and the Ohio Department of Highways (28). Generally a very good correlation was obtained between degradation obtained by this machine and field compaction. McRae (37) found that by changing the variable factors of the gyratory compactor (pressure, angle of gyration, and number of revolutions) he could obtain specimens corresponding to field conditions with regard to density and degradation. 
With regard to field and laboratory roller tests, investigators have attempted to study the factors affecting the degradation of aggregates by either actual test roads in the field or miniature tracks in the laboratory. Shelburne (50) was among the first to make detailed investigations using a construction roller on a special test road. He found that degradation of aggregate took place during mixing, during rolling, and throughout the life of the road. Degradation was slightly less for asphalt-coated aggregates than for uncoated ones, and for rounded gravel the degradation was less than for crushed gravel. He also investigated the effect of gradation, and type of aggregate. Many other investigators have done similar work with respect to surface treatments, and their results confirm much of Shelburne's work (9) (53). In the laboratory, circular tracks have been used in an attempt to simulate field conditions and control test variables while avoiding the excessive cost of field test sections (21) (48). Shelburne $(50)$ stated that small-scale tracks cannot duplicate field conditions completely due to "their large angle of nip of small diameter rollers, twisting action induced by small-diameter circular tracks, and pronounced edge effect of narrow rollers."

\section{Controlling Factors}

The following factors have been considered by many investigators to be effective in the degradation of aggregates; type of aggregate, maximum size and gradation of particles, shape of particles, asphalt content, and compactive effort. 


\section{Type of Aggregate}

Most investigators concerned with any of the numerous uses. of aggregates agree that the type of rock is a major factor with respect to 1 ts specific use. Mining and metallurgical engineers in handling ores (22) and chemical engineers in many phases of unit operations (5) have learned that the first important factor in comminution and grinding is the type of solid used. In civil engineering applications both producers and users of aggregates are interested in the type of aggregate and its characteristics with respect to crushing and resistance to factors such as load, weathering, etc. Shergold (54) in a study of the granulators used in the production of road aggregates concluded that the strength of the product, the energy consumption, and to some extent the grading of the product depend mainly on the type of rock used. Minor (39) from a study of the degradation characteristics of different rocks stated that "the degradation factors have ranged from below 10 for soft sandstones and shales to 89 for a very hard, fine-grained basalt."

Among the most important properties of rocks affecting the production and serviceability of aggregates are internal texture, structure, and composition of the rock and of the mineral particles of which it is composed. Rock particles may be composed of mineral crystals grown in place, fragments of crystals or rocks deposited individually, or of amorphous masses. Therefore, as a result of these variations each rock and mineral particle has a group of physical and chemical properties which controls the engineering qualities of its aggregate (47). Knight (29) confirms the effect of type of rock on degradation of aggregates in bituminous mixes by stating that fine-grained rocks with closely-knitted structure and tough constituents 
result in much less degradation than coarse-grained rocks with weak structure. Shelburne (50) found that two kinds of dolomite under equal conditions produced different percents of breakage. Shergold (52) also believes that texture and structure of rock exercises some influence on the engineering quality. He further emphasizes the importance of age of the rocks, especially sedimentary rocks, on their quality.

\section{Size and Gradation}

There are conflicting opinions regarding the influence of maximum size of particles on degradation. Vallerga et al, (61) noted that such a conflict also exists with regard to the influence of particle size on the strength of bituminous mixtures. It is thought by Scott (49) that fine material below the quarter-inch size is very susceptible to disintegration, and that the susceptibility decreases as size of the material is increased. Pauls and Carpenter (43), Shelburne (50), and Macnaughton (32) have found that the greater breakdown is in the larger sizes. Shelburne (50) has shown that when the maximum size was changed from $1 / 2^{\prime \prime}$ to $3 / 4^{\prime \prime}$ the surface area produced was doubled.

In bituminous pavement design, gradation of aggregate has been the subject of much investigation because the resistance to deformation and the flexibility of the bituminous road is influenced to a large degree by this factor. Since bitumen under normal conditions is a plastic, cohesive binding agent, the aggregate structure is the primary load-carrying component of parements. The resistance to deformation is provided by interlockIng of particles if an open gradation is used. In dense-graded mixtures, the stability is largely a result of frictional resistance to movement developed at the points of contact. In open mixtures, due to the fewer 
number of points of contact, higher stresses are developed and more breakage occurs at these points than in dense-graded mixtures.

Macnaughton (32) believes that degradation is much higher in open mixtures than in dense ones because of grinding at the points of aggregate contact. Thus, he suggests that aggregates for open mixtures must be of better physical quality than aggregates for dense-graded types. Shelburne (50) confirms Macnaughton's opinion by stating that a densegraded aggregate might be relatively free from degradation. He found that when aggregates were graded to a Fuller's maximum density curve, the degradation was minor and the resultant grading was still a Fuller's curve with smaller maximum size particles. In open-graded mixtures, a considerable amount of breakage resulted in a grading that appeared to be approaching a parabolic curve. Pauls and Carpenter (43) believe that in the harsher mixtures where the proportion of fine sand and dust is low, degradation tends to be more extensive than in mixtures in which the coarse aggregate is cushioned by a high percentage of fines. Knight (29), from subjecting a sample of one size aggregates to successive crushing tests, found that a final definite gradation will be obtained and further increase in compaction will result in little or no change in gradation.

\section{Aggregate Shape}

Generally two relatively independent properties, "sphericity" and "roundness", control particle shape. Mather (33) describes sphericity as a measure of flakiness or flatness of particles, and roundness as a measure of the relative sharpness or angularity of the edge and corners of the particles. The shape of particles depends largely upon the presence and spacing of natural parting or cleavage in the rock. Rhodes and Mielenz 
(47) state: "Wany mineral crystals possess planes of easy fracture, such that angular, faceted particles are produced by shattering of crystals. Vany rocks contain planes of parting or jointing which reflects the internal petrographic structure." The effect of particle shape on the strength of bituminous mixtures was studied by Herrin and Goetz (25) and by Vallerga et al (61). Herrin and Coetz (25) concluded that, regardless of the type of fine aggregate, the influence of an increase in the amount of crushed gravel in the coarse aggregate fraction on the strength of a bituminous mixture varied with the type of grading, the effect on strength tending to become less as the grading of the mixture became more dense.

With regard to the influence of particle shape on degradation of aggregate, most investigators are of the opinion that elongated, flakg particles break much more than cubical pieces (9) (29) (32). Rnight (29) found that as the percentage of flakg particles increased in the mixture, the mixture experienced more degradation. He also found that a rock which was highly susceptible to degradation had less breakage when no flaky particles were present than a resistant rock containing 100 percent flaky pieces. Shelburne $(50)$ in comparing round and crushed gravel found that 1.3 times as much degradation occurred in crushed as in uncrushed gravel from the same source.

Effect of Asphalt

The effect of asphaltic materials on degradation of aggregates has been studied by only a few investigators. The amount and consistency of asphalt in mixture have been found to be somewhat influential on aggregate degradation. Macnaughton (32) considered asphaltic materials as lubricants which ease the movement of particles during consolidation under 
rollers and traffic. He states that asphaltic materials with low penetration may not accelerate the rearrangement of particles, and thus the rate of degradation may be low, but new surfaces produced may not be coated with asphalt and the mixture may fail through ravelling. On the other hand, high-penetration asphaltic materials may ultimately coat the new surfaces produced, but the formation of additional fines may so improve the packing properties of the aggregate that mixtures may become unstable when the void space has been reduced to the point where it cannot accommodate the quantity of liquid present in the mixture. Knight (29), in a laboratory investigation to a large degree confirmed Macnaughton's views with respect to the effect of viscosity of asphaltic materials on degradation. He found that degradation increases with increase in temperature of the mixture owing to the greater lubrication afforded by the less viscous material. Comparing the degradation produced at different testing temperatures in mixtures made of tar and 200 penetration asphait, he concluded that "- - - at temperatures below $10^{\circ}$ centigrade the tar becomes brittle, hardly any relative movement of the particles takes place, and aggregate degradation is limited to the particles on the upper surface of the test piece." At $22^{\circ}$ centigrade the tar permitted the same degree of degradation as 200 penetration asphalt.

With regard to the effect on degradation of the percent of asphalt, Knight (29) found that depending on the type of aggregate, there is a certain percent of asphalt for which the degradation is minimum. In general, less degradation occurs when asphalt is present, but with some rocks the reverse has been shown to be true. Shelburne (50) in his surface treatment study found that when the particles are coated the degradation is slightly less than when particles are not coated. 


\section{Compactive Effort}

Degradation and relocation of particles are the result of compaction under rollers during construction and under traffic during the life of the parement. Energy is consumed in the process through contact pressure, which tries to reorient the particles and subjects them to forces which may cause breakage, or wear and abrasion. Almost all investigators are agreed that as compactive effort increases degradation increases too. The variables which have been studied with regard to compactive effort are type of loading, rate of loading, and magnitude of load.

Manj methods of loading have been used in the laboratory in an attempt to simulate field conditions including direct compression (32), vibratory compaction (44), repetitive loading (24), kneading compaction (11), gratory compaction (28) (44), and circular track and laboratory rolling (21) (48). For most of them, the conclusion has been reached that increase in compactive effort will result in more degradation. In the field, many studies have been performed on the type of loading and it has been found that most of the degradation occurs after few trips of the roller and that the weight of roller is more effective on degradation than the number of coverages (11) (29) (32) (50) (54).

Knight (29) states that the rate of loading is more influential than the amount of load on breakage of aggregates. Philippl (44) found that the rate of loading in direct compression has no effect on degradation of aggregates. He believes that laboratory degradation could be made to simulate field conditions more closely by proper aggregate orfentation as the compressive load is increased, or better still, by proper aggregate orientation at a low initial load before application of the full compressive load. 
It has been found from field studies that there is a direct relationshlp between magnitude of load and degradation. Shelburne (50) found that a ten-ton roller produced almost 1.5 times more breakage than a five-ton roller. Pauls and Carpenter (43) state that most aggregate degradation is caused by steel-wheel rollers used during construction. Macnaughton (32) noticed that degradation is more severe in the wheel track than at the edge of the pavement. This has also been confirmed by the Corps of Engineers $(60)$ in a study of degradation of aggregates. under channelized traffic of heavy military alrcraft.

\section{Other Factors Affecting Degradation}

Factors such as type of underlying structure (50), water (11) (39), time (51), and thickness of the layer (2) have been investigated by different research workers investigating degradation. Shelburne (50) found that more degradation occurred in surface treatment aggregates when la1d on a rigid base than on a flexible base.

Investigators in the northwestern states of this country have found that moisture is one of the main factors in degradation and they have recommended rattler tests on wet aggregate as a means for judging the quality of aggregates as base materials (39). The reason for severe breakage when the aggregate is wet has been attributed to the effect of water on some minerals such as clays which have a high affinity for molsture, and calcites which are water soluble. 
ANALYSIS OF MECHANISM OF DEGRADATION

Most investigators in CIvil Engineering concerned with degradation of aggregate believe that degradation is an energy-involved process and that particles reduce in size by virtue of work done by the forces that develop at contact points (54). However, a careful review of the existing literature seems to indicate that none have tried to analyze the problem using either the principles of energy consumption or fracture or breakage of solid pieces, nor have attempts been made to evaluate the factors affecting this process. It is interesting to note, however, that a vast amount of Information predicated on this principle is avallable in the mining and metallurgical fields. This is especially significant in the literature dealing with ore treatment processes where crushing and grinding is frequently the major item of cost.

Most cominution theories are concerned with the relationship between the cause and effect of particle size reduction. Of the many theories in the mining and metallurgical flelds which have been suggested for the relation between input energy (cause) and reduction in particle size of materials (effect) those of Rittinger, Kick, and Bond are of special interest (26). Rittinger in 1867 postulated that the energy required for size reduction of a solid would be proportional to the new surface area created during the size reduction. Kick in 1885 suggested that equivalent amounts of energy should result in equivalent geometrical changes in the size of the pieces of solid*. A more recent theory of commimution which can be considered 
a compromise between Kick's theory and Rittinger's theory was provided by Bond (4) in 1952. Bond's theory states; "The work, useful in breakage, which has been applied to a weight of homogeneous broken material is inversely proportional to the square root of the diameter of the product particles."

The three above-mentioned theories have been represented in a single, simple, empirical proposition by Charles (6) in 1957. Mathematically, the proposition may be stated as follows:

$$
d E=-c d x / x^{n}
$$

where $\mathrm{dE}=$ infinitesimal energy change

$$
\begin{aligned}
c & =a \text { constant } \\
d x & =\text { infinitesimal size change } \\
x & =\text { particle size, and } \\
n & =a \text { constant }
\end{aligned}
$$

This equation states that the energy required for a small change in the size of a particle is inversely proportional to the particle size to some power $n$, and directly proportional to the size change. Charles further proves that when $n=2$, Eq. (I) yields Rittinger's hypothesis. Kick's concept will be obtained for $n=1$, and the value $n=1.5$ w1ll result in Bond's theory. There are many experimental results which support the validity of each of the three hypotheses (4) (23) (48). However, Holmes (26) notes that due to the fact that the hypotheses do not consider the characteristics of the materials none of them can be accepted completely. He interprets the supports of the hypotheses as being due to the closeness of $n$ value of Eq. (1).

In order to develop any general equation for size reduction, the characteristics of the rocks must be considered. Real aggregates are 
generally composed of non-homogeneous rocks with internal weaknesses, plaws, cracks, cleavage planes, etc., within the particles. However, as the part1cle sizes decrease the influence of these weaknesses diminishes, and more energy is required to produce a unit surface area.

In coarse pieces breakage occurs due to rupture of Van der Wall's bonds between erystals, while in small particles (of sizes on the order of crystalline dimensions) if fractures occur they must occur in crystals and consequently sufficient energy must be available to overcome the covalent bonds. Thus, in the latter case the energy required to produce a unft surface area may be taken to be inversely proportional to the diameter of the particle to some unknown power.

In the development that follows it will be assumed that distribution of weaknesses in a group of particles of relatively uniform size is normal. The same assumption will be made for the energy required for the breakage of each particle. That is, the mean value of the energy distribution will be considered as a representative value for a particular particle size.

When an aggregation of particles of one size is subjected to external energy, a part of this energy is used to produce particles of smaller sizes. An increase in the input onergy will result in an increase of the number of particles of smaller sizes. Ultimately this process can be considered to produce particles of almost zero s1ze; that 18, any further increase In energy will cause chemical rather than physical changes. Symbolically, this can be stated as: a particle of size $d_{1}$ requires an input energy of $w_{1}$ to break into particles of zero size where $w_{1}$ Increases as $d_{1}$ increases. On the basis of this definition, $N_{i}$ particles of $d_{1}$ size will consume $N_{1} w_{1}$ units of energy to change into particles of zero size and $\Sigma N_{1} w_{1}=U$ will 
be the total energy that an aggregation of particles of different sizes require to change into particles of zero size. Considering $M$ the total mass of the material and $m_{1}$ the mass of each fraction, $\Sigma m_{1}=K$, we shall define $p_{i}=\left(m_{1} / M\right) 100$ as the percentage of material of size $d_{1}$, where $\Sigma p_{1}=100$. For simplicity, assuming spherical particles, we have:

$$
N_{1}=m_{1} /\left(\pi / 6 d_{1}^{3} \rho\right)=M p_{1} /\left(\pi / 6 d_{1}^{3} \rho\right)
$$

where $(\pi / 6) d_{1}^{3}$ is the volume of the particle and $P$ is the unit mass of the materlal. For other than spherical particles the volume can be considered A. $d_{i}{ }^{3}$, where $A$ is a shape factor.

At this point the question is posed: upon the application of a measurable energy input, what would be the most probable gradation of aggregate? In other words we seek the most probable distribution of values of $m_{l}^{\prime}$ s for each size $d_{i}$, where the $m_{i}$ 's may take any value from zero to $M_{0}$. The number of combinations of $\mathrm{m}_{1}{ }^{\prime} \mathrm{s}$ is given by the permutation formula as:

$$
W=M J /\left(\pi m_{1} d\right)
$$

where $M$ is total mass and $\pi m_{1} /$ is the product of $m_{1}{ }^{\prime \prime} \cdot 8$. For our purpose we seek the most probable combination of $m_{1}{ }^{\prime s}$ which in turn will correspond to a maximum $W$. Rather than maximizing $W$, for the sake of simplicity, we shall maximize In W; that 1s, writing the above expression as

$$
\ln W=\ln (M y)-\sum \ln \left(m_{1} l\right)
$$

and using Sterling's approxination for a factorlal (which says in (x') = $\left.\int_{1}^{x} \ln x d_{x}\right)$, we can write 


$$
\ln (M d)=\int_{1}^{M} \ln M d M=M \ln M-M+1
$$

Noting that $M$ is large in comparison to unity, and hence

$$
\ln (M !) \approx M \text { ln } M-M
$$

Eq. (I) can be written as

$$
\begin{aligned}
\text { In } W=M \text { In } M-M-\Sigma\left(m_{1} \text { In } m_{1}-m_{1}\right)= & M \text { In } M-M-\Sigma\left(m_{1} \ln m_{1}\right) \\
& +\Sigma m_{1}
\end{aligned}
$$

Whereas $\Sigma m_{1}=M$,

$$
\ln W=M \ln M-\sum m_{1} \text { ln } m_{1}
$$

Now, noting that $M=\sum m_{1}=$ const. and hence has a zero derivative, wo obtain

$$
\partial \ln w=-\Sigma m_{1} \partial \ln m_{1}-\sum \ln m_{1} \partial m_{1}=0
$$

where

$$
\partial \ln m_{1}=\partial m_{1} / m_{1}
$$

The first term in right hand side of the Eq. (2) can also be written as

$$
\Sigma m_{i} \partial m_{1} / m_{1}=\Sigma \partial m_{1}
$$

because $\Sigma m_{1}=M=$ const. and hence

$$
\Sigma \partial m_{i}=0
$$

Thus Eq. (2) will result in

$$
\sum \ln m_{1} \partial m_{1}=0
$$


If the $\partial m_{1}$ 's were independent of each other the coefficient of each would have to vanish separately in order that $\sum$ In $m_{1} \partial m_{1}=0$. But, the total mass $X$ was assumed to be constant, and the $\partial m_{1}$ 's are obviously related to each other as was specified in the state $\Sigma \partial m_{1}=0$; that 1s, an increase in one of the $\partial m_{1}^{\prime} s$ must be accounted for by a corresponding decrease in others.

After applying an input energy to an aggregation of particles the internal energy of the system, $U$, is given by

$$
\sum x_{1} w_{1}=\sum \frac{m_{1}}{\frac{\pi}{6} \rho d_{1}^{3}} w_{1}=v=\text { const. }
$$

If we use the value of $x_{1}$ for unit surface area of the particle rather than the particle as a whole we get for the relationship between the internal energy $\left(w_{1}\right)$ of a particle of $8120 d_{1}$ ) to the energy per unit surface $\operatorname{area}\left(B_{1}\right)$,

$$
w_{1}=\pi d_{1}^{2} s_{1}
$$

which when substituted into the above equation for $U$ yields

$$
\sum \frac{6 m_{1}}{\pi d_{1}{ }^{3}} w_{1}=\sum \frac{6 m_{1}}{\rho d_{1}} E_{1}=0
$$

or

$$
\frac{6}{p} \sum m_{1} E_{1} / d_{1}=U=\text { const. }
$$

Now, differentiating this expression with respect to $m_{1}$ we obtain as the second condition imposed on the $m_{1}^{\prime} 8$ (the first being Eq. 3)

$$
\partial U / \partial m_{1}=\Sigma\left(m_{1} / d_{1}\right) \partial m_{1}=0
$$

Hence the problem is resolved into determining the solution of Eq. (4) oubject to the conditions in Eqa. (3) and (5). 
By use of Lagrange's method of undetermined multipliers the governing equation, $\sum$ In $m_{i} \partial m_{i}$, and the two conditional equations can be written as

$$
\sum\left(\ln m_{1}-\ln \alpha+\beta E_{i} / d_{i}\right) \partial m=0
$$

where $(-$ In $\alpha)$ and $\beta$ are constants. Whereas the coefficients of each of the $\partial m_{1}$ 's in Eq. (6) is independent and hence must vanish, for any value of 1, we specify that

$$
\ln m_{1}-\ln \alpha+\beta E_{i} / d_{i}=0
$$

or

$$
m_{1}=\alpha e^{-\beta E} / d_{i}
$$

Recalling that $\sum m_{1}=M$, we now have

$$
M=\alpha \Sigma e^{-\beta E_{1} / d_{1}}
$$

Defining $\Sigma \bar{e}^{\beta E_{1} / d_{1}}=Z$, the previous expression can be written as $M=\alpha Z$, or $\alpha=M / Z$, whence recalling that $p_{1}=\left(m_{1} / M\right) \quad 100$,

$$
m_{1}=(M / Z) e^{-\beta E} E_{1} / d_{1}
$$

or,

$$
m_{1} / M=p_{1} / 100=(1 / 2)-\beta E E_{i} / d_{1}
$$

Noting in the limit that the summation may be replaced by an integration

$$
Z=\int_{0}^{E_{0} / D_{0}} e^{-\beta E_{1} / d_{1}} d\left(E_{1} / d_{1}\right)=(-1 / \beta)\left(e^{-\beta E_{0} / D_{0}}-1\right)
$$

where $D_{0}$ is maximum size of particles, and hence 


$$
p_{1}=\frac{-\beta}{-\beta E_{0} / D_{0}} e^{-\beta E_{1} / d_{1}}
$$

Consequently the total percent passing any eize may be expressed as

$$
\sum_{1=0}^{d_{1}} p_{1}=\frac{-100 \beta}{-\beta E_{0} / D_{0}} \int_{1}^{E_{1} / d_{1}} e^{\beta E_{1} / d_{1}} d\left(E_{1} / d_{1}\right)
$$

or

$$
P_{1}=\left(100 \bar{e}^{-\beta E_{1} / d_{1}}-1\right) /\left(\bar{e}^{\beta E_{0} / D_{0}}-1\right)
$$

Considering 100 percent of the material to be finer than $D_{0}$,

$$
P_{1}=\left(P_{0} \bar{e}^{\beta} E_{1} / d_{1}-1\right) /\left(\bar{e}^{\beta} E_{0} / D_{0}-1\right)
$$

which in turn can be written as

$$
P_{1}=P_{0} \frac{1-e^{\beta E_{1} / d_{1}}}{1-e^{\beta E_{0} / D_{0}}} \cdot \frac{e^{\beta E_{0} / D_{0}}}{e^{\beta E_{1} / d_{1}}}
$$

or

$$
P_{1}=P_{0} \frac{1-e^{\beta E_{1} / d_{i}}}{1-e^{\beta E_{0} / D_{0}}} e^{\beta\left(E_{0} / D_{0}-E_{1} / d_{1}\right)}
$$

Finally, noting that the values of $e^{\beta E_{1} / d_{1}}$ and $e^{\beta} E_{0} / D_{0}$ are much smaller than one and hence are of negligible order; we obtain for the percent of material finer than $d_{1}$ size after application of a certain amount of energy.

$$
P_{1}=P_{0} e^{\beta}\left(E_{0} / D_{0}-E_{1} / d_{1}\right)
$$


PURPOSE AND SCOPE

The primary purpose of this study was to evaluate the degradation characteristics of aggregates in bituminous mixtures and to analyze the factors which are effective in causing this degradation. Further it was the purpose of this study to relate aggregate properties such as toughness, hardness, shape, and gradation to the degradation problem in bituminous mixtures. Attempts also were made to establish a theoretical approach to the mechanism of aggregate degradation.

The factors which were investigated are as follows:

1) Type of aggregate: Due to the importance of aggregate quality In respect to degradation, three types of aggregate varying in characteristics from hard quartzite to soft limestone were chosen. Attempts were made to obtain each of them from a single geologic formation in order to eliminate the effects of non-unfformity on the results.

2) Gradation: To consider the effect of this factor on degradation, three gradations of each type of aggregates were tested. These gradations varied from open graded to a dense grading conforming to a Fuller's maximum density gradation. One of the three gradations met the specifications of Indians State Highway Coumlssion for hot Asphaltic Concrete Surface-Type B (medium texture).

3) Shape: In order to evaluate the effect of shape on aggregate degradation without changing the type of aggregate, rounded aggregate was prepared by subjecting crushed pieces of different sizes 
to few thousand revolutions in the Los Angeles machine.

4) Size: This factor was studied in two ways. First, samples containing only one-sized aggregate were tested, and the degradation as measured by change in size of particle was determined. Then, pieces of different sizes were dyed with different colors, blended, and compacted. This process showed the effect of gradation on degradation of each size fraction and also which fractions of a particular gradation were more sensitive to degradation.

5) Asphalt content: To evaluate the effect of asphalt on the degradation characteristics of aggregates, specimens were made with four different asphalt contents ranging from zero percent to six percent asphalt by weight of dry aggregate.

6) Compactive effort: Change of compactive effort was achieved in two ways in order to simulate the actual field condition. On the one hand, the magnitude of the compressive load was changed to correspond to the variation in wheel load, and on the other hand, the repetition of load was varied to simulate the traffic intensity.

The study was limited to a laboratory evaluation of cause and effect of degradation of aggregates in bituminous mixtures, and a gyratory testing machine was used to simulate the degradation of aggregate which occurs under traffic. 


\section{MATERIALS}

The bituminous mixtures used in this study were chosen so that the significant variables, type of aggregate, gradation of aggregate, aggregate shape, and percent of asphalt in the mixture, could be evaluated with respect to their effect on the degradation characteristics of the bituminous mixtures. For this purpose three different gradations which were used, one of which met the specifications of the Indiana State Highway Commission for Hot Asphaltic Concrete Surface - Type B (medium texture). The selection of percent of asphalt for the mixtures was not based on any strength or durability properties of the mixture, but was chosen merely to cover as wide a range as possible in each case in order to determine the variation of degradation of aggregate with change in asphalt content.

\section{Aggregates}

The three types of aggregates used in this study were obtained from the following sources:

1. RIdgeville, Indiana

2. Bloomington, Indiana

3. Baraboo, Wisconsin

The selection of sources and types of aggregates was based on their uniformity and abrasion resistance. Geologic information at each location is as follows: 
1. Ridgeville Dolomite

So1l and glacial drift $\quad 10.0 \mathrm{ft}$.

Huntington dolomite $\quad 38.0 \mathrm{ft}$.

2. Bloomington Limestone

Soil

Mooretown Sandstone

Paoll Iimestone

St. Genevive limestone

$4.0 \mathrm{ft}$

$13.6 \mathrm{ft}$.

$4.1 \mathrm{ft}$.

$51.6 \mathrm{ft}$.

3. Barsboo Quartzite

Soil

Baraboo Quartzite

Rhyolite and Granite

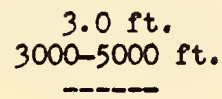

Ridgeville dolomite was obtained from the Huntington formation and is of middle Silurian age. The material is relatively medium to coarsely cyrstalline and has a high porosity, its vacuum absorption being 5.16 percent. When tested for specific gravity by ASTM methods C 127 and C 128 the following results were obtained:

Bulk specif1c gravity of coarse aggregate $=2.45$

Apparent specific gravity of coarse aggregate $=2.66$

Bulk specific gravity of fine aggregate $=2.62$

Apparent specific gravity of fine aggregate $=2.84$

Its Los Angeles and compressive strength test values are presented in Table 1.

Bloomington Iimestone was obtained from the St. Genevive formation and is of Mississipplan age. The material is fine grained and has a low porosity, its vacuum absorption being 0.7 percent. When tested for specific gravity by ASTM methods C 127 and C 128 the following results were obtained:

Bulk specific gravity of coarse aggregate $=2.66$

Apparent specific gravity of coarse aggregate $=2.72$

Bulk specific gravity of fine aggregate $=2.71$

Apparent specific gravity of fine aggregate $=2.75$

Its Ios Angeles and compressive strength test values are presented in Table 1. 
TABLE 1

RESULTS OF LOS ANGELES ABRASION

AND CONPRESSIVE STRENGTH TESTS*

Los Angeles Abrasion

\begin{tabular}{lccc}
\hline & \multicolumn{3}{c}{ Grading ** } \\
\cline { 2 - 4 } Type of Aggregate & A & B & C \\
\hline Ridgeville Dolomite & 40.0 & 41.0 & 33.0 \\
Bloomington Limestone & 26.7 & 25.0 & 27.5 \\
Baraboo Quartzite & 22.0 & 23.7 & 24.9 \\
\hline
\end{tabular}

Compressive Strength PSI***

\begin{tabular}{lcc}
\hline & \multicolumn{2}{c}{$\begin{array}{c}\text { Size of Specimen } \\
\text { Inches }\end{array}$} \\
\cline { 2 - 3 } Type of Aggregate & $1.0 \times 1.0 \times 1.0$ & $1.0 \times 1.0 \times 2.0$ \\
\hline Ridgeville Dolomite & 10,100 & 8,500 \\
Bloomington Limestone & 15,000 & 14,300 \\
Baraboo Quartzite & 25,200 & 29,600 \\
\hline
\end{tabular}

* Each value is the average of three tests

* According to ASTM Method C 131

* Rate of loading $.025 \mathrm{in} / \mathrm{min}$ 
Baraboo Quartzite was formed in the Precambrian era and is a well Indurated, vitreous, pink to purplish quartzite consisting of quartz grains with fine-grained sericic material and interstitial iron oxide which gives it a raddish color. (The quartz grains were first cemented by iron oxide and later by silica.) Its vacuum absorption is 0.5 percent. When tested for specific gravity by ASTM methods C 127 and C 128, the following results were obtained:

Bulk specific gravity of coarse aggregate $=2.67$

Apparent specific gravity of coarse aggregate $=2.69$

Bulk specific gravity of fine aggregate $=2.68$

Apparent specific gravity of fine aggregate $=2.70$

Its Los Angeles and compressive strength test values are presented in Table 1.

The aggregates, after being brought to the laboratory, were washed, dried, and crushed into required sizes as listed in Table 2. The crushed fractions were again washed and dried, and stored for blending. Figures $1-A, 1-B$, and $1-C$ show the texture of the three aggregate types used.

\section{Gradations}

The three gradations selected for this investigation are shown in Table 3. Grading 0 is an open gradation consisting of the top four sizes. Grading B meets the specifications of Indiana State Highway Commission for Hot Asphalt1c Concrete Surface - Type B. Grading F corresponds to the Fuller curve for well-graded materlal, and was obtained by the following empirical formula suggested by Fuller and Thompson.

$$
P_{1}=P_{0}\left(\frac{d_{1}}{D_{0}}\right)^{1 / 2}
$$

where: 


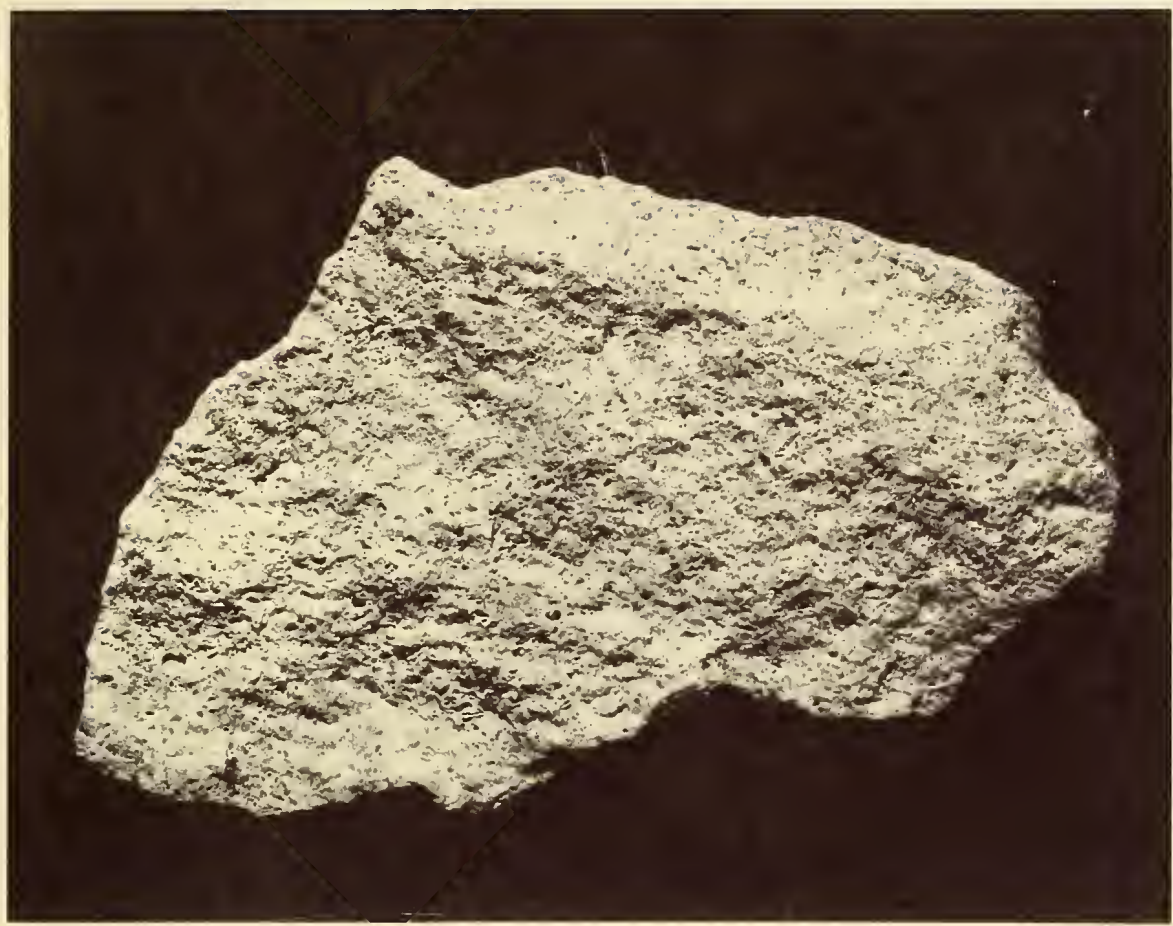

FIG. I-A RIDGEVILLE DOLOMITE 


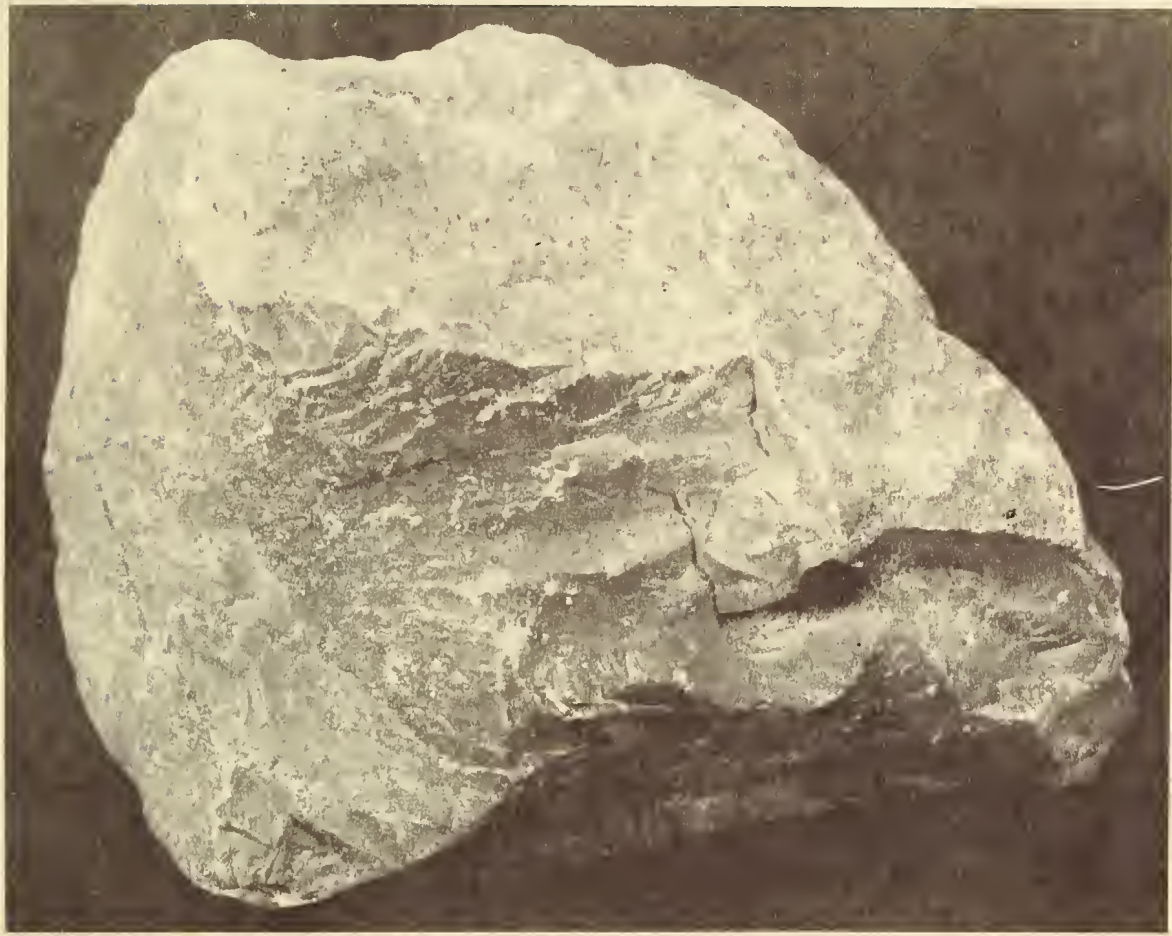

FIG. I-B BLOOMINGTON LIMESTONE 


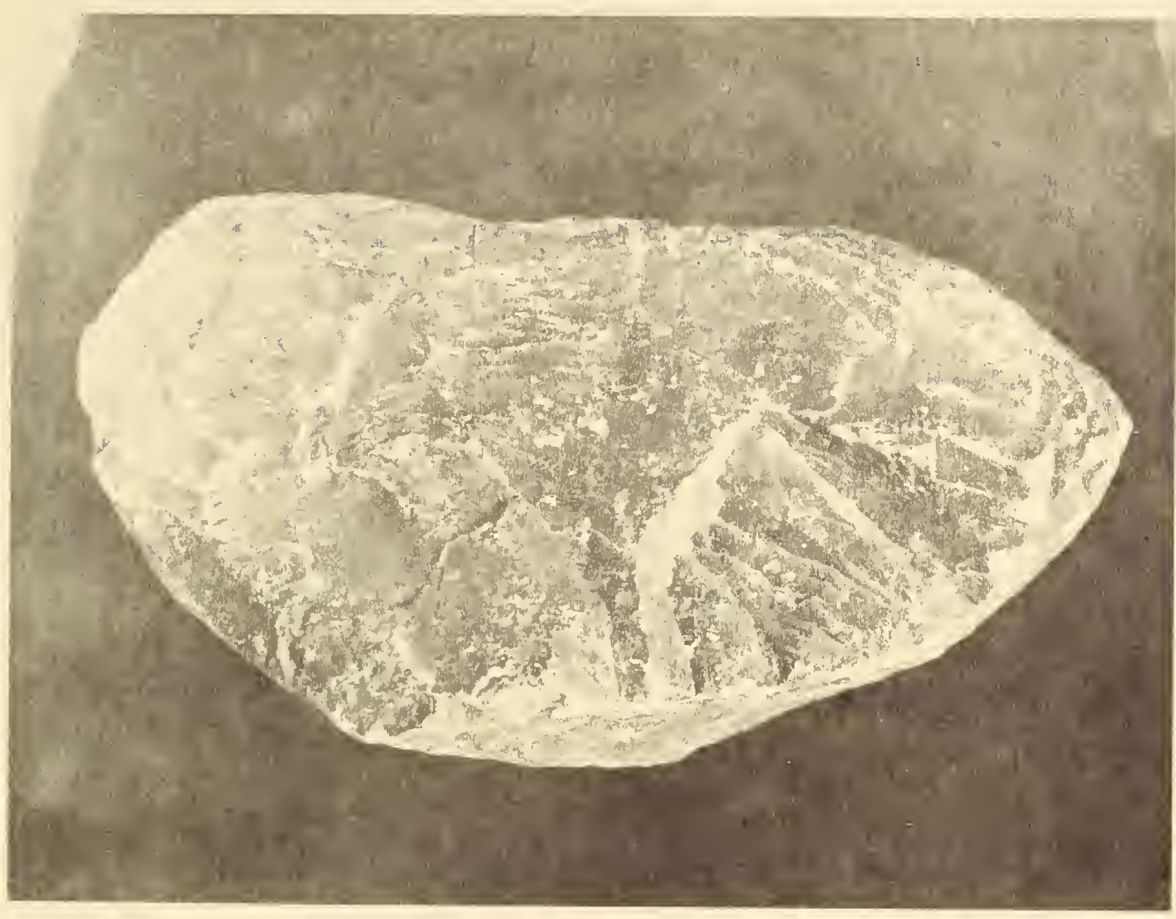

FIG. I-C BARABOO QUARTZITE 
TABLE 2

SIEVE-SIZE FRACTIONS USED IN GRADATION ANALISES

\begin{tabular}{cc}
\hline $\begin{array}{c}\text { U. S. Standard } \\
\text { Sieve No. }\end{array}$ & $\begin{array}{c}\text { Size of Opening } \\
\text { in Microns }\end{array}$ \\
\hline $1 / 2^{n}-3 / 8^{n}$ & $12700-9520$ \\
$3 / 8^{\prime \prime}-\# 3$ & $9520-6350$ \\
$\# 3-\# 4$ & $6350-4760$ \\
$\# 4-\# 6$ & $4760-3360$ \\
$\# 6-\# 8$ & $3360-2380$ \\
$\# 8-\# 12$ & $2380-1680$ \\
$\# 12-\# 16$ & $1680-1190$ \\
$\# 16-\# 30$ & $1190-590$ \\
$\# 30-\# 50$ & $590-297$ \\
$\# 50-\# 100$ & $297-149$ \\
$\# 100-\# 200$ & $149-74$ \\
Passing \#200 & 74
\end{tabular}




\section{TABLE 3}

\section{ORIGINAL GRADATIONS}

\section{Percent Passing}

Sleve No.

Grading 0

Grading B

Grading $\mathrm{F}$

$1 / 2^{\prime \prime}$

100.0

100.0

100.0

$3 / 8^{\prime \prime}$

75.0

86.0

86.6

\#3 $\left(1 / 4^{n}\right)$

50.0

62.0

70.7

\#4

25.0

50.0

61.2

\#6

0.0

45.0

51.4

颉

36.0

43.3

$\# 12$

25.0

36.3

\#16

16.0

30.0

\#30

11.0

22.0

\#50

6.0

15.0

$\# 100$

4.0

10.9

\#200

3.0

7.7 


$$
\begin{aligned}
& P_{1}=\text { percent smaller than } d_{i} \\
& P_{0}=\text { percent smaller than } D_{0} \\
& D_{0}=\text { maximum size of particles }
\end{aligned}
$$

The maximum size of all three gradations is $1 / 2$ in., and Figure 2 shows a graph of these three aggregate gradings.

\section{Asphalt}

An 85-100 penetration grade asphalt cement was used in this study. Results of tests on the asphalt are presented in Table 4. 


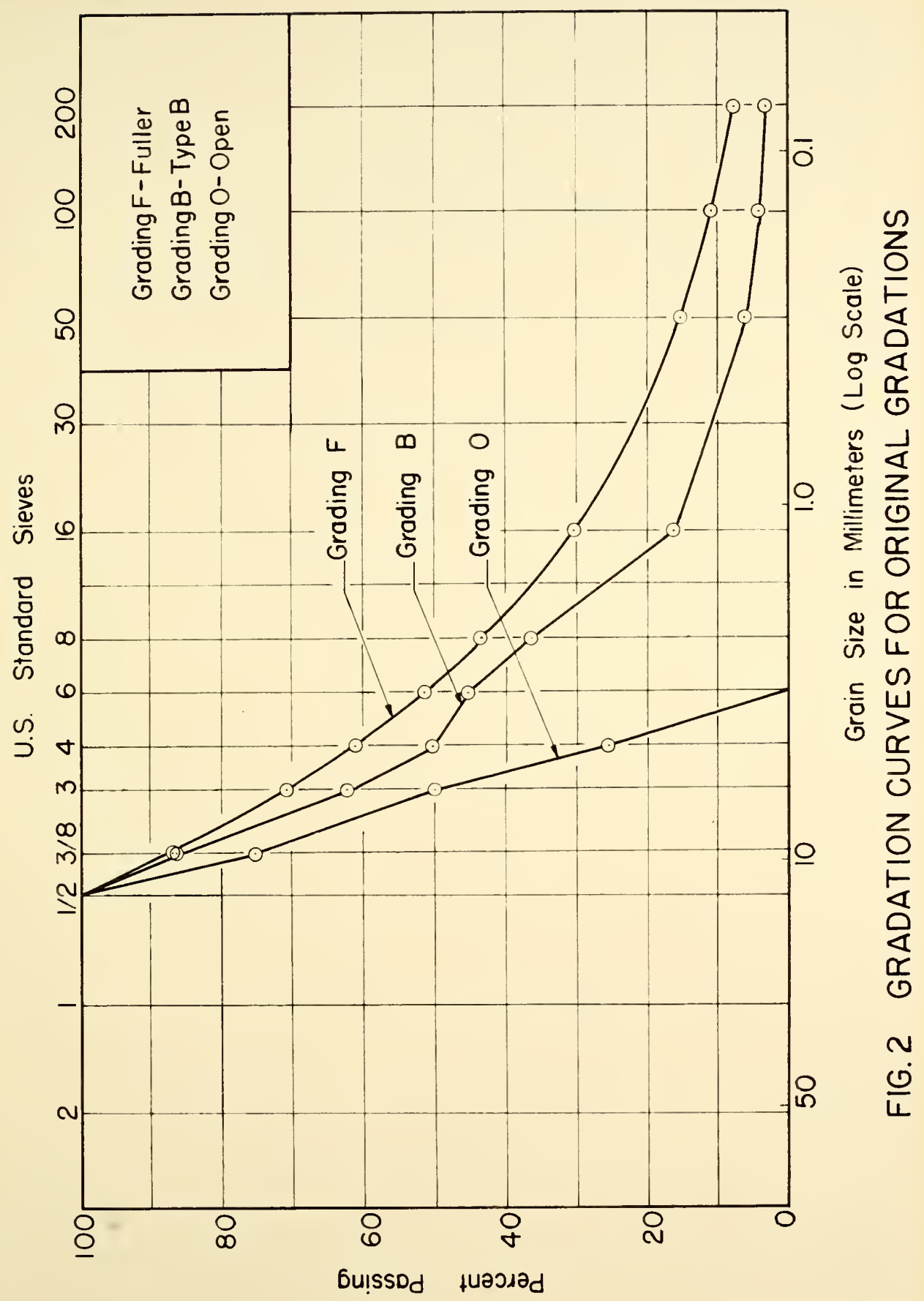


TABLE 4

RESULTS OF TESTS ON ASPHALT CEMENT

$\begin{array}{lc}\text { Specific Gravity, 77/770F } & 1.032 \\ \text { Softening Point, Ring and Ball, }{ }^{\circ} \mathrm{F} & 114.0 \\ \text { Ductility, } 77^{\circ} \mathrm{F}, \mathrm{cm} . & 200+ \\ \text { Penetration, } 100 \text { grams, } 5 \text { sec., } 77^{\circ} \mathrm{F} & 90 \\ \text { Penetration, } 100 \text { grams, } 5 \text { sec., } 32^{\circ} \mathrm{F} & 20 \\ \text { Flash Point, Cleveland Open Cup, }{ }^{\circ} \mathrm{F} & 600 \\ \text { Solubility in } \mathrm{CCl}_{4} \text {, percent } & 99.8\end{array}$


PROCEDURES AND EQUIPMENT

This section describes all detalls relating to the tests performed. Each aggregate was batched, mixed with asphalt, and the specimen formed and tested. Then the asphalt was extracted, a sieve analysis was made on the dried aggregate and a dust correction was added.

\section{Batching and Mixing}

The aggregates used for each specimen were batched by component fractions according to the blend formula. Batching was accomplished with cold dried aggregates using a Toledo scale sensitive to one gram. A batch consisted of 1000 grams. The blended aggregates for specimens containing asphalt were heated to $275^{\circ} \pm 10^{\circ} \mathrm{F}$ in a Peerless gas oven. The asphalt was heated separately to $290^{\circ}-300^{\circ} \mathrm{F}$. The hot aggregate was placed in a heated mixing bowl, and then the mixing bowl was placed on the scale and the specified percentage of heated asphalt was added. The direct-reading fan of the scale permitted control of the amount of asphalt added to the nearest gram. The mixing was accomplished using a Hobart electric mixer (Kodel A-200) modified with a special mixing paddle and a scraper. The mixing was continued for two minutes. For those cases in which the aggregate was tested without asphalt, the aggregate was not heated or subjected to the mixing operation with the Hobart mixer. 


\section{Compaction}

Due to the fact that this study was restricted to a laboratory invegtigation on degradation characteristics of aggregates in bituminous mixtures, it was desired that the specimens insofar as possible have the same characteristics as the compacted mixture in the parement. The first step in this approximation of the field conditions is to consider specimen compaction. A reliable laboratory study is assured only when the specimens are produced through the manipulation of the mixture in a manner that will produce results similar to those produced by the action of construction equipment and traffic loade. Goetz (17) has stated that $n$ - - - the most important phase of the present design problem is not how to test a laboratory specimen, but how to form a laboratory specimen that represents the mixture as it is used in service." Monismith and Vallerga (40) further substantiate this by stating, "In the design of asphaltic paving mixtures by means of laboratory tests, the object of laboratory compaction procedure should be to produce specimens which are representative of materials of similar composition compacted by construction equipment and traffic in the field."

The major differences between field compaction and laboratory compaction Ile in the matters of orientation and degradation of aggregate. In the fleld there is a tendency for the long axes of the aggregate pieces to I1e in horizontal position. In the laboratory, specimens are compacted in molds and in many of the compaction methods there is no possibility for aggregate to rearrange its position (38). Thus it can be seen that the confinement used in producing laboratory specimens may cause the particles to have random orientation and consequently the compacted specimens to have a structure that is different from the material on the road. 
The differences between field compaction and laboratory compaction grow larger as compective effort increases. Nevitt (41) states, "The structural difference from varied types of compaction are accentuated by the degree to which the material is compacted. The small energy input corresponding to construction compaction may not develop enough variation between most methods to appear significant while under traffic compaction the situation is crucial because compaction may not greatly further increase the density even though it represents a manyfold increase in the compaction effort, but its effect on the stability of the pavement may be critical."

A tire rolling over a bituminous mixture on the road pushes the material before it and allows the particles a great many chances for orientation. This pushing action is caused by horizontal forces which procuce shear. This shear decreases as depth increases. The horizontal forces due to the movement of the tire are considered the main cause of differences between field and laboratory compaction (41). Endersby and Vallerga (13) have stated that the more pushing around the particles get, the more likely it is that they will reach a stable condition. This pushing around or kneading action provides the needed movement for the particles to align themselves into a position of preferred orientation. Therefore, laboratory specimens which do not have this internal particle arrangement cannot be safely taken to represent the mixture in service.

Present practice in preparing laboratory specimens is based principally upon the concept of equal density with most of the methods incorporating some material agitation varying in some degree from direct static loading. Equal density without regard to orientation and degradation of particles cannot produce representative specimens, and unfortunately there 
is no way to measure the structure of specimens quantitatively in the laboratory. The only way in which it seems possible to compare the structure of the compacted materials is to compare the forces involved in producing the laboratory specimen and field mat. The methods that incorporate horizontal forces and apply shear to the specimen throughout its depth would seem to be the most suitable ones.

\section{Gyratory Testing Machine}

The gyratory testing machine, Figure 3, developed by the Soils Division of the Waterways Experiment Station in Vicksburg, Mississippi, is based on a compaction technique devised by the Texas State Highway Department employing a gyratory principle. This type of compactor produces a shearing action to the sample by a gyratory motion of the steel mold while pressures are maintained at each end against steel loading plungers whose faces remain parallel to each other (36). The amount of shearing action imparted by this gyration is limited by a tilted guide ring. The degree of tilt is called degree of gyration. The machine operates so that the kneading action can be either fixed deformation, variable stress type - that 1s, the sample is forced to deform through a fixed amount and the resisting shear stress may vary as it will; or fixed stress, variable deformation type - that is, the gyrating stress can be relieved.

The gyratory motion is recorded on a chart and results in a gyrograph. Three types of rollers provide for different stress - strain characteristics. These are a fixed roller, a roller with an oil-filled chamber, and a roller with an air-filled chamber. See Figure 4. The oil-filled roller acts essentially as a fixed roller but it indicates the pressure developed 


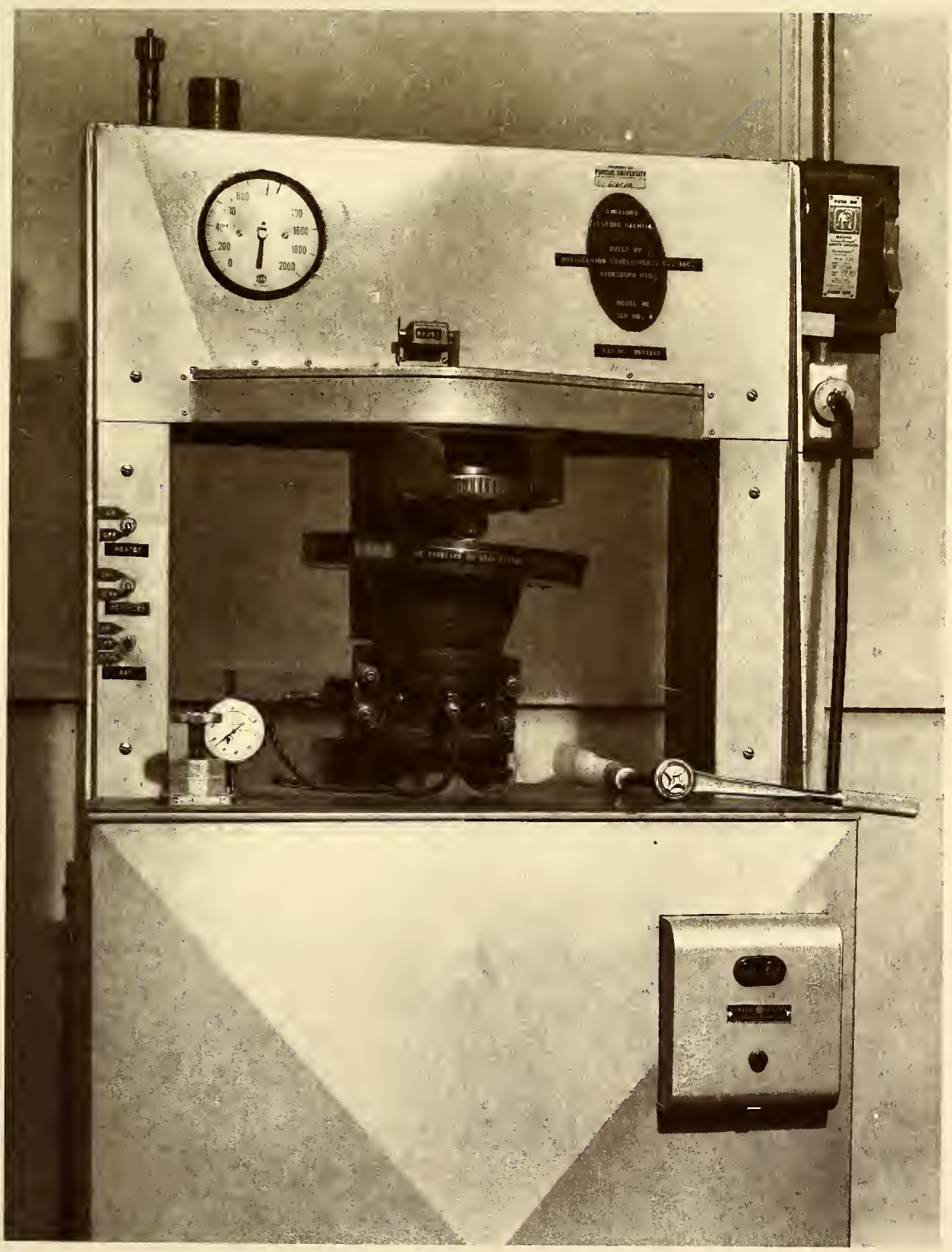

FIG.3 GYRATORY TESTING MACHINE 

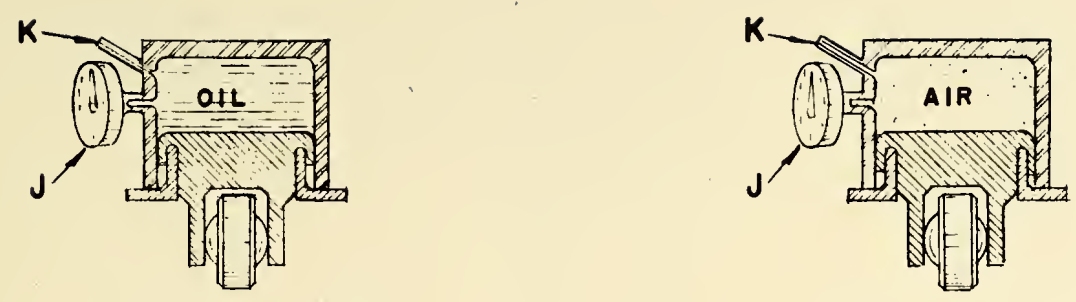

UPPER ROLLER (OIL FILLEO CHAMBER)

$$
\text { UPPER ROLLER }
$$
(AIR FILLED CHAMBER)

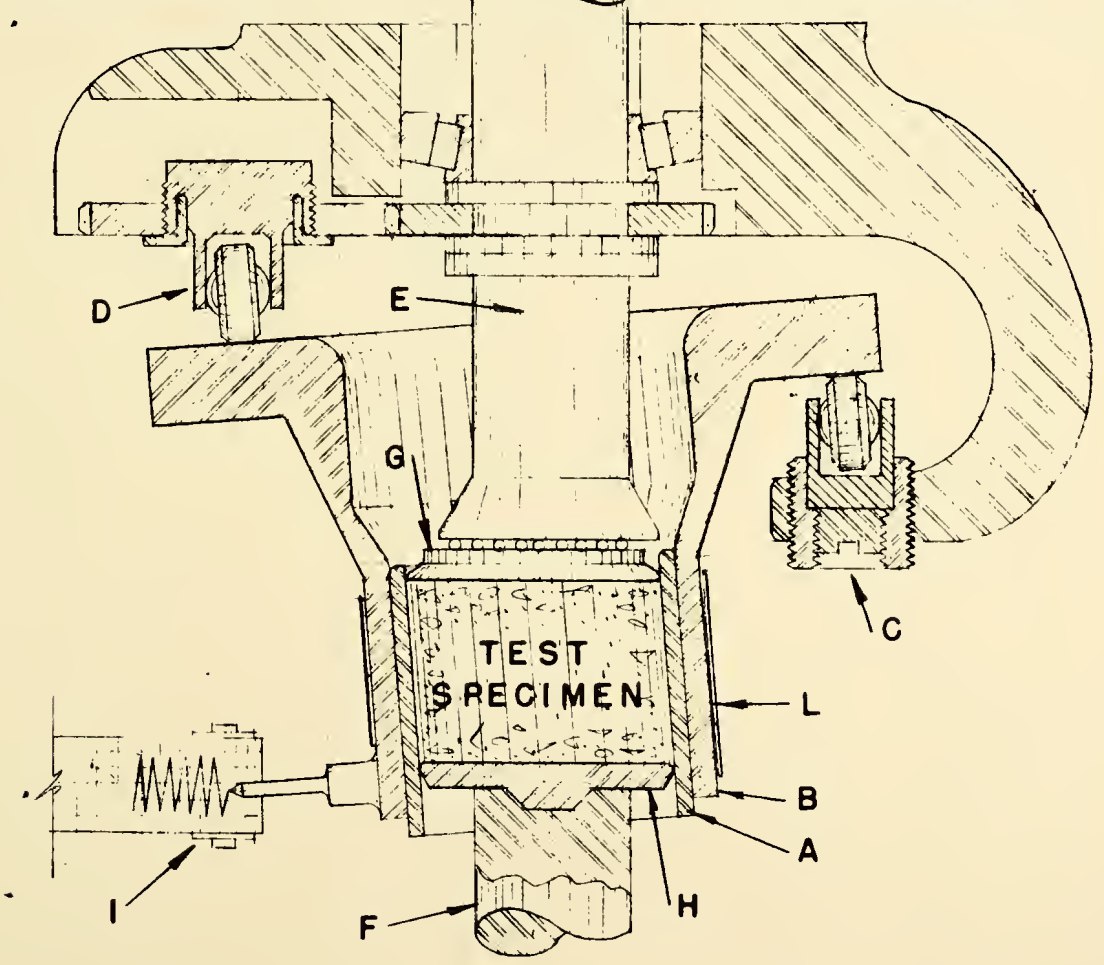

FIG. 4 SCHEMATIC SIDE VIEW OF SECTION THROUGH GYRATING MECHANISM (AFTER CORPS OF ENGINEERS) 
Key to Details of Figure 4

$\begin{array}{ll}\text { A } & \text { Specimen Mold } \\ \text { B } & \text { Mold Chuck } \\ \text { C } & \text { Lower Roller } \\ \text { D } & \text { Upper Roller } \\ \text { E } & \text { Upper Ram Shaft } \\ \text { F } & \text { Lower Ram Shaft } \\ \text { G } & \text { Upper Head } \\ \text { H } & \text { Lower Head } \\ \text { I } & \text { Gyrograph } \\ \text { J } & \text { Pressure Gage } \\ \text { K } & \text { Filling Valve } \\ \text { L } & \text { Heating Element }\end{array}$


due to the resistance to deformation of the test specimen. The air-filled roller acts in such a manner as to permit the degree of kneading to adjust as the test proceeds, and if the resistance to kneading or densification under the applied stresses is sufficiently great, the roller will simply back up to the point where compaction ceases (37). It is believed (59) that changes in gyratory angle indicate changes in the plastic properties of the material being tested; the more easily the material jields to stress the larger will be the Eyratory angle. McRae (59) points out that not only is the gyratory compactor able to produce a satisfactory range of densities, but it produces a specimen that is representative of the parement from the standpoint of stress-strain characteristics which are the main controlling factors in the structure and subsequently degradation of aggregate. These considerations, that the gratory testing machine is able to produce a specimen with structure, density, and progressive compaction similar to that produced by traffic compaction were the basis for selecting it as a suitable means of producing the action required for this study. The compactive effort was changed in two ways, by varying vertical pressure and the number of gyrations. The angle of gyration could also be used as another variable, but all of the tests in this study were made under a one-degree angle of gyration using the fixed roller. An increase in the angle of gyration would subject the specimen to a higher lateral pressure and a larger deformation and therefore might represent conditions present in military airfields rather than highways where the contact pressure between tires and surface is not so large. The vertical pressures used in this study in most cases were 50, 100, 200, and 250 psi; the number of gyrations ranged from 30 to 250 , for the most part, but in some cases 
up to one thousand gyrations were used. For some specimens with zero percent of asphalt the vertical pressures were limited to 200 psi in fear of damage to the mechanical system of the compactor if higher pressures were used. The mixtures were brought from the mixing temperature to a temperature of $230^{\circ} \mathrm{F}$ and were placed in the eyratory machine for compaction. Electric heating elements around the mold were used to provide an elevated temperature throughout the test.

After each $\mathrm{mix}$ had been subjected to the gyrating action, an extraaction test was made on the whole specimen by the use of a Dulin Rotarex extractor, and the gradation of the extracted aggregate was determined for comparison with the gradation before mixing and compaction.

\section{Production of Rounded Aggregate}

In order to study the effect of angularity on the degradation characteristics of aggregates, artificially rounded pieces were produced from crushed Baraboo quartzite. This was done by placing a quantity of crushed stone of one size in the Los Angeles abrasion machine, without the steel balls, and subjecting it to the wearing action of a few thousand revolutions of the machine. In order to obtain uniform roundness for all sizes, the number of revolutions of the machine had to be decreased with decrease in aggregate size. Therefore, this number was changed from 12,500 revolutions for materials of size $1 / 2^{n}-3 / 8^{\prime \prime}$ to 5000 revolutions for materials of size \#16 - \#50 sieves. After every 2,500 revolutions the aggregate in the Los Angeles machine was washed in order to remove the fine particles adhering to the coarse pieces. Samples of the original crushed quartzite and the artificially rounded pieces are pictured in Figure 5. 


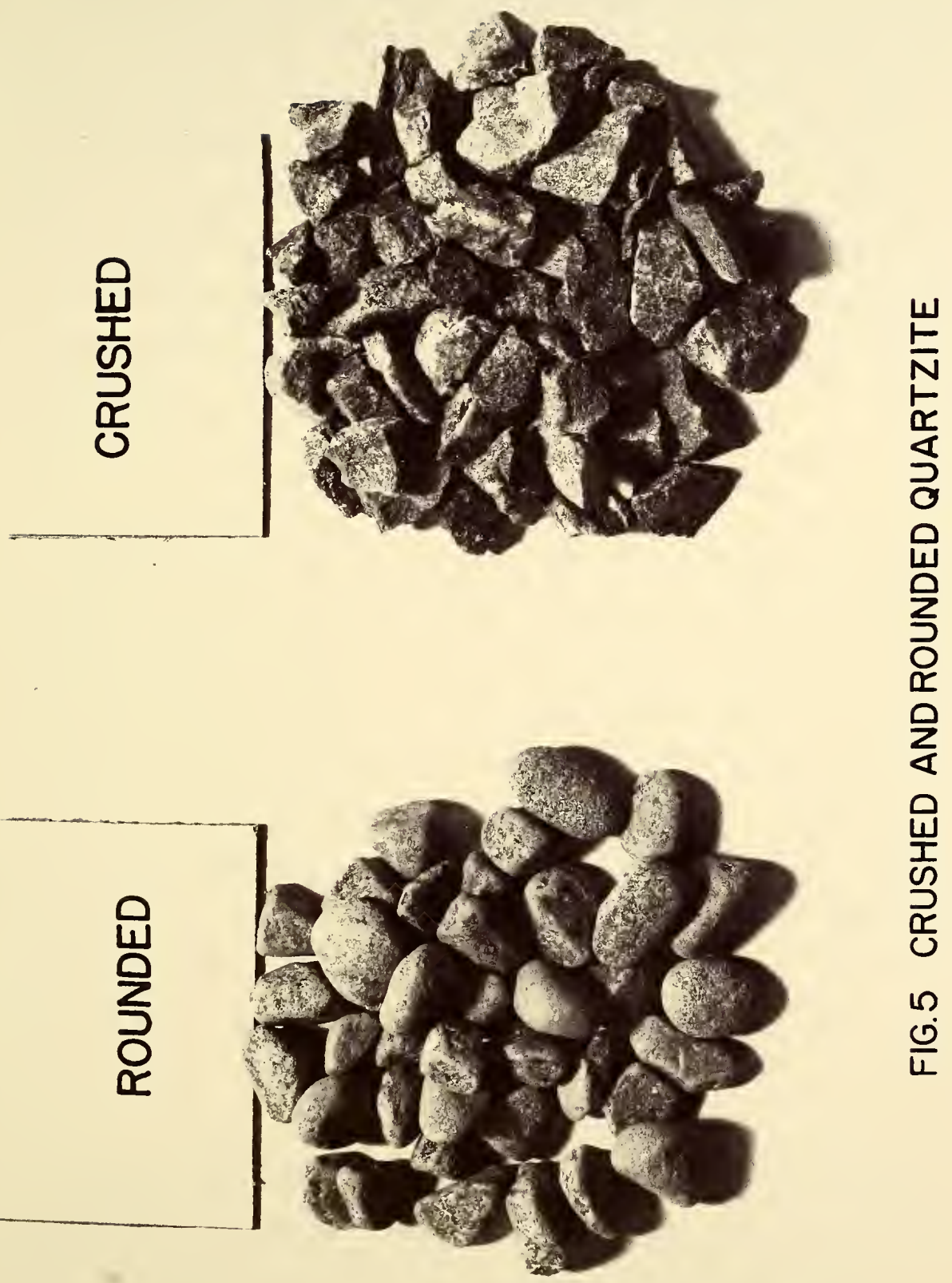


Quartzite was selected for this rounding process because it is the hardest of the materials used in this investigation and the chance of its breakage is much less than for the other two types of aggregates. Therefore, it was thought that the difference between the degradation of its crushed and rounded pleces, especially in dense-graded mixtures, should be a good measure of wearing action as opposed to degradation by breakage. In other words, in mixtures made of rounded aggregate, the action of wear is minimized and the change in gradation is due principally to crushing of the pieces.

\section{Dyeing Process}

In order to find out that how various sizes of aggregate degrade in an aggregation of pieces of different sizes, the three top sizes; namely, $1 / 2^{n}$ - 3/8", 3/8" - \#3, and \#3 - \#4 were dyed different colors so that after compaction and extraction of asphalt the newly-produced sizes could be associated with the original piece by colored faces. For this purpose the dyes had to be soluble in water, stay on the surface of piece, and not be soluble in asphalt or trichlorothylene used in extraction. The following three dyes produced by Allied Chemical Co. were found to have such characteristics:

\section{Orseillin BB Red \\ 2. Crystal Violet \\ 3. Malachite Green Oxalate}

Bloomington limestone was found to be the best among the three types of aggregate for use in the dyeing studies due to fts low porosity, natural color, and surface adhesion. Figure 6 shows the colored sizes and the natural color of Bloomington limestone. 
FIG. 6 DYED AND NATURAL COLOR OF TOP FOUR SIZES OF LIMESTONE 


\section{RESULTS}

In this section, the test results from this study are presented along with a discussion and evaluation. Summarized data are included with graphical illustrations of trends shown by the data. The section is divided into three sub-sections; results of studies on single-sized aggregate, results of studies on dyed aggregate, and results of detailed studies of degradation of aggregate in bituminous mixtures.

of the several methods available to represent the degradation characteristics of aggregate, two were chosen for this study: one was a simple gradation curve of percent smaller than certain sizes, and the other was based on surface-area concepts. The first method, which is commonly used by civil engineers for representing materials of different sizes, does not require explanation. Using the surface-area concept, measurenents of the degradation are made on the basis of surface-area increase as determined by sieve analysis. The factors used for computing surface areas are given in Table 5 for an assumed specific gravity of 2.65. These values are similar to those used by Shelburne (1) and are calculated on the assumption that all material passing the No. 4 sieve was spherical and that retained was one-third cubes and two-thirds parallelopipedes with sides of $1: 2: 4$ proportions.

It was decided that numerical increase in surface area, which is merely the difference between the final surface area and the original surface area, is not a satisfactory measure of aggregate degradation. For example, when 
TABLE 5

SURFACE AREA FACTORS

\begin{tabular}{ccc}
\hline \multicolumn{2}{c}{ Fraction of Material } & \multicolumn{2}{c}{ Factor } \\
\hline Passing & Retained & Sq. cm. per gram \\
\hline $1 / 2^{\prime \prime}$ & $3 / 8^{\prime \prime}$ & 2.2 \\
$3 / 8^{\prime \prime}$ & $1 / 4^{\prime \prime}(\# 3)$ & 3.2 \\
$\# 3$ & $\# 4$ & 4.5 \\
$\# 4$ & $\# 6$ & 5.7 \\
$\# 6$ & $\# 8$ & 7.9 \\
$\# 8$ & $\# 16$ & 12.7 \\
$\# 16$ & $\# 50$ & 30.0 \\
$\# 50$ & $\# 100$ & 100.0 \\
$\# 100$ & $\# 200$ & 205.0 \\
$\# 200$ & Pan & 615.0
\end{tabular}

Note: Assumed sp. $\mathrm{gr} .=2.65$. For values other than 2.65, multiply the above factors by 2.65 sp. gr. 
a mixture with an original surface area of $2.2 \mathrm{~cm}^{2} / \mathrm{gr}$ has increased 2.2 $\mathrm{cm}^{2} / \mathrm{gr}$ in surface area after compaction, and another mixture with 67.3 $\mathrm{cm}^{2} / \mathrm{gr}$ has increased the same amount, we cannot consider that the two mixtures have undergone equal degradation. The first mixture has gained 100 percent in surface area or in other words its final surface area is twice the original, while the second mixture has increased only 3 percent in surface area. Therefore, it was decided to express the data in percent increase in surface area rather than increase in surface area. Another advantage of the percentage method is the elimination of the necessity for correction of surface area values for specific gravity. The following equation shows that the value of specific gravity does not affect the percent increase in surface area.

$$
\begin{aligned}
& \text { \% increase in surface area }=\frac{\left(S_{.} A_{. f}-S_{.} A_{0}\right) \frac{2.65}{S p_{0} \text { gr. }_{0}}}{\left(\text { S.A.0) } \frac{2.65}{\text { sp. gr. }}\right.} \\
& =\frac{\left(S_{0} A_{0_{f}}-S_{0} A_{0}\right)}{\left.S_{0} A_{0}\right)}
\end{aligned}
$$

where:

$$
\begin{aligned}
& \text { S.A. } f \text { final surface area } \\
& \text { S.A. }=\text { original surface area } \\
& \text { sp. gr. = specific gravity of material }
\end{aligned}
$$

The term degradation is used in this study to include all of the aggregate breakdown due to mechanical action regardless of the type of mechanical action causing it. Degradation can result from aggregate fracture or breakage through the piece, from chipping or corner breakage, and from the rubbing action of one piece or particle against another. In parts of this study, 
attempts were made to separate degradation into two parts, one due to fracture through the piece and designated as breakage, and the other due to corner breakdown and attrition which collectively has been designated as wear.

\section{Single-sized Aggregate}

Size of particles and maximum size of particlesare cited in the literature among the factors controlling degradation. In order to determine whether or not change of size will change the degradation characteristics of an aggregate, and in order to investigate the effect of combinations of pleces of different sizes on degradation, specimens of one-sized aggregate were tested. The results are presented in Table 6. This table includes the results of sieve analysis together with percent increase in surface area for 12 specimens. Specimens containing one thousand grams of one-sized aggregate of $1 / 2^{\prime \prime}-3 / 8^{n}, 3 / 8^{n}-\# 3$, \#3 - \#4, and \#4 - \#6 of each of the three aggregates, dolomite, limestone, and quartzite, were compacted in the gyratory compactor under 200 psi ram pressure and 100 revolutions.

Figures 7, 8, and 9 show the results of sieve analysis on these specimens for each type of aggregate. From these figures it can be seen that regardless of size and type of aggregate, all the curves appear to be approaching a parabolic shape. The figures also indicate that as the original size of particles decreases there is a corresponding increase in fine material, which might suggest that degradation increases as size of the particle decreases. Figure 10 presents the percent increase in surface area versus average size of original particles for the three kinds of aggregate. This figure shows that as the size of one-sized aggregate increases 


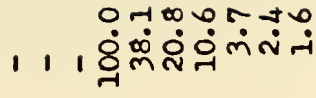

O Ommman

1 1 ठ্ণ

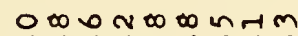

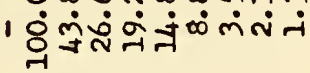

O०พaOmo-n-

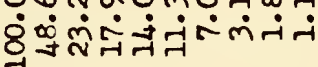

ODMONma

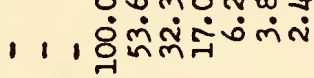

omaramon

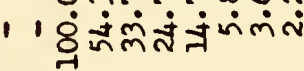

0 t 1 -

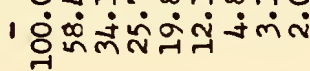

Omoaninram

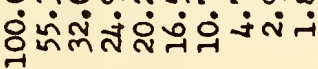

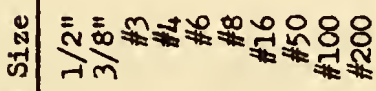

ஜ

审

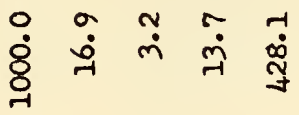

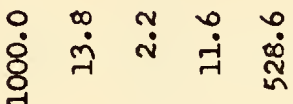

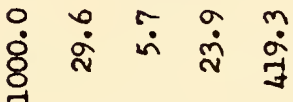

요

ஸूँ

ஸूँ

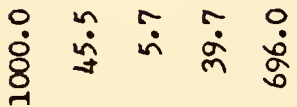

茯

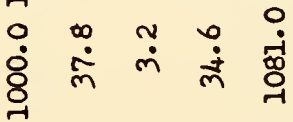

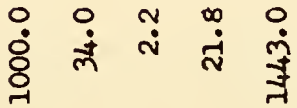

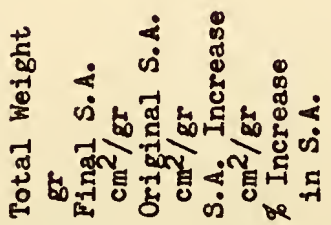




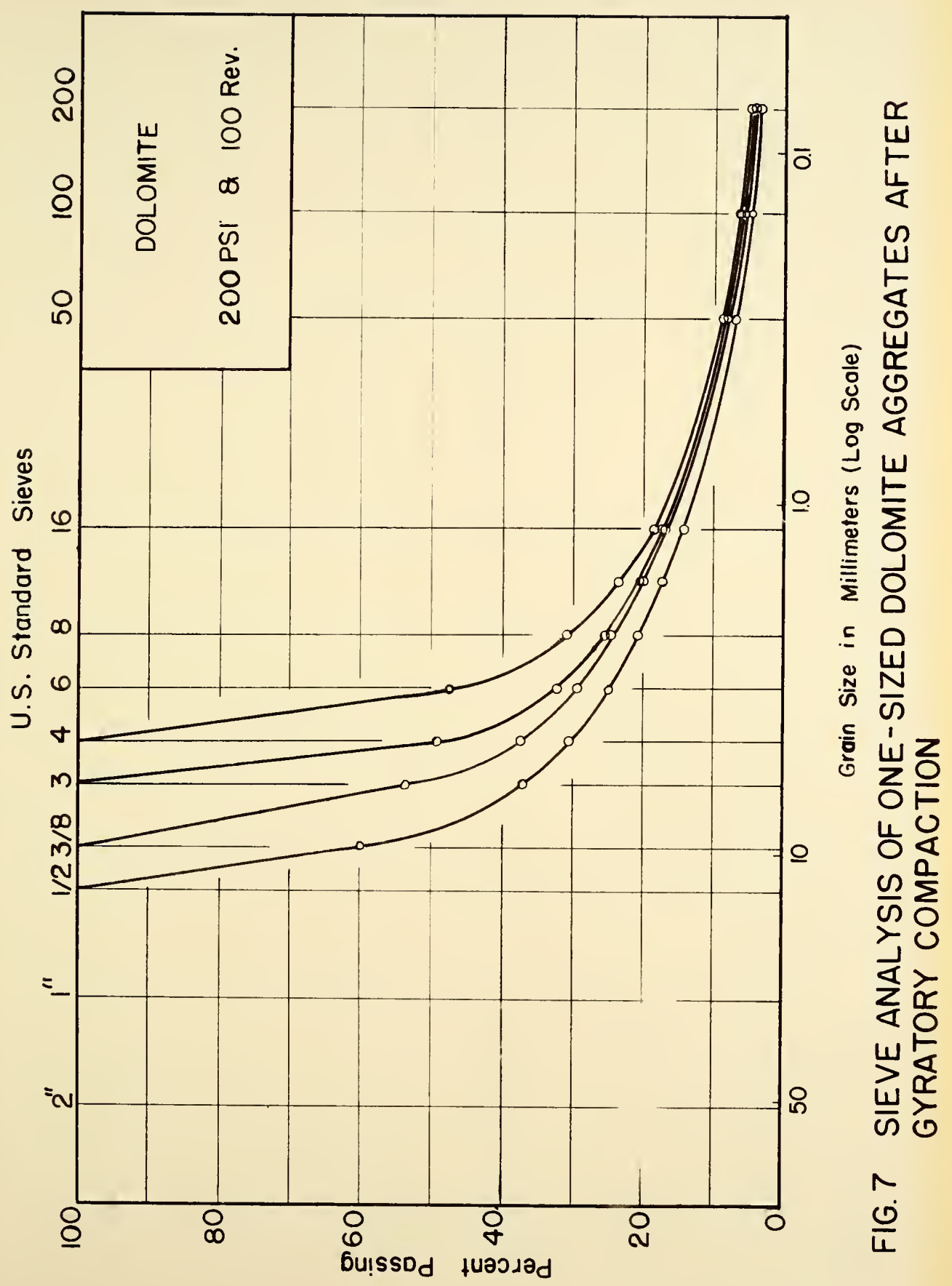




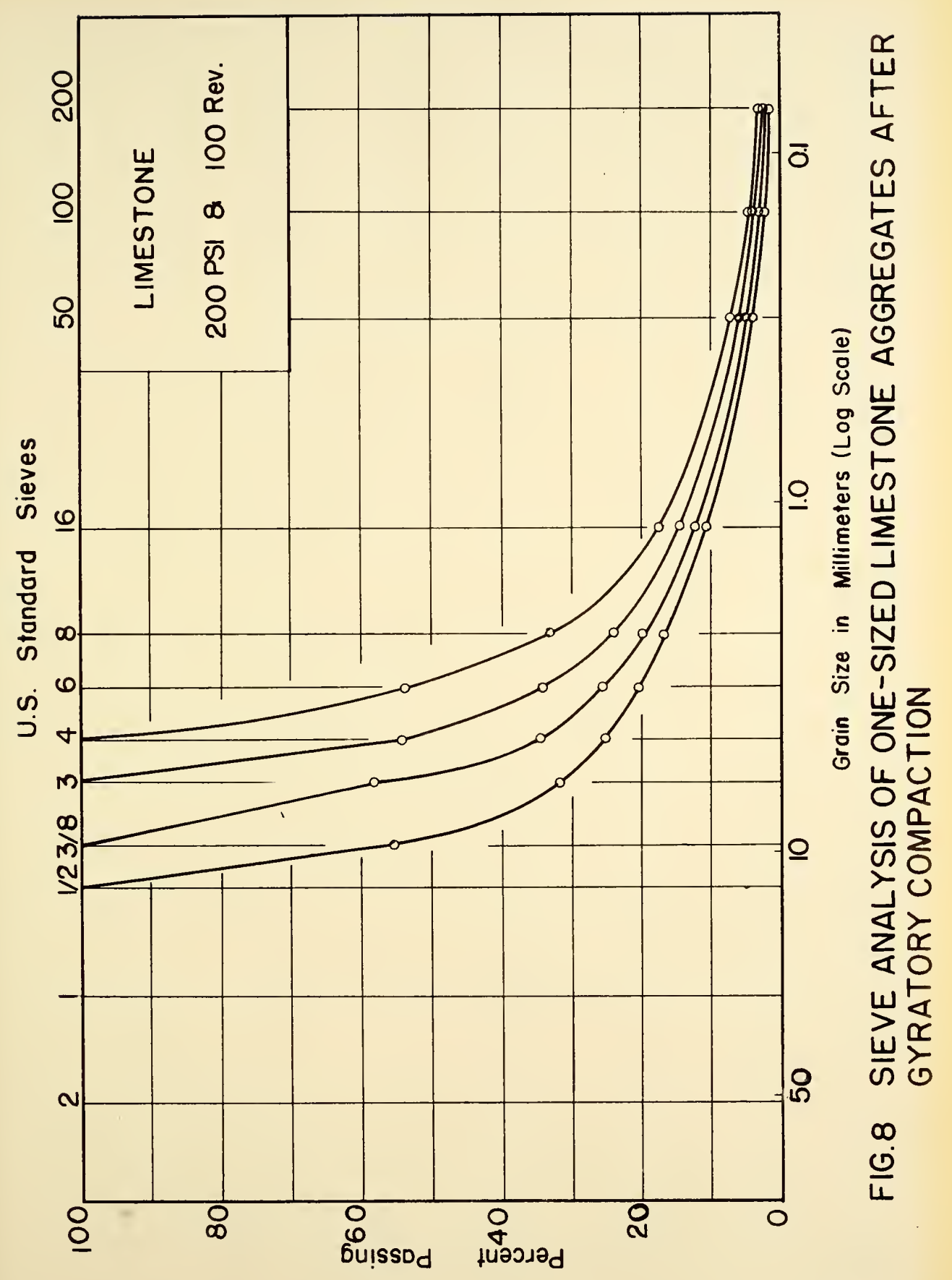




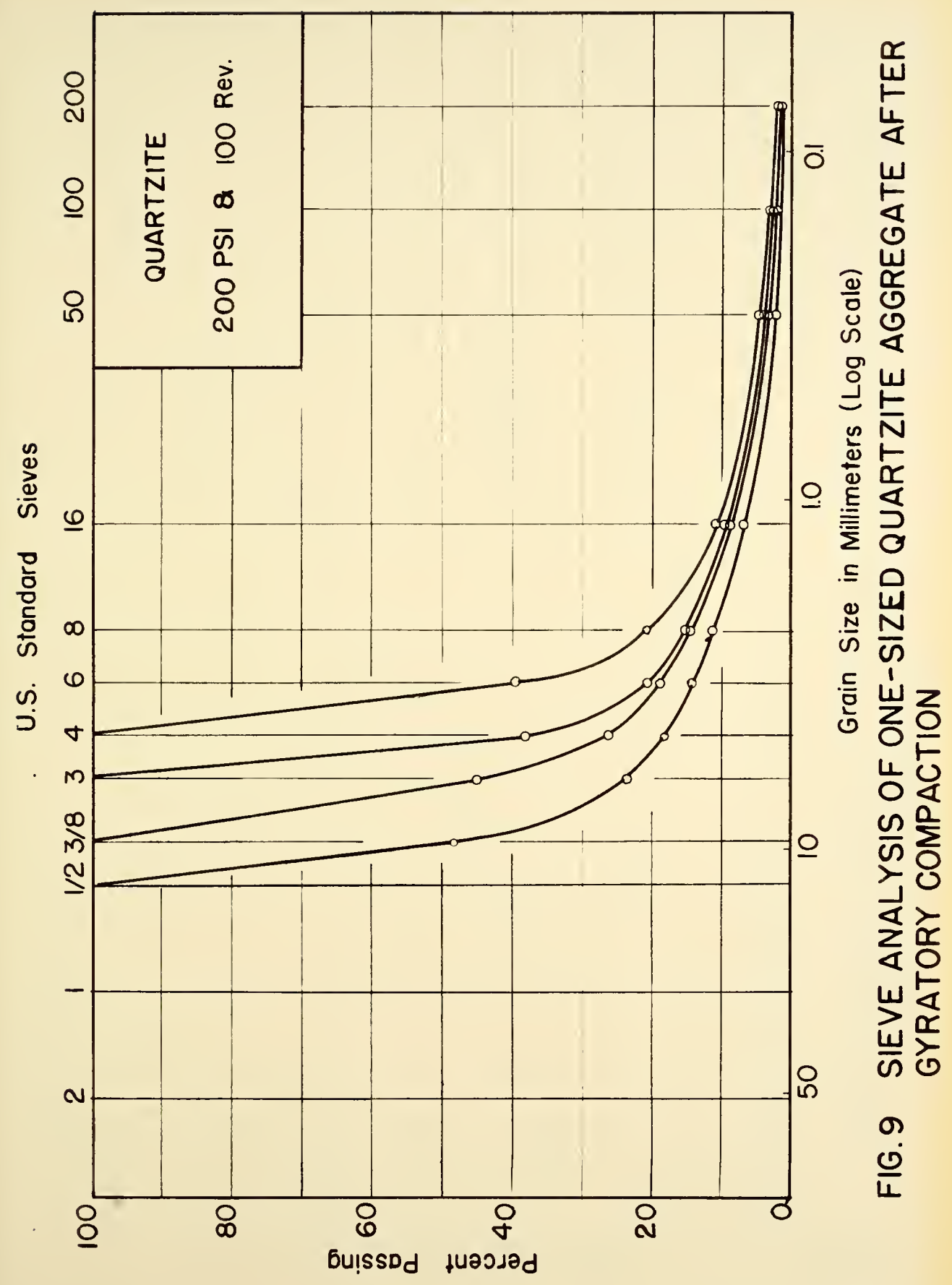




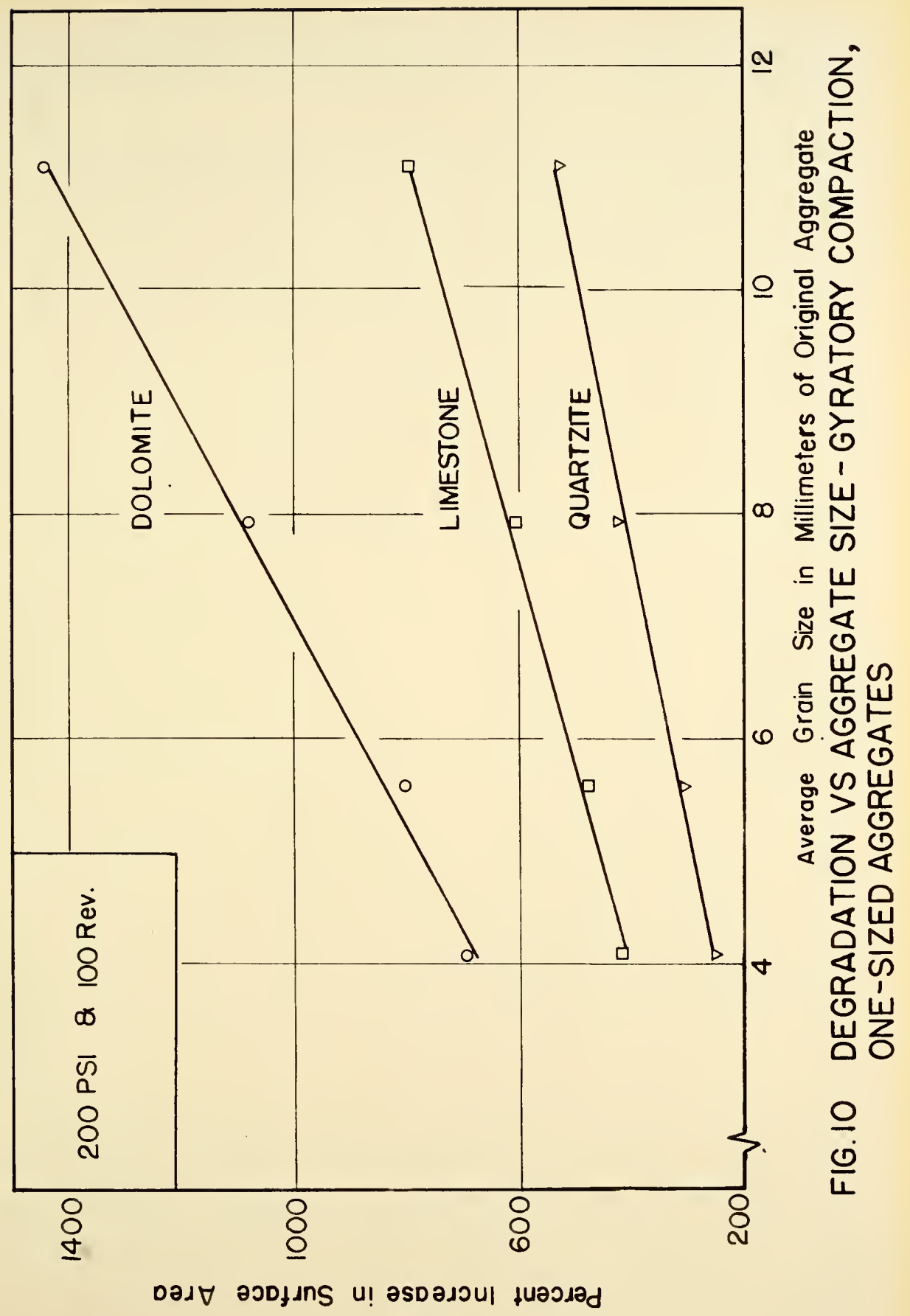


the degradation under equal compactive effort (200 psi and 100 revolutions) increasea.

Therefore, at first glance it appears that the results of the two methods, sieve analysis and percent increase in surface area, are in conflict. Clarification lies in the fact that sieve analysis representation only indicates what percent of material is of which size, without considering through what changes this material has gone and what was its original condition. If sieve analysis representation was a good measure of degradation, then two specimens of different-size particles would have undergone equal degradation if the percent passing a certain sieve were equal for each of them, which obviously is not the case. A piece of larger size has to undergo more breakdown than a smaller particle to become of a certain size. Therefore, it can be seen that sieve analysis representation, although it is an excellent means for studying the pattern of degradation, by no means can be used as a measure of degradation and the concept of percent increase in surface area obtained by relating the produced area to the original area, is a much better means of measuring degradation.

Figure 10 also shows that degradation increases from quartzite to limestone to dolomite, which follows the same pattern as indicated by the Los Angeles rattler test. In other words, degradation of one-sized material increases as the material becomes weaker and softer (higher Los Angeles value).

Pigure 11 illustrates the percent increase in surface area for different original one-sized fractions versus Ios Angeles values of the three kinds of aggregate. Points on each line represent specimens made of particles of sizes indicated on the curves. The ordinate of each point represents 


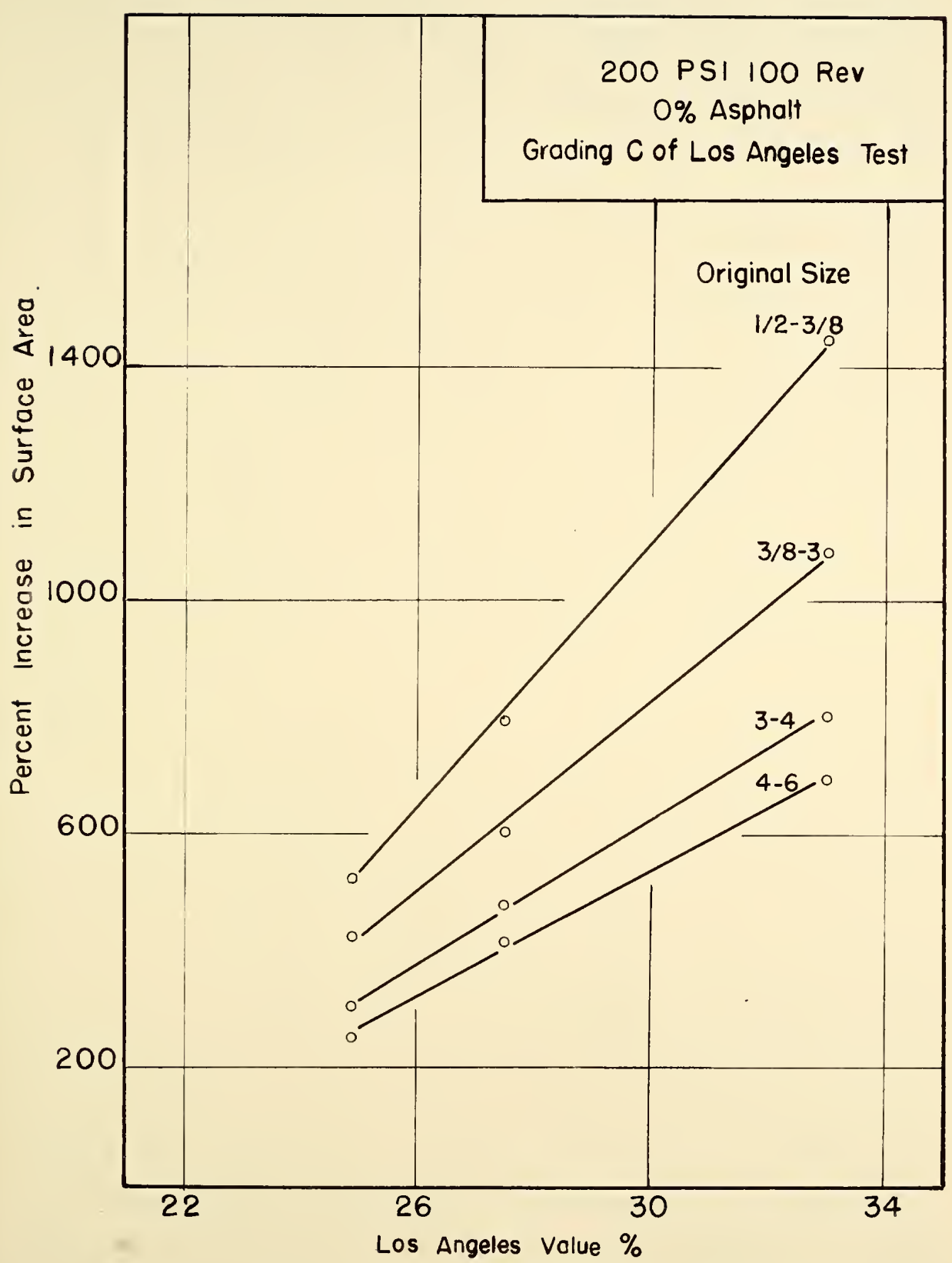

FIG.II DEGRADATION VS LOS ANGELES VALUE-GYRATORY COMPACTION, ONE-SIZED AGGREGATES 
the degradation obtained on a sample of the specified size of particles by gyratory compaction using $200 \mathrm{psi}$ and 100 revolutions, while its abscissa is the Los Angeles value of that kind of aggregate when tested at grading C. A detailed discussion of this result is presented later in this discussion.

From compaction of one-sized aggregate in the gyratory machine it was concluded that the curve shape of sieve analysis representation is similar for all sizes and all kinds of aggregates used. It also was found that changing the size of aggregate only changes the magnitude of degradation rather then its pattern. Therefore, it was decided to use $1 / 2$ in. as the maximum size of particles in the balance of this study. This size is also close to the maximum size allowable for 4-inch diameter specimens and it is the maximum size specified by specification of the State Highway Commission of Indiana for Hot Asphaltic Concrete Surface - Type B (medium texture).

Since it was found that changing the size of particle does not change the shape of the resulting sieve analysis curves for degradation of onesize aggregate in the gyratory machine, it was decided to find out whether the method of compaction will cause a change in such a curve. For this purpose one-sized pieces of the three kinds of aggregate were compacted in the Calfornia kneading compactor under the standard procedure of 500 psi foot pressure and 150 tamps and under static loading applied at the rate of $0.05 \mathrm{in./min.} \mathrm{to} \mathrm{a} \mathrm{maximum} \mathrm{pressure} \mathrm{of} 250$ psi. The results of sieve analysis and percent increase in surface area are tabulated in Table 7 and sieve analysis results are plotted in Figures 12, 13, and 14. Figure 12, which shows the sleve analysis for the three kinds of aggregate when tested 


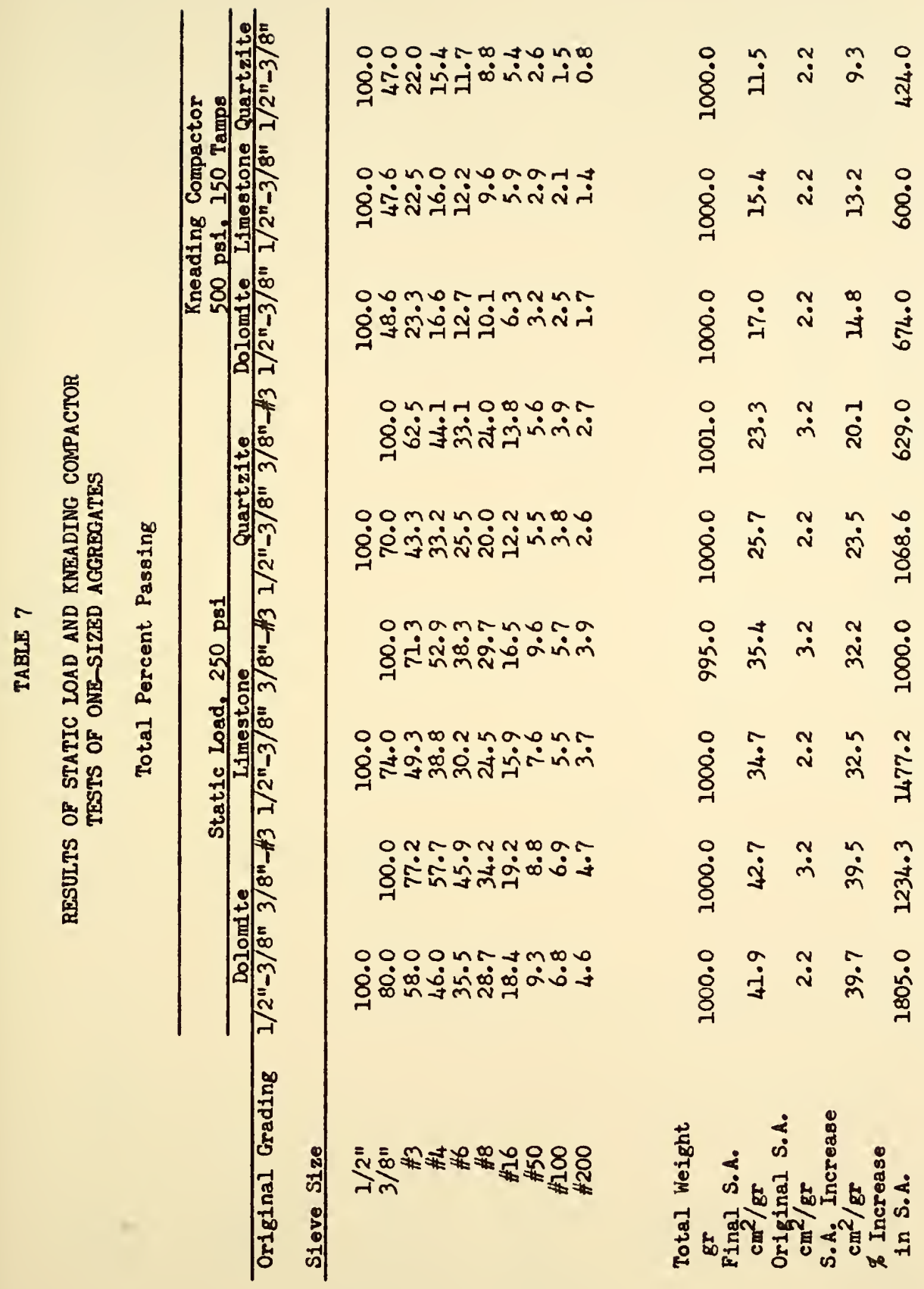




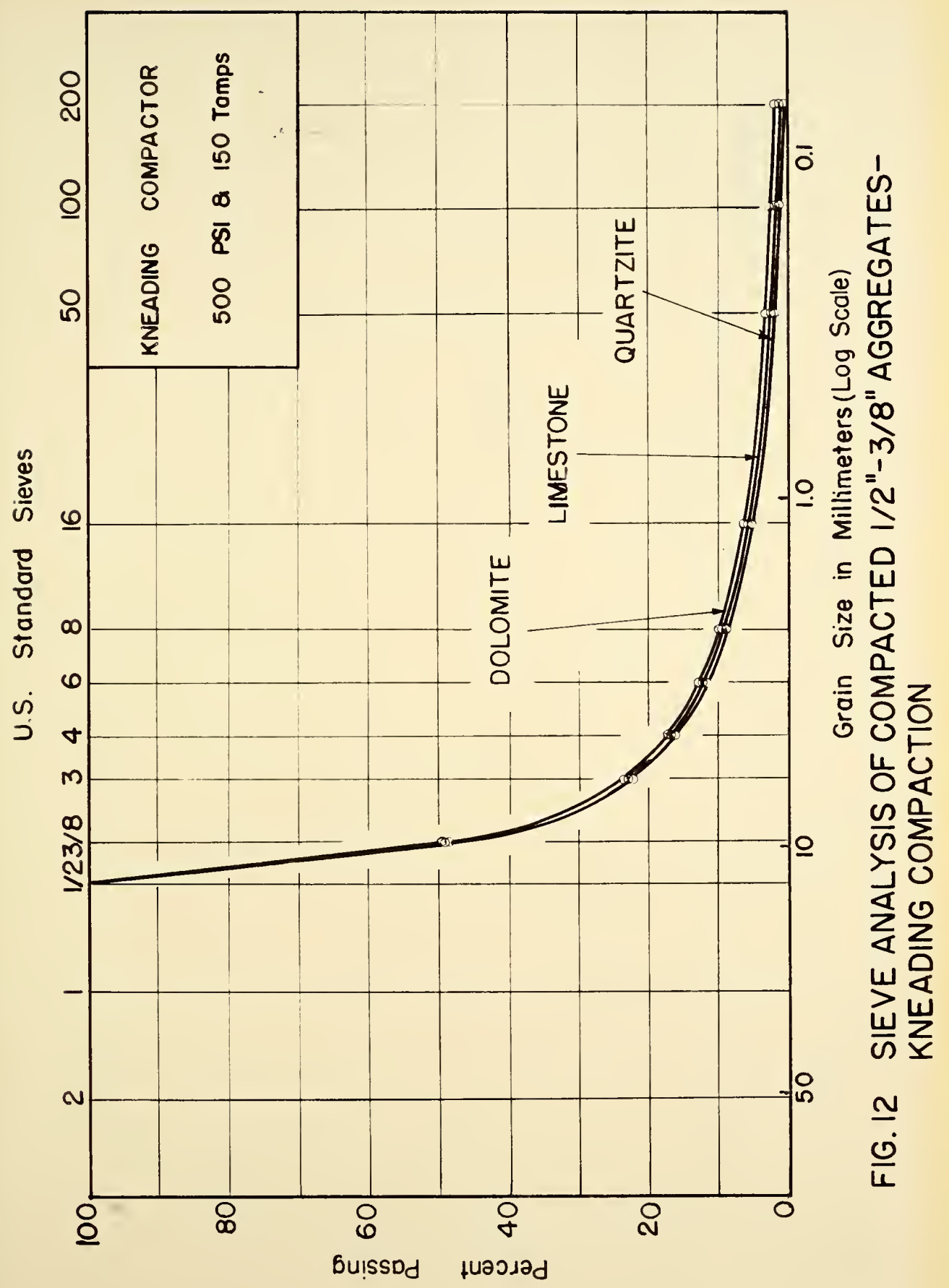




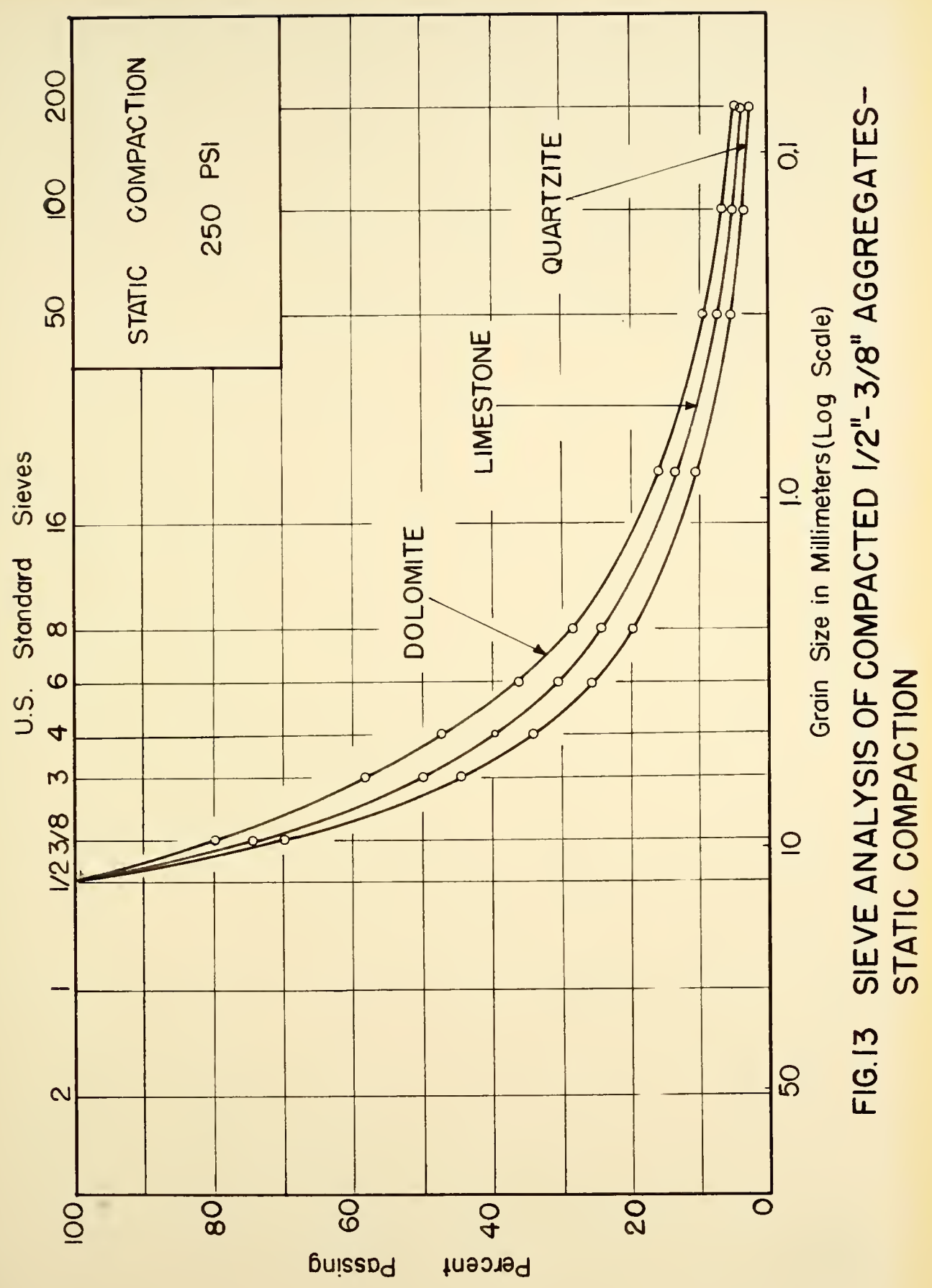




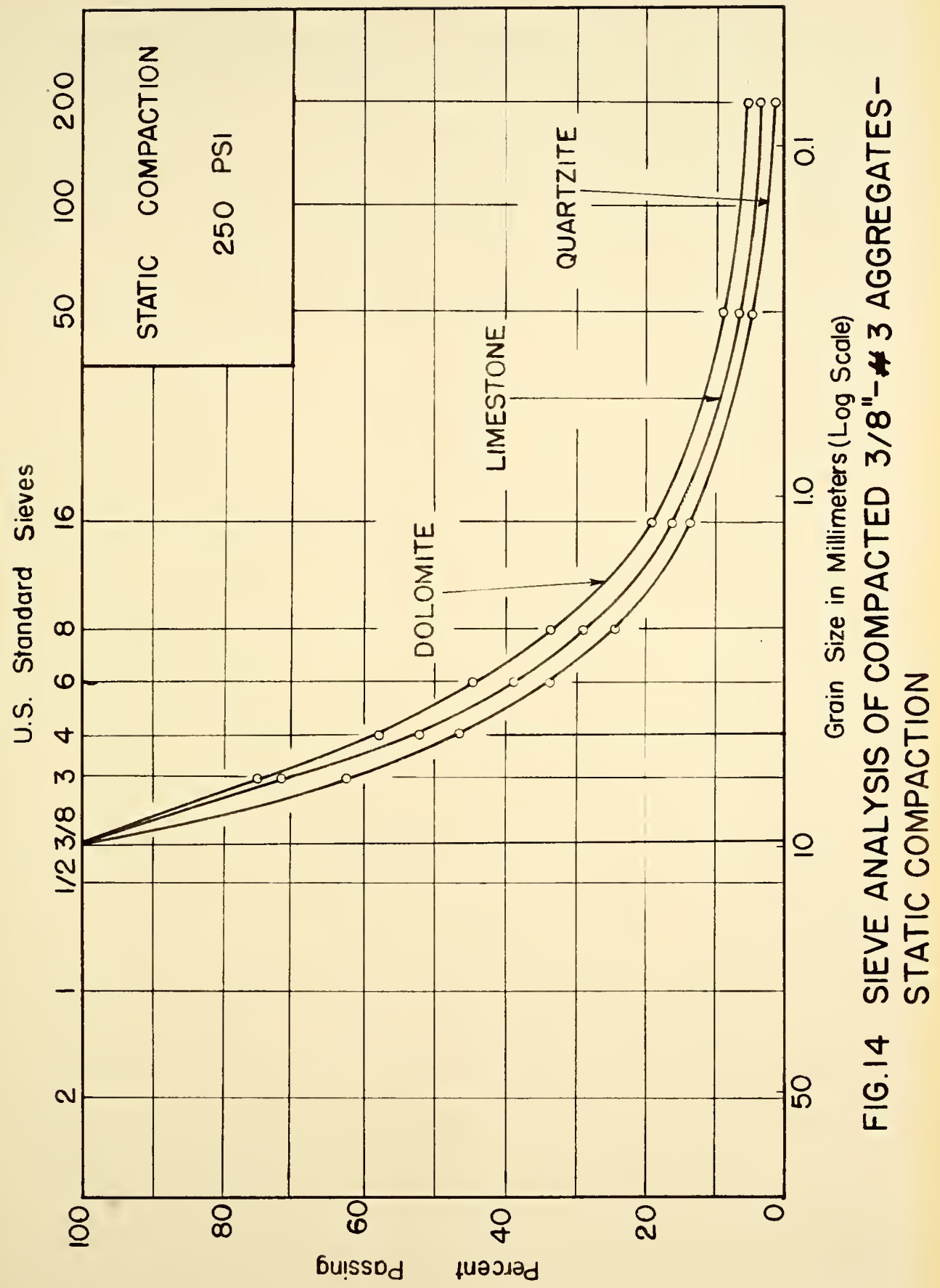


in the Kneading Compactor using one-sized material of $1 / 2-3 / 8$ in. size, indicates that the curves are approaching a parabolic curve as was the case for gyratory compaction (Figures 7, 8, 9). Figure 13 shows the results obtained from static compaction of one thousand grams of pleces of size $1 / 2-3 / 8$ in. for the three kinds of aggregate. Here 1 t can be noted again that the curves have the same general shape as those for gyratory and kneading compaction; however, the lower portions of the curves have shifted upward.

Figure $\mathcal{H}_{4}$ shows the sieve analysis results for static compaction of the $3 / 8$ in. - No. 3 size of the three aggregates. It can be seen that again the curves are parabolic in shape. Therefore, from these results, It could be concluded that grading of compacted one-sized aggregate approaches a parabolic curve regardless of type of compaction, type of aggregate, and size of particles. From the results it was also established that soft aggregate under equal conditions produces a curve which occupies a higher position indicating more degradation than for hard aggregate.

Figure 15 shows degradation versus los Angeles values of the three kinds of aggregate for one-size materlals compacted under kneading and static compactions. This figure presents results similar to those of Figure 10. From this figure it can be seen that although the degradation of an aggregate increases as the Los Angeles value increases, the relationship between degradation and Los Angeles value is not linear as was the case for gyratory compaction. This point is discussed in more detail in a later section. Figure 15 also indicates that under static compaction the larger the original size, the more the degradation produced. 


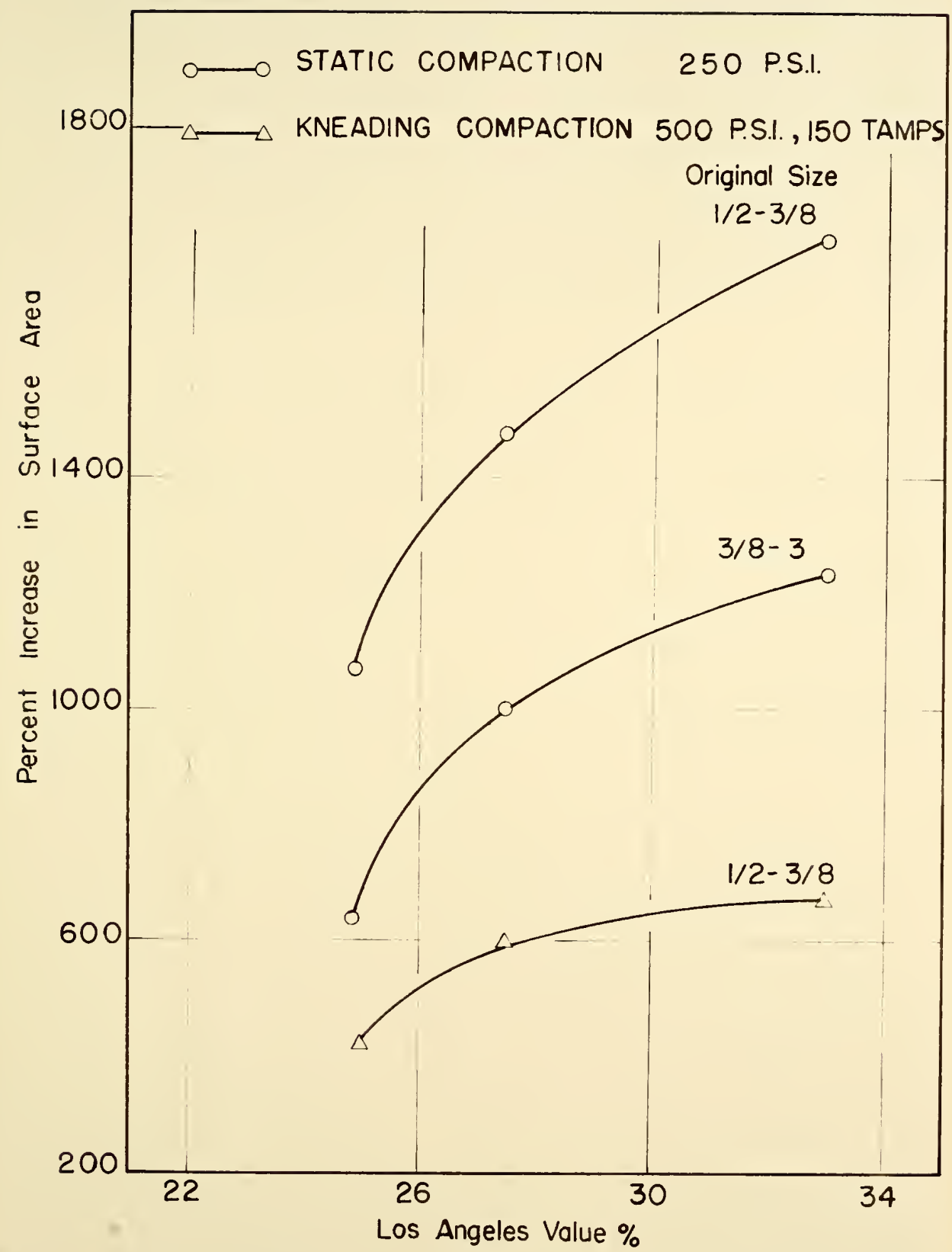

FIG. I5 DEGRADATION VS LOS ANGELES-STATIC AND KNEADING COMPACTION- ONE-SIZED AGGREGATES 
The last point investigated in this section on one-sized material was the effect of the number of revolutions of the gyratory machine on degradation. For this purpose five specimens of each kind of aggregate having an original size of $3 / 8$ in - No. 3 were compacted under 100 psi ram pressure and five different numbers of revolutions in the gyratory machine. Table 8 gives the results of sieve analysis and percent increase in surface area for each specimen. The number of revolutions used ranged from 50 to 1000.

Figures 16, 17, and 18 show the results of sieve analysis of material after compaction. Numbers on each curve indicate the number of revolutions to which the specimen was subjected. These figures also indicate that the general shape of the gradation curve is not changed by a change in compactive effort; as compactive effort increases the curve only shifts upward. The other point worth noticing is that the space between the curves increases as the material becomes softer or weaker. In Figure 18, which shows the results for quartzite, the lower portions of the curves are very close to each other while in Figure 16, which is for dolomite, the lower portions of the curves are wide apart. This Indicates that soft or weak materials are more susceptible to change of compactive effort than hard and strong ones. This point is affirmed by Figure 19 which shows the degradation versus number of revolutions. It can be seen that as compactive effort increases the degradation also increases, but generally a significant portion of the degradation occurs under first few hundred revolutions and then the curves start leveling off. The figure also indicates that as the material becomes softer or weaker, the slope of the latter part of the curves increases, which again indicates that such materials are more susceptible to change in compactive effort. 


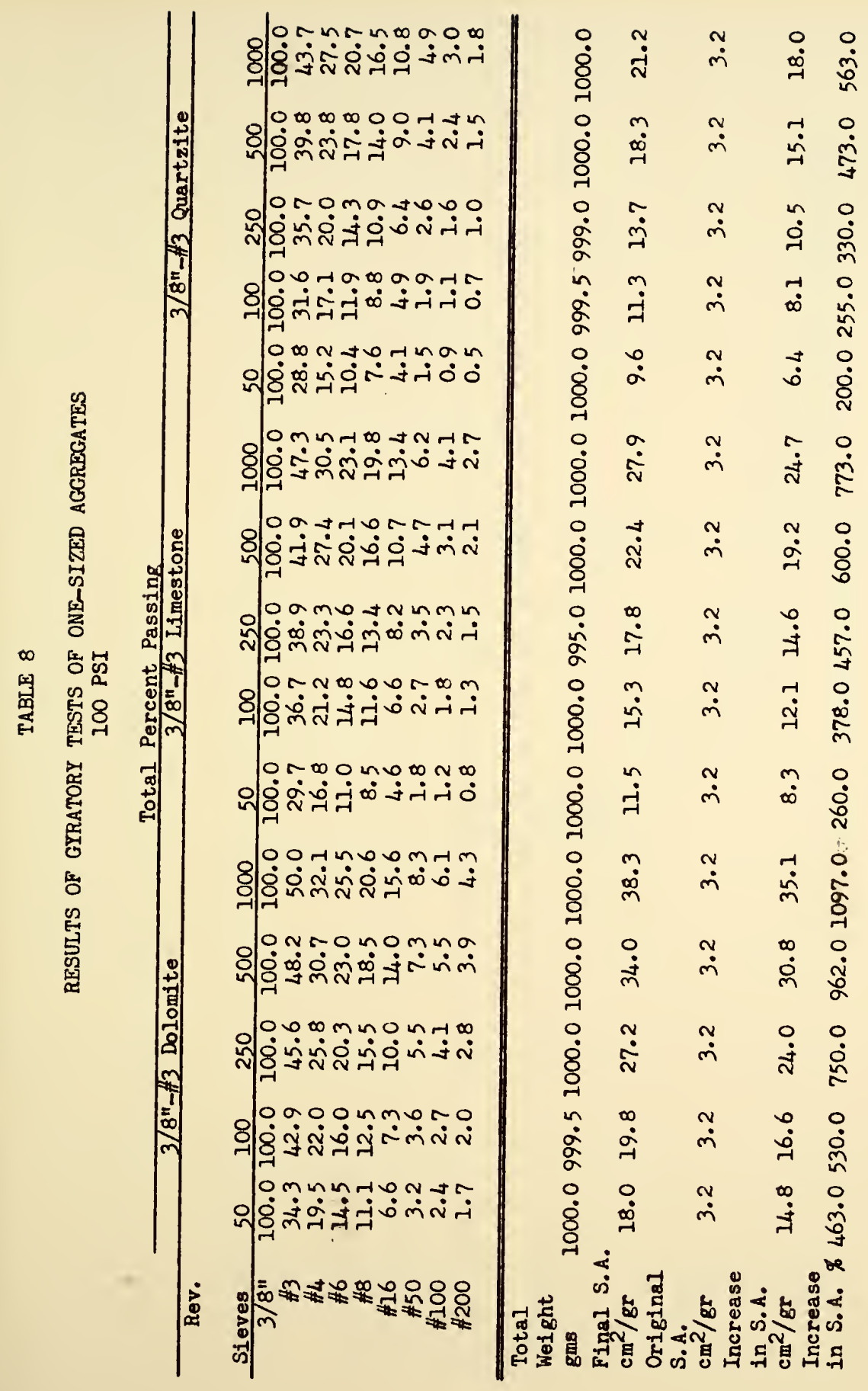




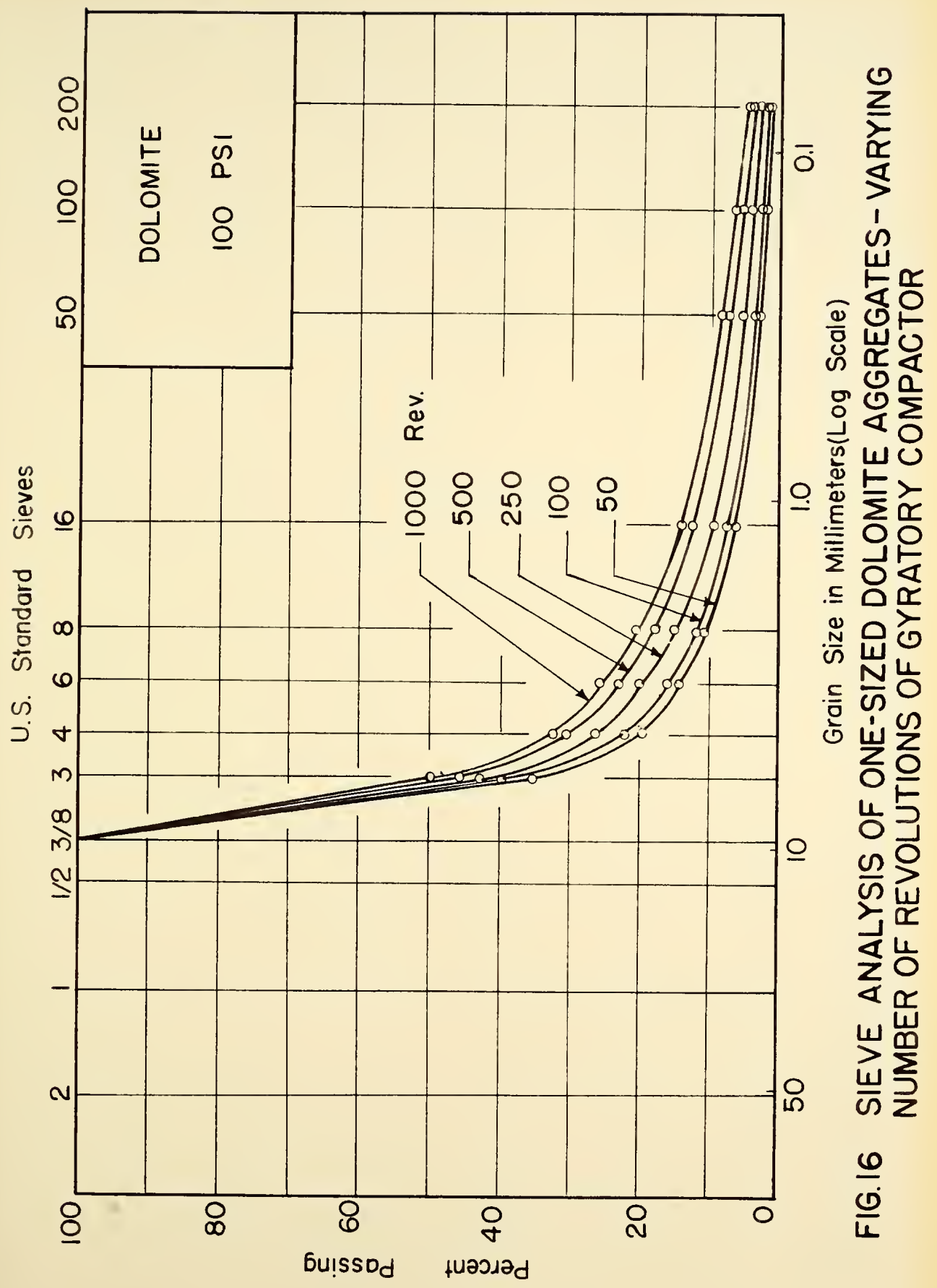




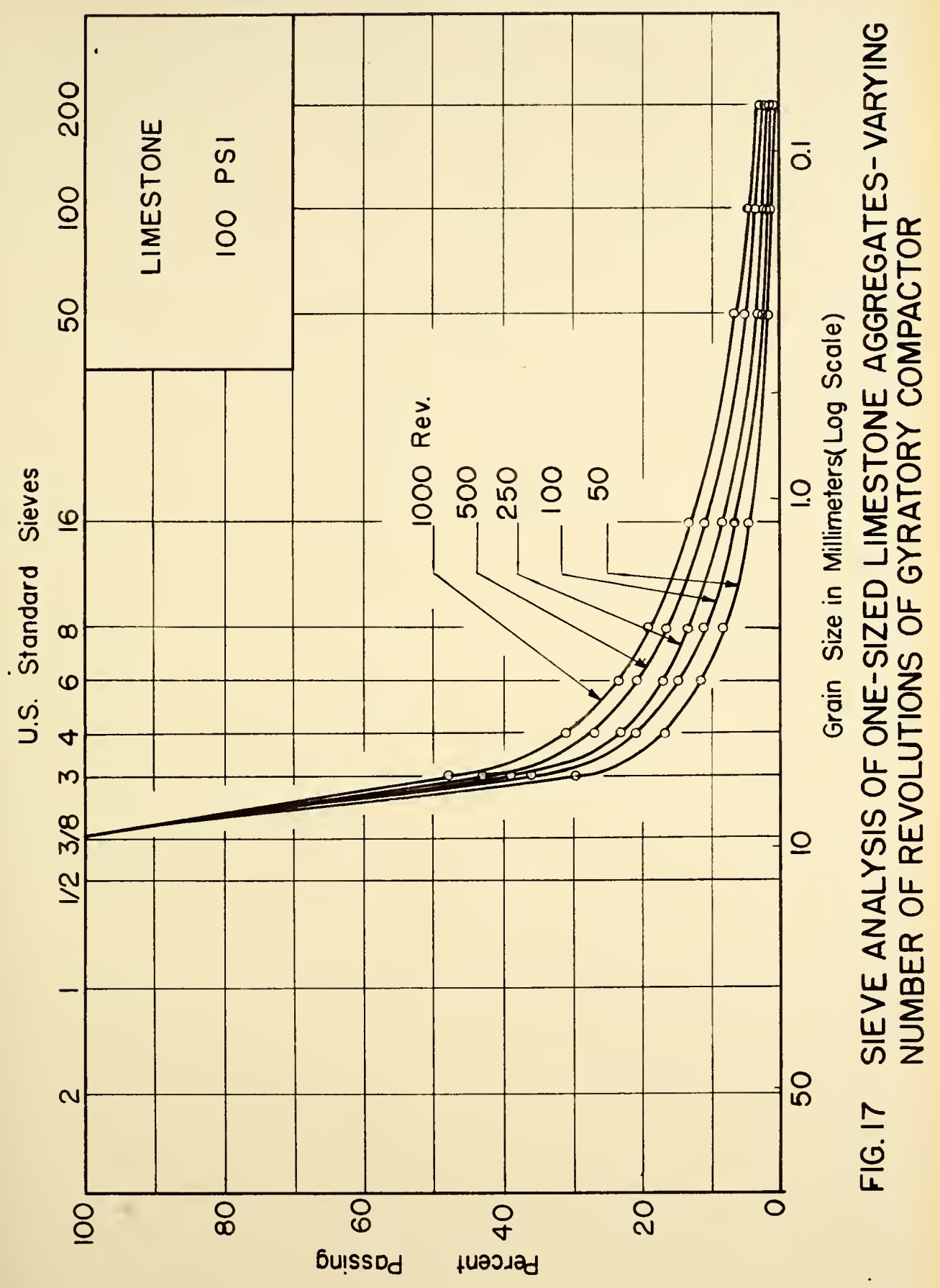




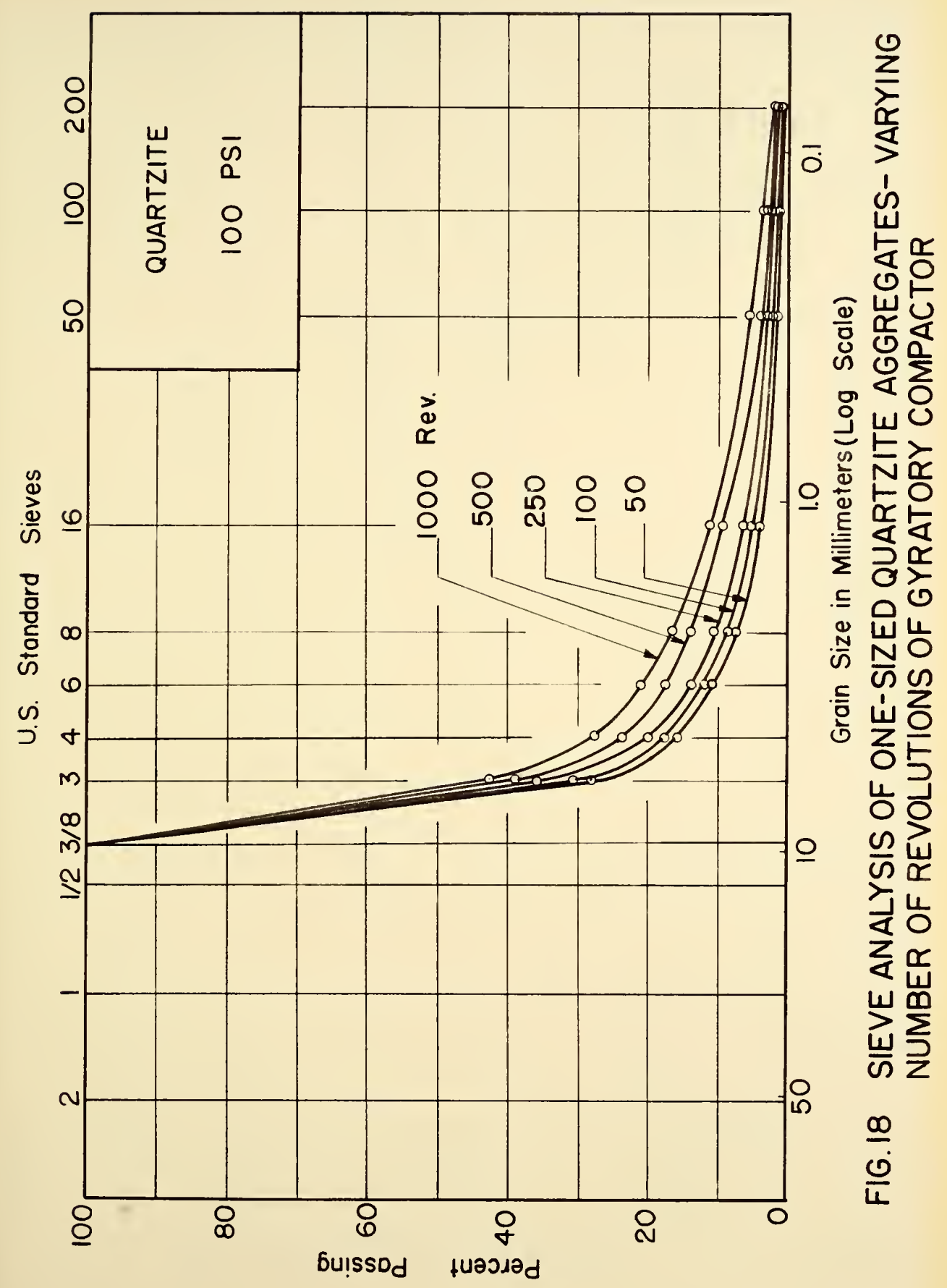




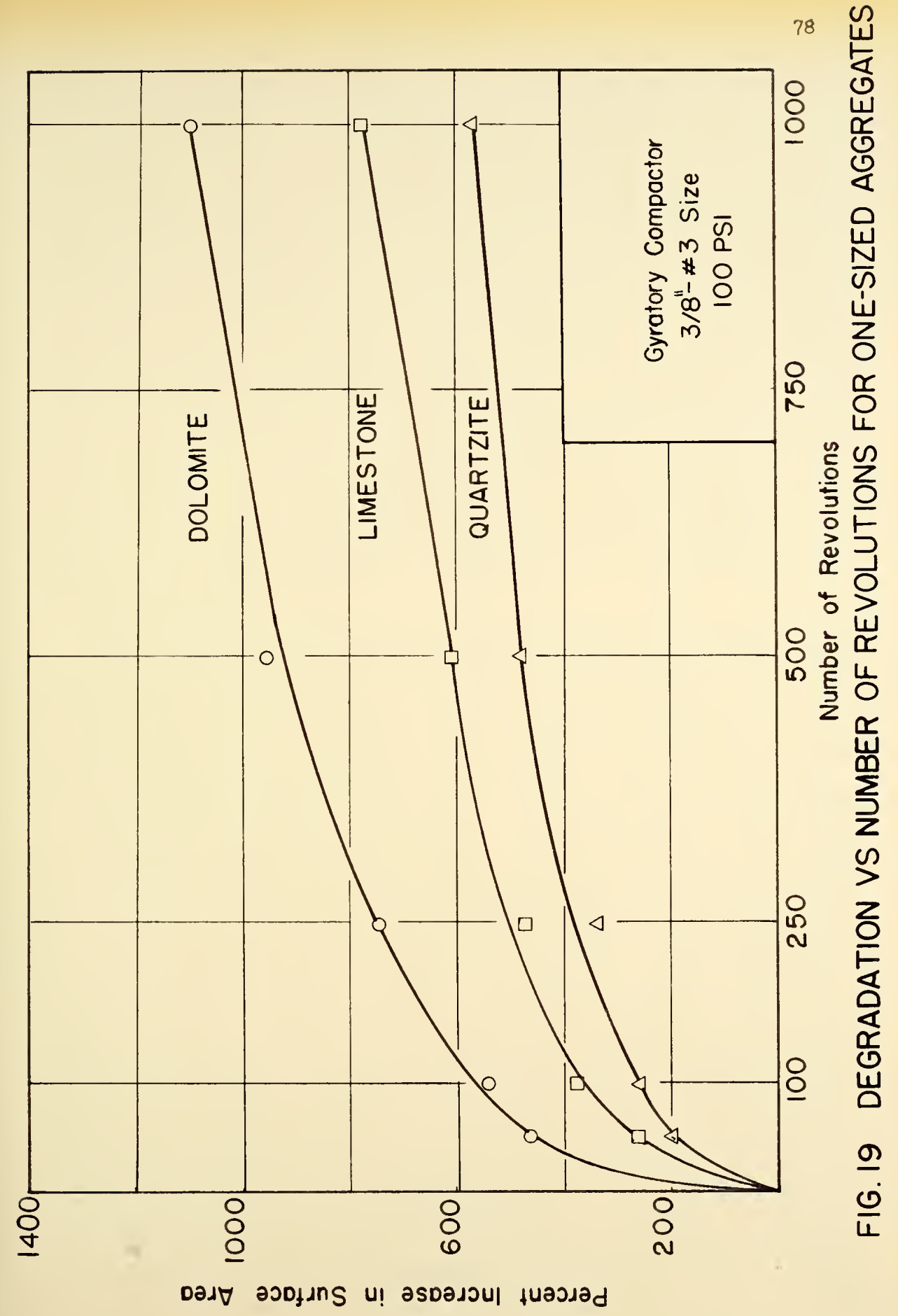




\section{Dred Aggregates}

From the previous section it was found that degradation of one-sized aggregates when illustrated by sieve analysis curves has a constant pattern of a smooth curve approaching a parabolic one. It also was found that size of aggregate, kind of aggregate, method of compaction and degree of compactive effort have no influence on the shape of the sieve analysis curve, while the magnitude of degradation is a function of these variables. In addition it was found that; the larger the size of particle, the greater the degradation; increase in compactive effort increases degradation; and aggregates with high Los Angeles values degrade more than those with low Los Angeles values.

After these preliminary studies, it was decided to study the effects of combinations of particles of different sizes on degradation since this is the actual case in the field. Before making a detailed analysis of the effect of variables on degradation of different mixtures, it was necessary to investigate the changes which might occur in degradation characteristics of each size of particle due to the presence of other sizes in the specimens. In other words it was decided to find out how degradation of each size will change due to the presence of pieces of other sizes in the original mix. For this purpose, a dyeing process was utilized to determine the size fraction from which each particle was produced during compaction. Because it was found from studies on single-sized aggregate that kind of aggregate only changes the magnitude of degradation and has no effect on its pattern, it was decided to use only one kind of aggregate for this part of the study. The limestone which had the intermediate Los Angeles value and which could be satisfactorily dyed was used. 
Due to the time-consuming process of separating the fractions of different colors by hand, It was decided to dye only the top three sizes; namely, $1 / 2 "-3 / 8^{\prime \prime}, 3 / 8^{\prime \prime}-\# 3$, and \#3 - \#4. If a difference in pattern of degradation due to the size was noticed, then other sizes would have been dyed also. The materials smaller than the No. 50 sieve could not be separated by hand; therefore, separation of fractions for the first series of tests was done up to the No. 50 sieve and in the next two series it was done only up to the No. 30 sieve. For size fractions down to and including the No. 8 sieve, the entire sample was separated, but for material between the \#8 - \#16 and \#16 - \#30 sieves, representative samples were ueed for separation. The separated fractions were weighed and the total fraction of each color was then calculated through the ratio of the representative sample to the total fraction weight. The factors which were considered as variables in this part of the study were gradation of aggregate, compactive effort, and presence or absence of asphalt.

The three gradations which are given in the section on materials, gradings $0, B$, and $F$, were used in this part of the study. Grading 0 , which is made of the top four sizes only, offered the possibility of determining how the four sizes of particles degrede in the presence of each other. The $1 / 2^{\prime \prime}-3 / 8^{\prime \prime}$ size was colored violet, the $3 / 8^{\prime \prime}$ - \#3 size was colored red, the \#3 - \#4 size was colored green, and the \#4 - \#6 size remained its natural color.

Compactive effort applied by the gyratory machine was varied in two different ways, by change in ram preseure and by change in number of revolutions. Two ram pressures, $100 \mathrm{psi}$ and $200 \mathrm{psi}$, and two numbers of revolutions, 30 and 100, were used. Their combination provided four levels of 
compactive effort. Other methods of compaction were not used because it was shown previously that change of method of compaction does not change the pattern of degradation.

Asphalt content as a factor affecting degradation was intended to be used in the detailed study of degradation; therefore, it was desired to find its effect on degradation of each fraction of the aggregate component of bituminous mixtures. For this purpose a 4 percent asphalt content on the basis of dry weight of aggregate was used with the intention of seeing whether the presence of asphalt would change the pattern of degradation or would only affect the magnitude of degradation compared to the results obtained from specimens with no asphalt.

The twenty-four samples which were used in this part of the invest1gation were of three gradations, grading 0 , grading $B$, and grading $F$, with and whout asphalt, and were tested under four different compactive efforts in the gyratory machine. The results of sleve analysis of each fraction (colored for identification), along with sieve analysis of the total specimen are presented in tabular form in Tables 9 through 14 , and are 1llustrated in Figures 20 through 47.

Table 9 contains the sieve analysis results for four specimens of original grading $O$ (open gradation) compacted without asphalt at four different compaction levels. Gradations are presented in total percent passing each sieve and compactive level of each specimen can be read on the top of the section for that specimen. There are five columns for each specimen. The first column is the sieve analysis of material with original size of $1 / 2$ $3 / 8$ in. The second, third, and fourth columns, each shows the results of sleve analysis of materials which originally belonged to sizes $3 / 8^{n}$ - \#3, 


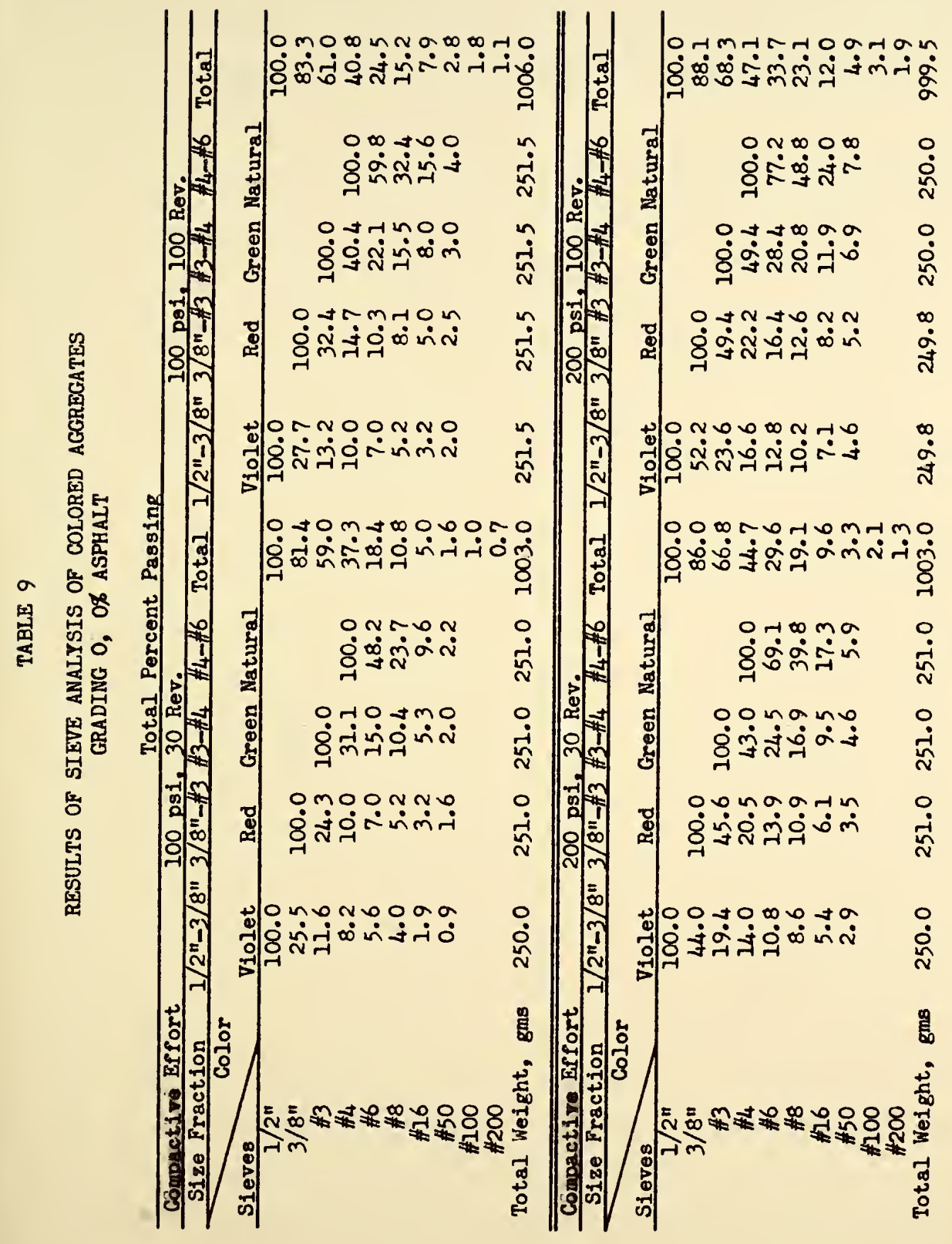


\#3 - \#4, and \#4 - \#6 respectively. The fifth column is the sieve analysis of the total specimen. The total weight of each fraction is shown at the end of the corresponding column, and the last value of the fifth column shows the total weight of each specimen.

Figure 20 shows the sieve analysis of each fraction after being tested in the gyratory machine under 100 psi ram pressure and 30 revolutions. Each curve shows the sieve anslysis of the material of a certain original size. From left to right the curves show the degradation of particles of original sizes of $1 / 2^{\prime \prime}-3 / 8^{n}, 3 / 8^{n}-\# 3$, \#3 - \#4, and \#4 - \#6. These curves indicate that the degradation of each fraction has a constant pattern of a smooth curve approaching a parabolic one. Figures 21, 22, and 23 show the degradation of each fraction of the original gradation under various compactive efforts. These figures illustrate similar patterns for degradation as compared to Figure 20. As compactive effort increases the space between the curves increases too. This indicates more severe degradation at higher compactive efforts than at lower compactive efforts.

Figure 24 shows the sieve analysis curves after compaction under different compactive efforts of fractions of original size $1 / 2-3 / 8$ in. when used in the open grading. Compactive effort for each curve is indicated on the curve and it can be seen that as compactive effort increases the curves shift upward without changing their pattern. A significant point to note is the effect of change of ram pressure on degradation. Figures $24,25,26$, and 27 show that increase in magnitude of ram pressure produces more severe degradation than increase in the number of revolutions. It can be seen that the curve of 100 psi ram pressure and 100 revolutions lies below the curve of 200 psi ram pressure and 30 revolutions. In other words, 


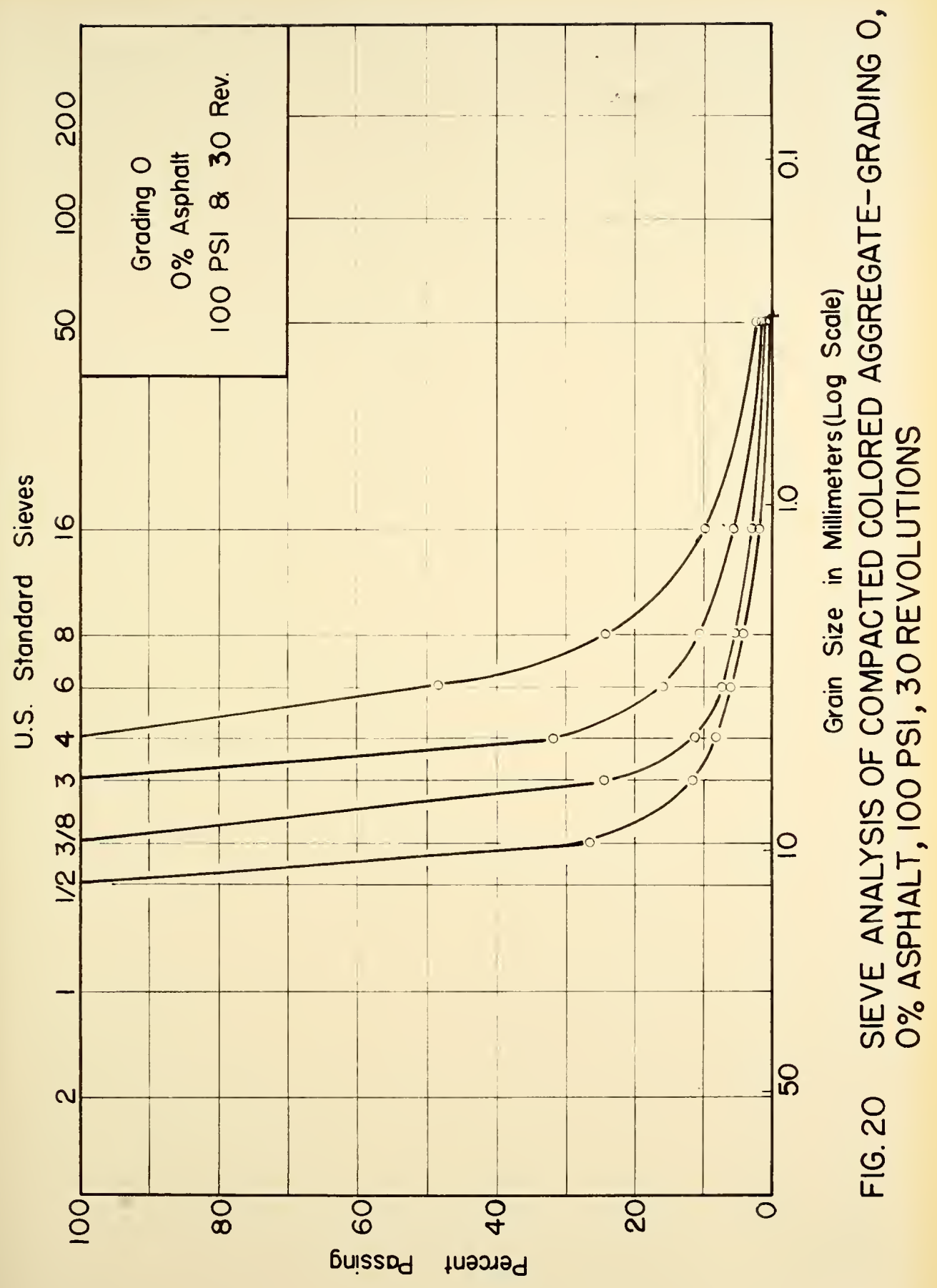




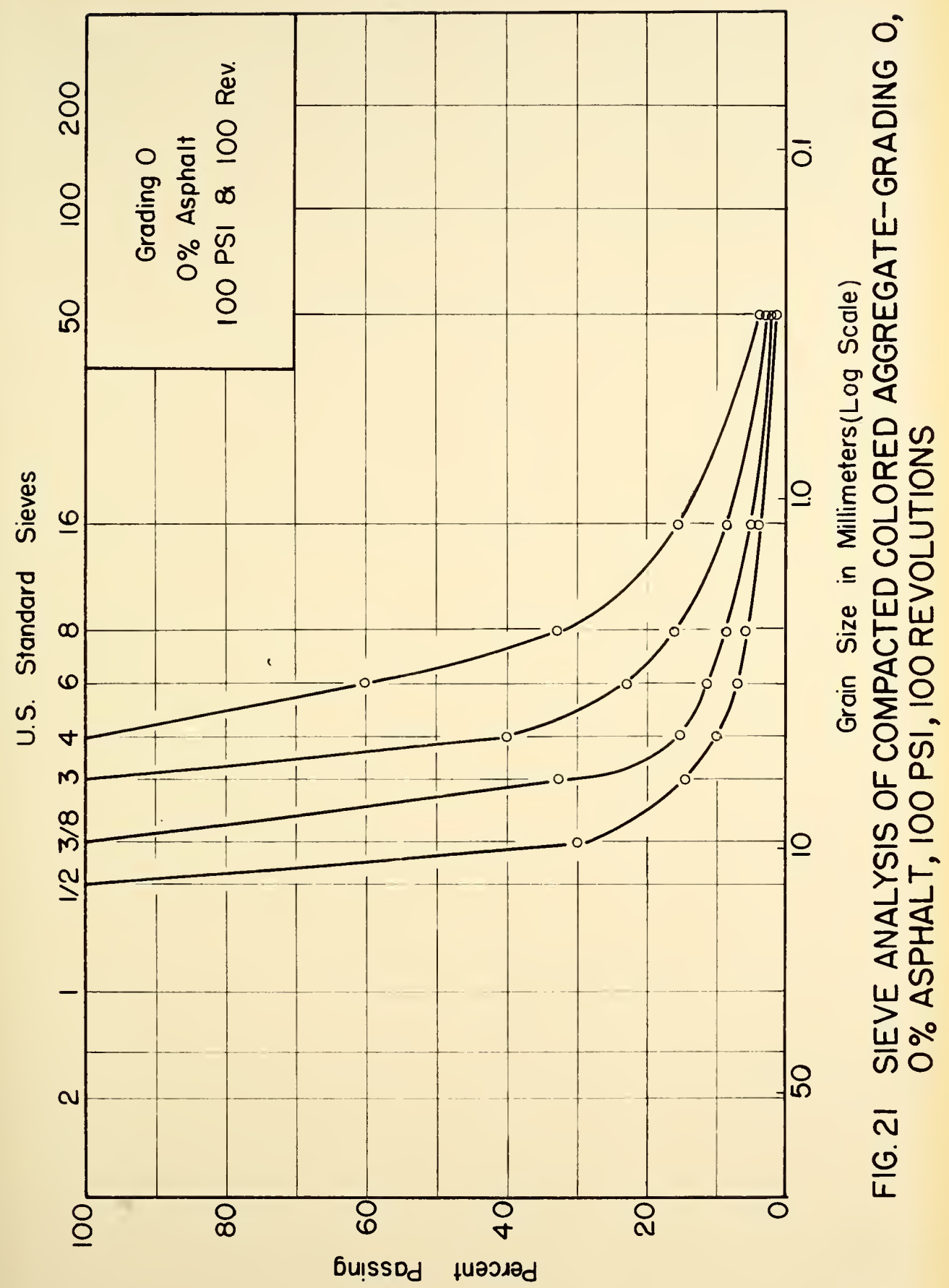




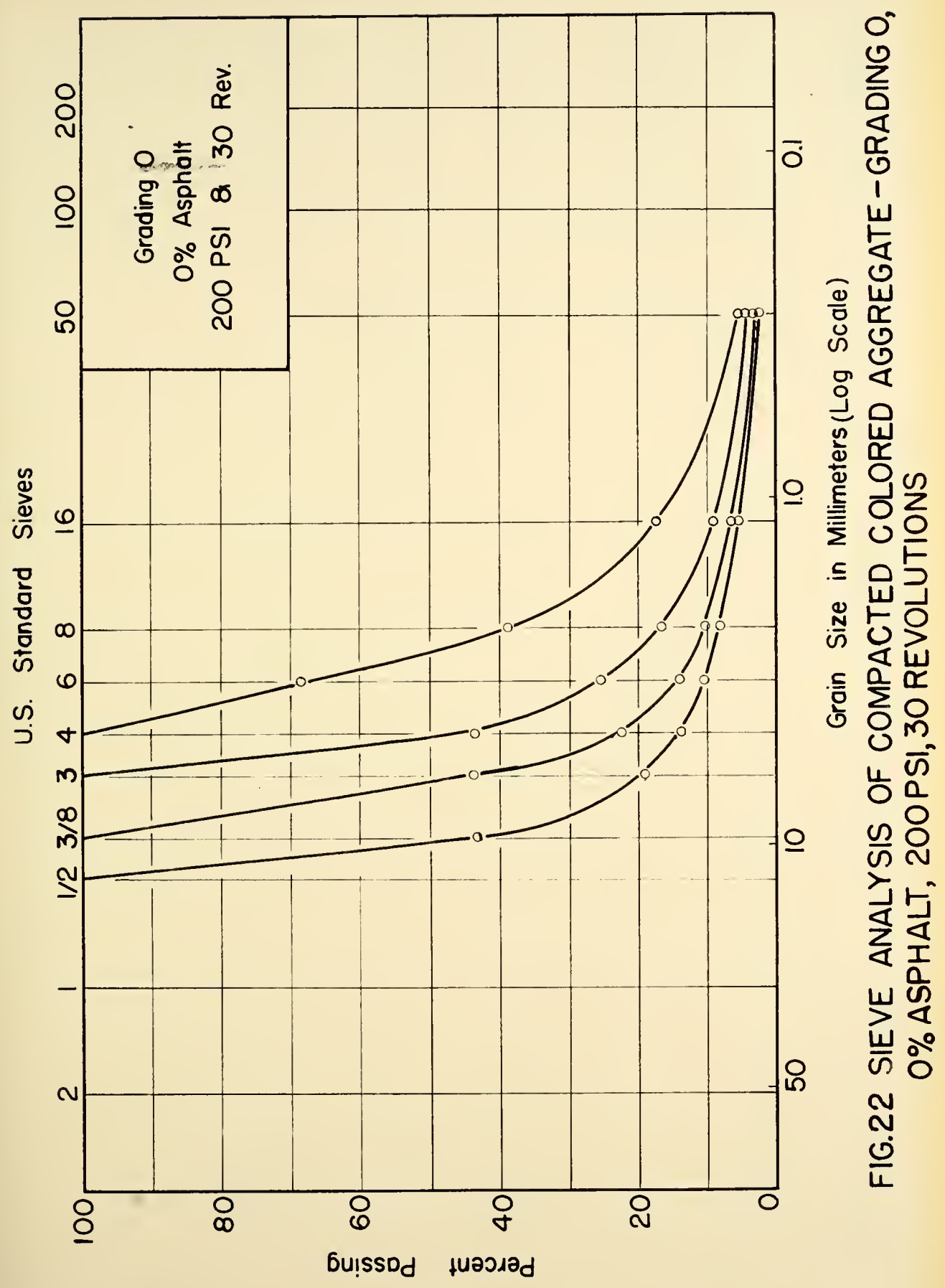




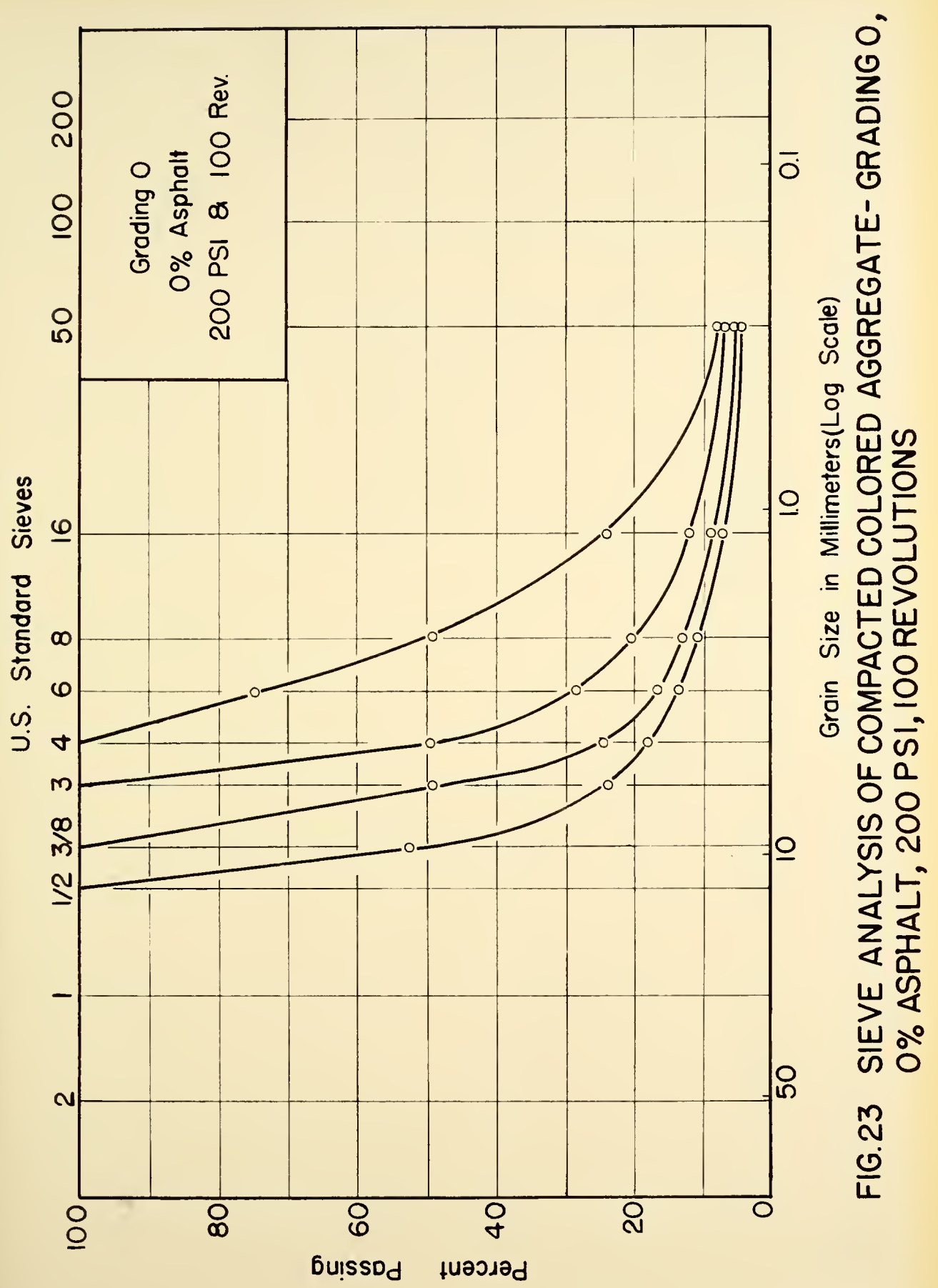




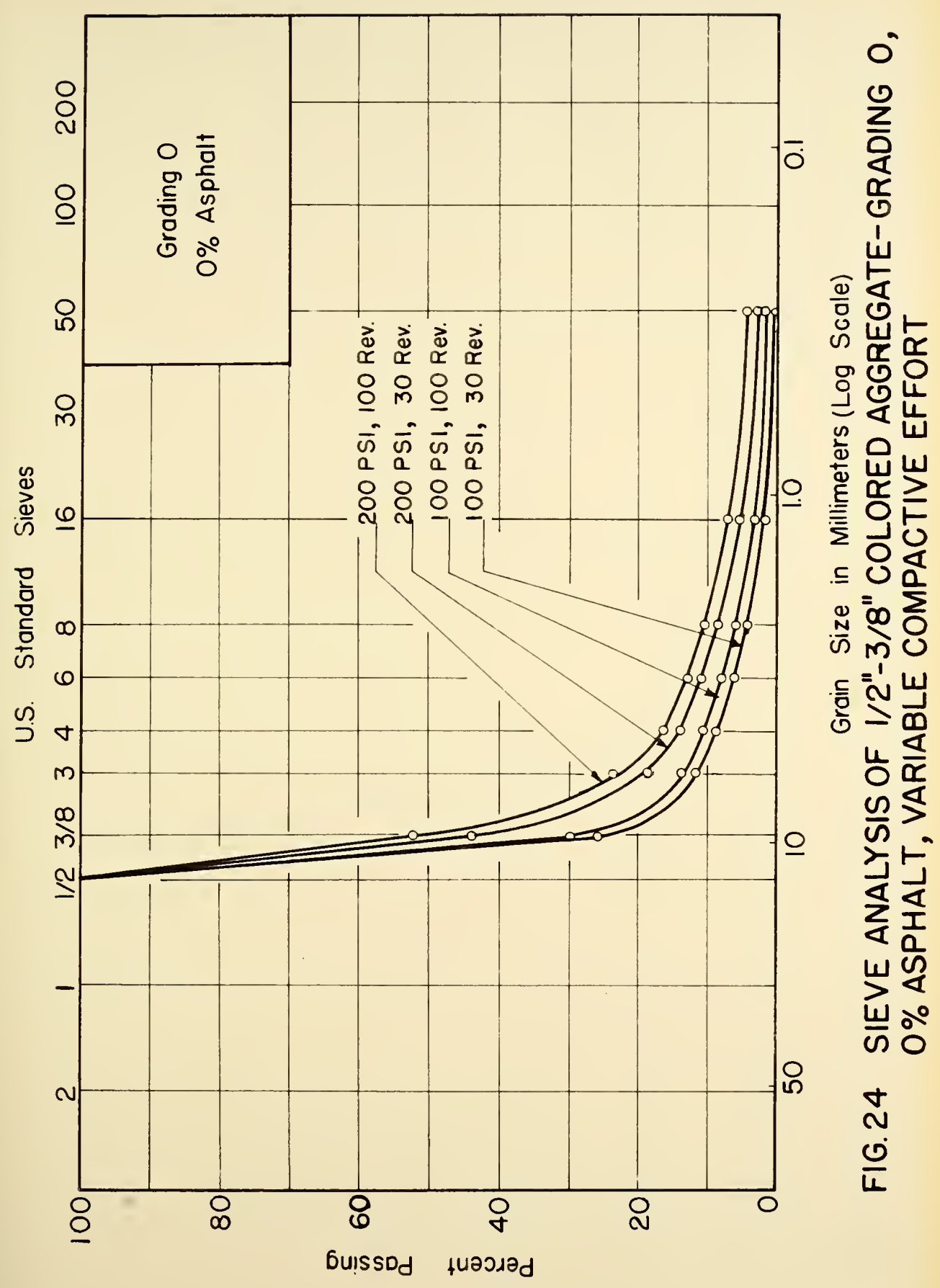




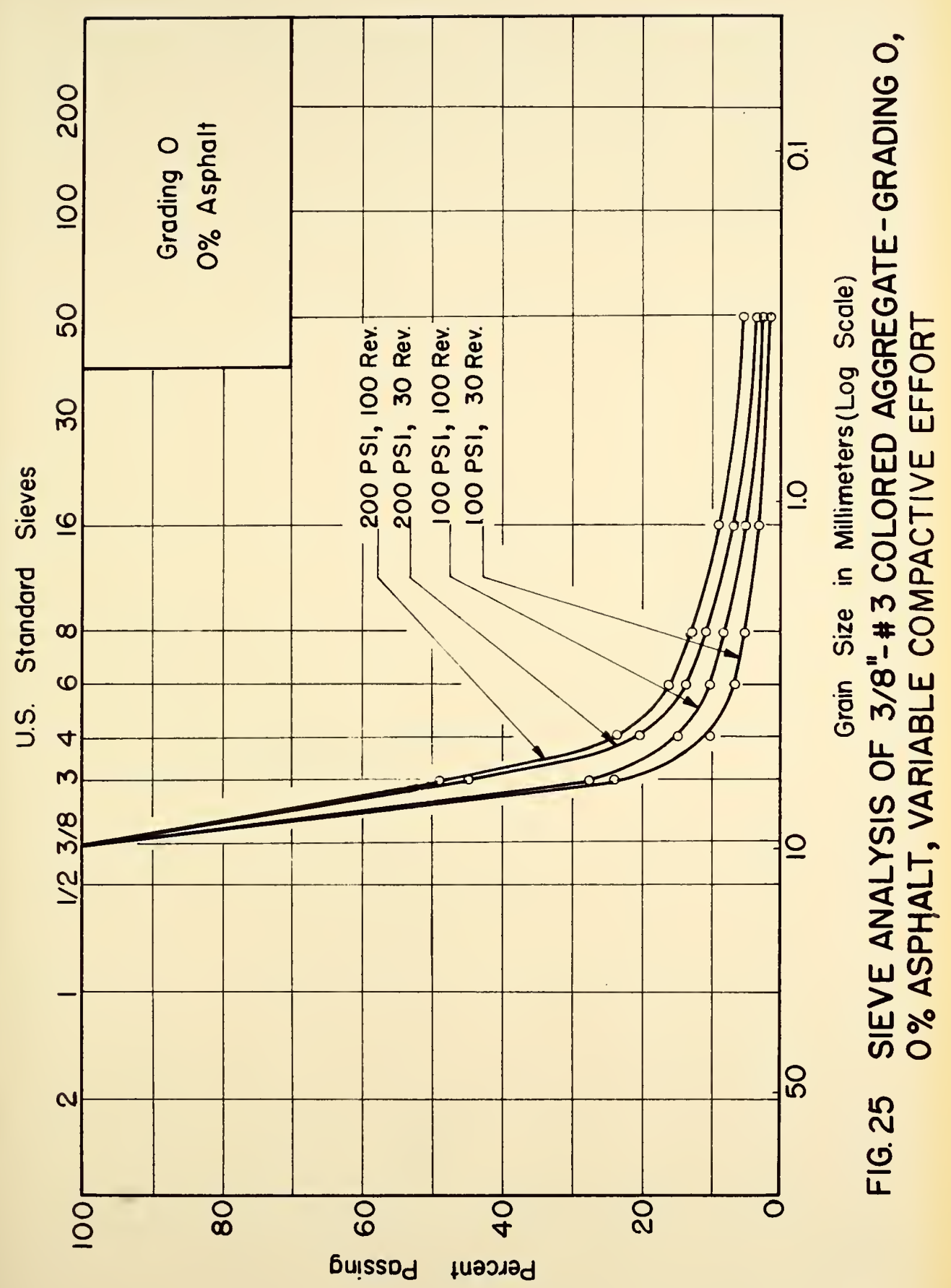




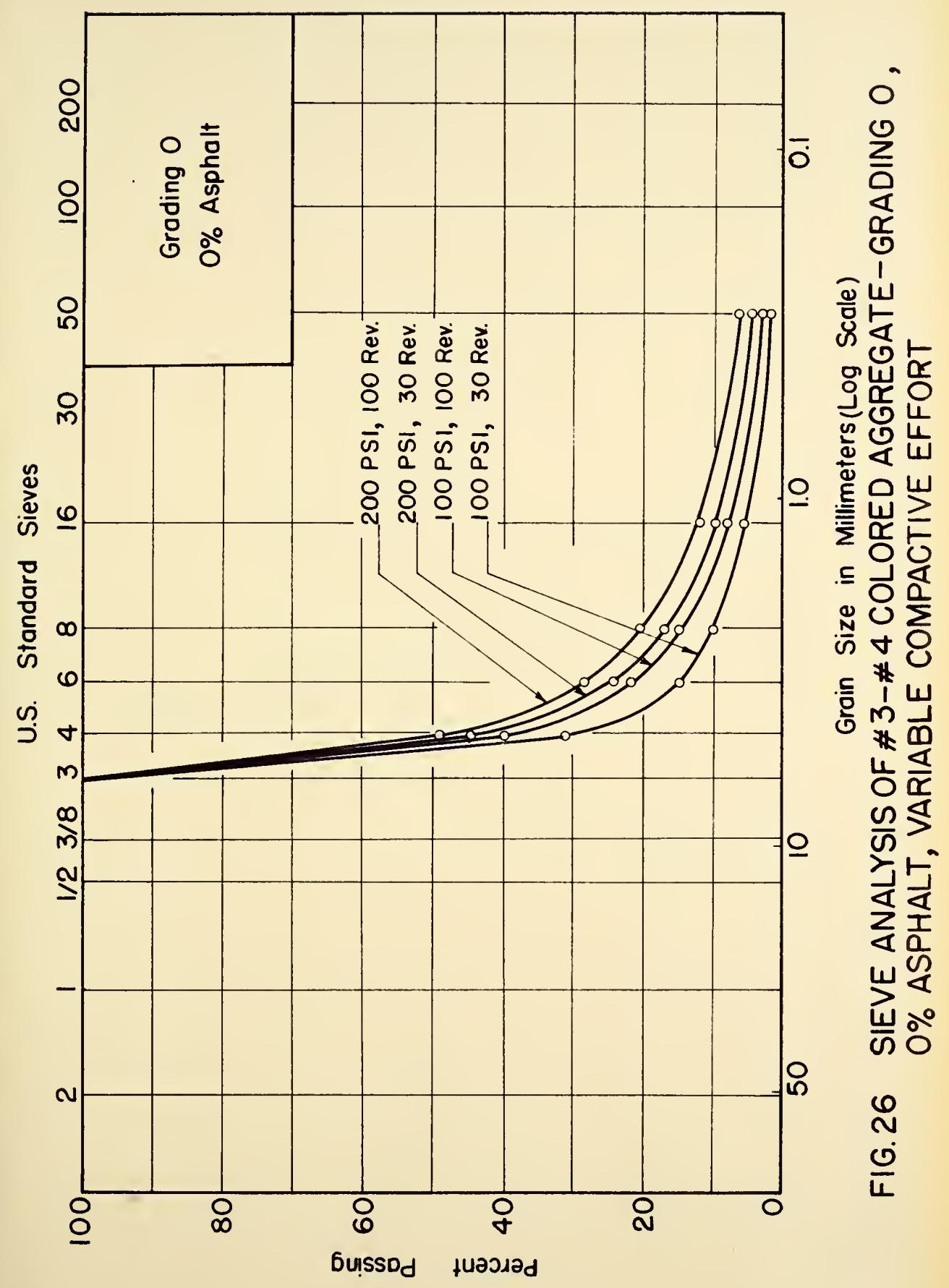




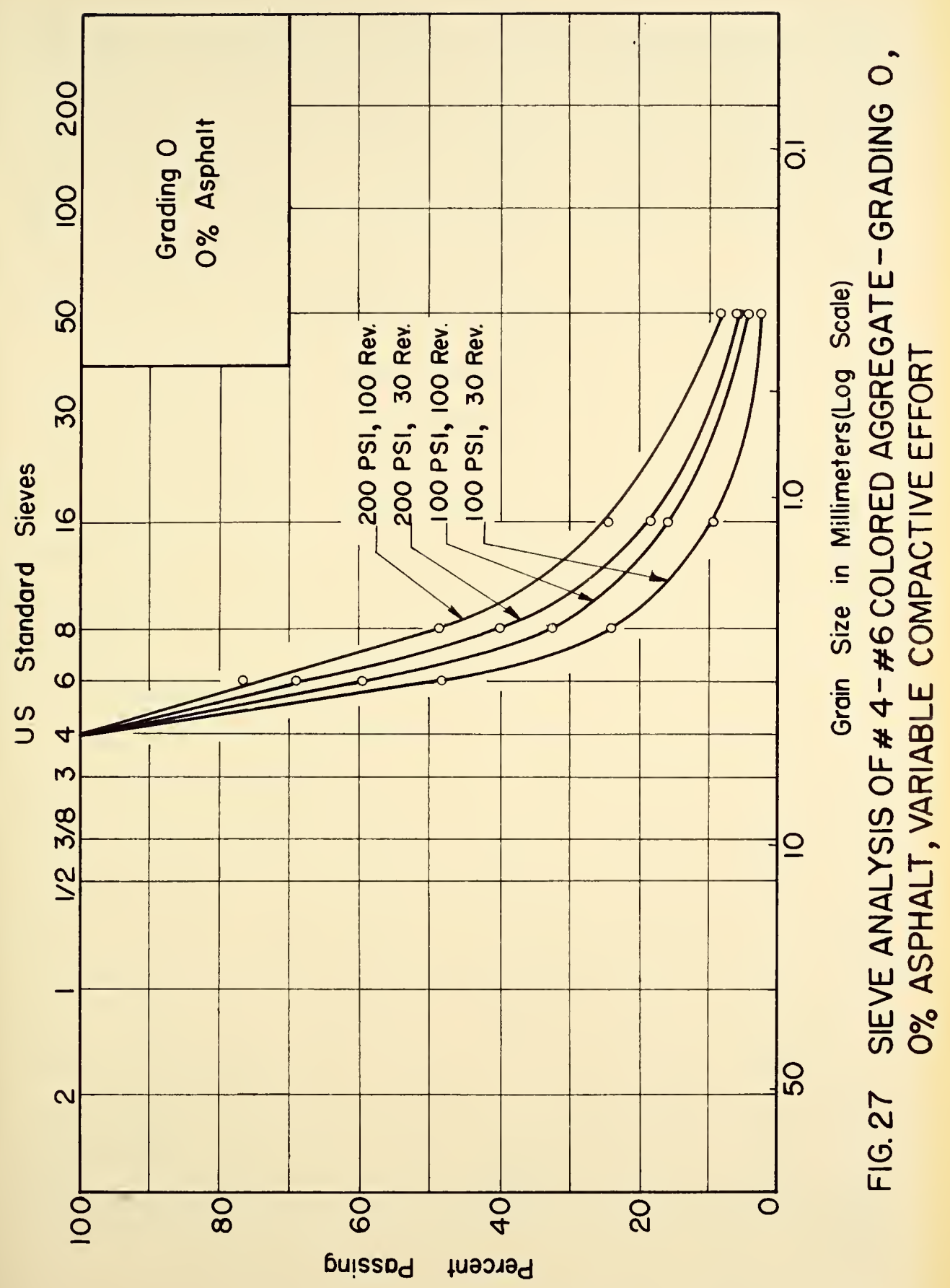


degradation is increased more rapidly by incresse in load than by Increase in repetition of load. Figures 25, 26, and 27 show the sieve analysis curves of the $3 / 8^{n}-\# 3, \# 3$ - \#4, and \#4 - \#6 fractions of the open-graded mixture compacted under different compactive efforts. In all of these figures the same pattern, sensitivity of degradation to load rather than repetition of load, is signiflcant. Generally, these curves indicste that as compactive effort increases the material undergoes a more severe degradation.

Table 10 contains the results of sleve analysis of each fraction of open-graded mixtures when mixed with 4 percent asphalt and compacted under different compactive efforts in the gyratory compactor. The fractions of each size were separated by their colors after the asphalt was extracted and the aggregates were then separated on certain sieves. The table contains the results of sieve analyols of four specimens. The compactive efforts can be seen on the top of each section, and each column represents the gradation of a certain size material after compaction.

Flgures 28, 29, 30, and 31 show the results of sieve analysis of each fraction after compaction under a certain compactive effort. For example, Figure 28 shows the sleve analysis of different fractions of a specimen after being compacted under $100 \mathrm{p} 81$ ram pressure and 30 revolutions in the gratory compactor. These figures show that esch fraction after compaction, has a smooth curve representing its sieve analysis as was the case for testa without asphalt. This indicates that presence of asphalt in the mixture does not change the pattern of degradation of each fraction. Therefore, It can be sald that although the presence of asphalt changes the magnitude of degradation of each fraction in an open-graded mixture, it does not affect the pattern of degradation. In other words particles in an open-graded 


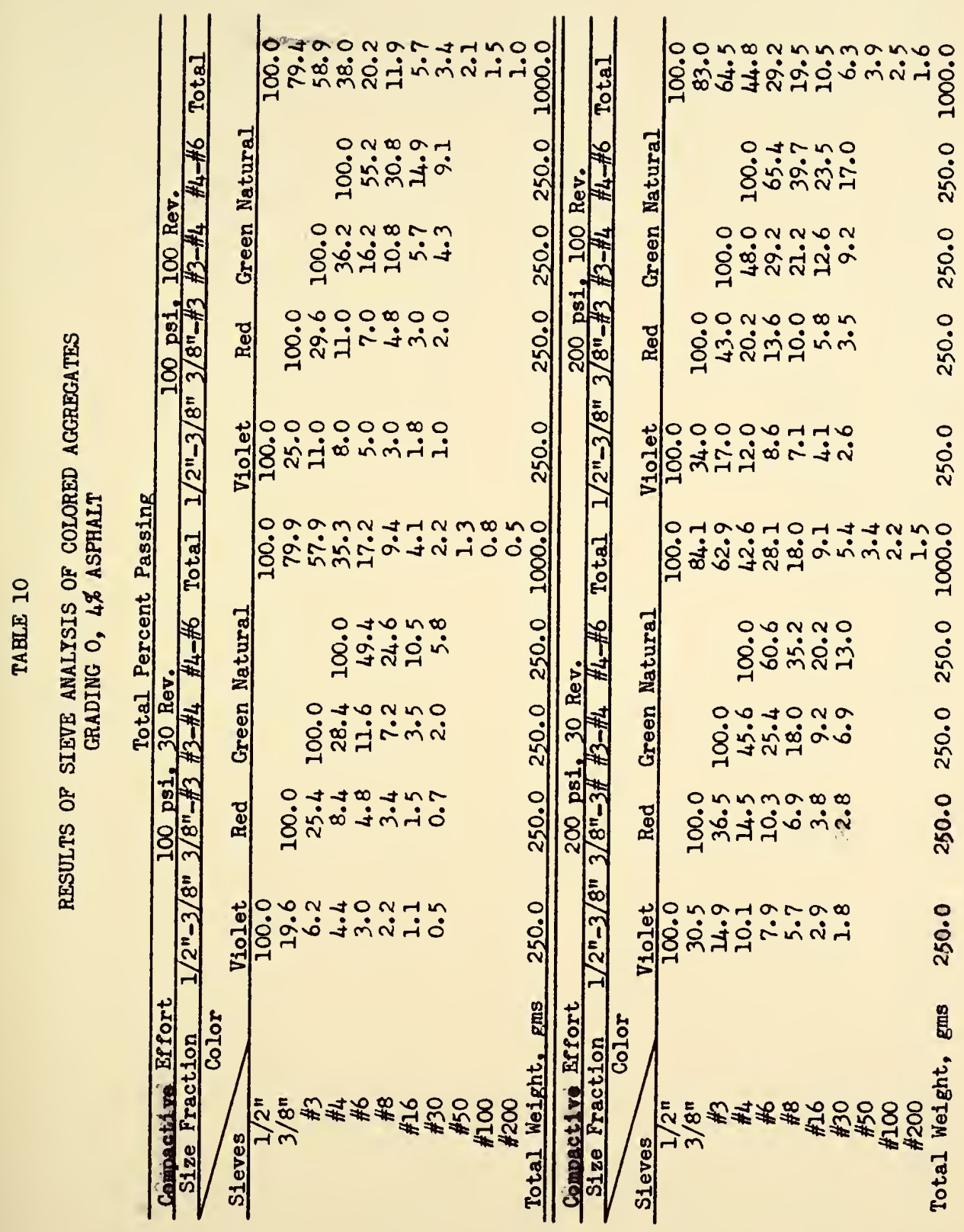




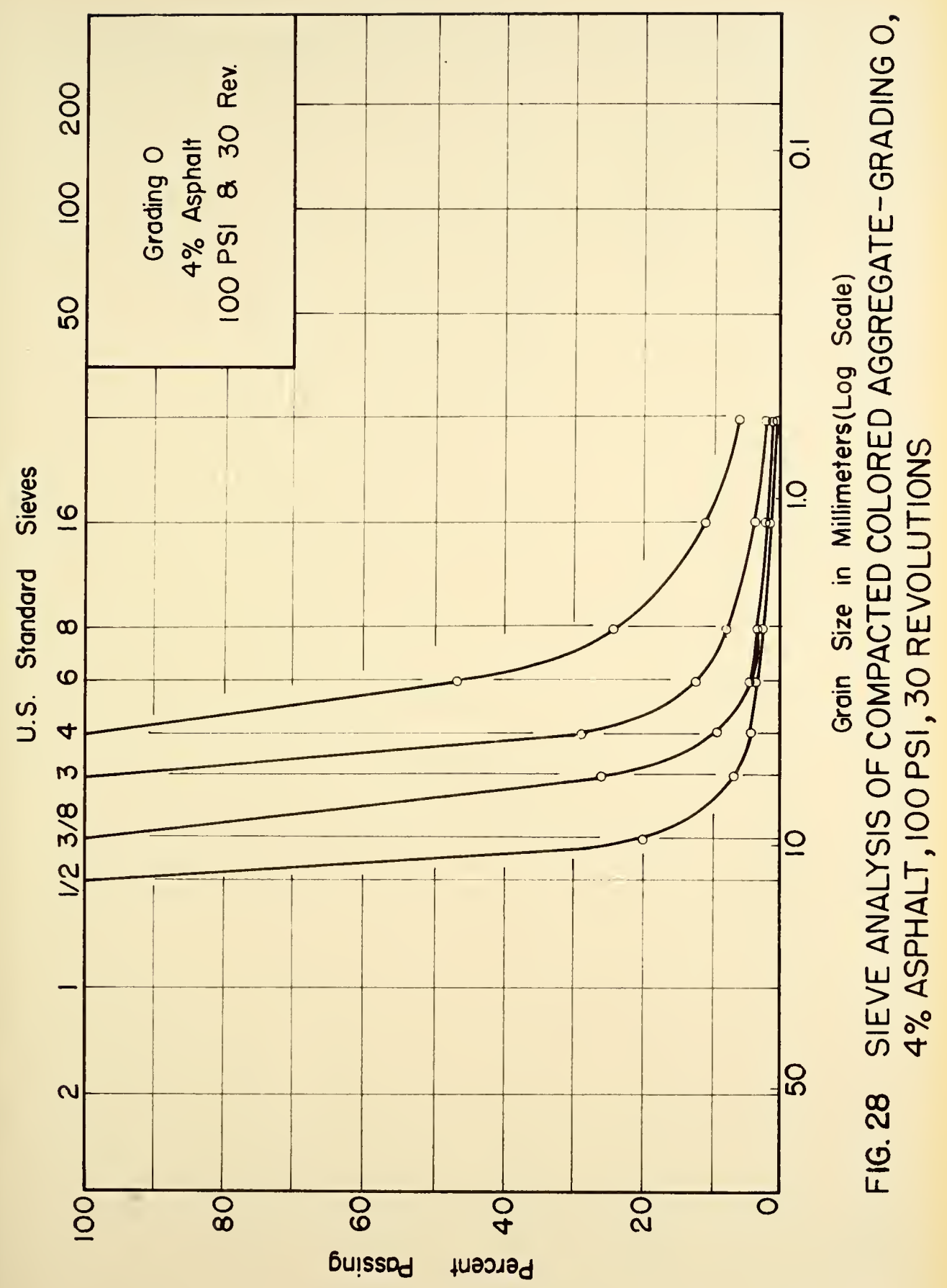




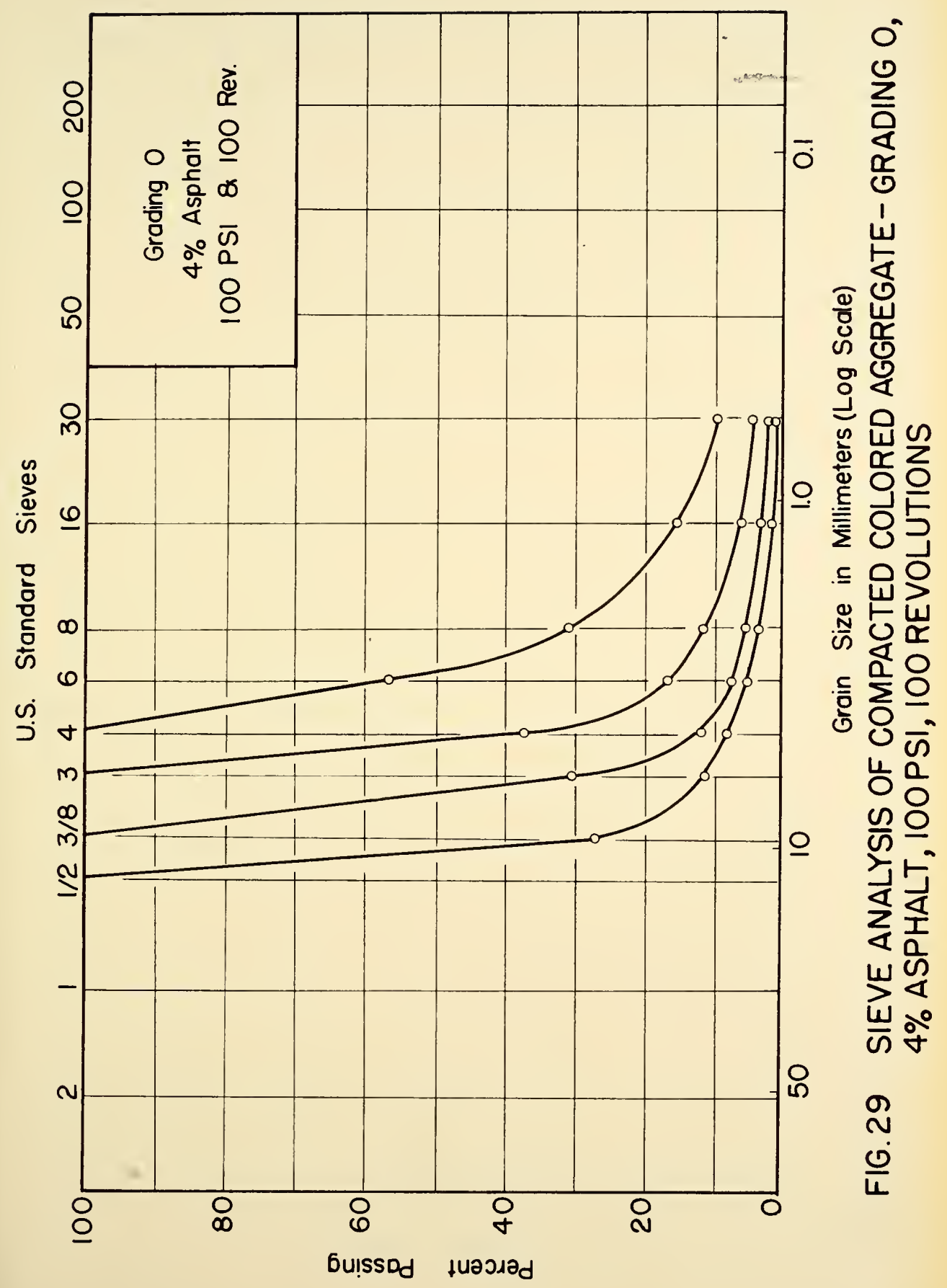




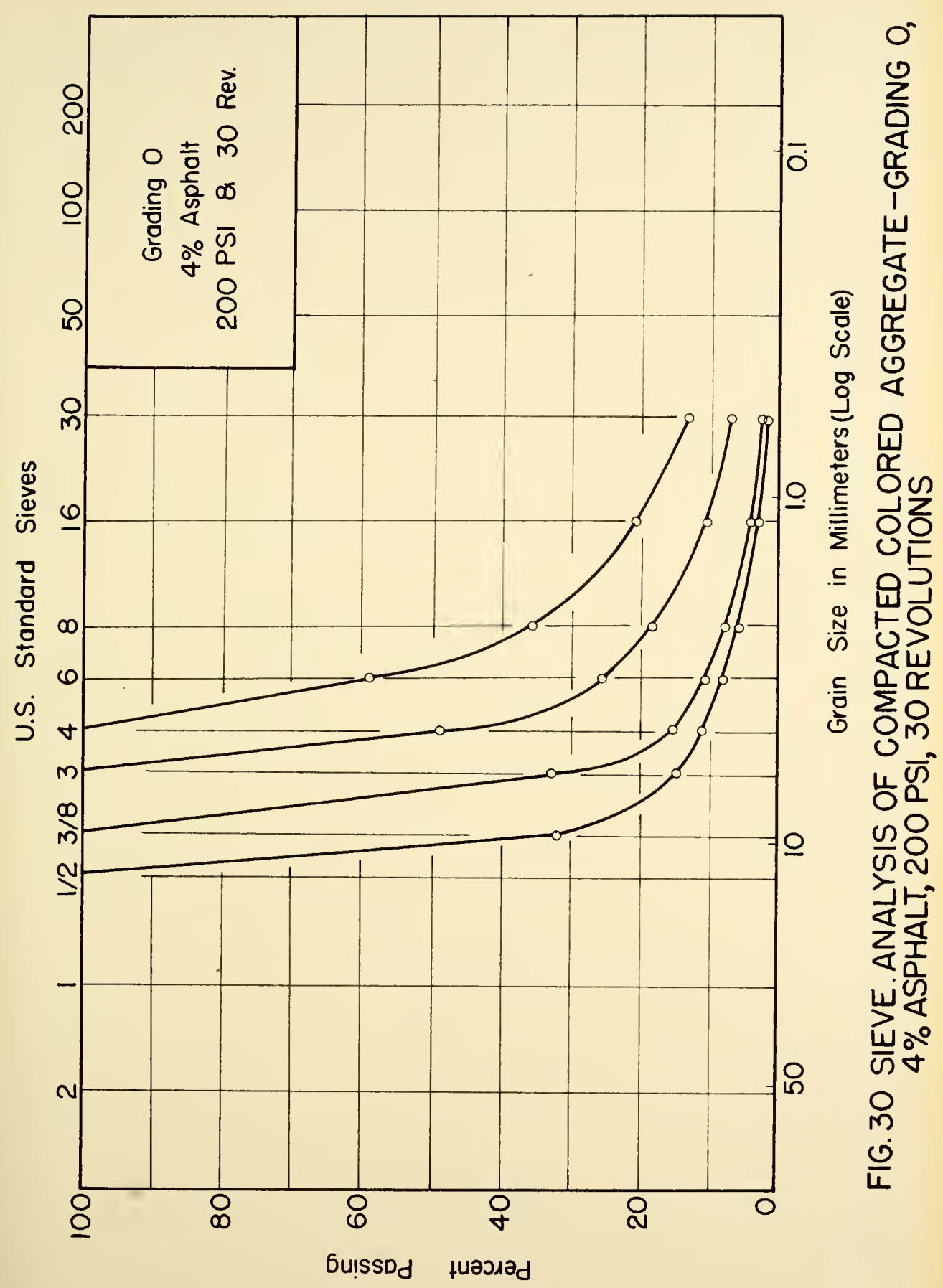




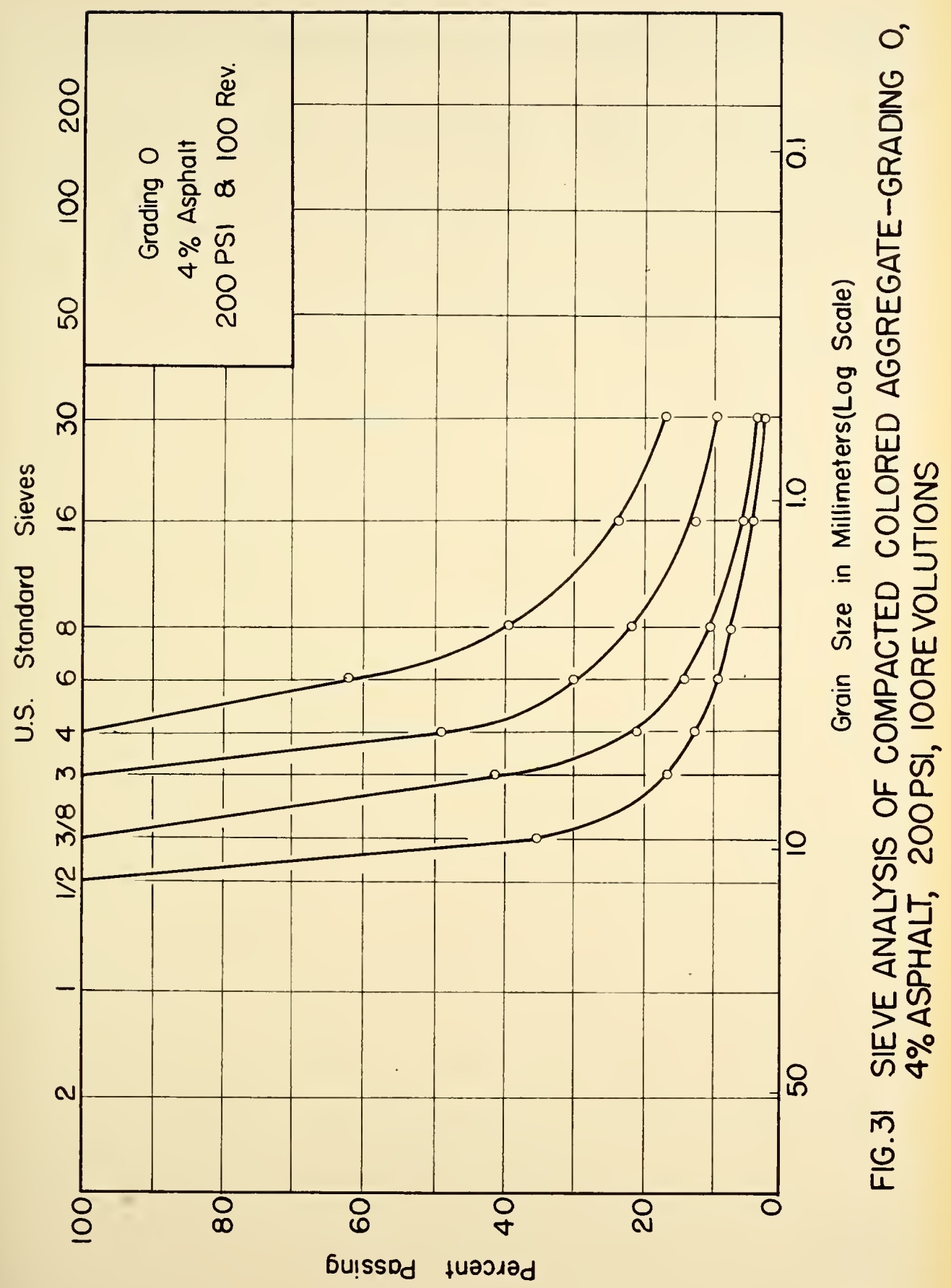


mixture degrade in a certain manner regardless of whether asphalt is present or not.

Considering that pattern of degradation is dependent upon the direction and/or the distribution of load, and magnitude of degradation is dependent upon the magnitude of load, we can conclude that presence of asphalt will change the magnitude of load rather than its direction and distribution.

It was found, so far, that each fraction of material in an open-graded mixture will break and degrade in such a manner that its sleve analysis has a certain pattern which is independent of original size, magnitude of compactive effort, and presence of asphalt. In order to find out the effect of change of gradation on this pattern, colored aggregates were used as the fractions of mixtures which had original gradations $B$ and F. Specimens with these gradations were compacted under different compactive efforts, either without asphalt or with 4 percent asphalt.

Table 11 gives the results of sieve analysis of the top three sizes, along with the total gradation, of four specimens which has original grading $B$ and were compacted under different compactive offorts. The compactive effort can be read on the top of each section. The first three columns of each section are headed by the size of the original fraction. The fourth column gives the gradation of all material smaller than the \#4 sieve which had not been dyed. The fifth column is the gradation of the total sample after being tested. Figures $32,33,34$, and 35 show the gradation of the three top eizes of each specimen. These figures indicate, as did the results of tests using the open-graded mixture, that pattern of degradation does not vary with size of the aggregate fraction. 


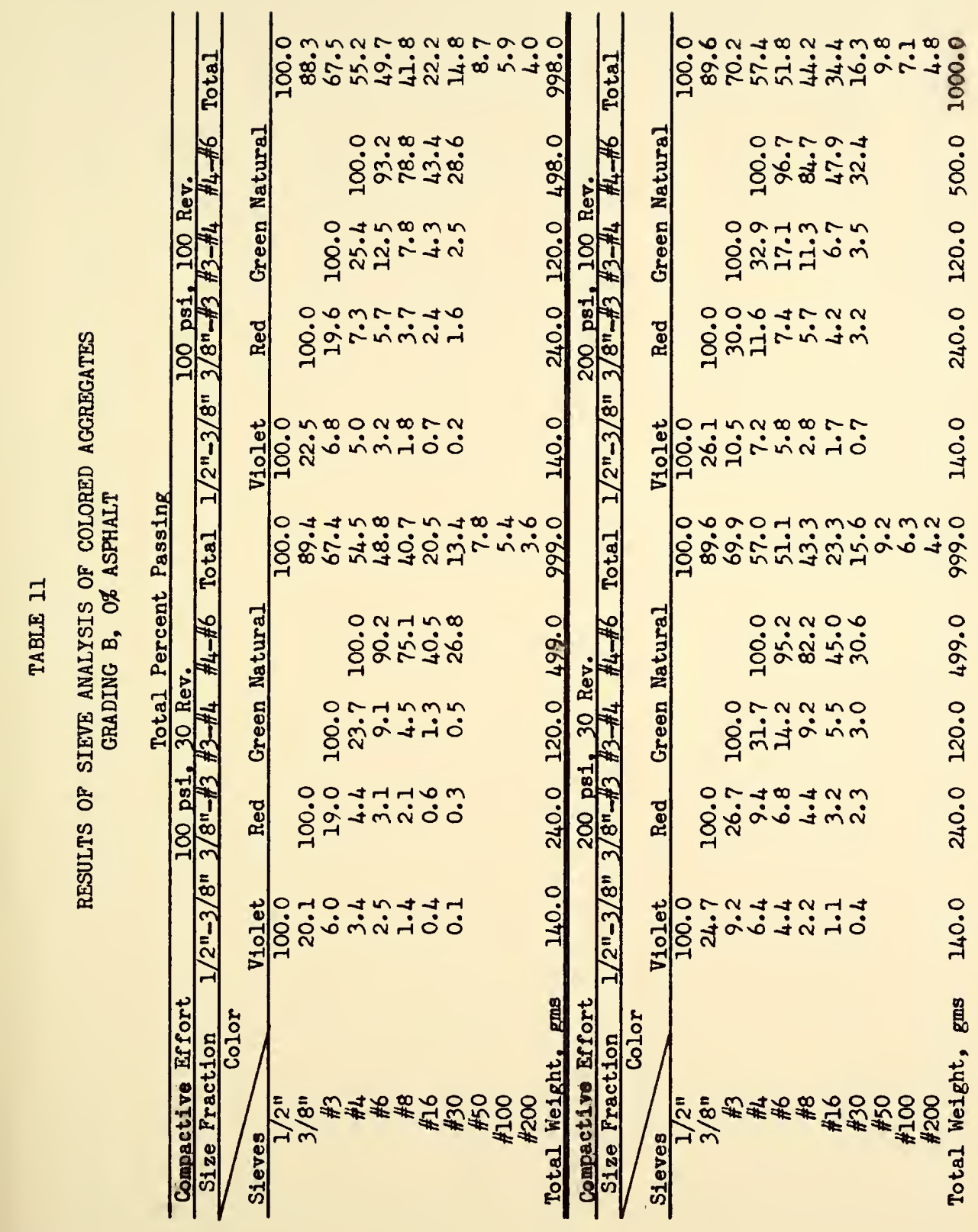




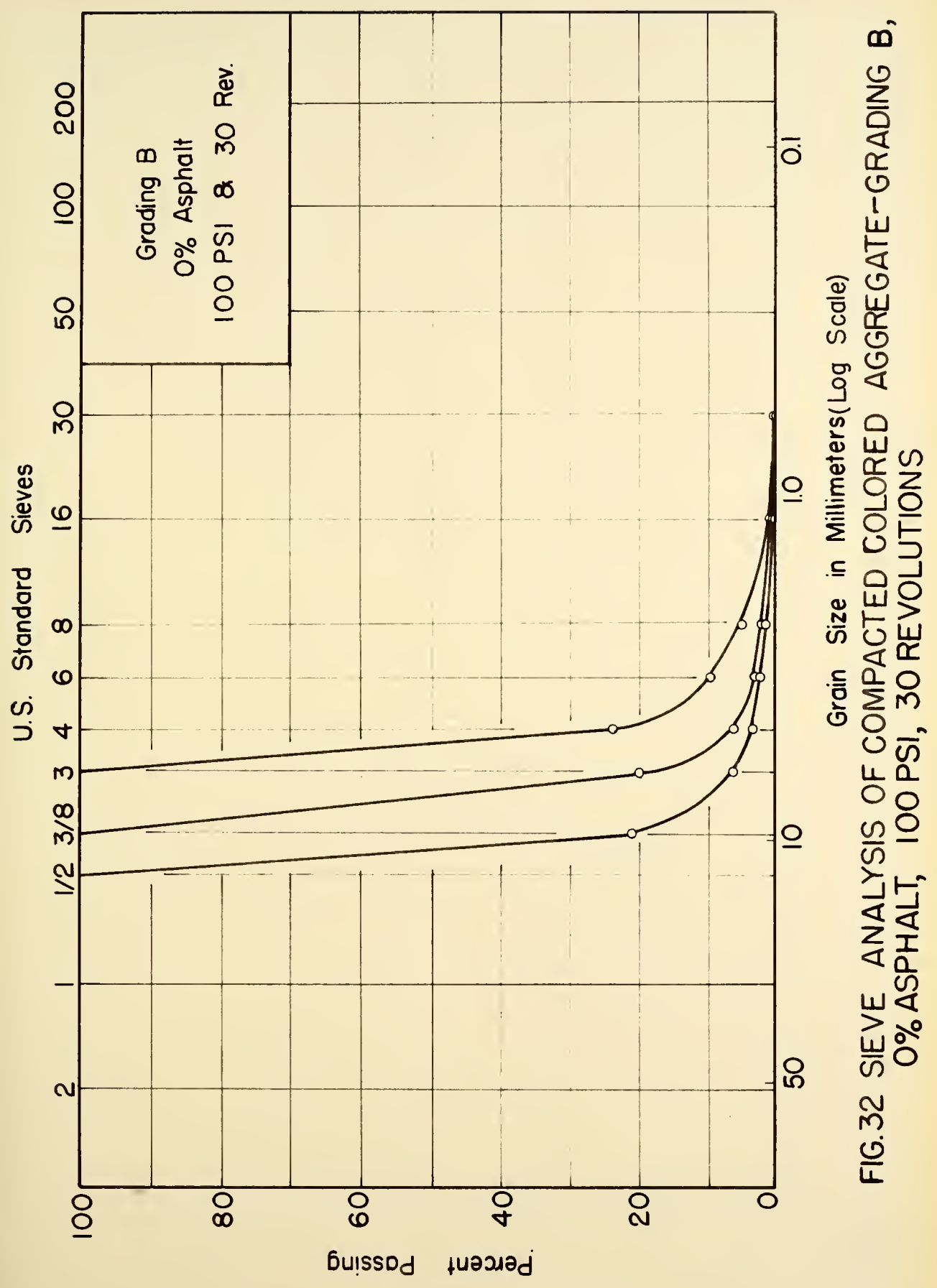




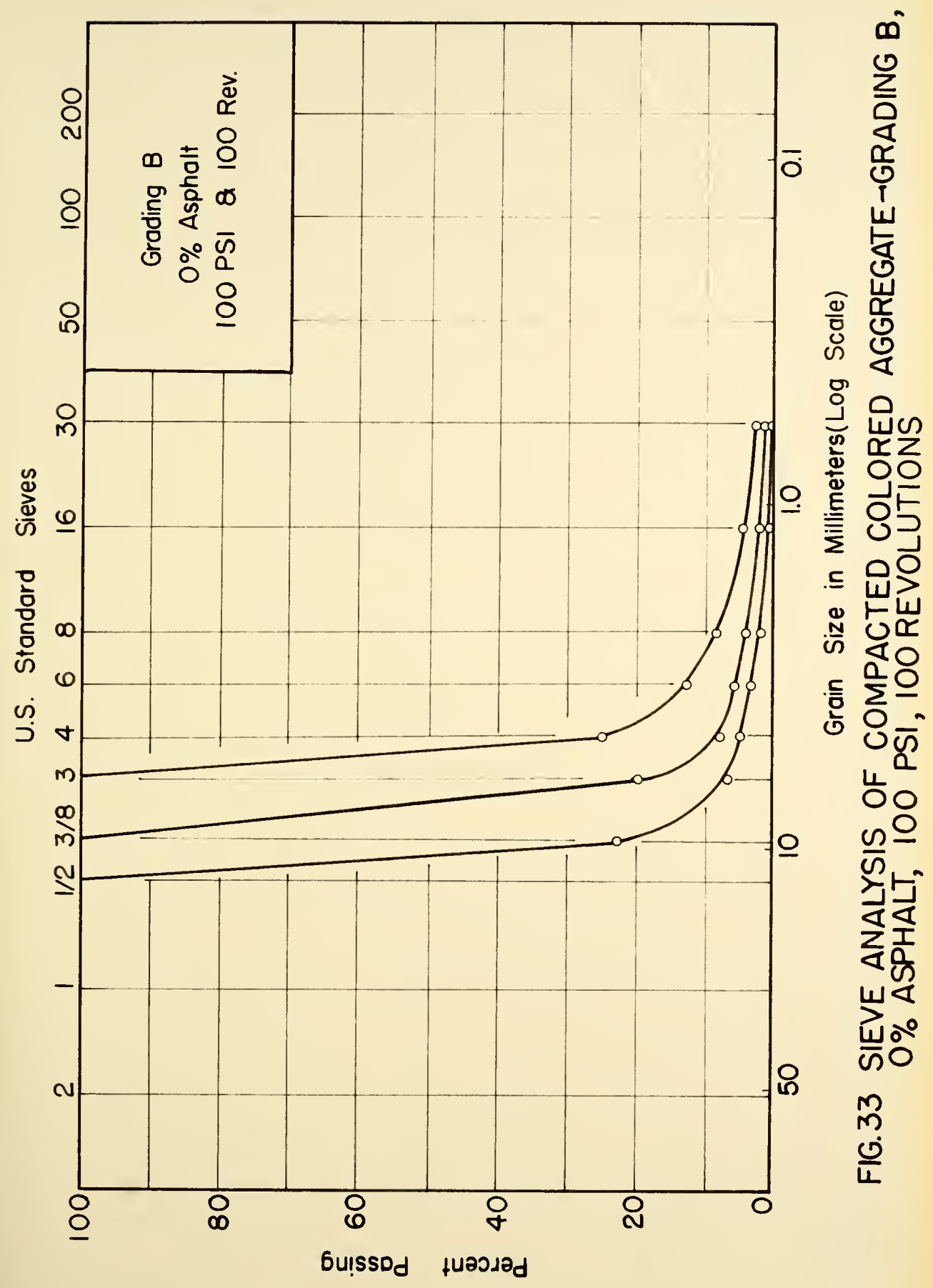




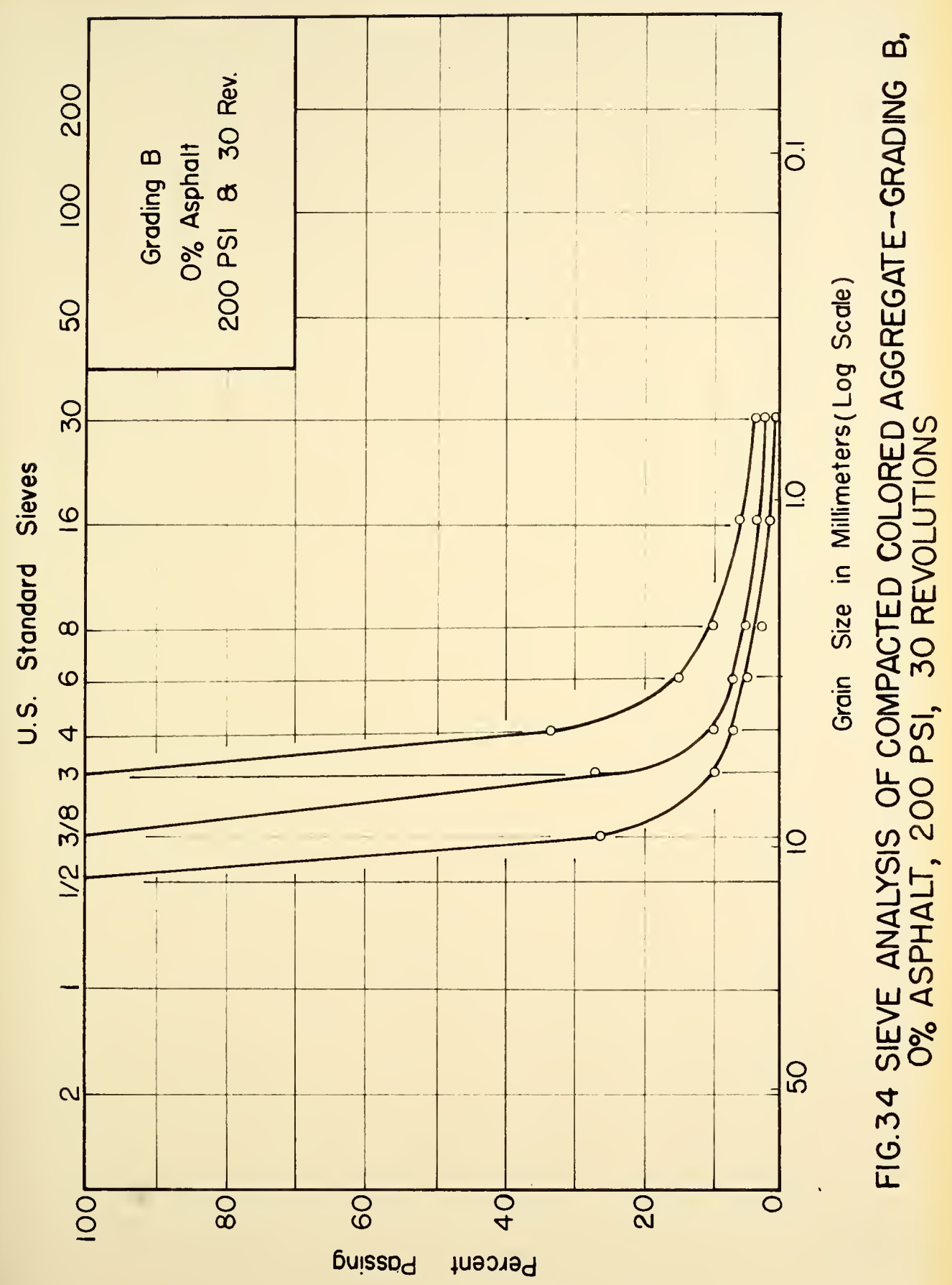




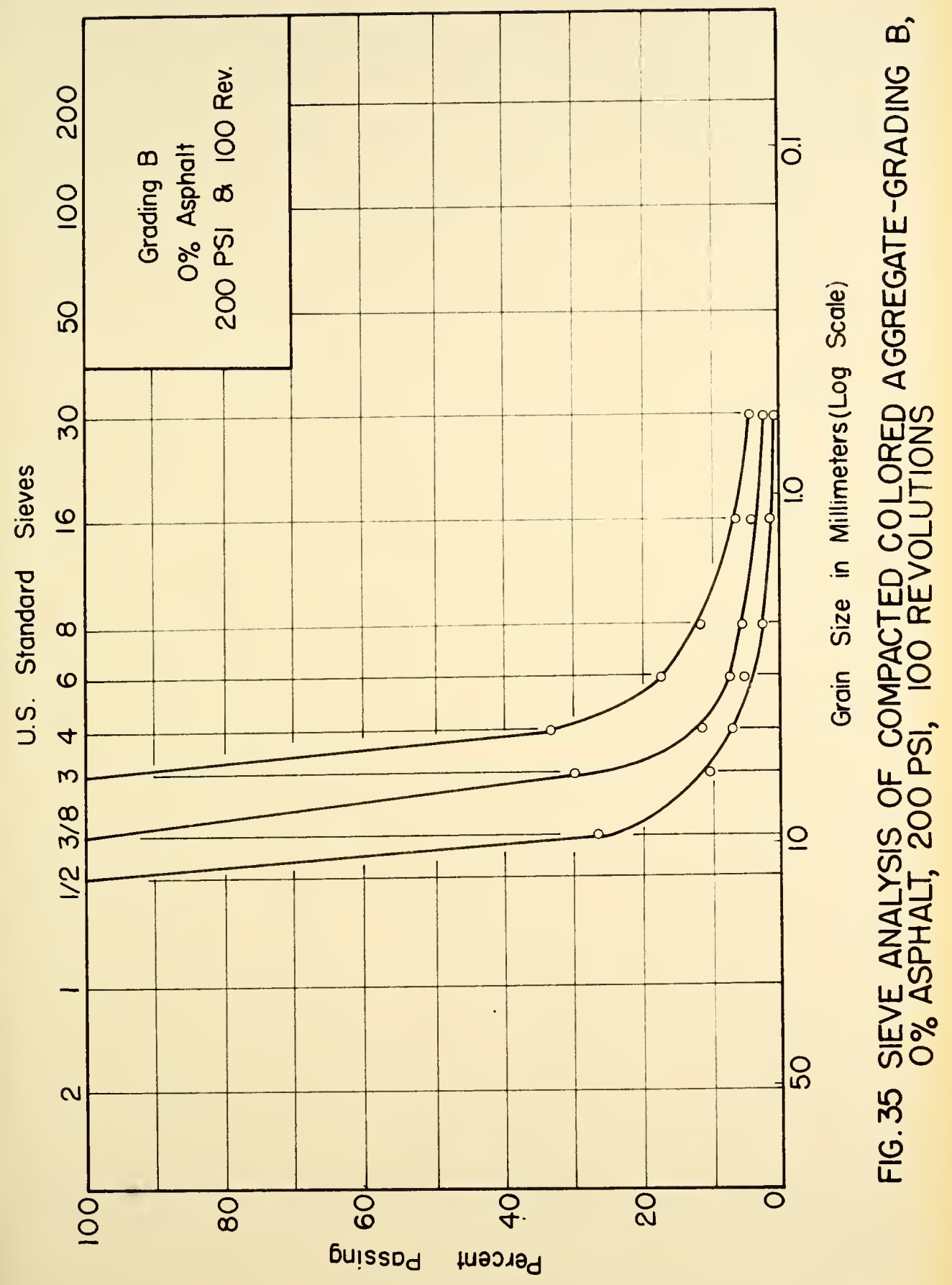


Table 12 shows the sieve analysis results of four specimens of grading B with 4 percent asphalt. These specimens were compacted under similar compactive efforts to those in Table 11. Compact1ve efforts and gradation of each fraction after compaction can be seen in the same order as in Table 11. Figures 36, 37, 38, and 39 show the gradation of the top three aggregate sizes in each specimen after being compacted and the asphalt extracted. These figures also show that the curves are smooth and are approaching a parabola in shape.

Table 13 includes the results of sieve analysis of the top three aggregate sizes from specimens having the Fuller gradation after being compacted under different compactive efforts in the absence of asphalt. Compactive efforts and arrangements of the table are the same as in Tables 11 and 12. The original weight of each fraction can be read in the last row of each section. For example, 134 grams in the first data column of Table 13 means that this much material was of the $1 / 2-3 / 8$ in. size in the original gradation. Figures $40,41,42$, and 43 show the sieve analysis results for each fraction after being compacted under the indicated compactive effort.

Table 14 contains the results of sieve analysis after testing for the top three sizes of aggregate from specimens of the Fuller gradation with 4 percent asphalt. Figures $44,45,46$, and 47 show plots of these results. Again, the curves are smooth ones approaching a parabola in shape.

From the results obtained on colored aggregate it can be seen that, when particles of different sizes are mixed together and subjected to a certain compactive effort, each size will break down into smaller particles whose new gradation has a characteristic size distribution. The produced size distribution follows a curve which is smooth and approaches 


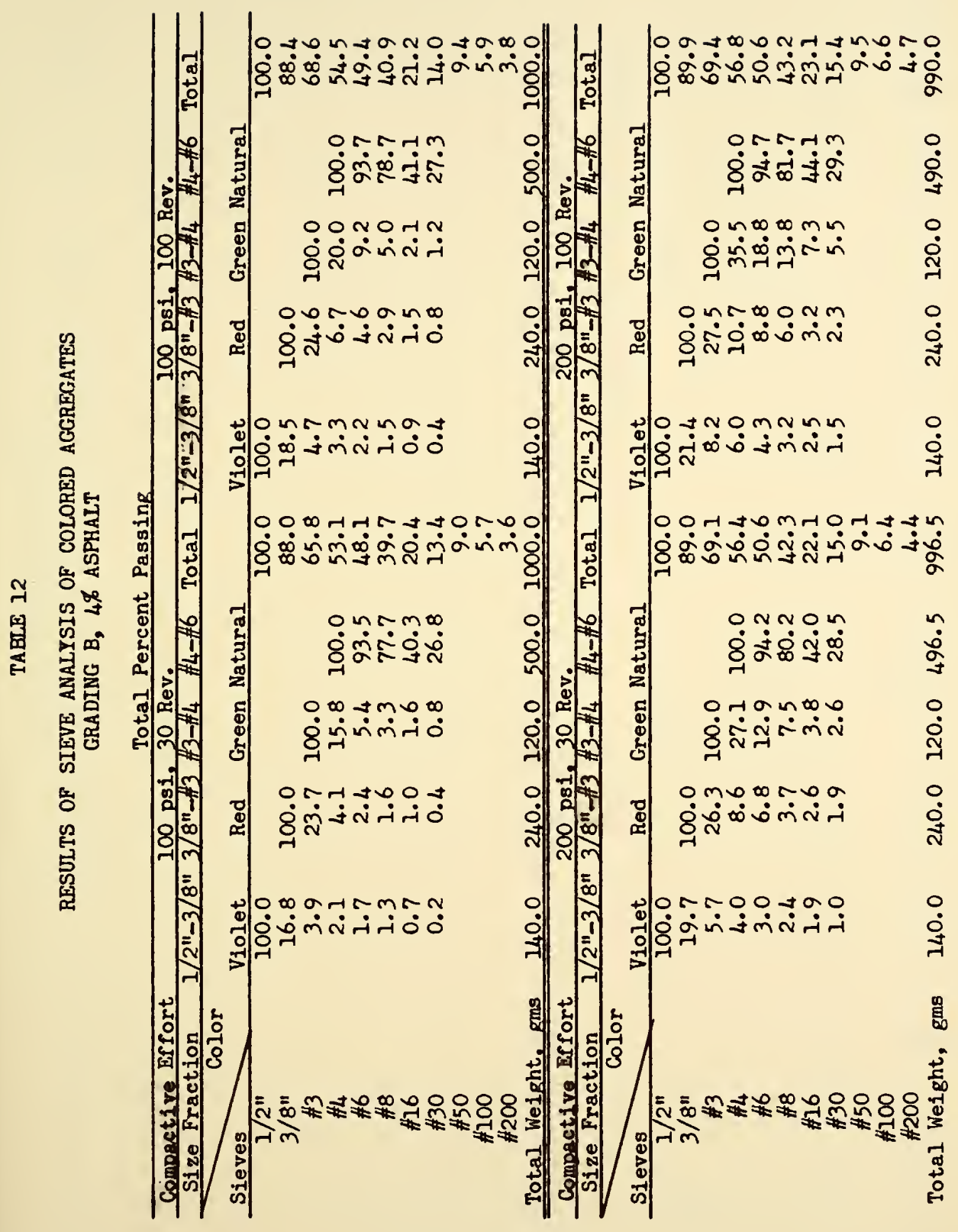




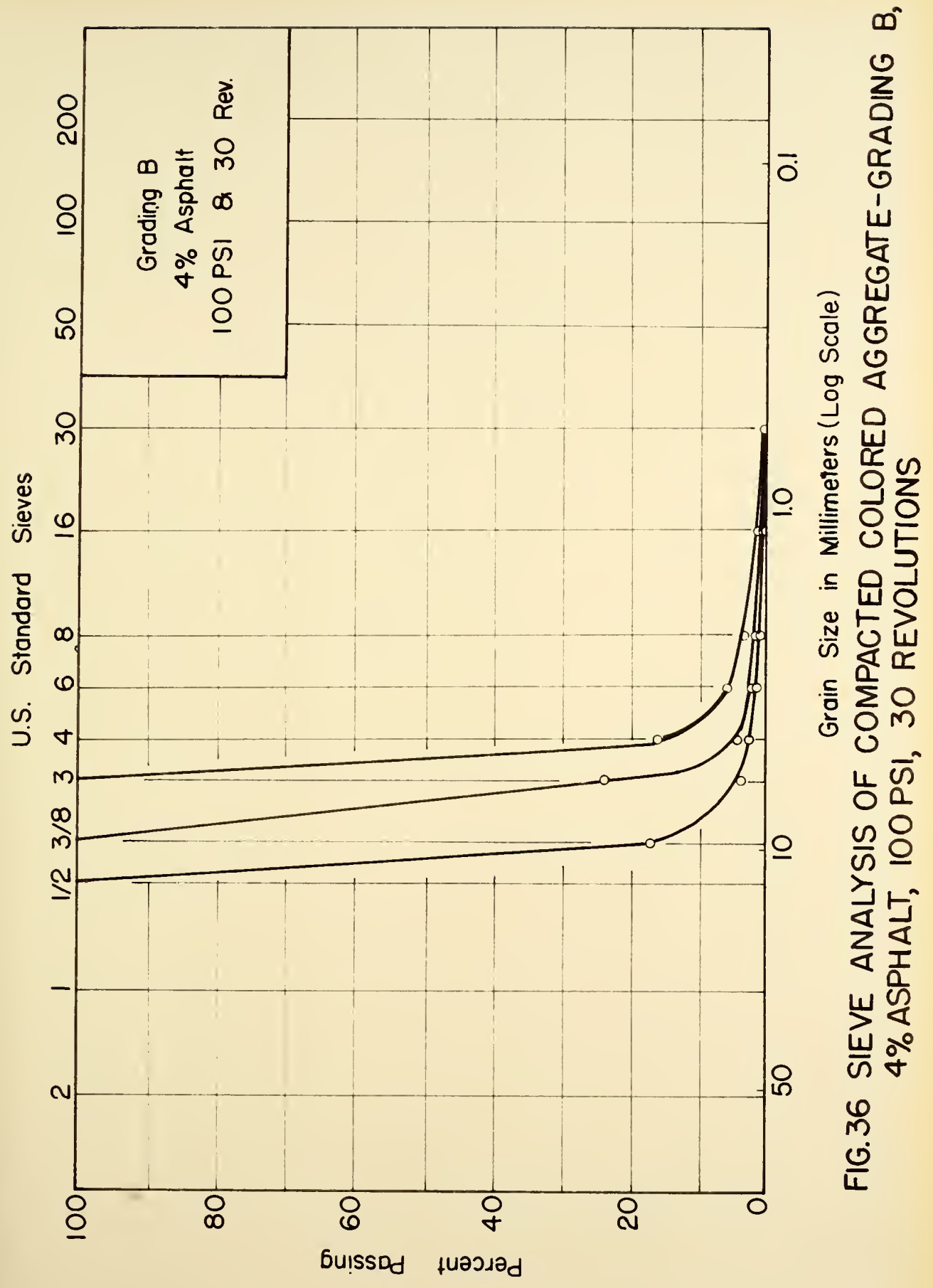




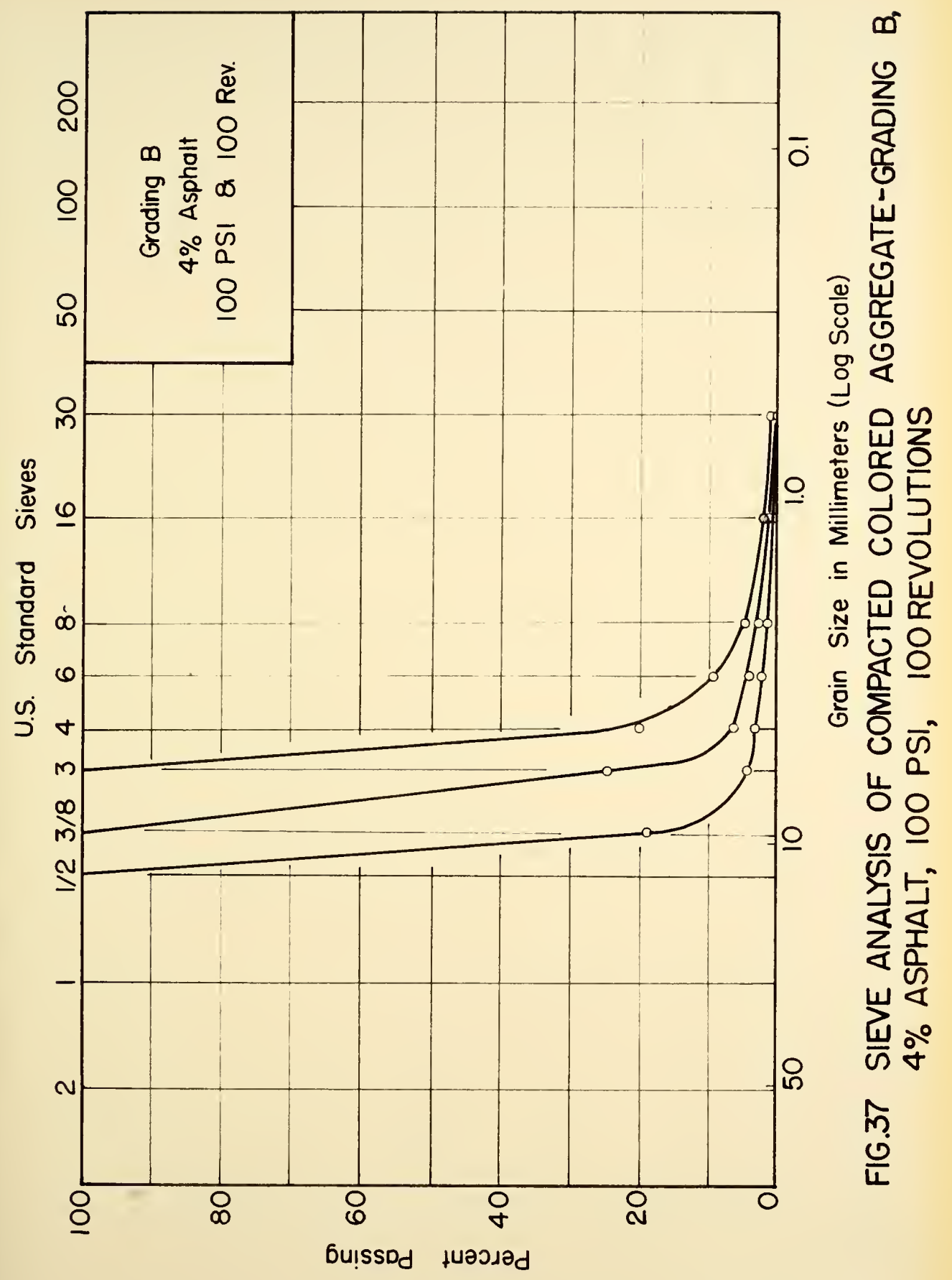




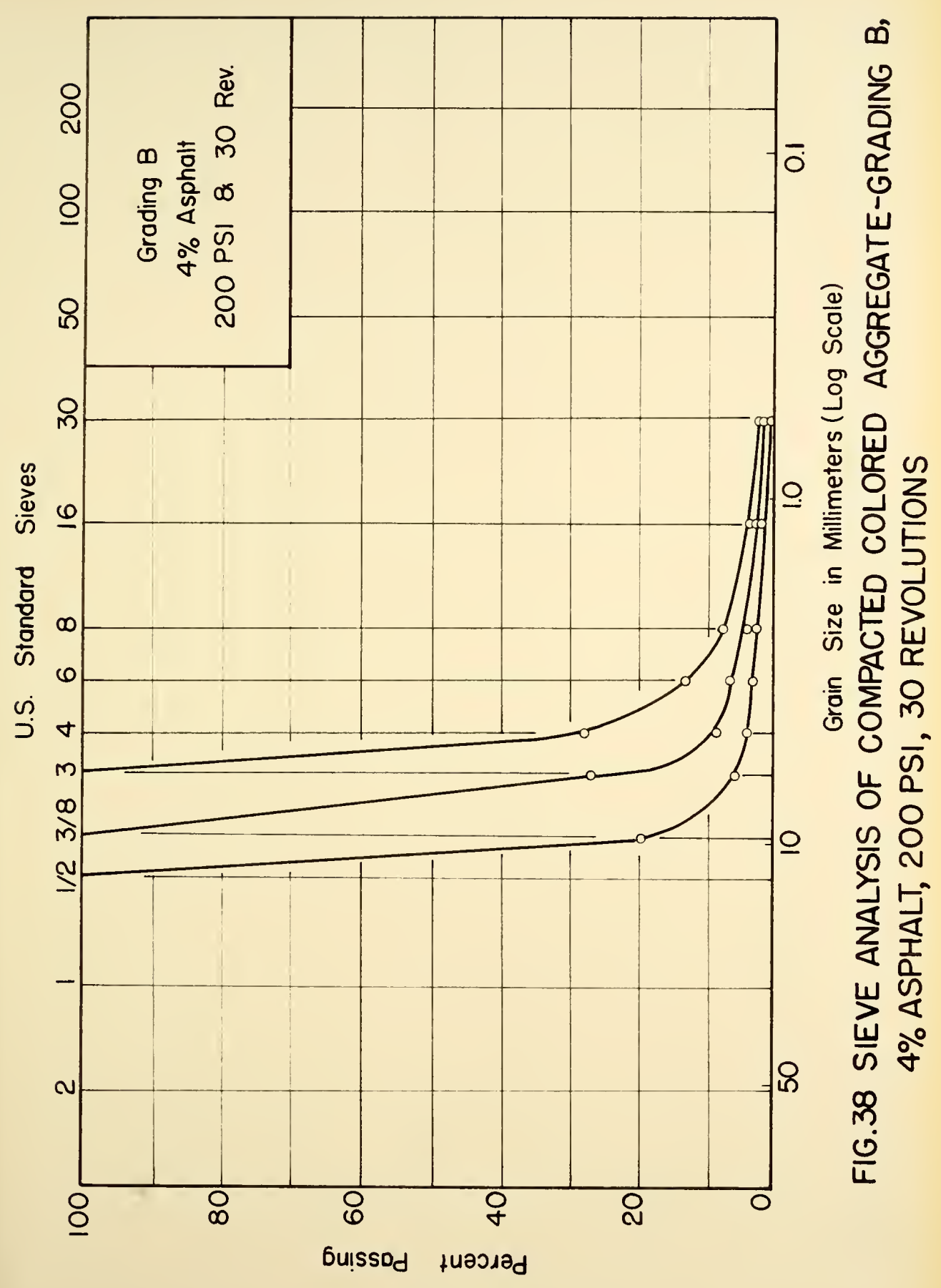




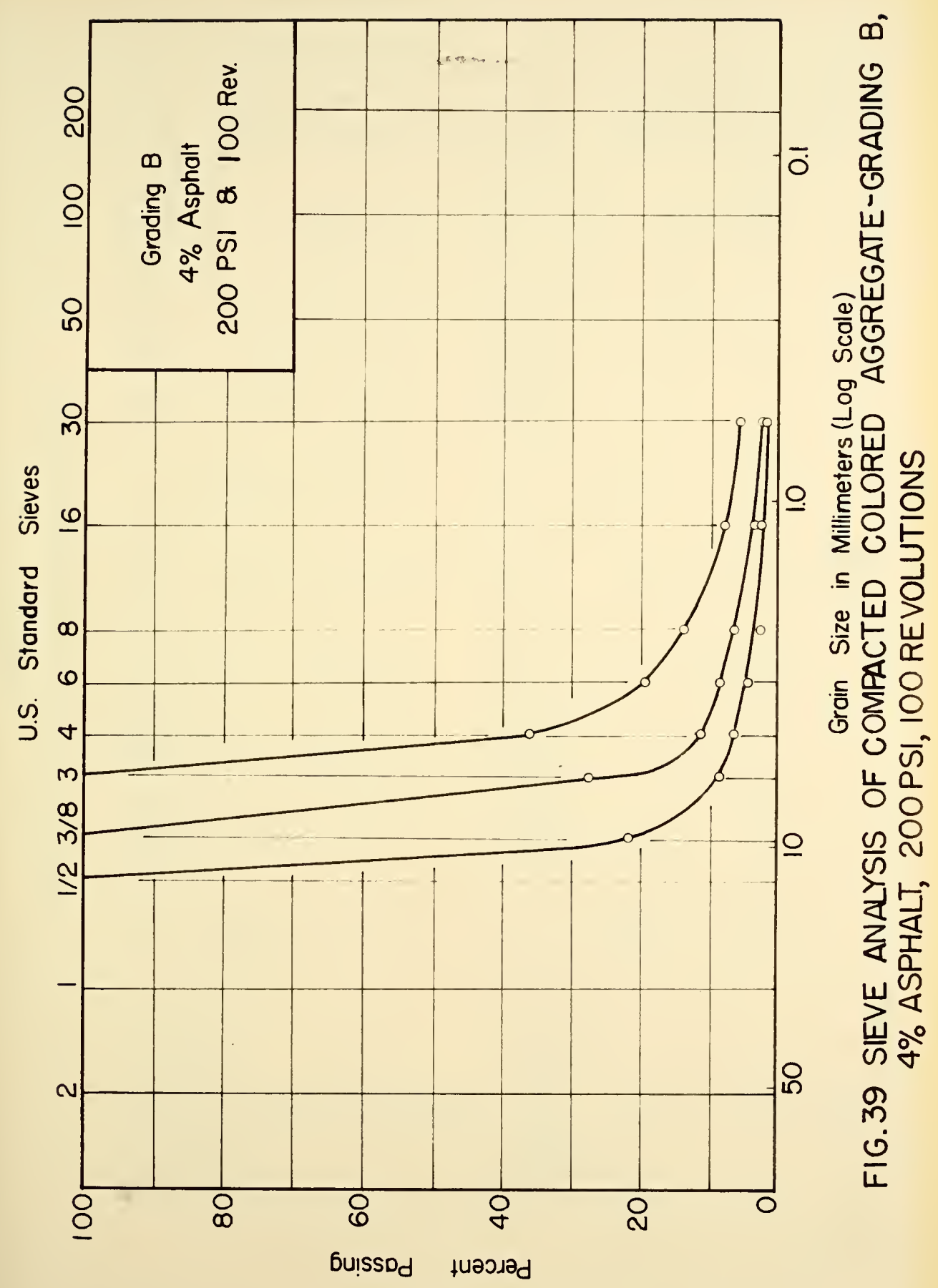




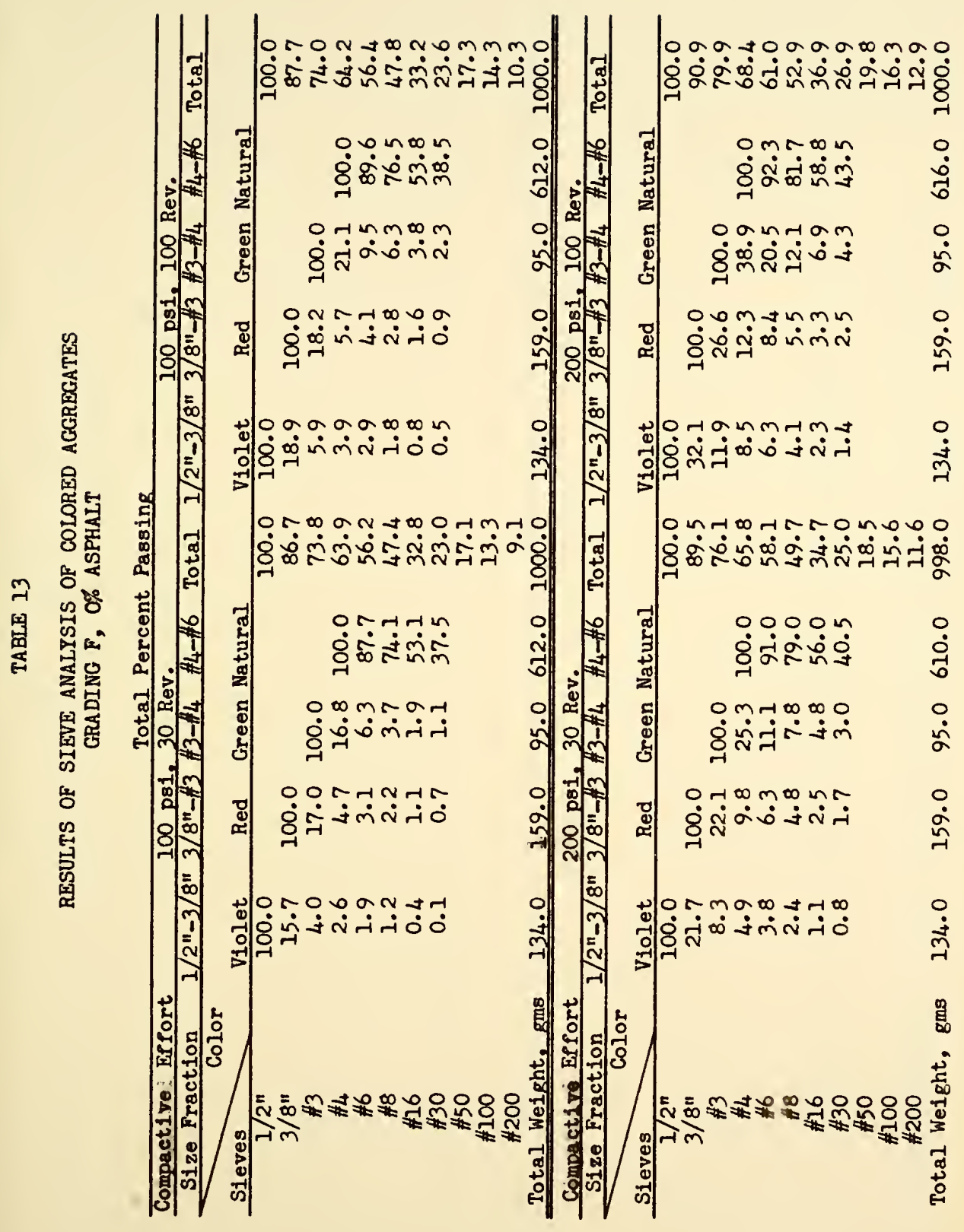




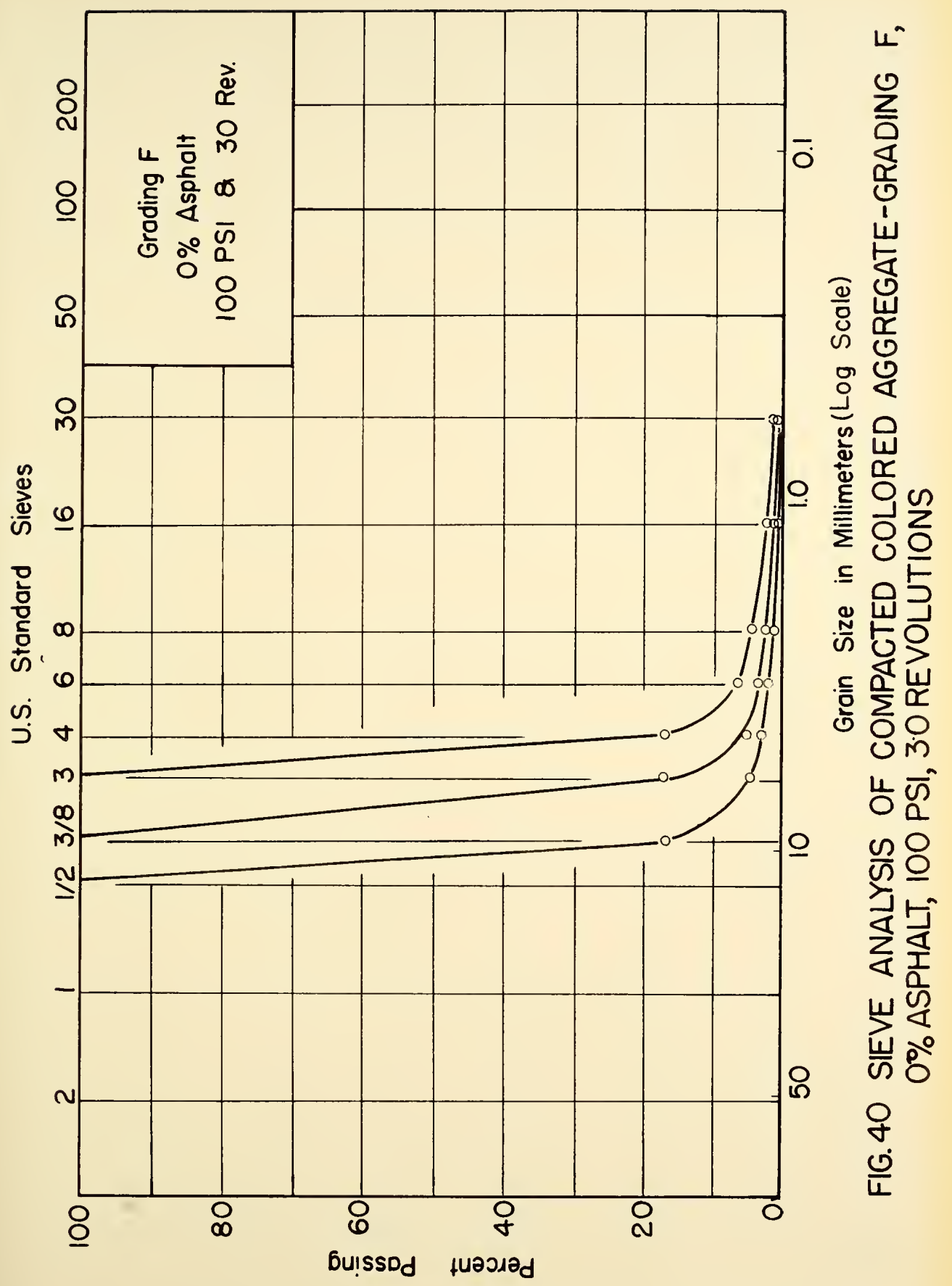




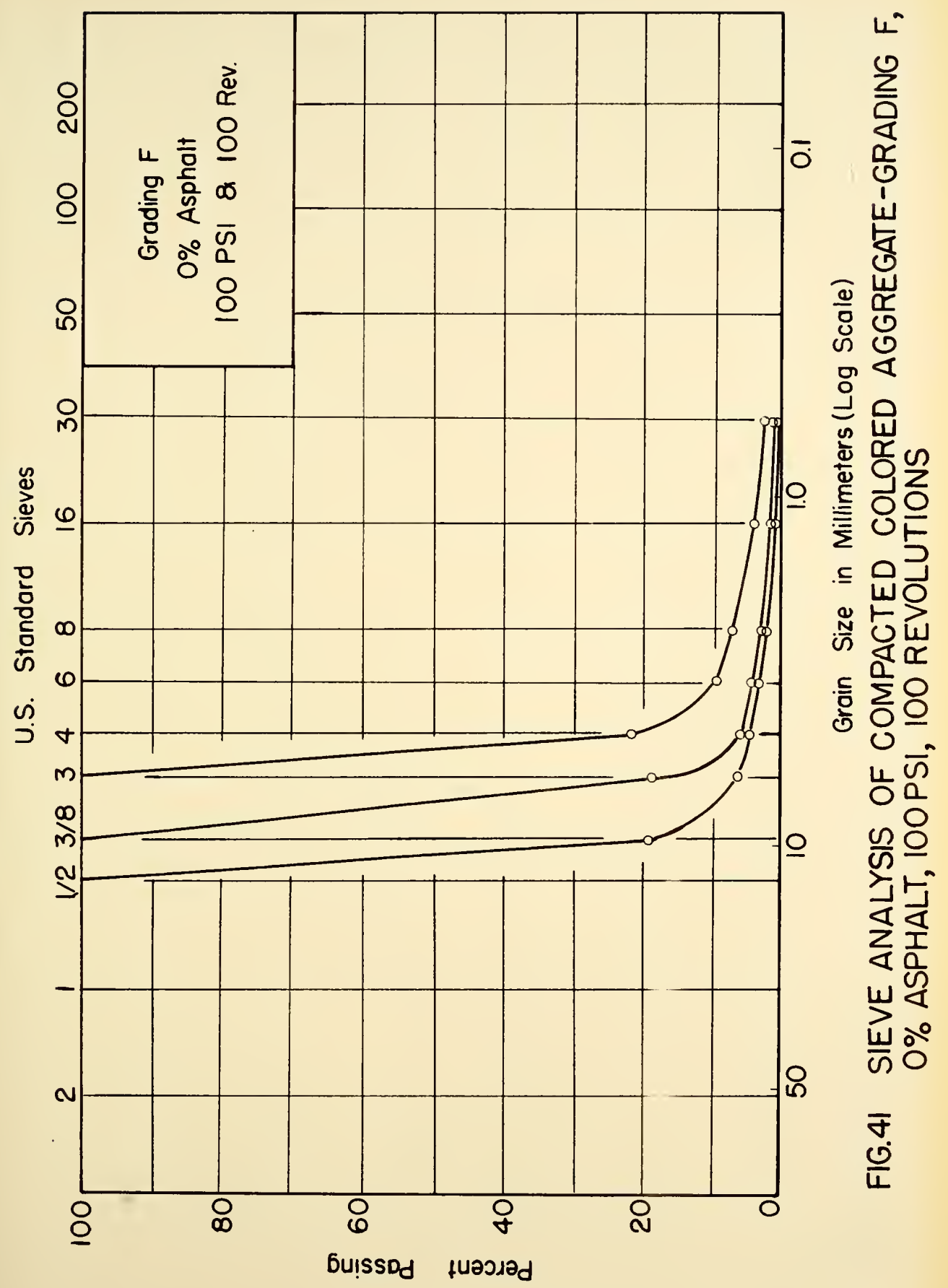




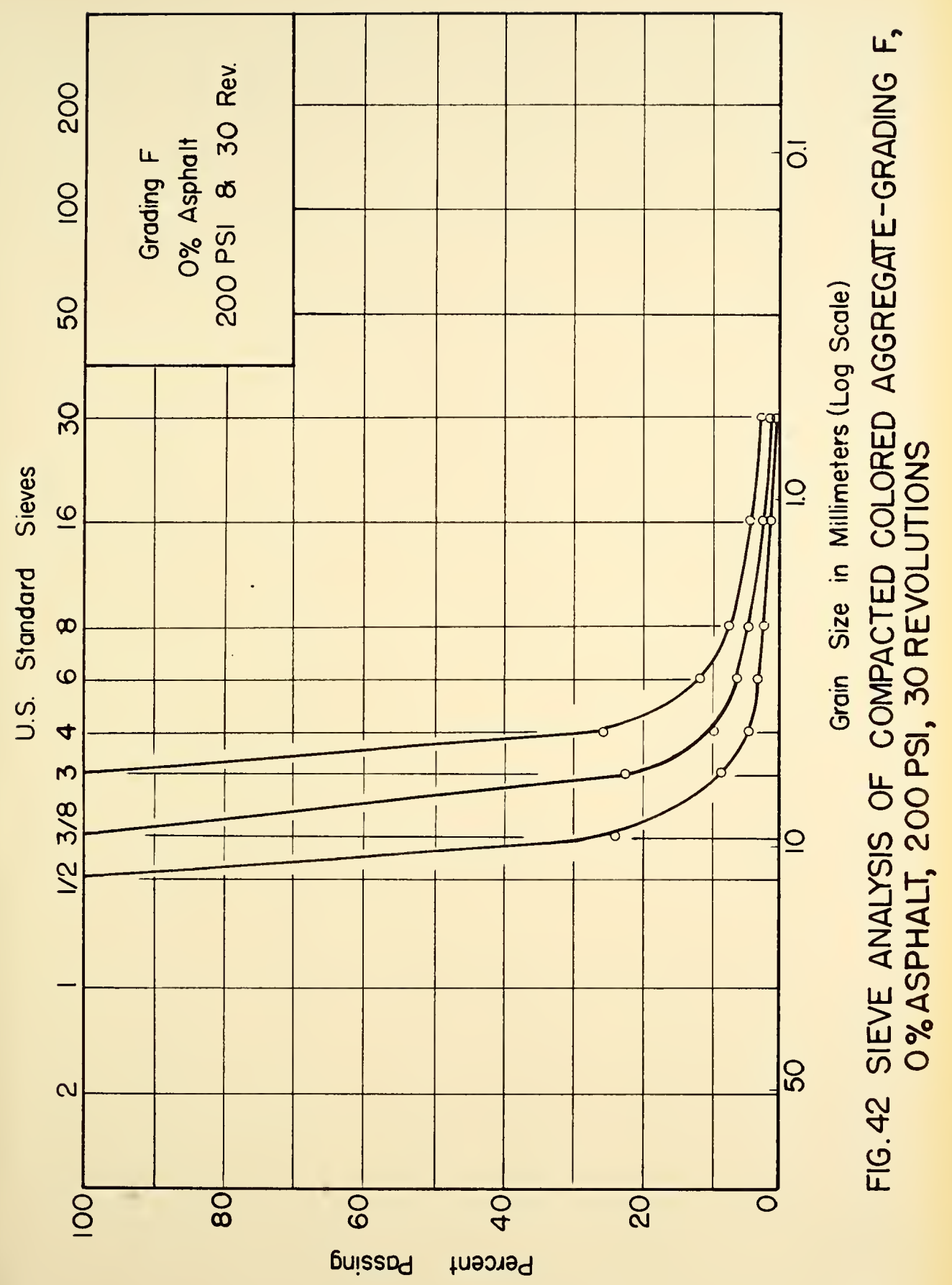




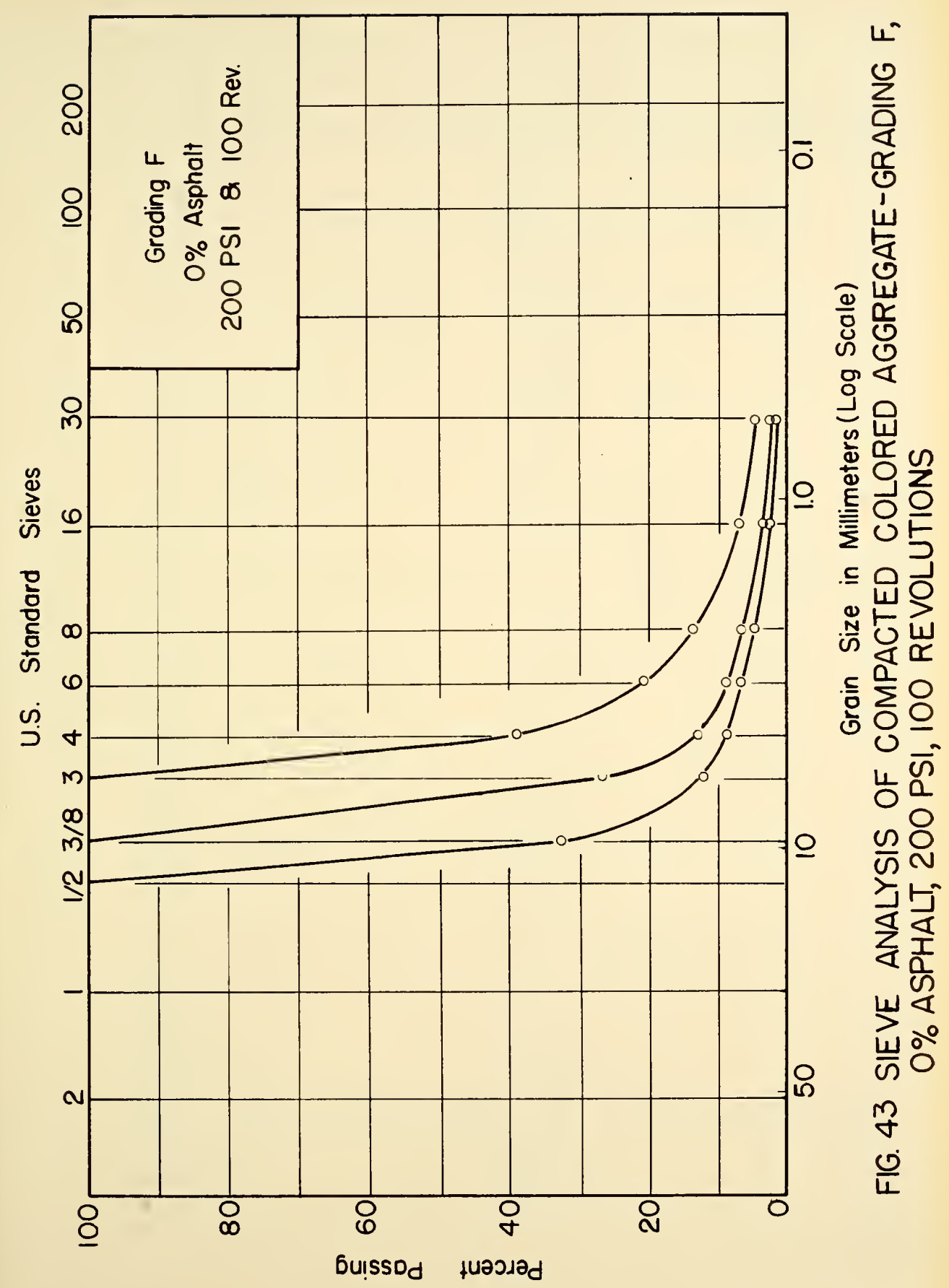




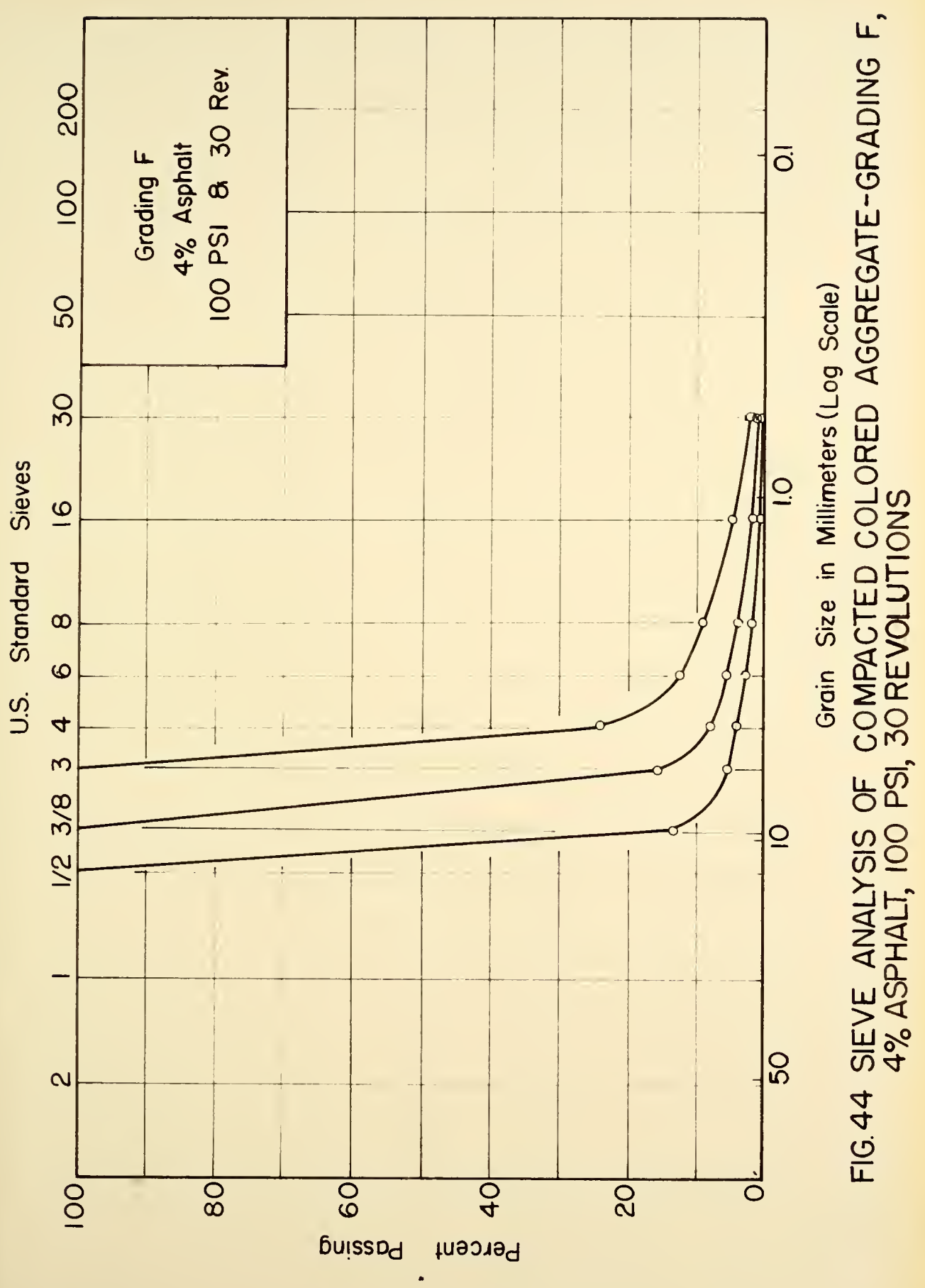




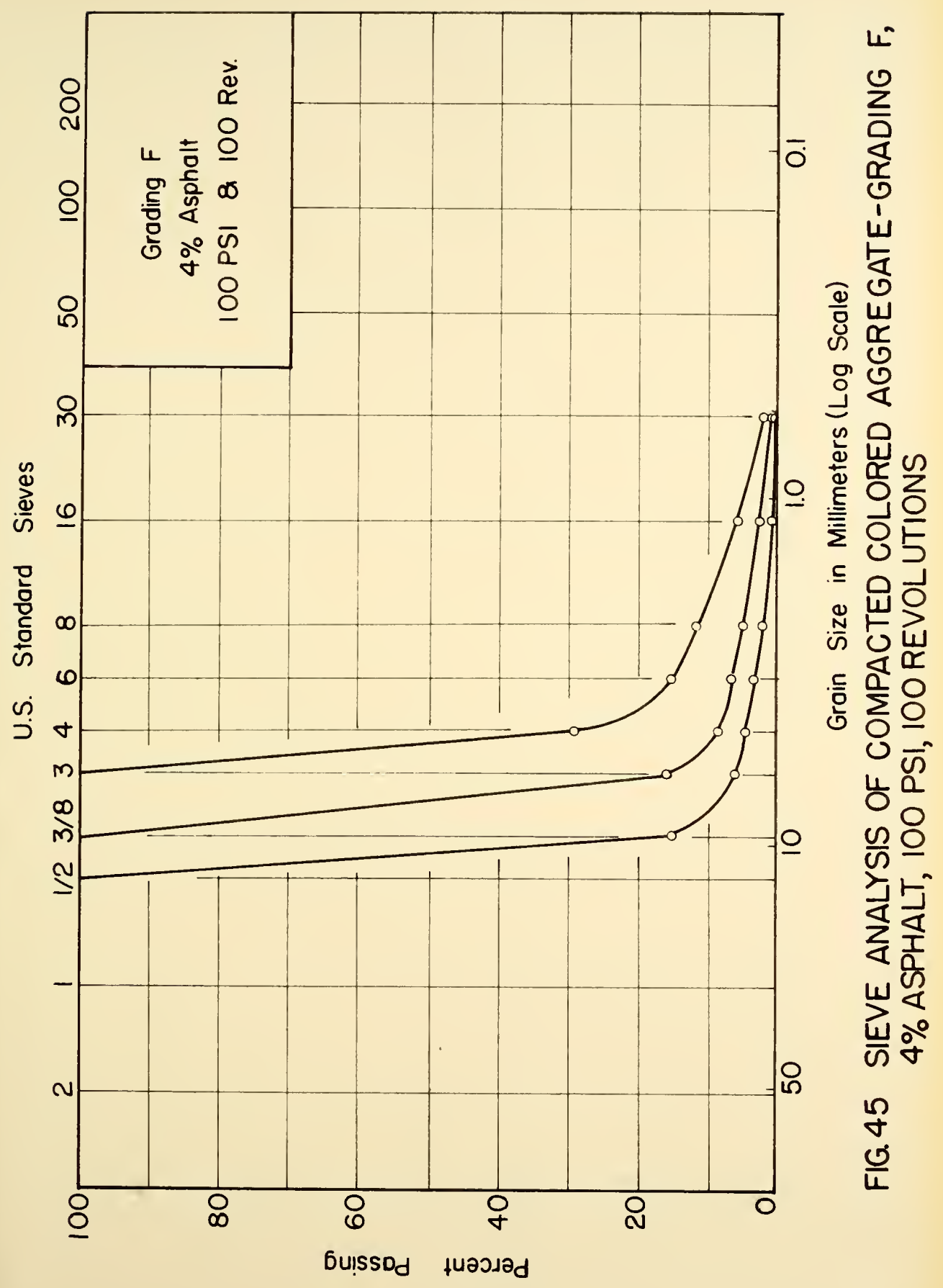




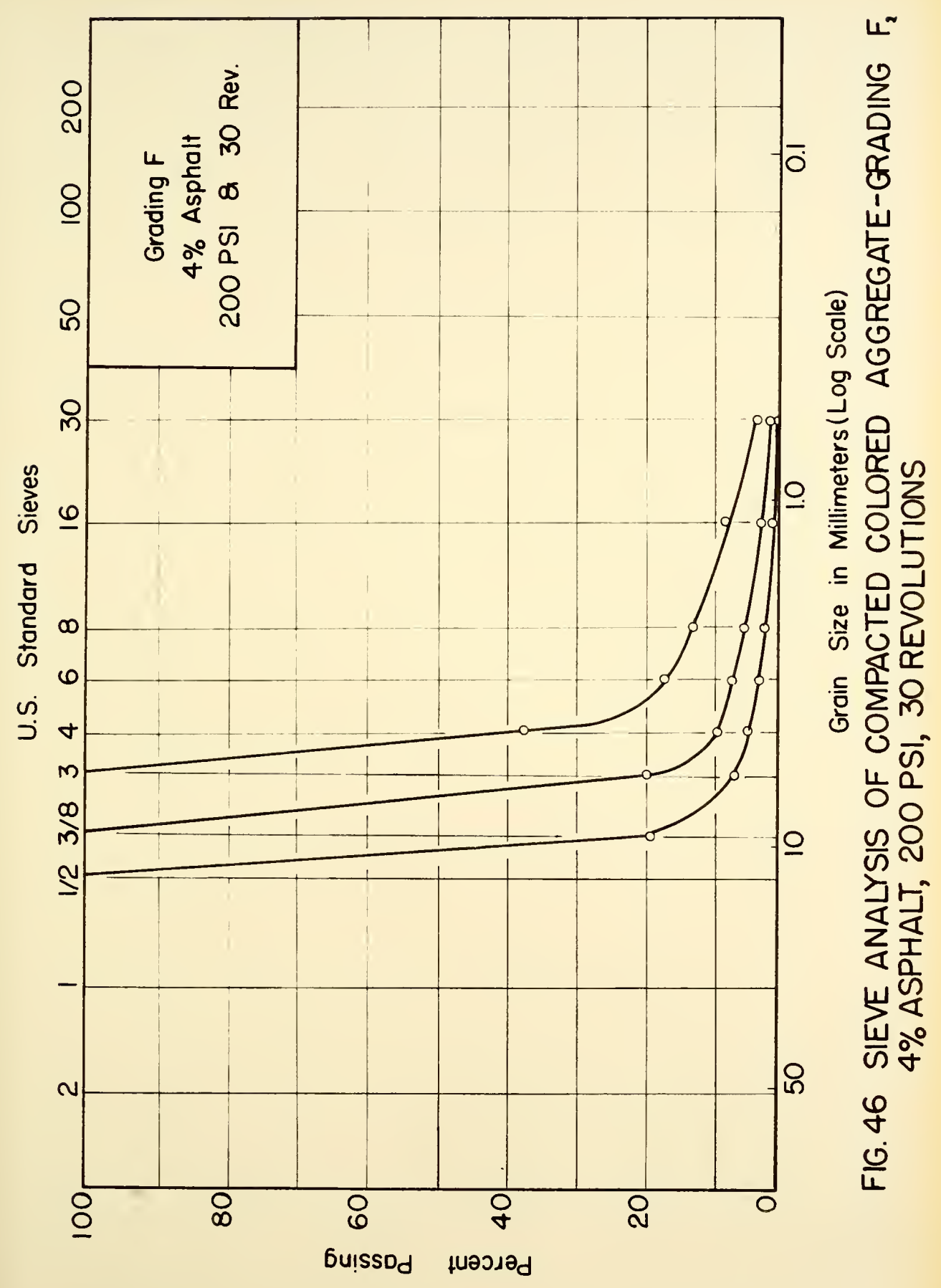




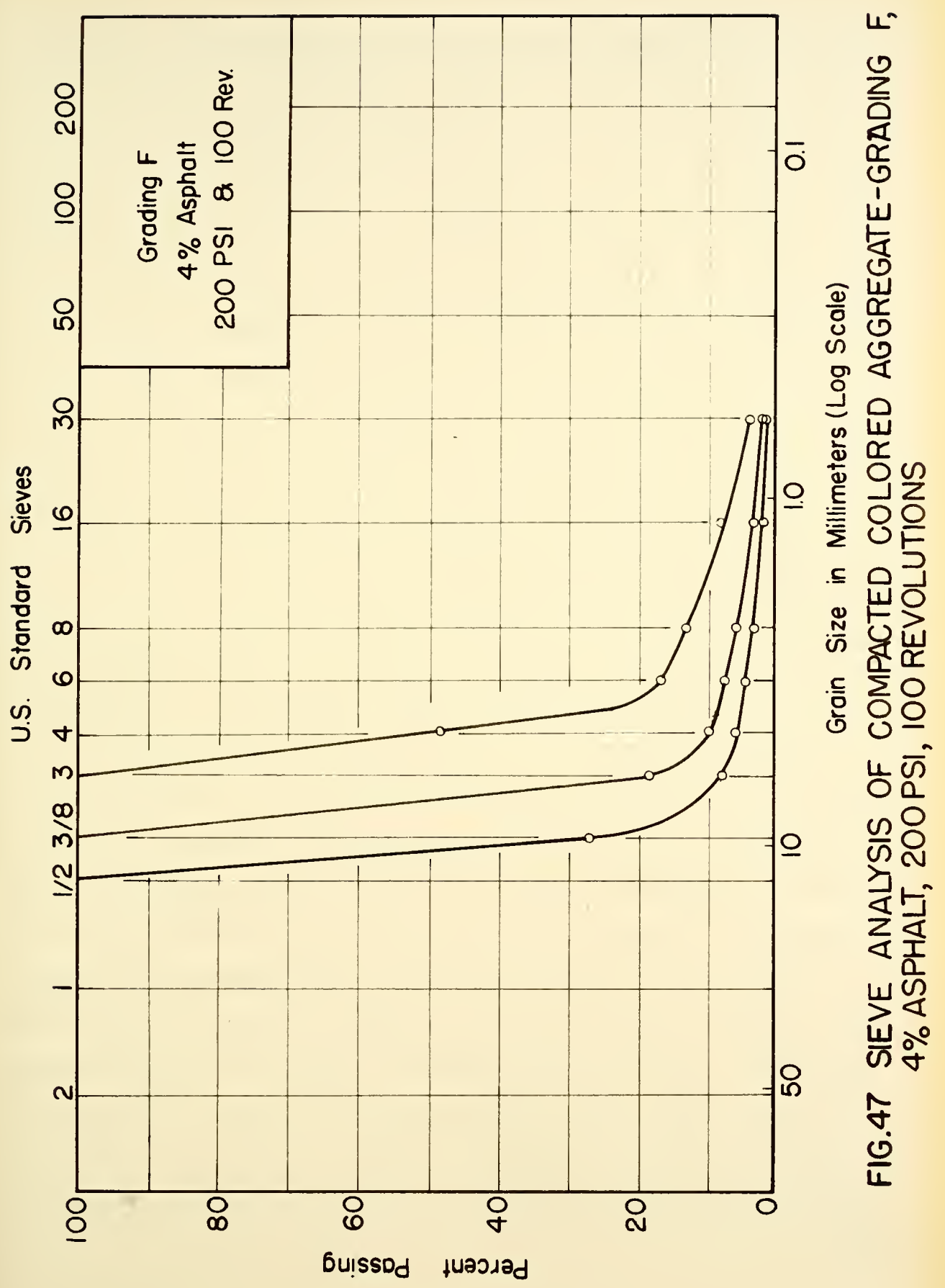


a parabolic one similar to the curves obtained for specimens made of onesized aggregates tested separately. Therefore, this portion of the study indicates that degradation of particles of one-size follows a definite pattern regardless of its size or the gradation with which it is associated, magnitude of compactive effort, or presence of asphalt. Also, from the first part of the study it was found that the degradation pattern is independent of kind of aggregate and method of application of compactive effort. Hence, it can be concluded that when the pattern of degradation of each fraction is constant, then the combination of particles of different sizes wll have a pattern which depends only on the blending ratios of these sizes rather than on type of aggregate or magnitude of compactive effort.

Thus, it can be stated that if pattern of degradation is a matter of concern, which is the case in ore treatment and in mining and metallurgical engineering, then this pattern can be predicted beforehand by knowing the gradation of feed material. But if magnitude of degradation is a matter of concern, additional variables have to be investigated thoroughly before any prediction can be made concerning this factor. In other words, In addition to gradation, the magnitude of degradation in a degradation process is dependent upon compactive effort, shape of particles, and type of rock even though these factors do not affect its pattern. For example, a change of gradation will not eliminate production of a certain size of particles when particles of larger size than this size are produced. The change in gradation will reduce or increase each size in such a proportion that the final gradation of each fraction will follow a smooth curve apm proaching a parabolic one. However, this change of gradation will change the magnitude of degradation, because the magnitude of degradation depends 
on energy consumed for breakage. So any factor affecting the breakage energy will affect the magnitude of degradation. For example, higher compactive effort corresponds to higher breakage energy and thus has to result in higher degradation. But the pattern of degradation is not energy dependent and can be considered as a constant.

Since, for any original gradation, the pattern of degradation is constant, and it is only the magnitude of degradation which varies with other factors, we can deduce that the effects of degradation on the properties of a given bituminous mixture have to be due to the magnitude of degradation. Therefore in the detailed study which follows only the magnitude of degradation has been considered, and attempts are made to find which factors are more effective in reducing the magnitude of degradation and what protective measures can be taken against degradation of aggregate in bituminous mixtures.

\section{Detailed Study}

In this section the magnitude of degradation, measured by percent increase in surface area, was determined for the three types of aggregates, dolomite, limestone, and quartzite. Three gradations, grading 0 , grading $B$, and grading F, were used. Compactive effort applied by the gyratory compactor was changed both in ram pressure and number of revolutions. The ram pressures which were used ranged from 50 psi to 250 psi. The numbers of revolutions used were $30,60,100,250,500$, and 1000. Asphalt contents utilized were $0,2,4$, and 6 percent by weight of dry aggregate. In this part of the study, 450 specimens were formed and tested, the asphalt was extracted, and a sieve analysis made on the dry aggregate from which the percent increase in surface area for each specimen was calculated. 
Tables 15, 16, and 17 include the percent increase in surface area for each kind of aggregate. Each value is for a specimen whose original gradation, percent asphalt, and effort used in testing it can be read from the table. Table 15 contains the resulte obtained from 150 specimens made from dolomite. Table 16 presents data for percent increase in surface area for specimens made of limestone, while Table 17 contains similar results for quartzite. On specimens with zero percent asphalt using gradings $B$ and $F$, tests were not made at $250 \mathrm{psi}$ ram pressure due to the possibility of damage to the gyratory machine. A few tests were performed on these specimens at $50 \mathrm{psi}$ ram pressure. Iimestone and quartzite specimens of the open gradation could not be made with 6 percent asphalt due to the low porosity of these aggregates and the open character of the mixtures. Because previous tests indicated that the results would not be significant, tests on specimens with 2 and 6 percent asphalt at high numbers of revolutions, which were time consuming, were not made. At such high numbers of revolutions only specimens with zero and 4 percent asphalt were tested.

Figure 48 1llustrates the percent increase in surface area versus number of revolutions for specimens made of limestone. The ram pressures are indicated on each curve. All pecimens were made of grading 0 , and curves of zero percent asphalt can be differentiated from curves of 4 percent asphalt by their legends. This figure shows that degradation increases very rapidy in the first part of the test and then continues to increase at a decreasing rate until about 250 revolutions after which the rate of Increase remains constant in each case. It can also be noticed that as ram pressure increases the degredation in the flrst fow revolutions increases drastically. For a ram pressure of 250 psi, almost 70 percent of the 


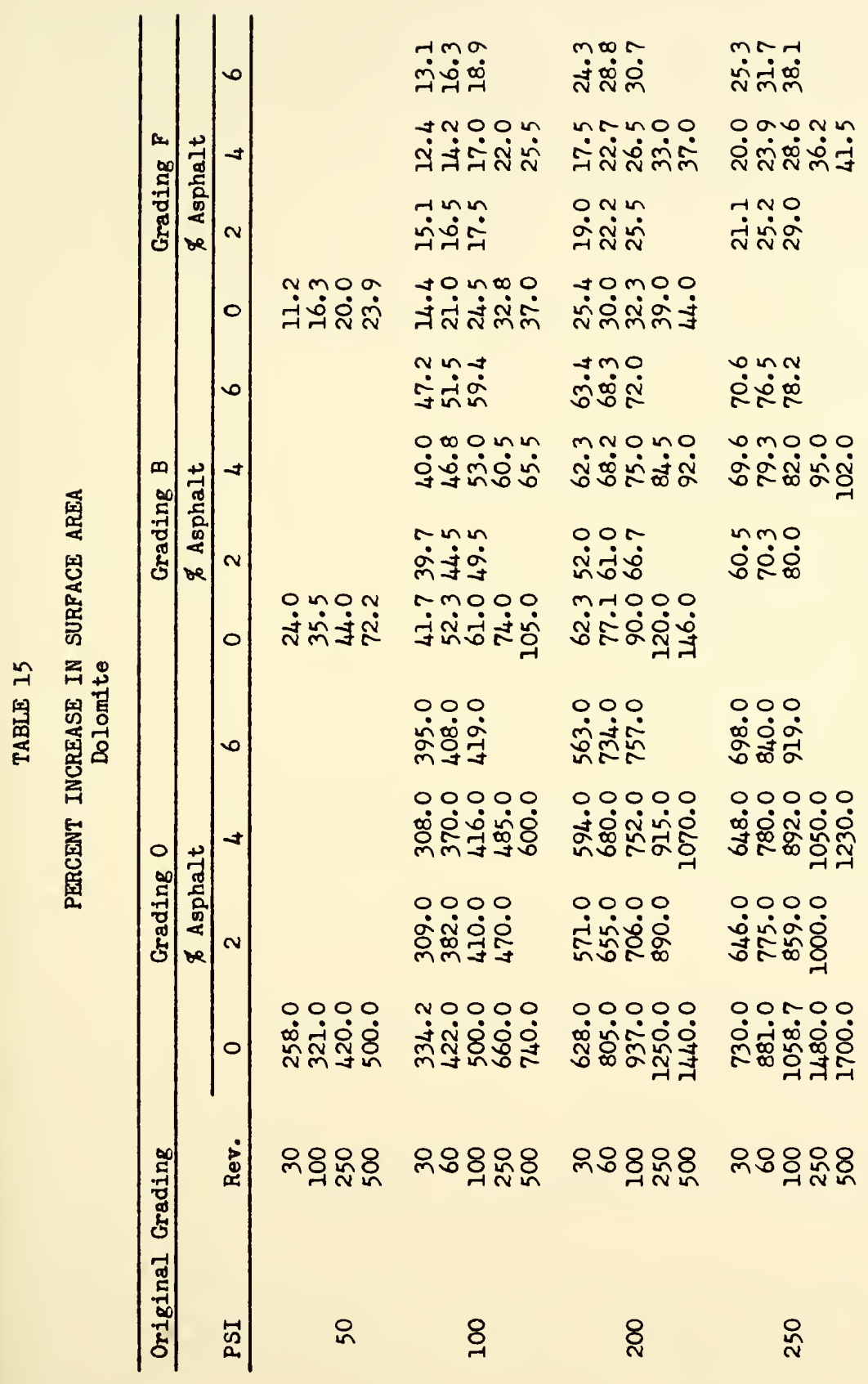




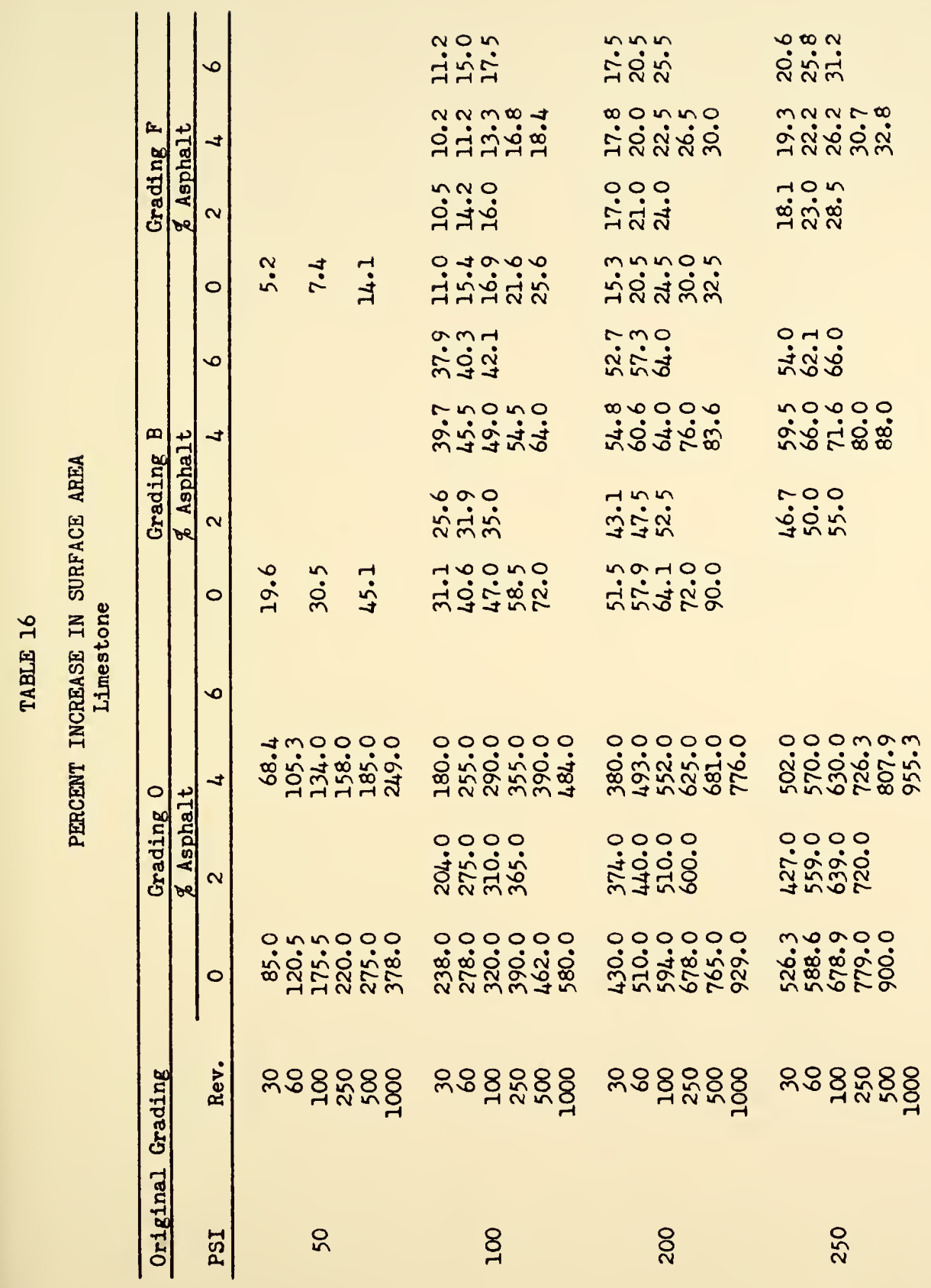




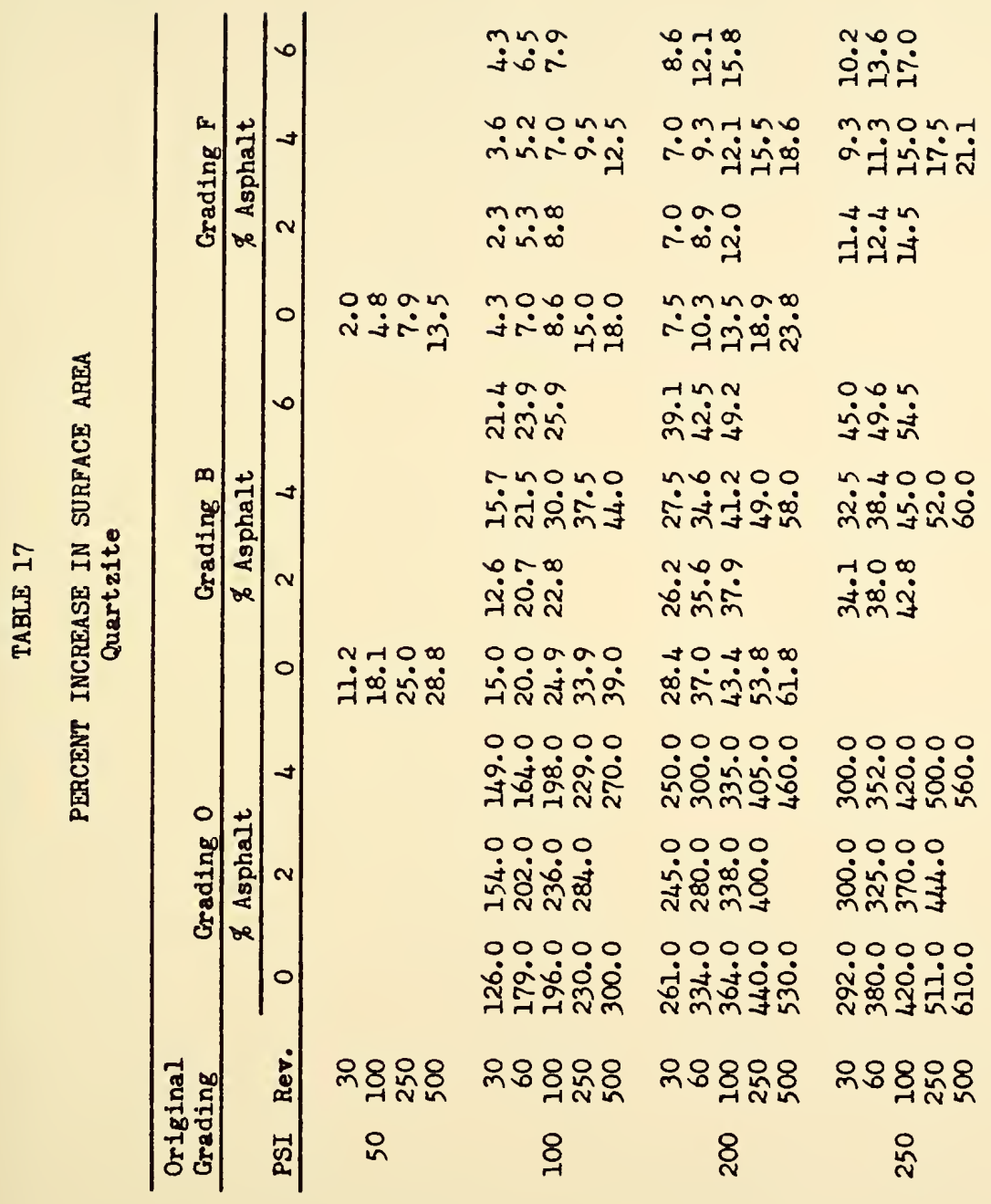




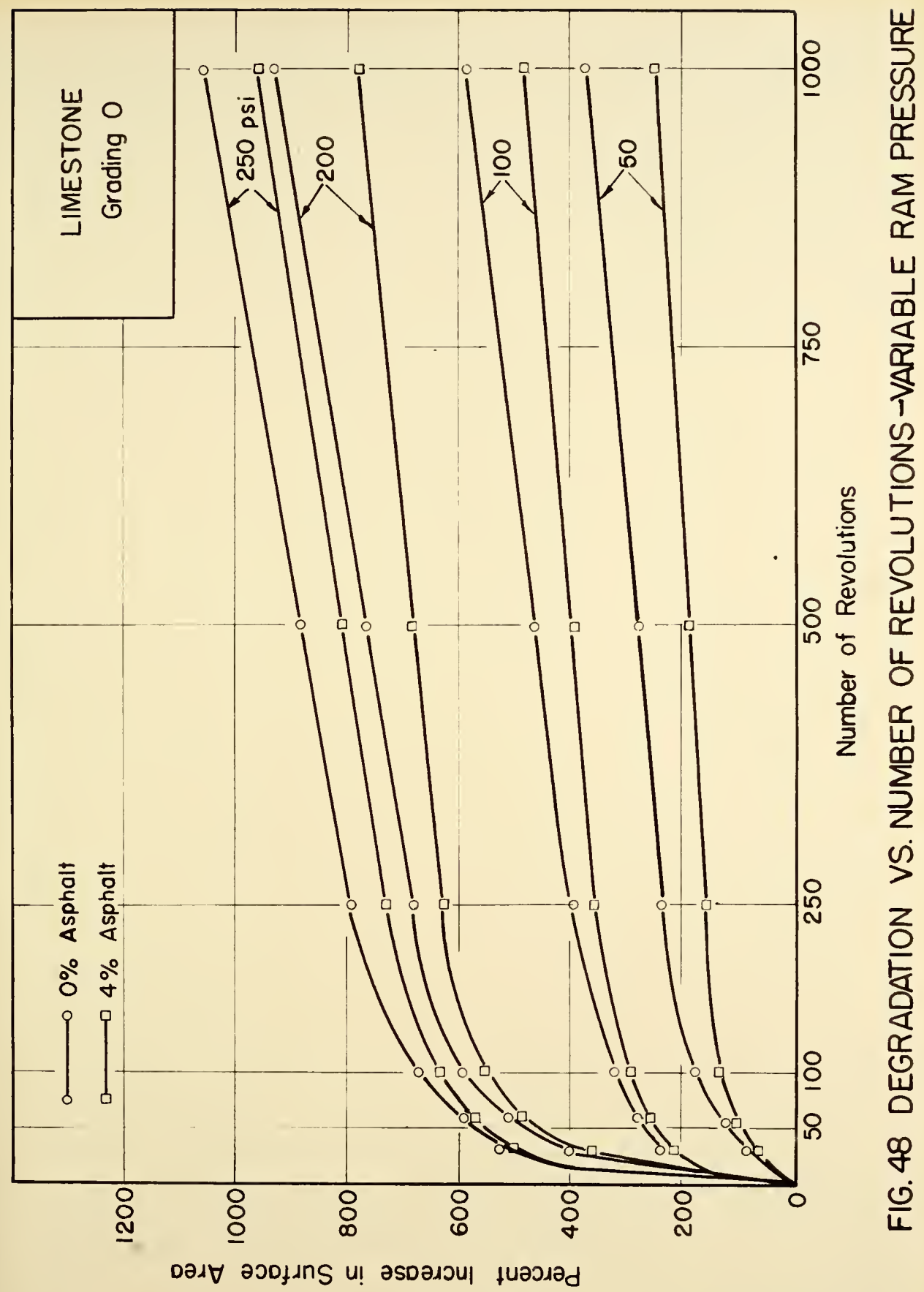


degradation that occurred at 1000 revolutions has occurred in the first hundred revolutions, while at $50 \mathrm{psi}$ ram pressure only 50 percent of the degradation has occurred in the first hundred revolutions. Furthermore, it can be noted that the slope of the straight-line portion of the curves after 250 revolutions are steeper as ram pressure increases, which also indicates that degradation is more severe as ram pressure increases. These curves also show that the presence of asphalt only affects the amount of degradation and not the degradation pattern.

Figures 49, 50, and 51 show degradation versus ram pressure for specimens made with zero percent asphalt using three gradations of the three kinds of aggregate. Degradation on the ordinate is plotted on a log scale, while ram pressure on the abscissa is plotted to an arithmatic scale. Each curve is for a certain number of revolutions which can be read on the curve. Gradation designations of original mixtures are shown at the left side of the curves. Type of aggregate can be read in the lower right hand corner of each figure along with the percent of asphalt. The dotted portions of the curves are extrapolations where no specimen was tested under those conditions. Figures 52, 53, and 54 show similar results obtained from specimens mixed with 2 percent asphalt, while Figures 55, 56, and 57 are for specimens mixed with 4 percent asphalt and Figures 58, 59, and 60 are for specimens mixed with 6 percent asphalt. Each figure, which is for one kind of aggregate and one asphalt content, indicates that degradation increases both with increase in ram pressure and increase in number of revolutions. This means that degradation increases with increase in compactive effort. Also, it can be seen that in most cases the major part of the degradation occurred under the first hundred psi of ram pressure. 


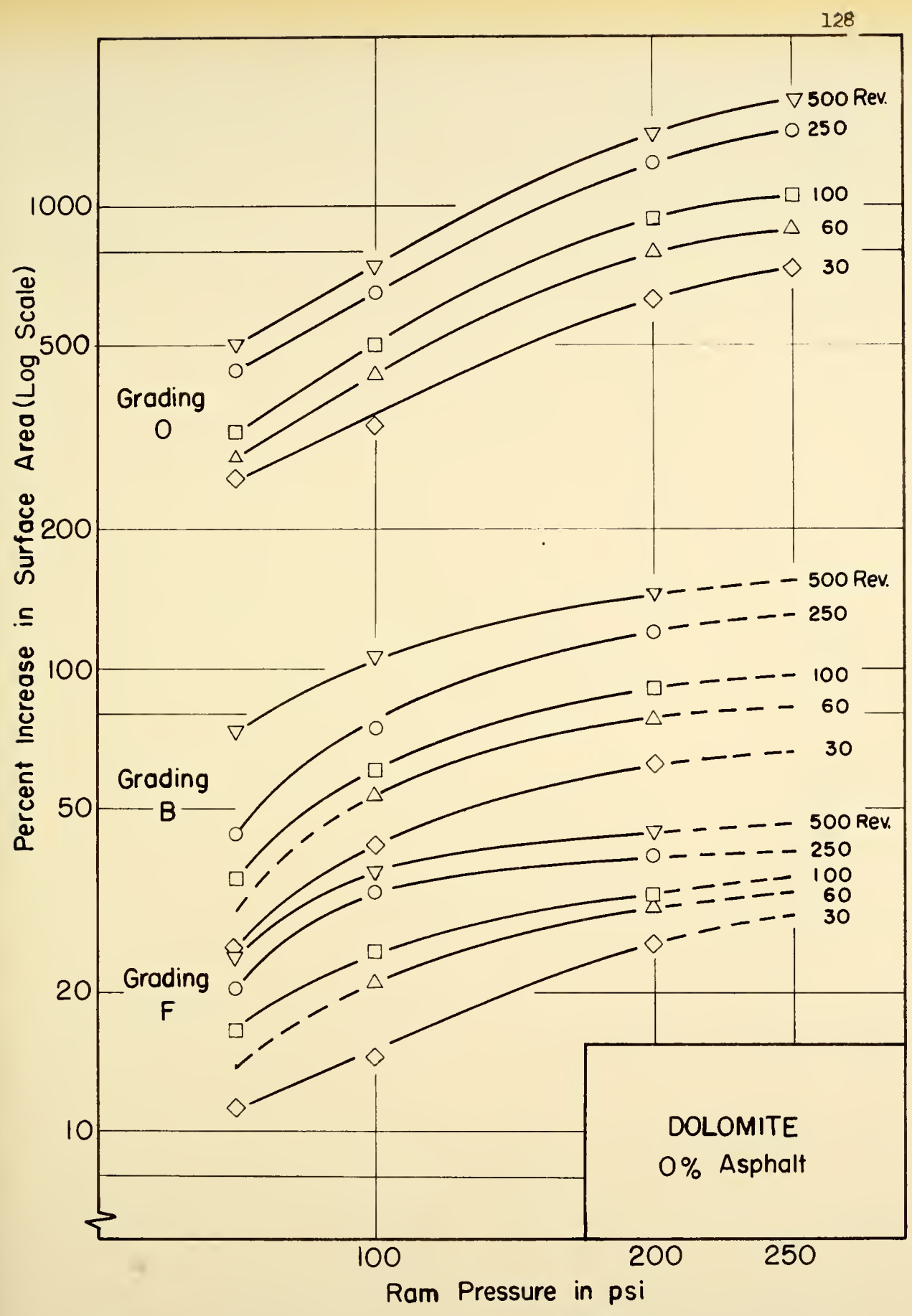

FIG. 49 DEGRADATION VS RAM PRESSURE FOR DOLOMITE, O\% ASPHALT 


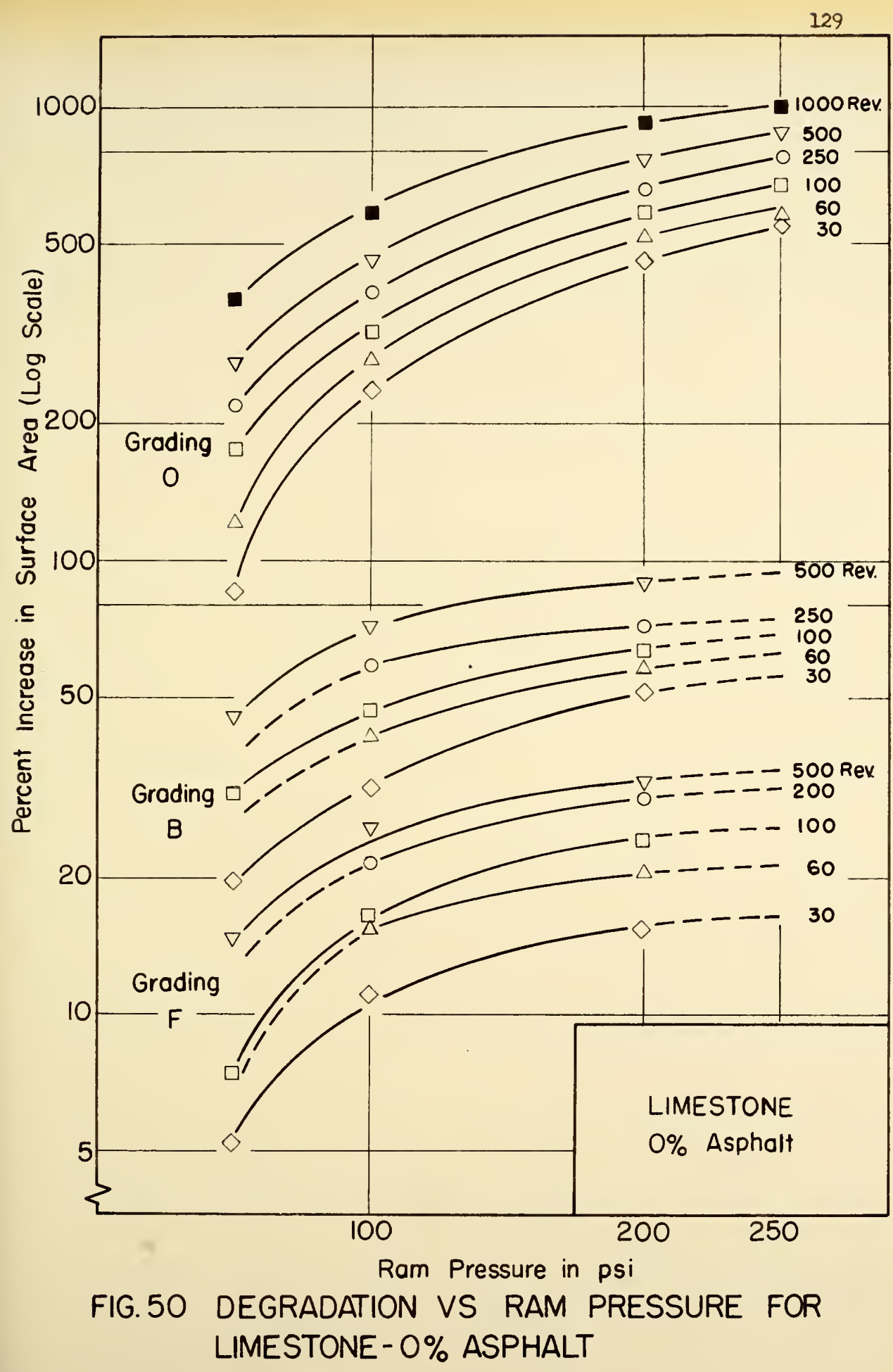




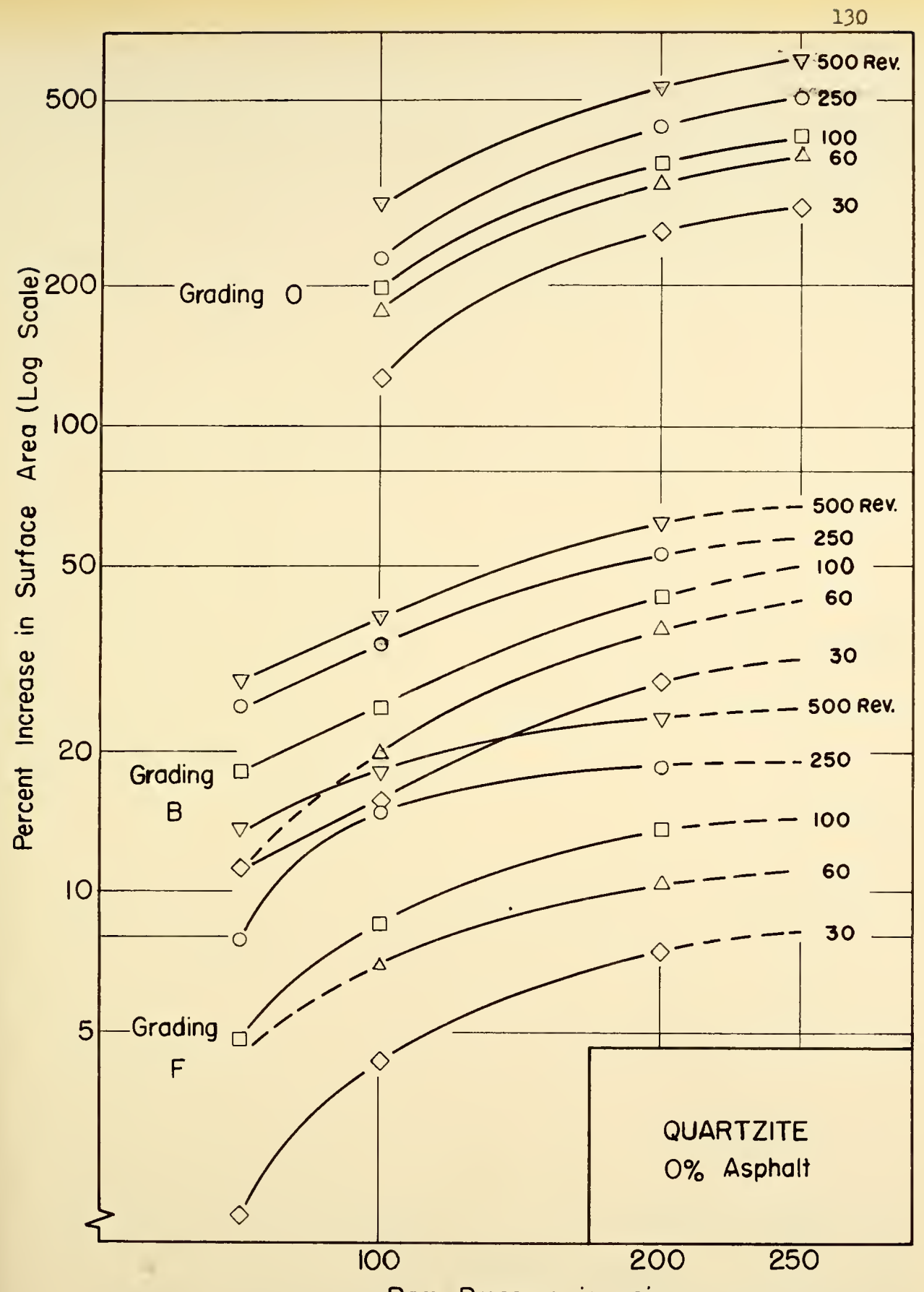

Ram Pressure in psi

FIG. 5 I DEGRADATION VS RAM PRESSURE FOR QUARTZITE- O\% ASPHALT 


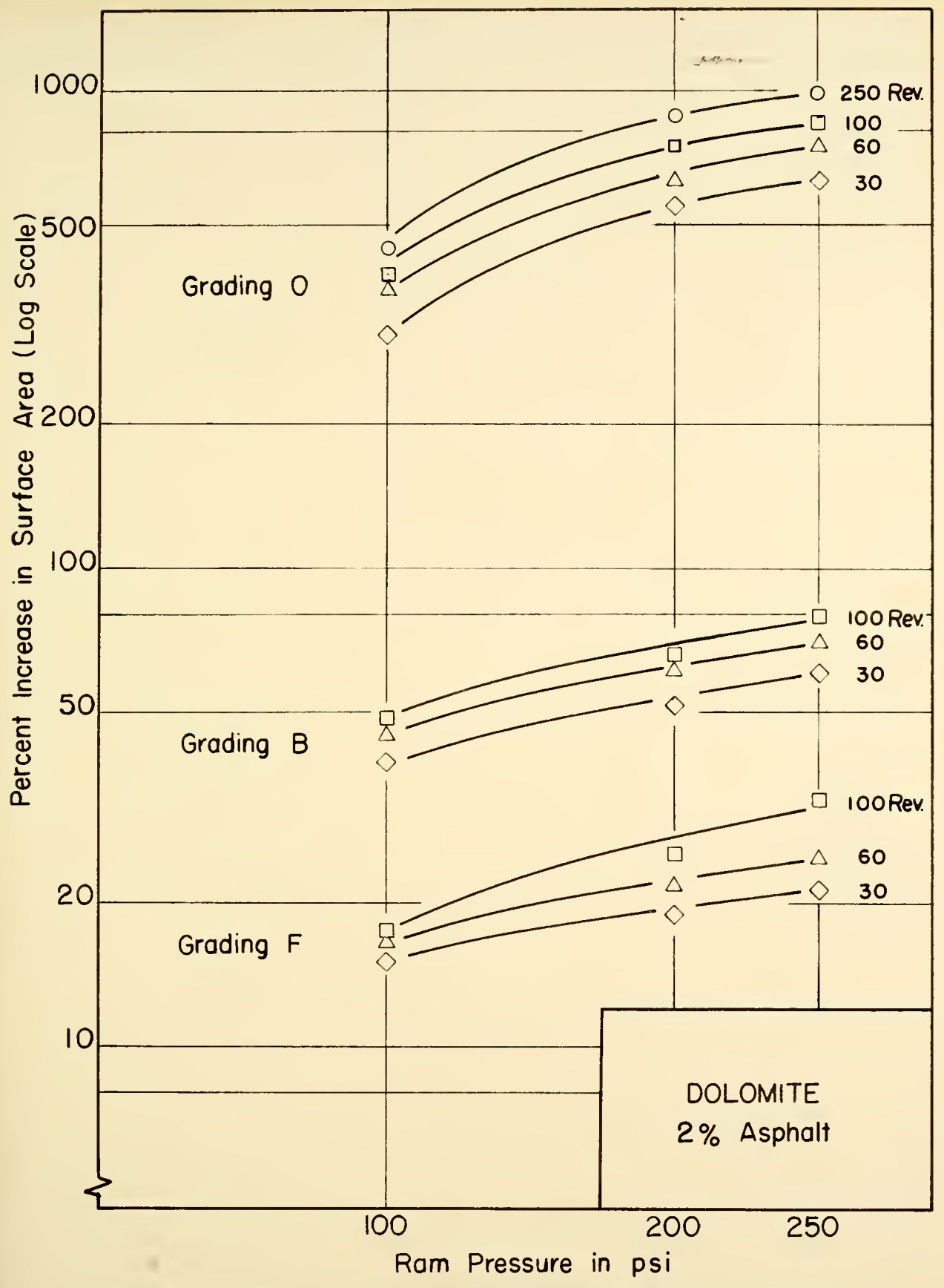

FIG. 52 DEGRADATION VS RAM PRESSURE FOR DOLOMITE- $2 \%$ ASPHALT 


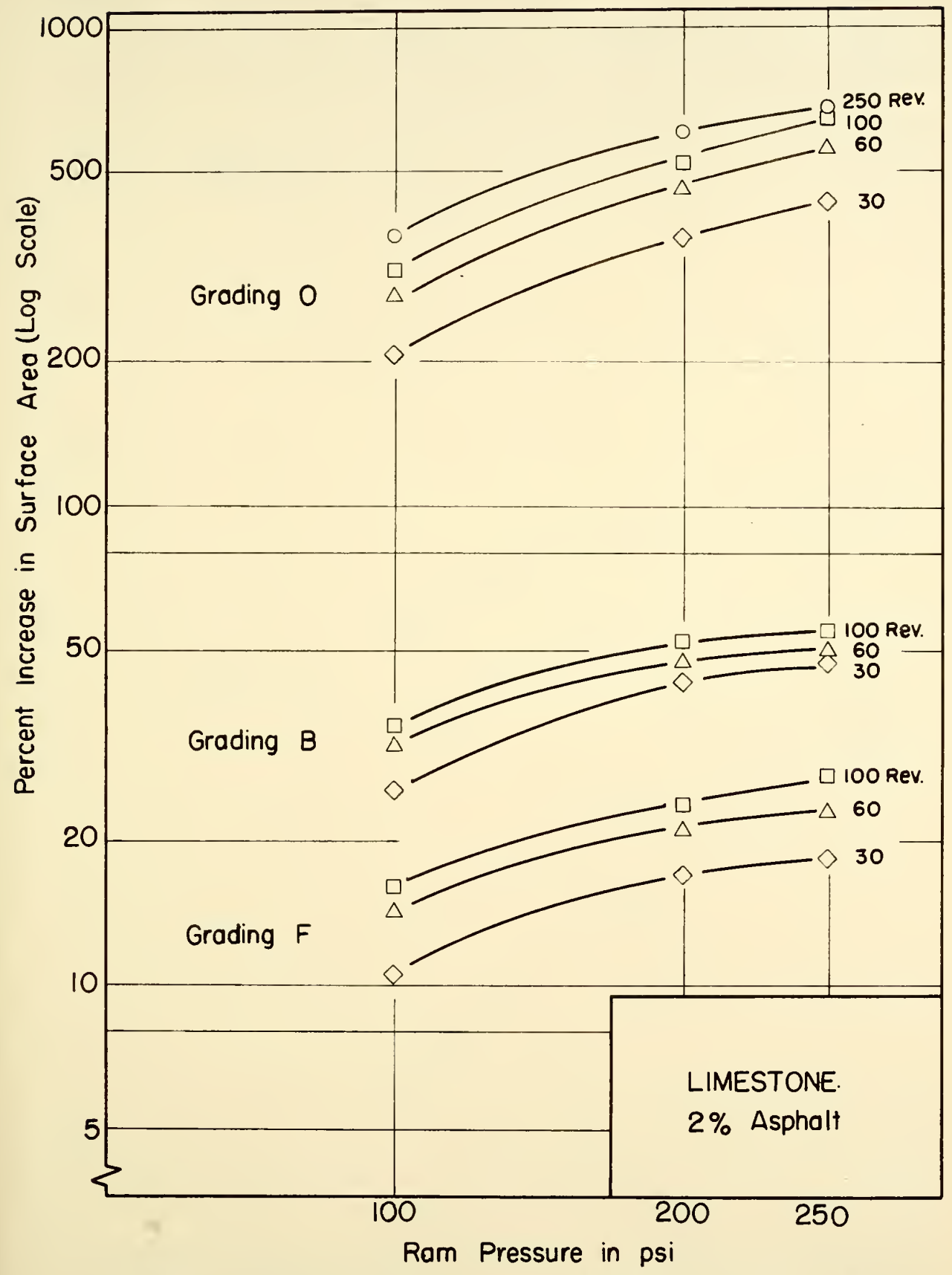

FIG. 53 DEGRADATION VS RAM PRESSURE FOR LIMESTONE- 2\% ASPHALT 


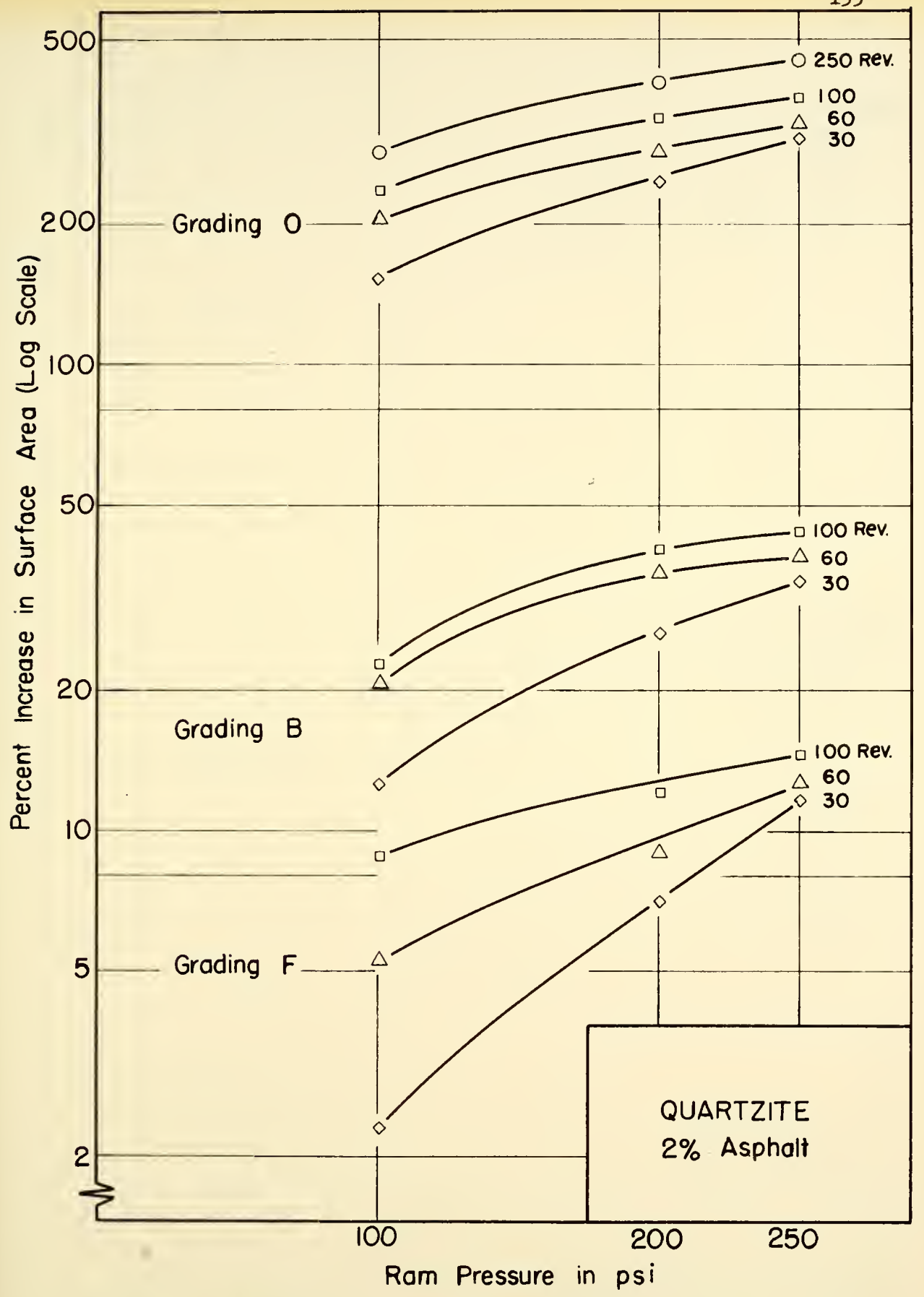

FIG. 54 DEGRADATION VS RAM PRESSURE FOR QUARTZITE - $2 \%$ ASPHALT 


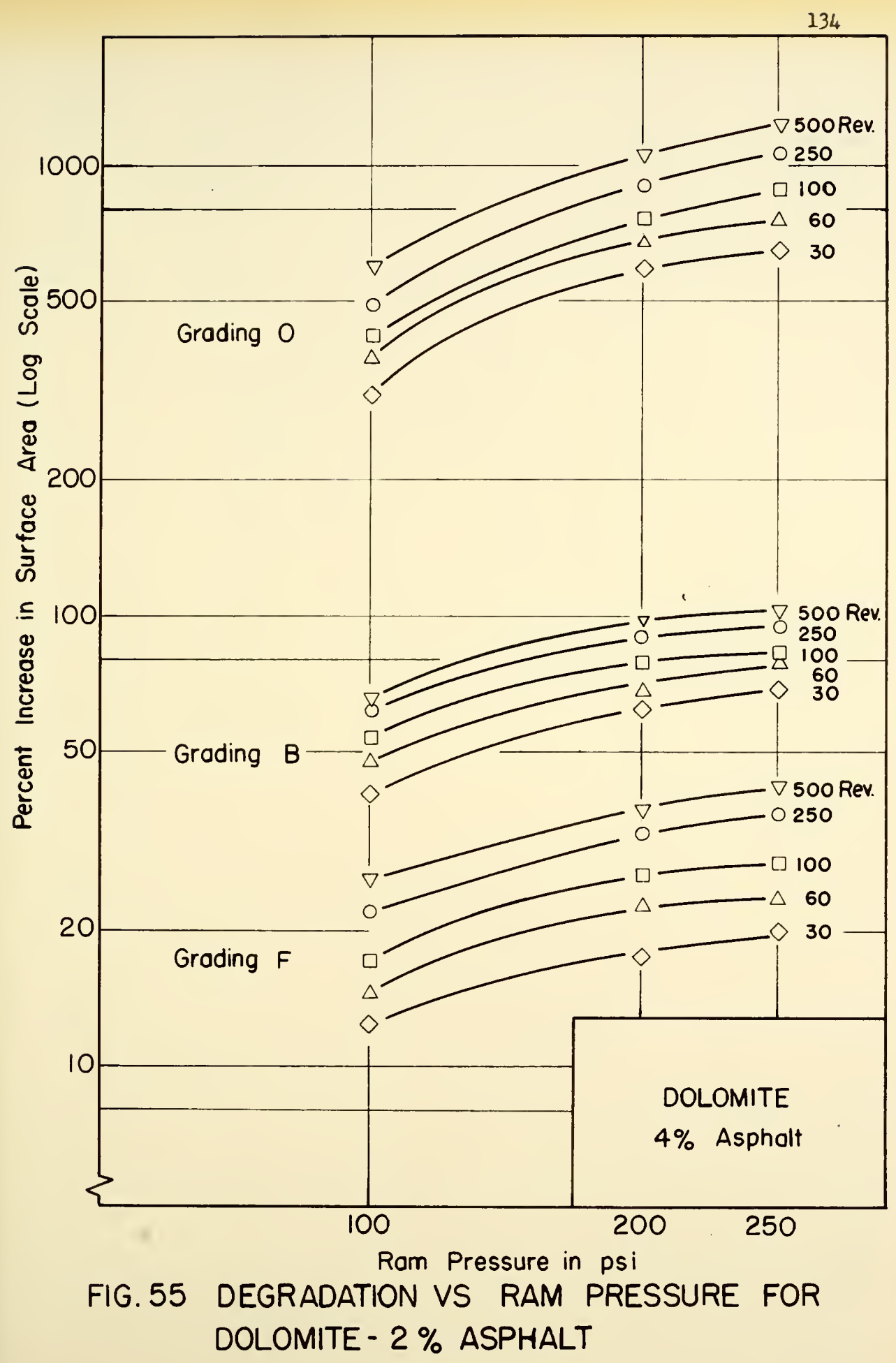




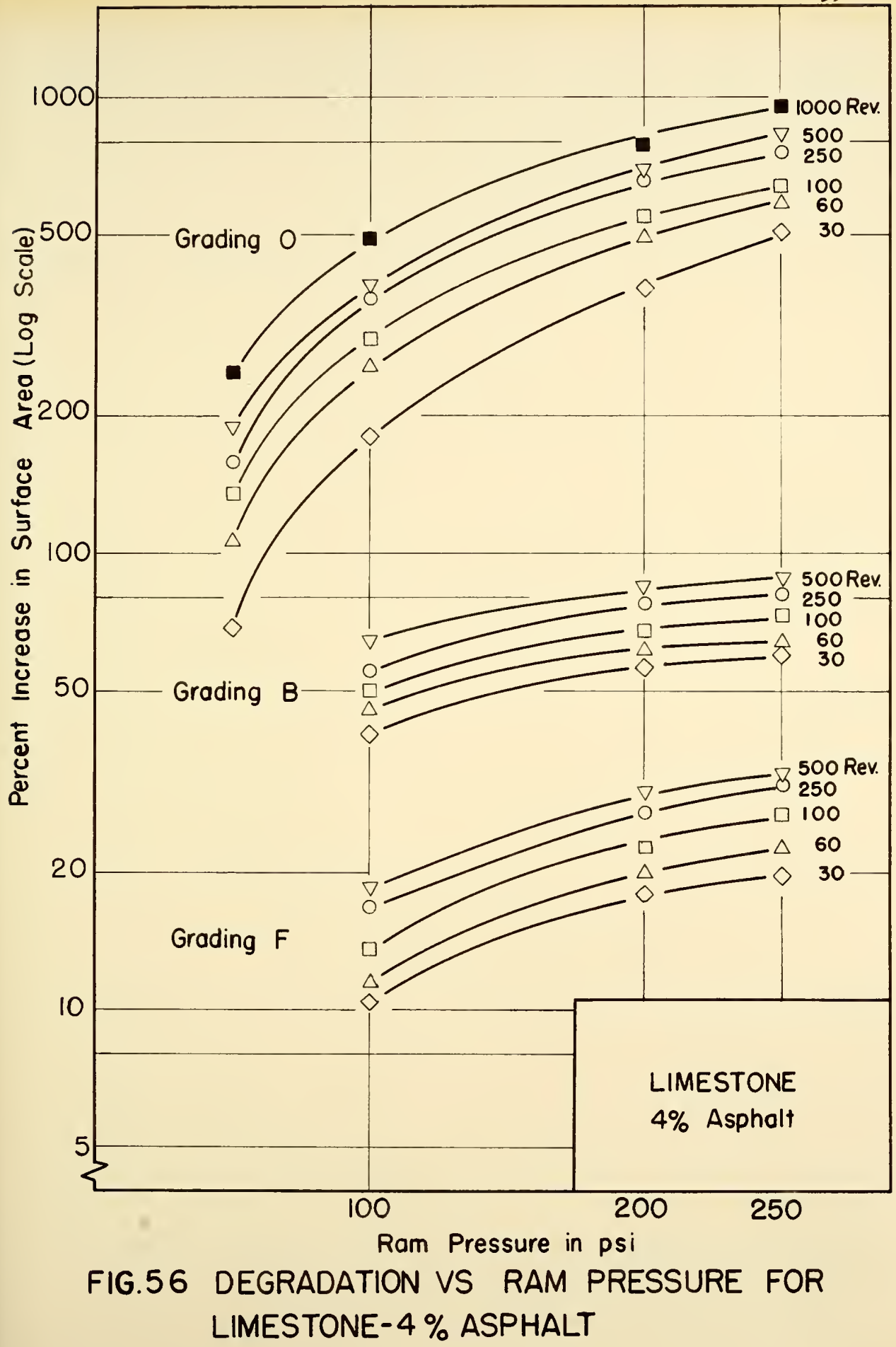




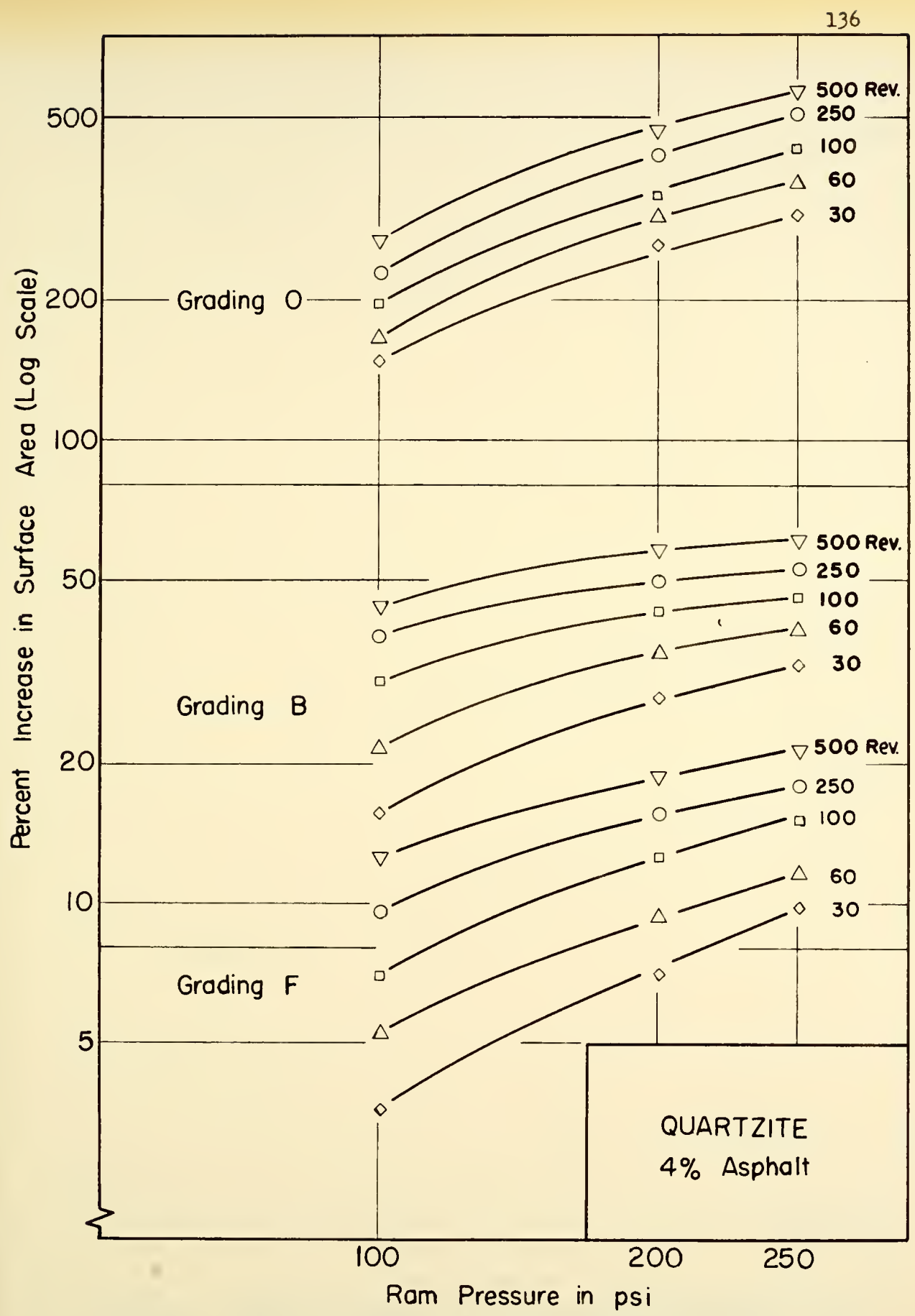

FIG.57 DEGRADATION VS RAM PRESSURE FOR QUARTZITE-4\% ASPHALT 


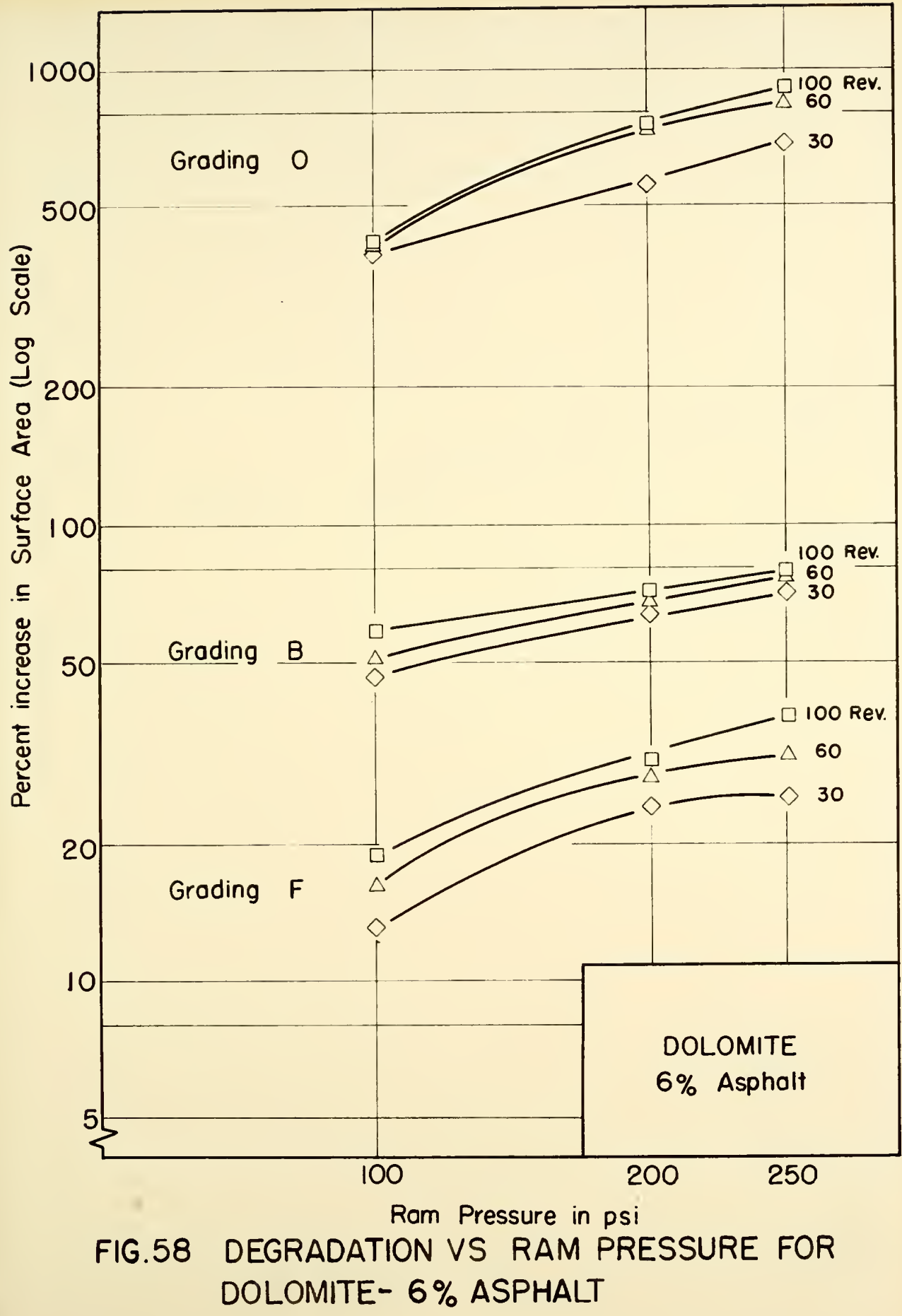




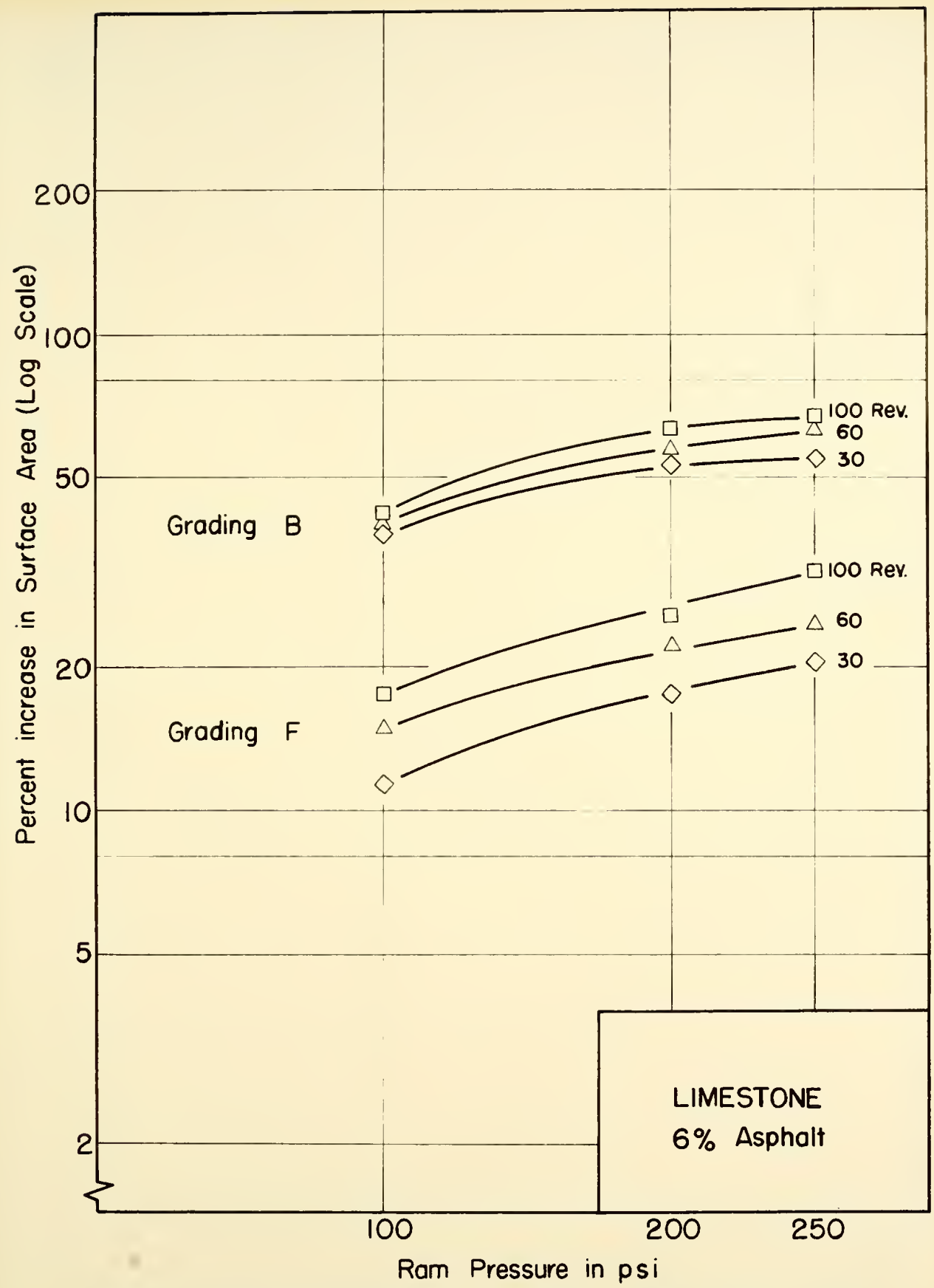

FIG.59 DEGRADATION VS RAM PRESSURE FOR LIMESTONE- $6 \%$ ASPHALT 


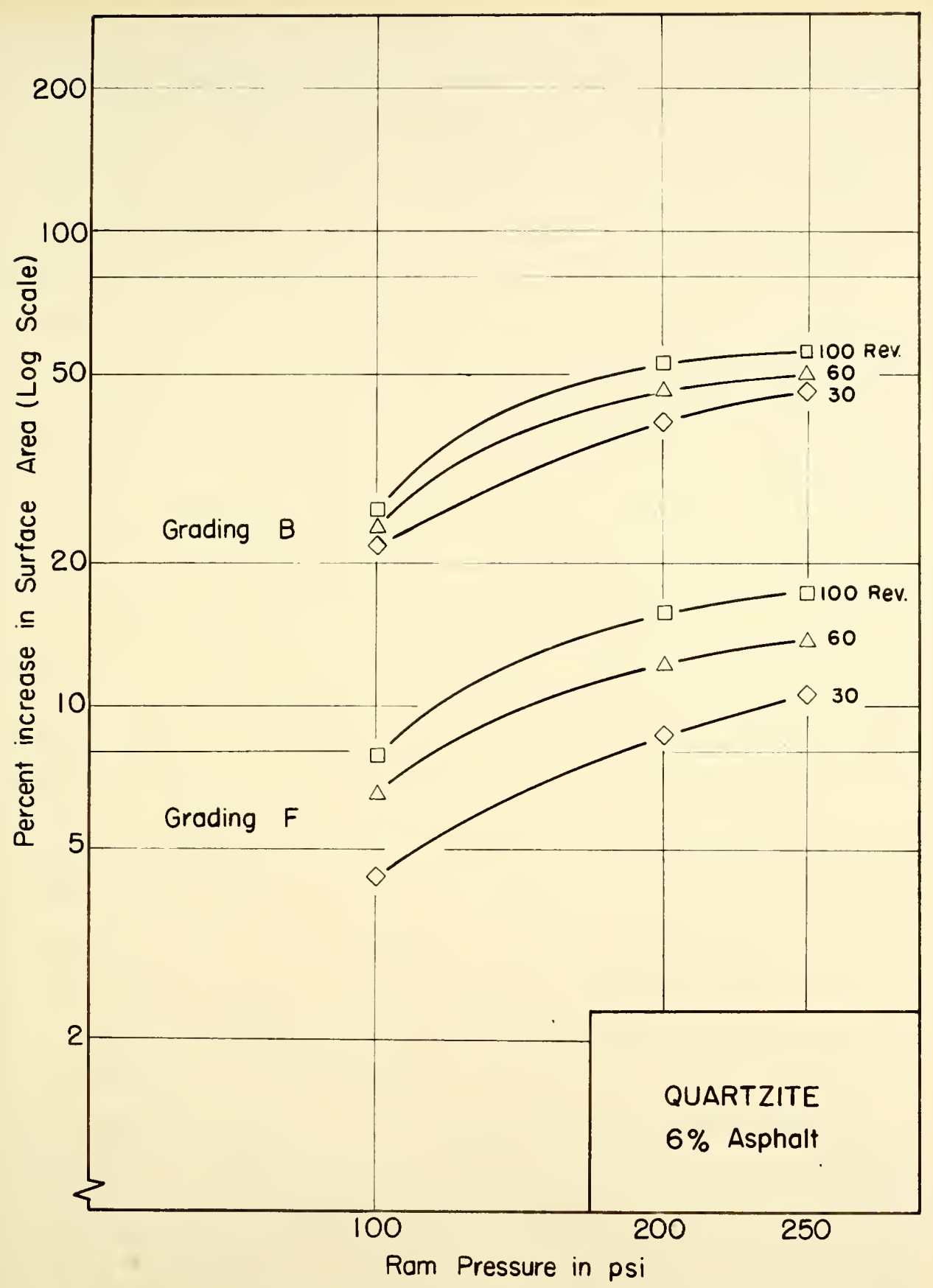

FIG.60 DEGRADATION VS RAM PRESSURE FOR QUARTZITE-6\% ASPHALT 
Even more pronounced than the effect of compactive effort is the effect on degradation of the original gradation of the mixtures. It can be noted that as gradation becomes more dense, degradation decreases. Open-graded mixtures which contain only the four top sizes of aggregate produced the highest degradation for all three kinds of aggregate, at all compactive levels, and for all asphalt contents. At the same time, grading $F$ which corresponds to Fuller's gradation for maximum density gave the lowest values of degradation under the same conditions. Although it isn't at once apparent because a $\log$ scale has been used to plot degradation, it should be noted that open-graded mixtures experienced some twenty times more degradation than dense-graded mixtures under the same conditions.

In Figures 61, 62, 63, and 64 degradation is plotted versus number of revolutions. Each curve is for a single ram pressure as indicated on the curve. Each kind of aggregate can be distinguished by the legend. In these figures degradation for each gradation is plotted on different scales, and from left to right the results are for grading $0, B$, and $F$, respectively. Figure 61 1llustrates the results obtained from specimens containing no asphalt, while Flgures 62,63 , and 64 illustrate results for mixtures containing 2, 4, and 6 percent asphalt, respectively. These figures generally Indicate that as compactive effort increases degradation also increases.

It can be noticed that when ram pressure was kept constant and compactive effort was increased only by the number of revolutions, the increase in degradation depended on type of aggregate and gradation of aggregate. The softer and weaker the aggregate (higher Ios Angeles value) the greater was the increase in degradation caused by increase in number of revolutions, while the harder (lower Los Angeles value) the aggregate the less was the 


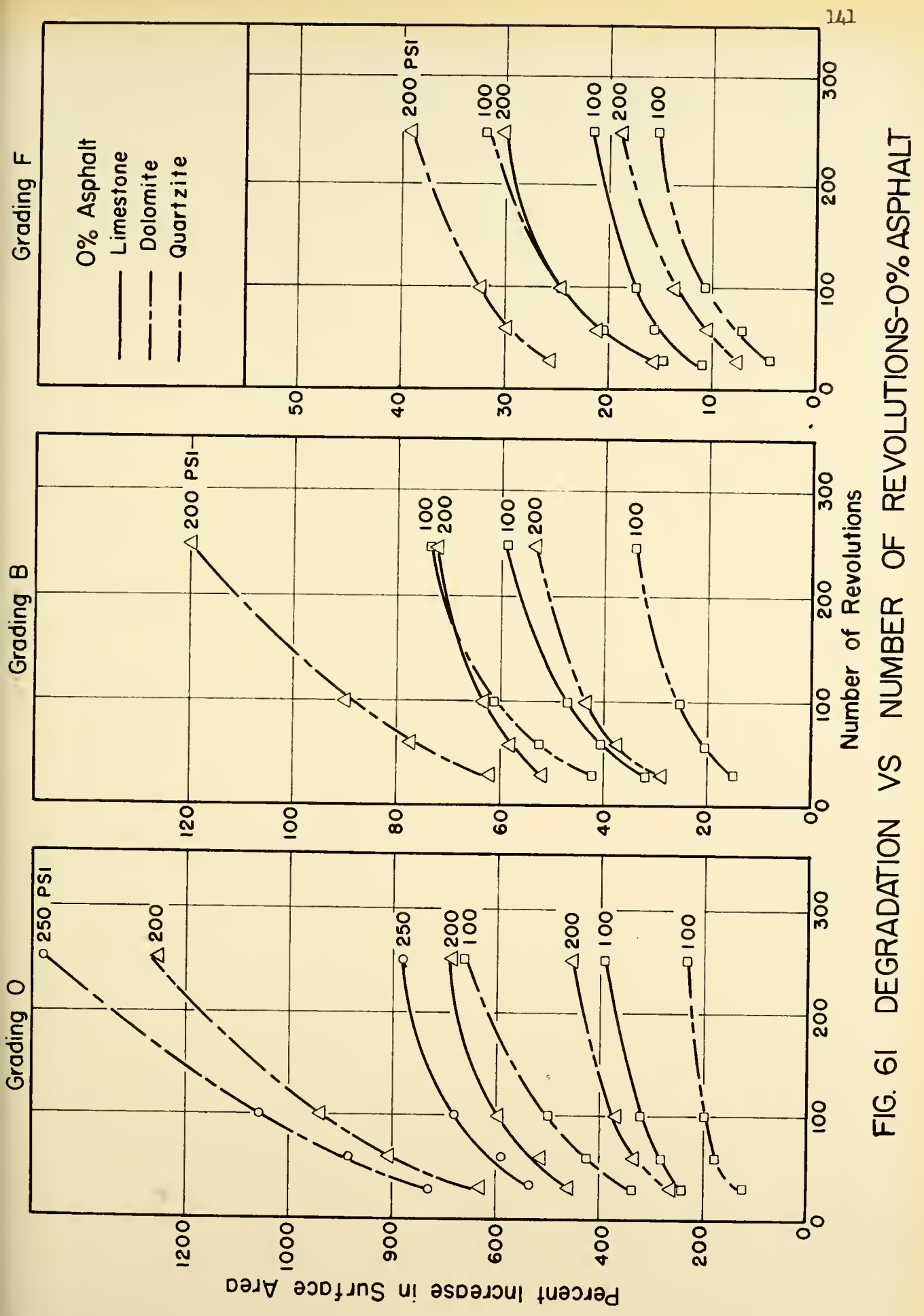




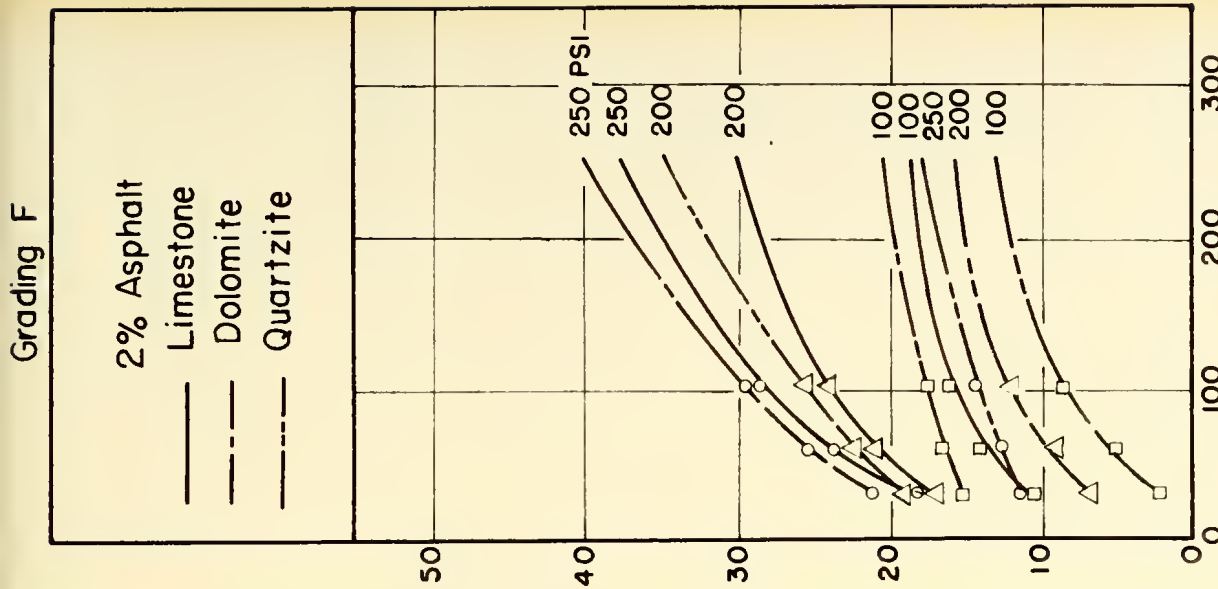

음

ㅇ $\frac{1}{\frac{1}{a}}$

ํำ

$\frac{1}{5}$

๓

a

언 융유을 윴으

을 늠

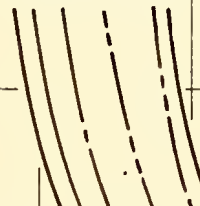

11
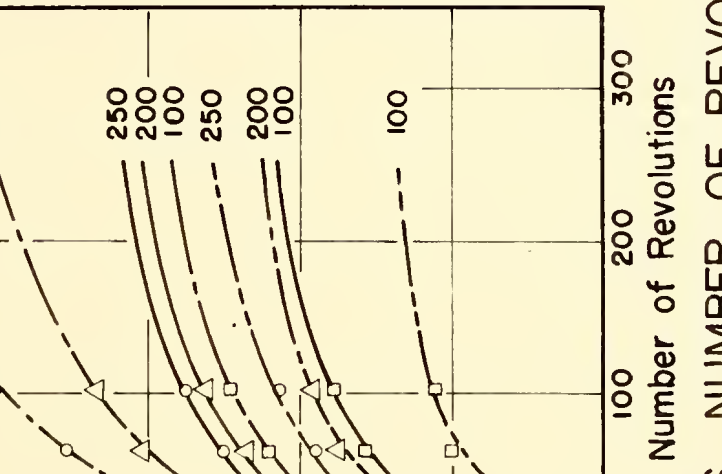

4

용

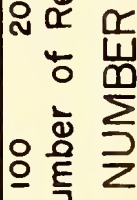

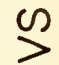

号

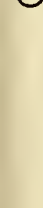




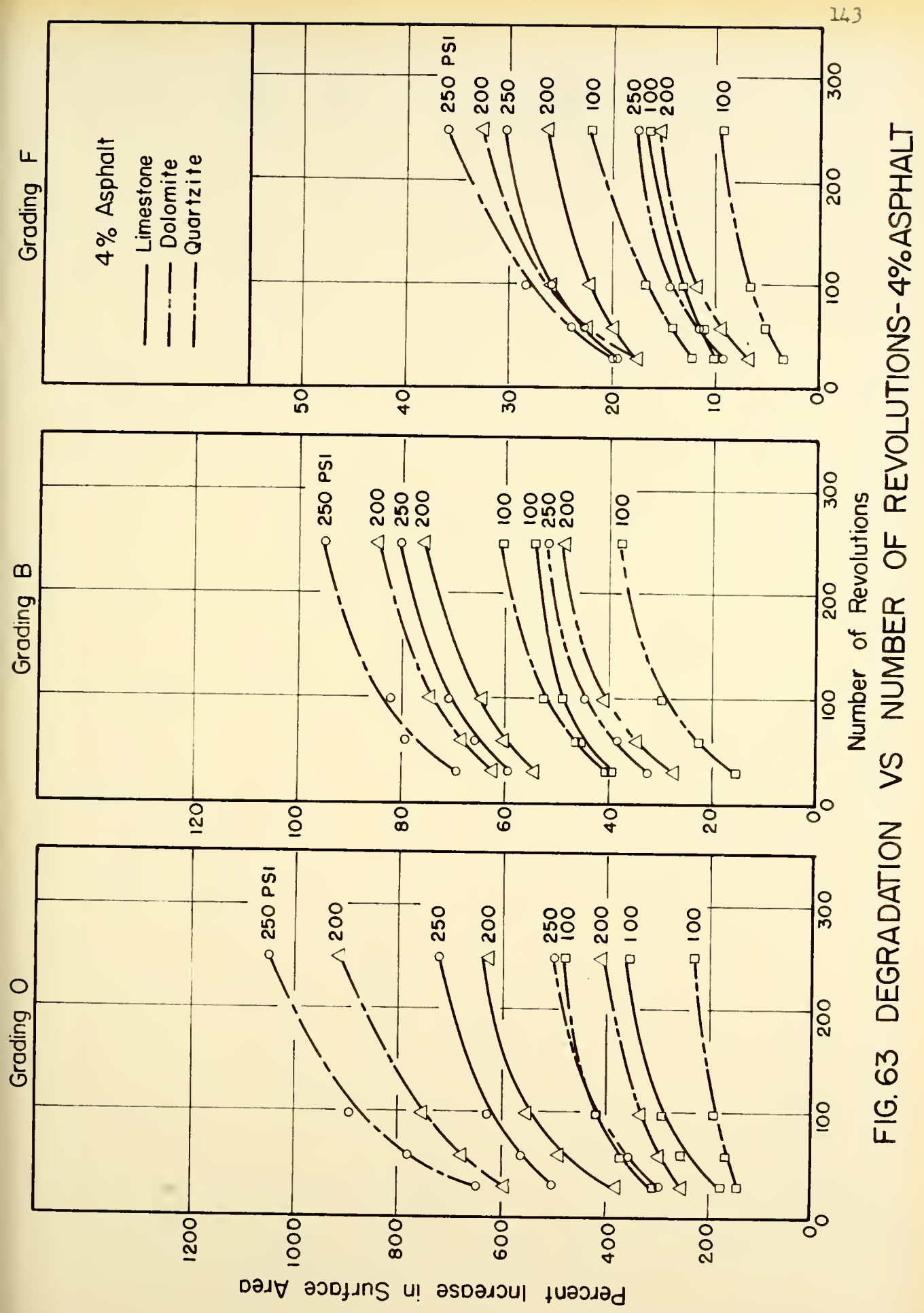


increase in degradation from this cause. These figures also show that increase in degradation caused by increase in number of revolutions depends upon gradation. The slopes of curves for open-graded mixtures are much steeper than those for dense-graded mixtures.

Figures 61 through 64 indicate that degradation also depends on kind of aggregate. The softer and weaker (higher Los Angeles value) the aggregate the more the degradation. The curves for dolomite always lie above the curves for the other two kinds of aggregate. However, the effect of aggregate softness and strength on degradation also depends on gradation of the mixtures. For example, in Figure 61, the change in degradation due to kind of aggregate is a matter of few hundred percent for the case of the open-graded mixtures, while for the dense-graded mixtures this change is around 50 percent at most.

Cognizance of the scale of degradation for each gradation in Figures 61 through 64 makes one aware that original gradation of aggregate has a very pronounced effect on magnitude of degradation. Degradation for opengraded mixtures (grading 0) ranges from 100 percent to 1400 percent dependIng on the type of aggregate and compactive effort, while for dense-graded mixtures (grading F) this range is between 5 and 40 percent, or only about $1 / 20$ to $1 / 35$ of the values obtained for open-graded mixtures. This indicates that the original aggregate gradation is the controlling factor in degradation, because the results indicate that changes in compactive effort, changes in kind of aggregate, or changes in aggregate shape (as discussed later), did not produce as much change in degradation as changes in gradetion.

This point can be easily related to the previous finding with regard to mechanism of degradation. In a previous section it was said that 
magnitude of degradation depends on magnitude and distribution of forces applied to the specimen. Therefore, when a dense mixture is used the number of contact points is numerous and any applied force will be distributed to many more points in much less intensity then for more open mixtures, which in turn produces much less breakage. In open mixtures the number of contact points are few, and particles are subjected to much higher contact pressure which in turn causes much more breakage than in dense-graded mixtures.

\section{Asphalt Content}

Figures 65, 66, and 67 illustrate the change in degradation due to change in asphalt content for the three gradings of each type of aggregate. In each figure, one for each aggregate, the results obtained for the open grading are plotted on the left side for different ram pressures which can be read directly under each part. The percent of asphalt is plotted on the abscissa and the number of revolutions can be read on each curve. Similar results for gradings $B$ and $F$ can be seen in the middle and right side of the figures.

These figures indicate that depending on compactive effort, kind of aggregate, and gradation of aggregate there is in general an asphalt content for which the degradation is minimum. These figures also indicate that degradation does not depend on asphalt content directly regardless of other variables. This means that asphalt content is not an independent variable as was shown to be the case for gradation and kind of aggregate. For an independent factor, such as kind of aggregate, we could say that when aggregates become softer the degradation increases regardless of other variables, but for the asphalt content variable there is no such trend. 

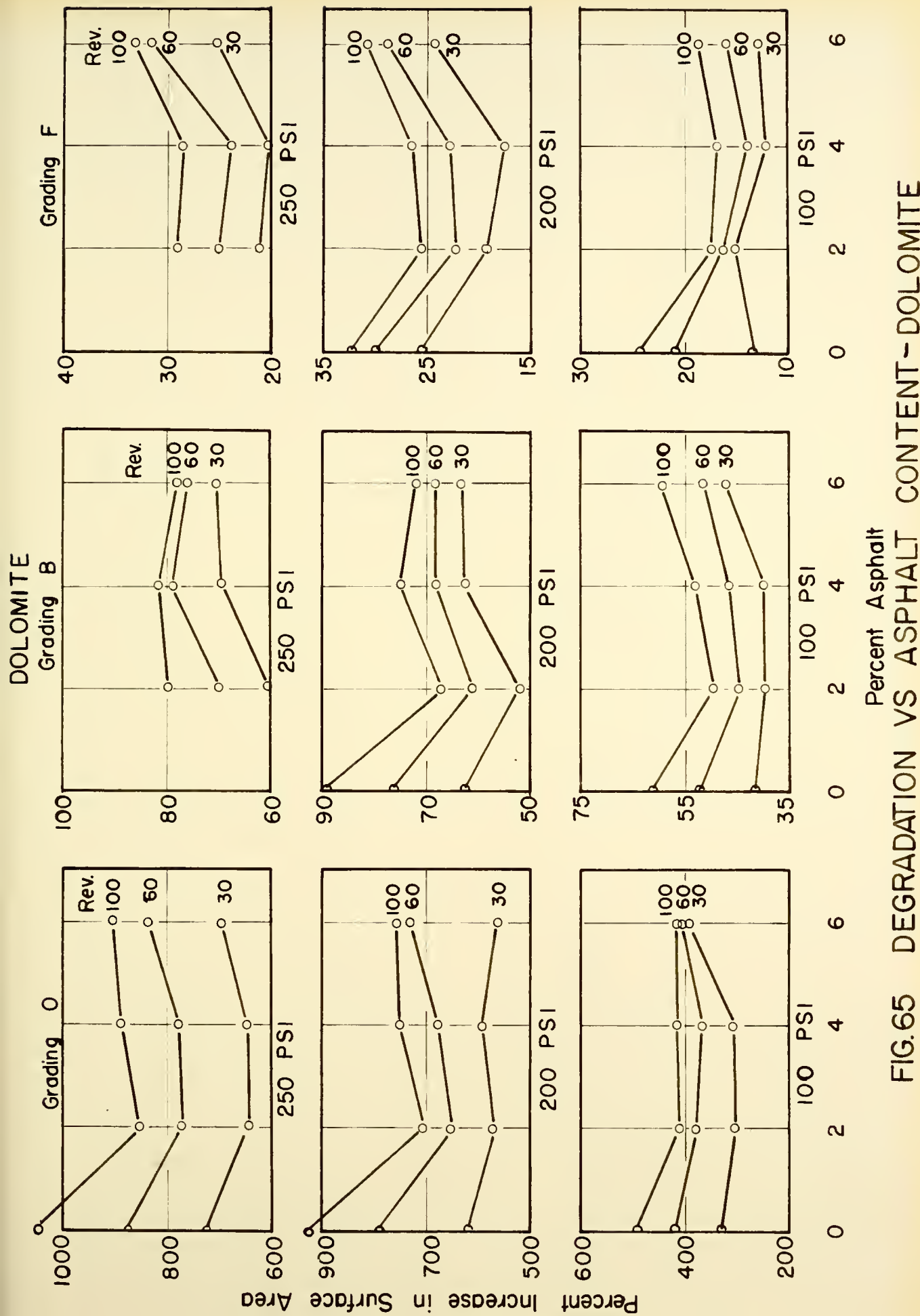

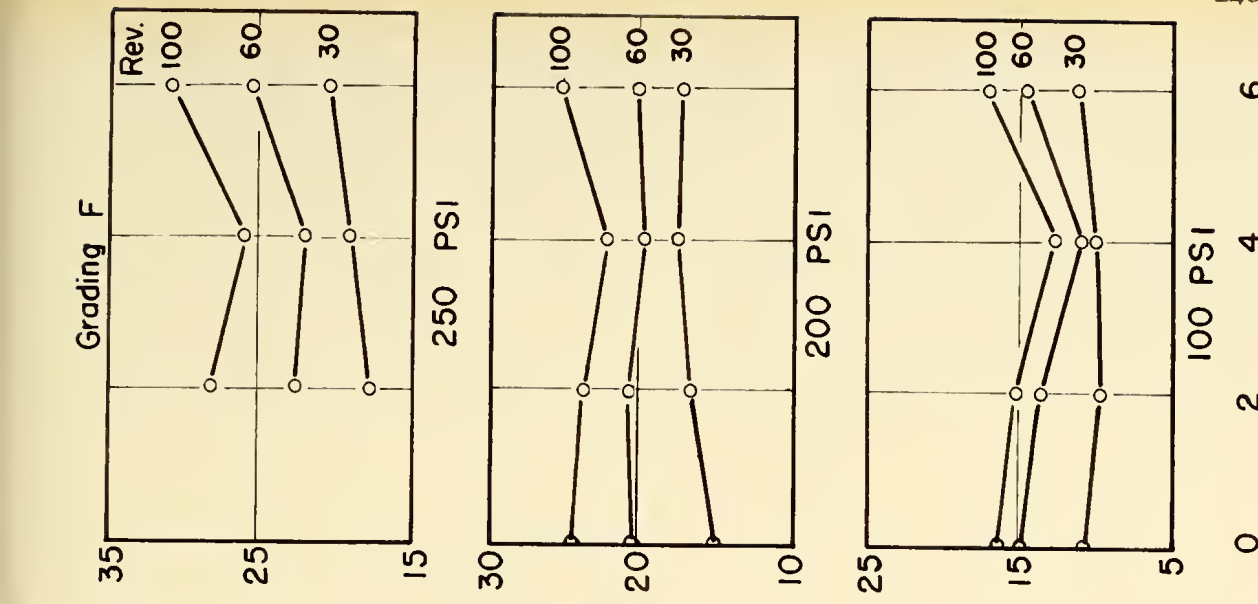

148

10
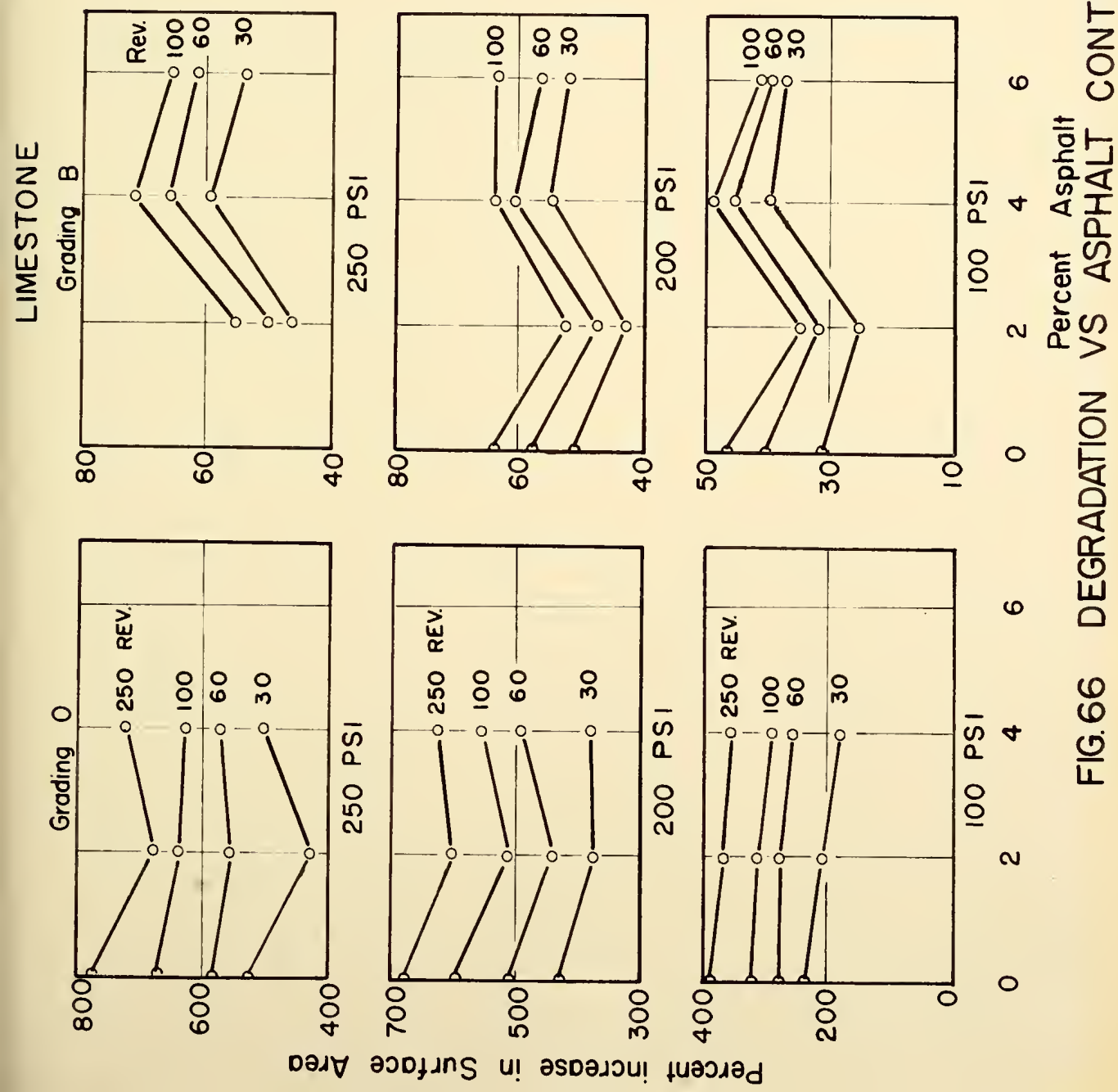

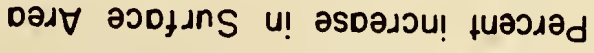



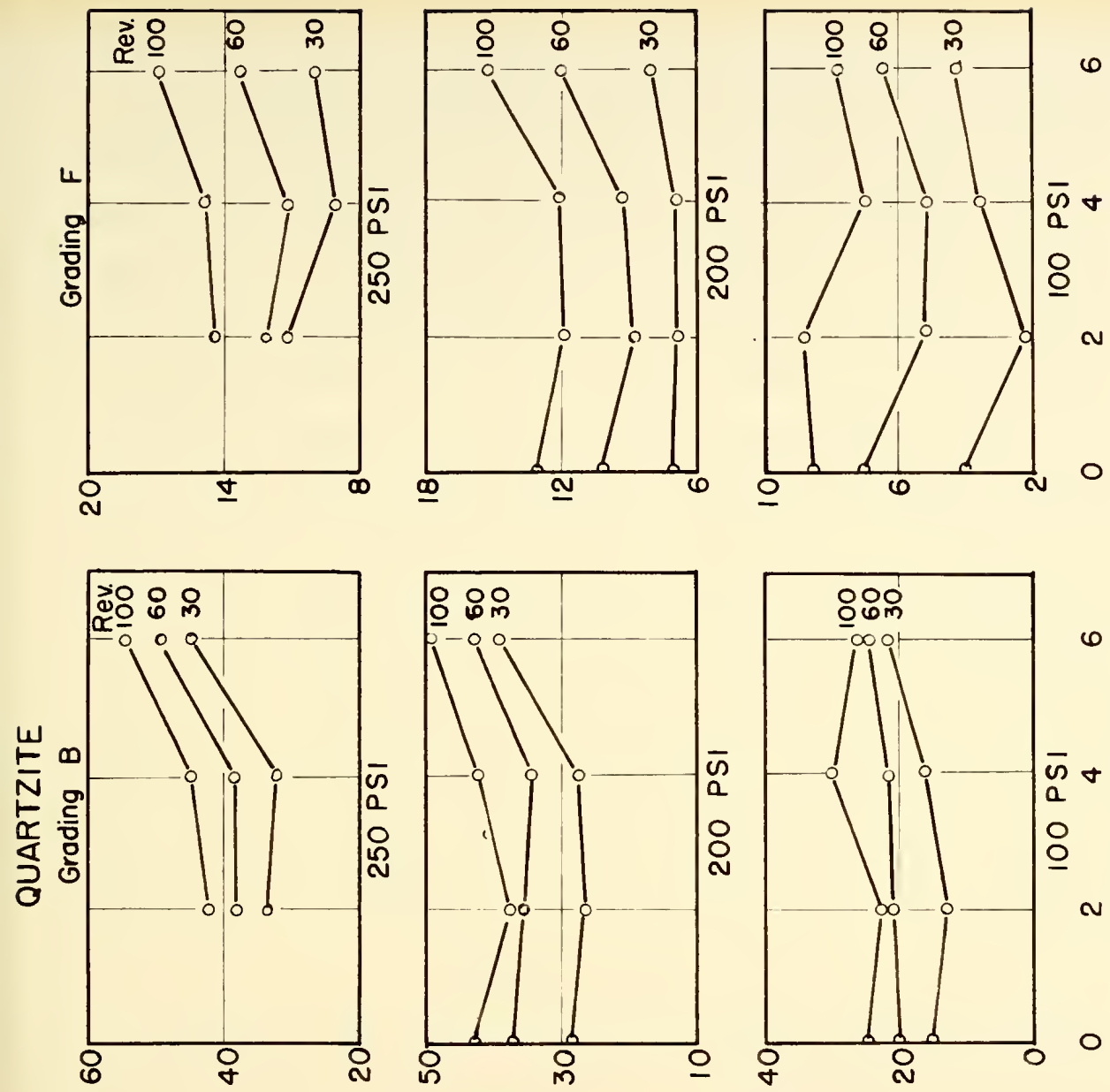

0

$\frac{w}{\frac{w}{}}$

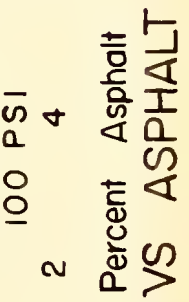
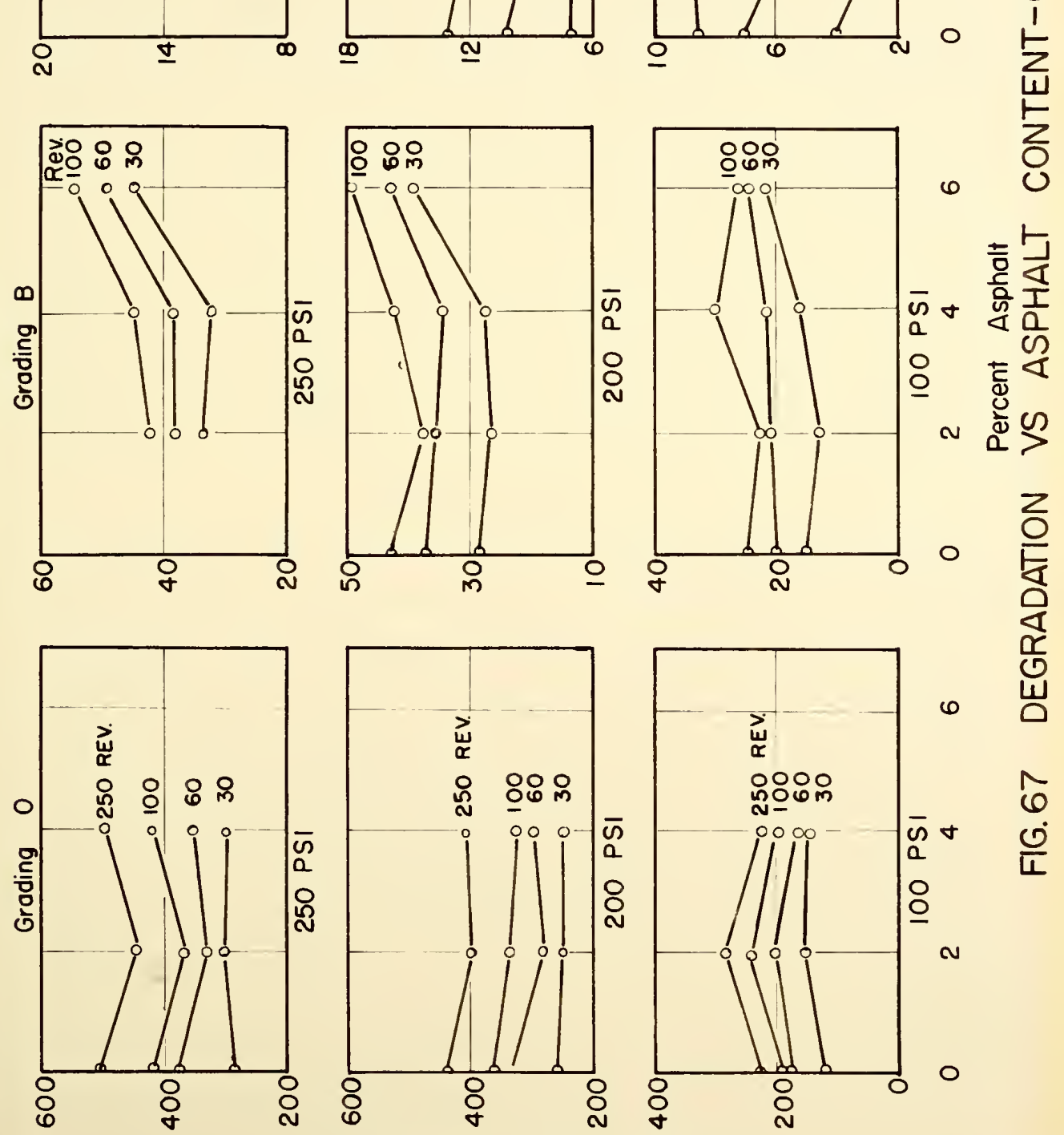

Das 
This result may be viewed with respect to the role of asphalt in the mechanism of degradation. It was found that magnitude of degradation depends on distribution of load and intensity of contact pressures. Considering asphalt as a viscous material which covers the particles, its effect on degradation may be influenced by the effect of its viscosity on magnitude of contact pressure. Also, for a particular arrangement of particles and a particular condition of load the viscosity of asphalt may help the particles to rotate and slip over each other. Rotation and slippage of particles will increase the probability of wear of corners of particles and will also Increase the probability of obtaining a denser mixture. The change of contact pressure, if it is in the direction of increasing the contact pressure, will increase degradation, but if it is in direction of reducing the contact pressure, it reduces the breakage. Since these effects of asphalt change as the specimen undergoes densification, the net result is a complex one in which no definite pattern for effect of asphalt on degradation is apparent.

\section{Aggregate Shape}

In order to investigate the effect of aggregate shape on degradation, a limited number of tests were performed on specimens made of rounded pieces of quartzite. Table 18 contains the percent increase in surface area for such specimens. The same three gradings ( $O, B$, and $F)$ as used before were used in this part of the study. The levels of compactive effort used were 100,200 , and 250 psi ram pressure, and 30, 100, and 250 revolutions. Eighteen specimens of each grading were tested, half of them without asphalt and the other half with 4 percent asphalt. Therefore, a total of 54 specimens were used. 
TABLE 18

PERCENT INCREASE IN SURFACE AREA Rounded Quartzite

\begin{tabular}{|c|c|c|c|c|c|c|c|}
\hline \multirow{2}{*}{\multicolumn{2}{|c|}{$\begin{array}{l}\text { Original } \\
\text { Grading }\end{array}$}} & \multirow{2}{*}{\multicolumn{2}{|c|}{$\frac{\text { Grading } 0}{\text { \% Asphalt }}$}} & \multicolumn{2}{|c|}{ Grading B } & \multicolumn{2}{|c|}{ Grading $\mathrm{F}$} \\
\hline & \multirow[b]{2}{*}{ Rev. } & & & $8 \mathrm{~A}$ & halt & $\not 1 A$ & halt \\
\hline PSI & & 0 & 4 & 0 & 4 & 0 & 4 \\
\hline 100 & $\begin{array}{r}30 \\
100 \\
250\end{array}$ & $\begin{array}{r}67.8 \\
116.0 \\
138.0\end{array}$ & $\begin{array}{r}82.9 \\
110.0 \\
135.0\end{array}$ & $\begin{array}{r}7.2 \\
14.0 \\
19.0\end{array}$ & $\begin{array}{l}10.8 \\
16.5 \\
20.5\end{array}$ & $\begin{array}{l}1.0 \\
1.9 \\
4.2\end{array}$ & $\begin{array}{l}0.7 \\
3.2 \\
6.0\end{array}$ \\
\hline 200 & $\begin{array}{r}30 \\
100 \\
250\end{array}$ & $\begin{array}{l}114.0 \\
178.0 \\
212.0\end{array}$ & $\begin{array}{l}142.4 \\
173.4 \\
198.0\end{array}$ & $\begin{array}{l}12.2 \\
21.5 \\
28.0\end{array}$ & $\begin{array}{l}20.0 \\
23.5 \\
28.5\end{array}$ & $\begin{array}{l}2.6 \\
4.8 \\
7.7\end{array}$ & $\begin{array}{l}2.5 \\
5.5 \\
8.0\end{array}$ \\
\hline 250 & $\begin{array}{r}30 \\
100 \\
250\end{array}$ & $\begin{array}{l}128.0 \\
185.0 \\
231.0\end{array}$ & $\begin{array}{l}175.0 \\
215.0 \\
250.0\end{array}$ & $\begin{array}{l}13.3 \\
23.0 \\
29.0\end{array}$ & $\begin{array}{l}23.3 \\
27.5 \\
32.0\end{array}$ & $\begin{array}{l}2.9 \\
5.7 \\
8.6\end{array}$ & $\begin{array}{l}4.5 \\
6.2 \\
9.0\end{array}$ \\
\hline
\end{tabular}


Figures 68 and 69 show the degradation of rounded aggregate versus ram pressure. Each curve is for a certain gradation and certain number of revolutions. The top three curves are for specimens made of grading 0 , the middle three curves are for grading $B$, and the bottom three curves are for grading F. Figure 68 is for tests made on specimens with zero percent asphalt, while Figure 69 is for specimens containing 4 percent asphalt based on the dry weight of aggregate. The degradation, shown in terms of percent increase in surface area, is plotted on the ordinate to a log scale.

These figures indicate that degradation 1 is increased by an increase in compactive effort, and that gradation of original mixture has more effect on degradation than other factors. Comparison of these results with those presented in Figures 51 and 57 shows that the slope of the curves for rounded aggregate are much flatter than corresponding curves for angular pieces. This indicates that the amount of degradation for rounded aggregate is less dependent on compactive effort than is the case for angular material. This phenomenon is more easily observable from Figures 70 and 71 which give a comparison of the degradation of rounded with angular quartzite. In these figures degradation is plotted versus number of revolutions and each curve is for a single ram pressure. Figure 70 presents the results obtained from specimens without asphalt, while Figure 71 shows the results for specimens with 4 percent asphalt.

These figures show that the curves for rounded aggregate lle below those for the angular material. Also, both the flatness and spacing of the curves for rounded pieces are less than those for angular ones, indicating that increase in compactive effort produces less degradation in the case of rounded aggregate regardless of whether the increase is due to 


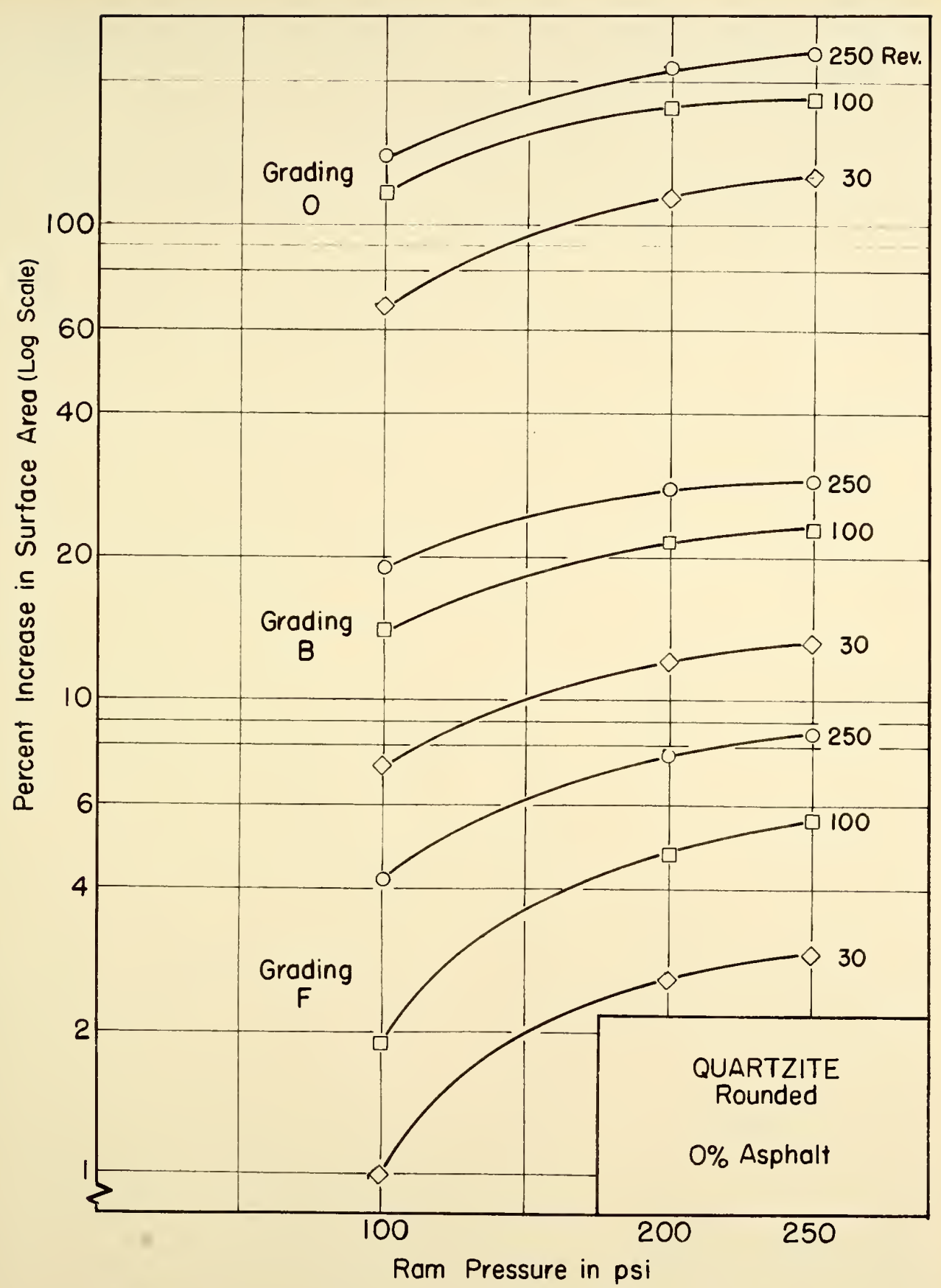
FIG.68 DEGRADATION VS RAM PRESSURE FOR ROUNDED QUARTZITE- O\% ASPHALT




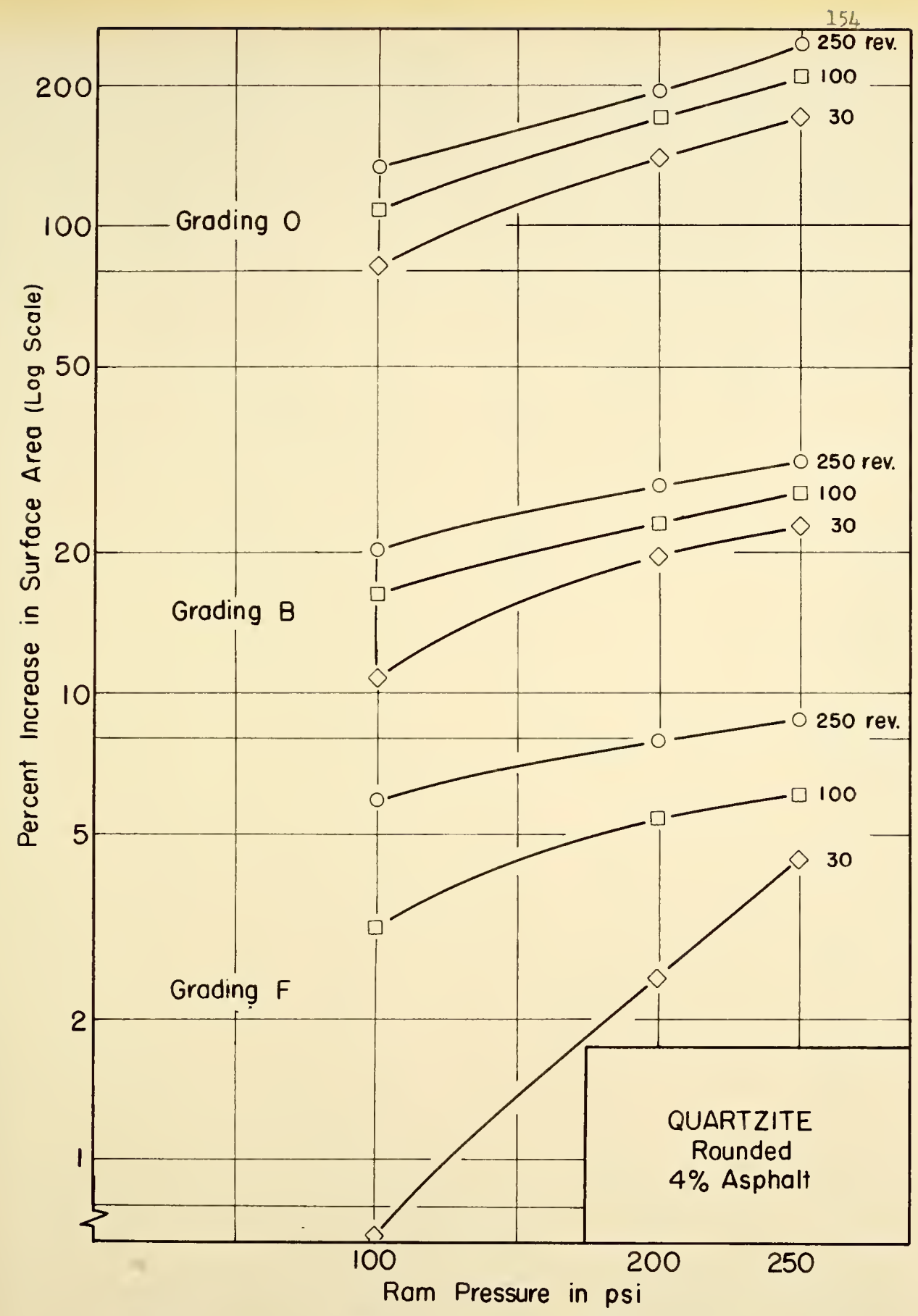

FIG.69 DEGRADATION VS RAM PRESSURE FOR ROUNDED QUARTZITE- 4\% ASPHALT 


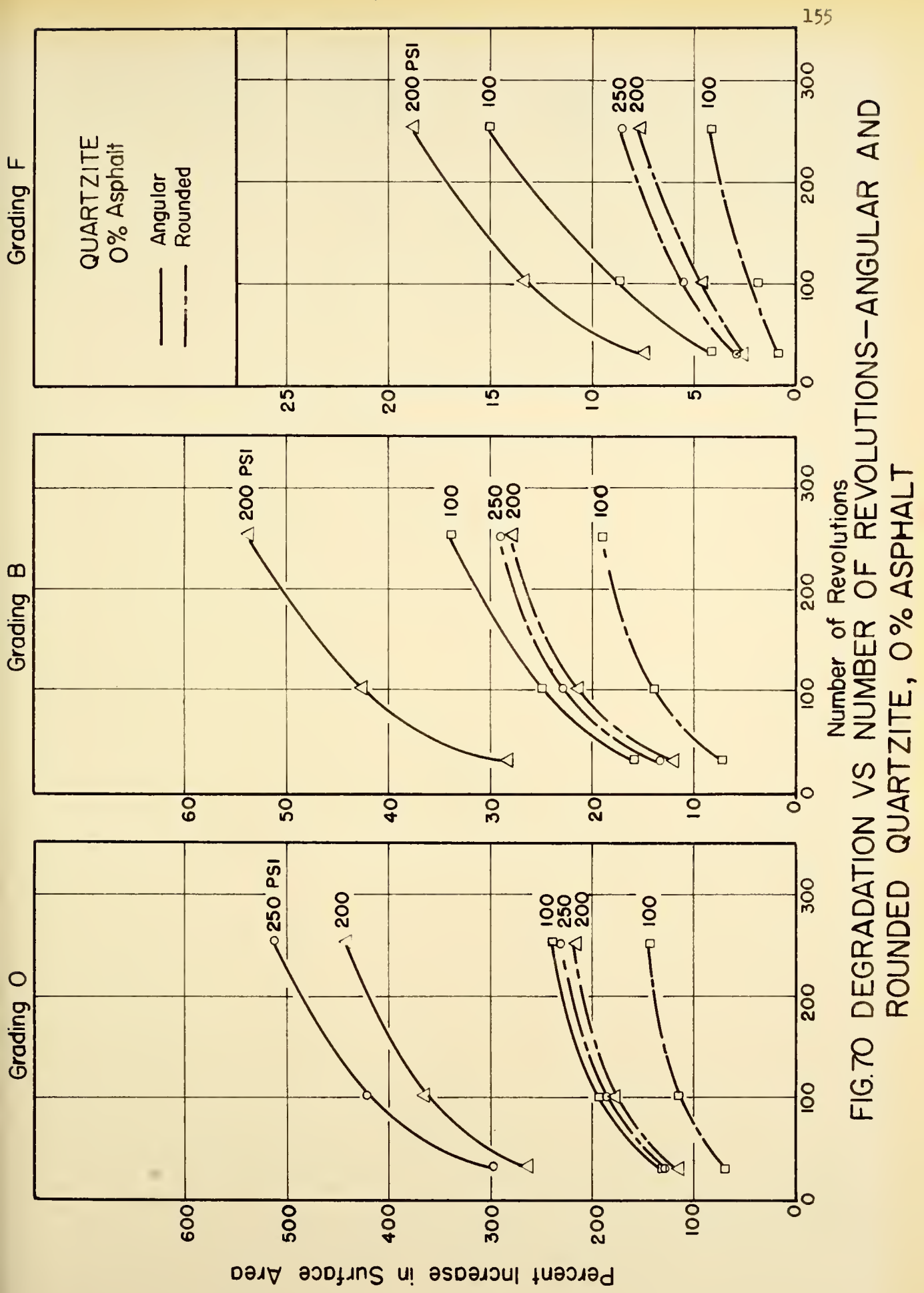




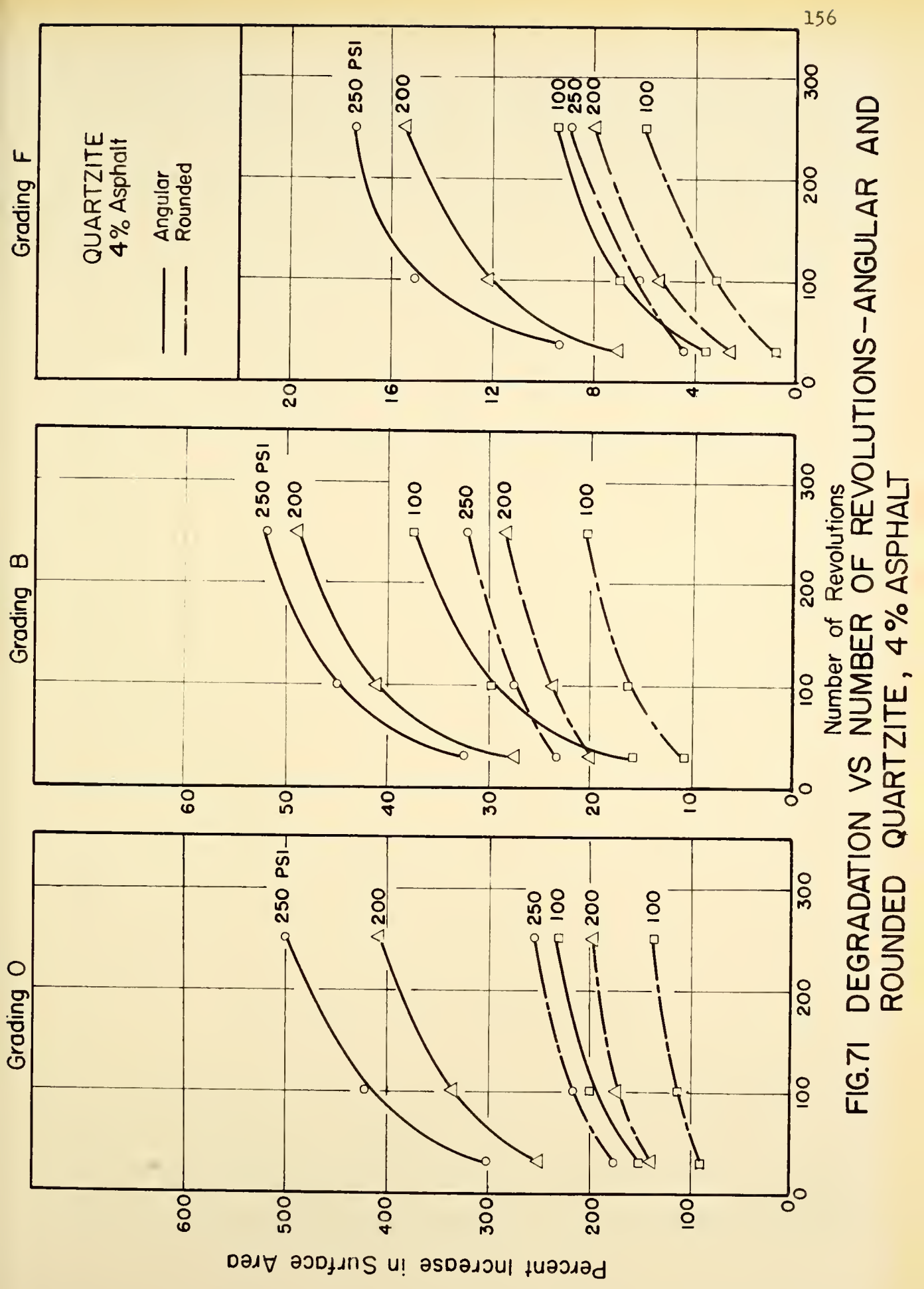


pressure or number of revolutions. The cause of this phenomenon can be attributed to the reduction, in the case of rounded aggregate, of that part of degradation which is due to wear rather than breakage. Wear phenomenon occurs due to the rounding off of corners of particles when they rotate or slip over each other. Breakage occurs when the contact pressure between two particles exceeds their strength, resulting in fracture or splitting. Theoretically, by using rounded particles we should be able to eliminate that portion of degradation due to wear. Practically, however, we can only reduce this portion rather than eliminate it, because when particles start to break, the newly produced pieces are no longer rounded and wear starts to occur.

This reasoning leads to the conclusion that the major part of the difference between degradation of rounded and angular particles can be considered as reduction of wear. Figures 70 and 71 show that the rounded aggregate experienced almost 50 percent less degradation than the angular one, which then can be considered as almost 50 percent less wear. This reduction of degradation due to the shape of particles should decrease as softer mater1al is used, because in soft aggregates probability of breakage is high and, thus, after few applications of load, the amount of angular pieces should increase and wear start. This was one reason that in this section the quartzite which had the lowest Los Angeles value was used.

\section{Degradation Versus Los Angeles Value}

In order to see whether there is any relationship between the Los Angeles value and degradation of aggregates, degradation values were plotted versus the Los Angeles values for the three kinds of aggregate used in this investigation. ASTM specifications recommend that the Los Angeles test be made 
on different sizes of material depending on the use of material. Among the three gradings used for the Los Angeles test (Table 1), grading $C$ was used to determine the correlation between Los Angeles value and degradation merely because the maximum size of grading $C$ is the closest to the maximum size used in this investigation. Figures 72 through 78 show the plots of degradation as measured by percent increase in surface area versus Los Angeles value. Each figure is for a single ram pressure which can be read on the upper left corner of the figure.

Figures 72,73 , and 74 show the results obtained from testing grading 0 of the three aggregates, while Figures 75 and 76 , and 77 and 78 show the results for gradings $B$ and $F$, respectively. Each curve is for a certain number of revolutions which $c$ an be read on the curve. The three points on each curve are the results obtained from specimens made of the three kinds of aggregate tested under equal efforts. On each curve, the point at the left is for specimens made from quartzite, the middle point is for specimens made of limestone, while the point on the right is for specimens made of dolomite. The abscissa of each point is the Los Angeles value of that kind of aggregate when tested in the Los Angeles machine for grading $C$ of the ASTM specification.

Figure 72 shows that as the Los Angeles value increases the degradation value also increases, but the rate of increase is not constant, and the relationships are not linear. In other words under 100 psi ram pressure and 30 to 500 revolutions specimens with grading 0 do not show severe enough degradation to provide a linear relationship with Los Angeles values. Figure 73 shows that for the same grading 0 this linearity can be obtained under 200 psi ram pressure and 250 revolutions. Below 250 revolutions the Los Angeles machine produces more degradation for soft or weak aggregate 


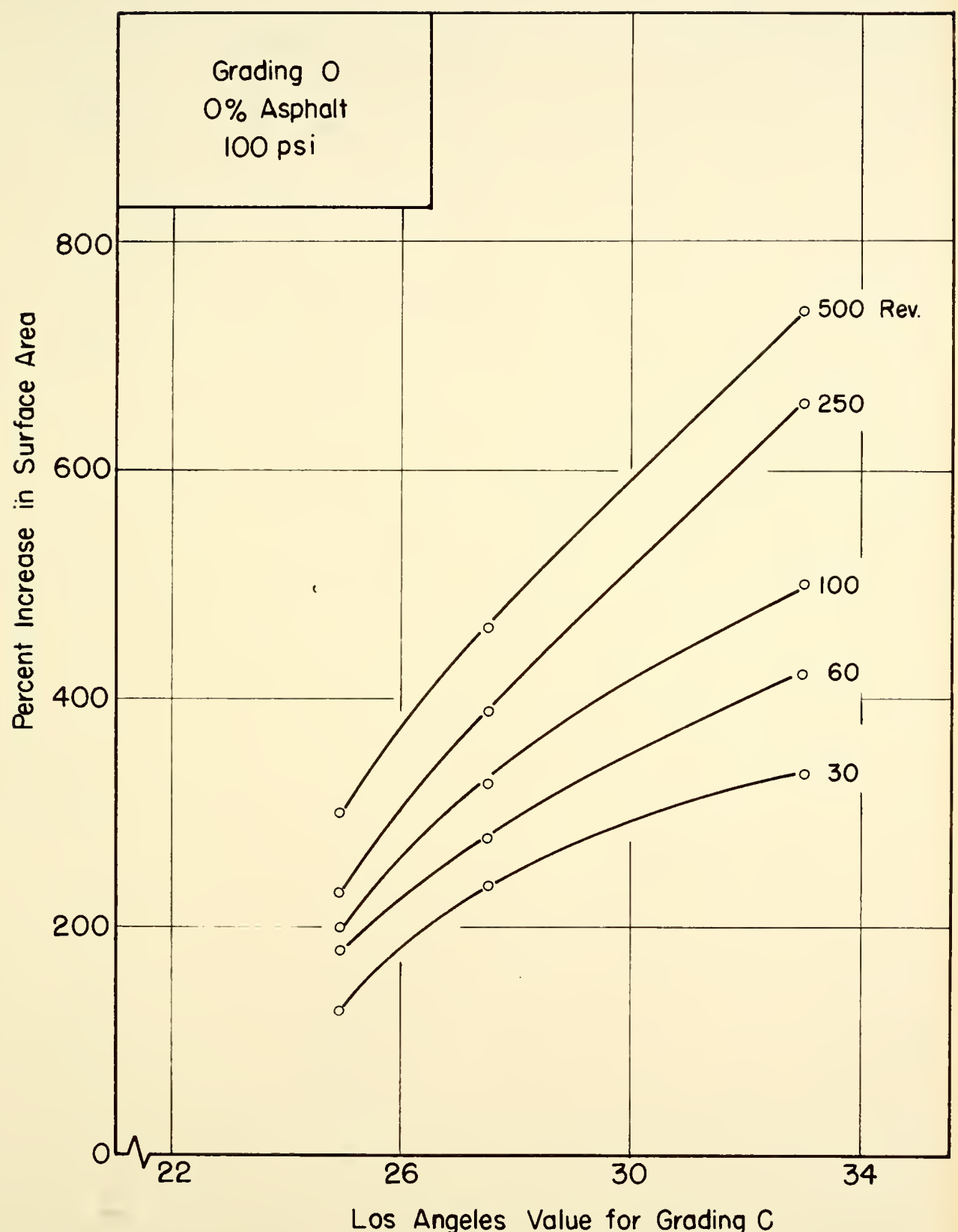

FIG. 72 DEGRADATION VS LOS ANGELES VALUE, GRADING O, IOO PSI 


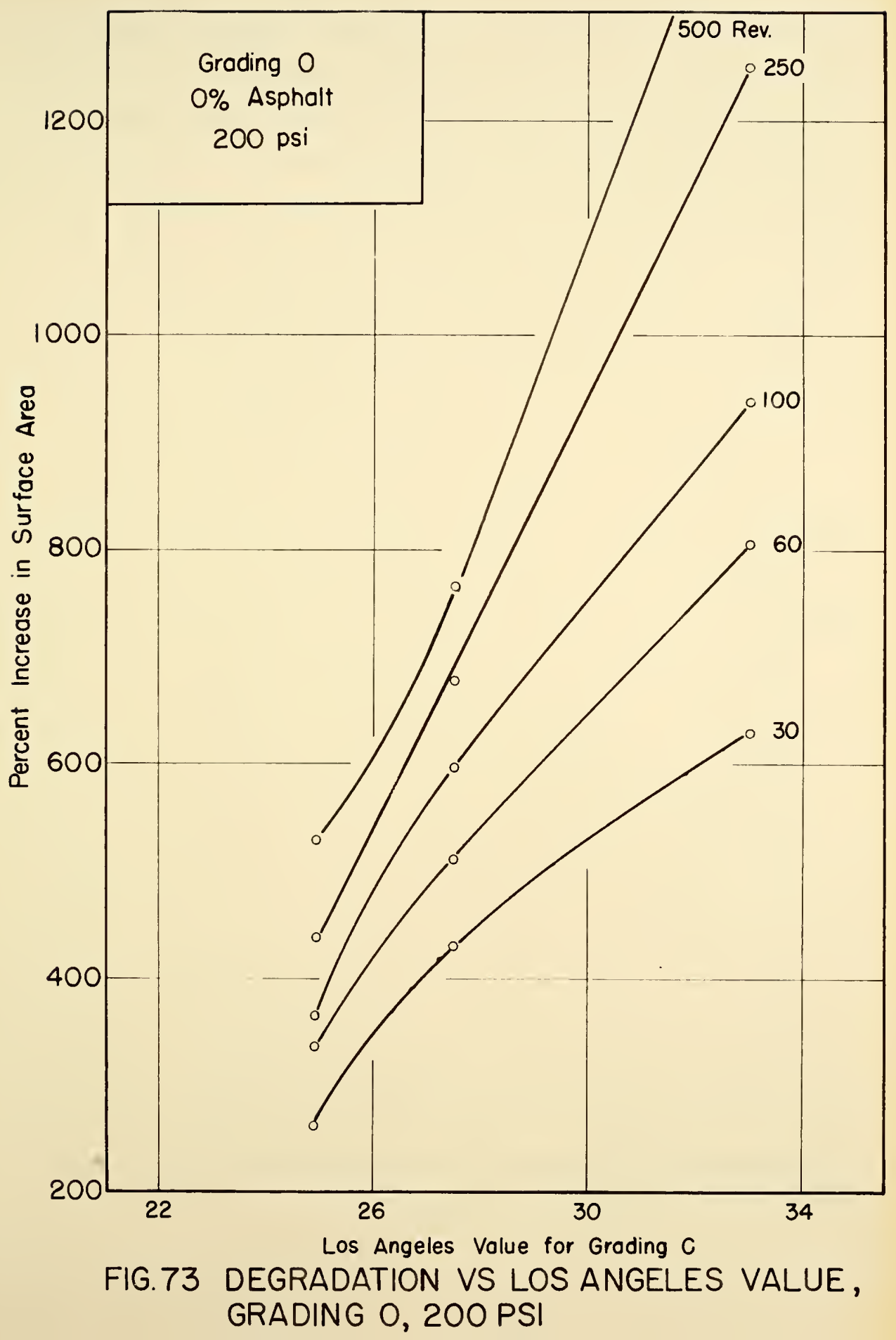


than the gyratory machine, while above 250 revolutions more degradation is experienced by the less resistant material in the gyratory compactor than in Los Angeles machine because the curve for 500 revolutions is concave rather than convex. Figure 74 shows that when ram pressure is raised to 250 psi this linearity occurs somewhere between 100 and 250 revolutions for the ame grading. From Figure 76 it can be seen that for grading B linearity between degradation and Los Angeles values occurs at 200 psi and 250 revolutions. Figures 77 and 78 show that such linearity was not reached for specimens with grading $F$ under compactive efforts used in this study. The foregoing discussion indicates that, depending on gradation of the aggregate, there is a certain level of compaction for which the plot of degradation versus the Los Angeles values of the aggregates is a straight line. For compactive efforts higher than that, soft and weak aggregates experienced more degradation in the gyratory machine than in the Ios Angeles machine, and for compactive efforts below that soft and weak materials experienced more degradation in the Los Angeles machine. Therefore, as far as degradation is concerned, depending on the gradation of the material, The Los Angeles test corresponds only to a certain level of compaction. This level of compaction, as can be seen in Figures 72 to 78 , increases as gradation of material becomes more dense. Noting that these levels of compaction, especially in dense-graded materials, are much higher than those the material is normally subjected to in the field, imposes some doubts on the validity of the Los Angeles test as a measure of quality of aggregate with respect to degradation. This becomes especially apparent when it is noted that the dolomite aggregate with a high Los Angeles value (Figures 61 to 64 ) when tested in a Fuller gradation produced less than one-tenth of 


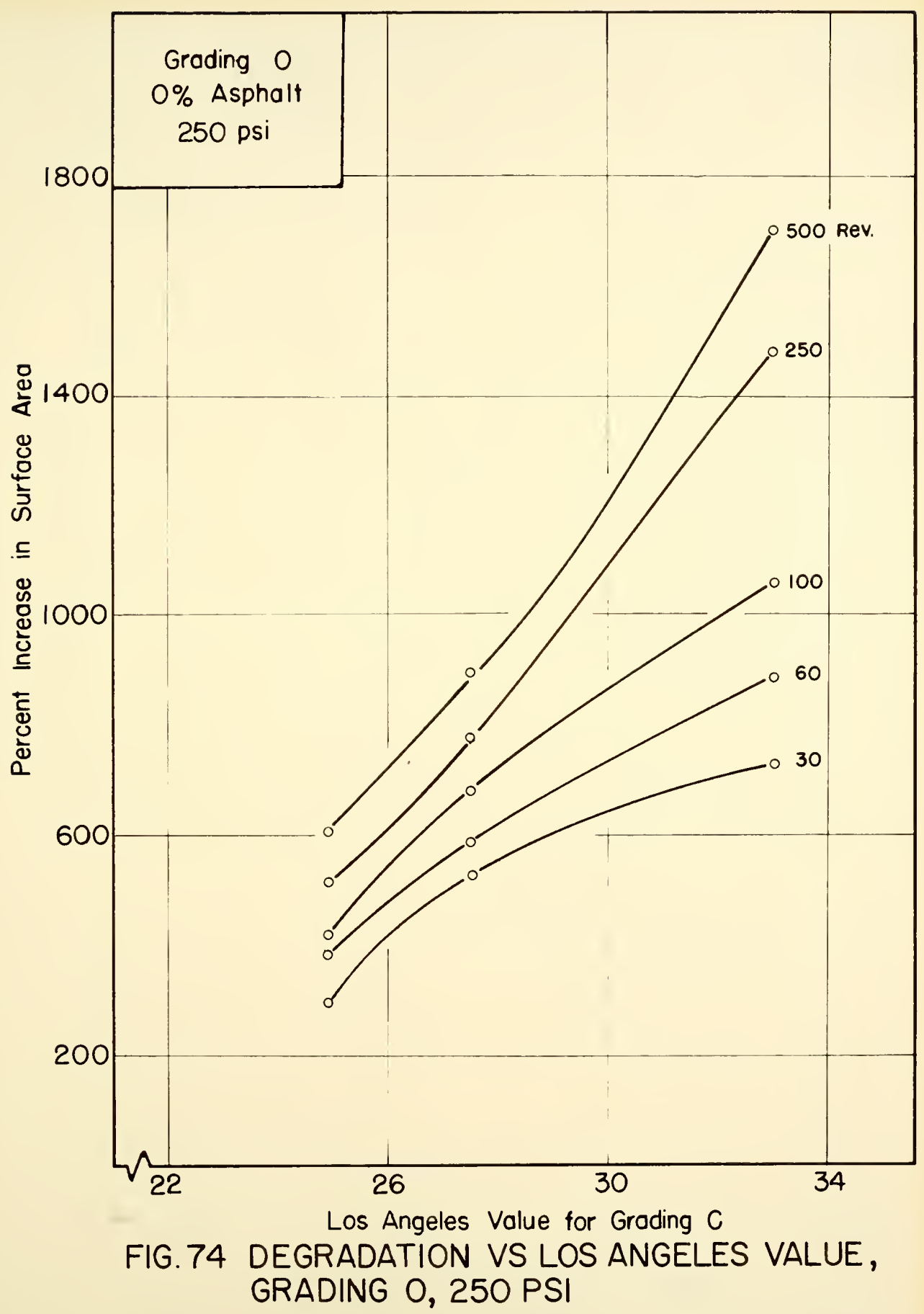




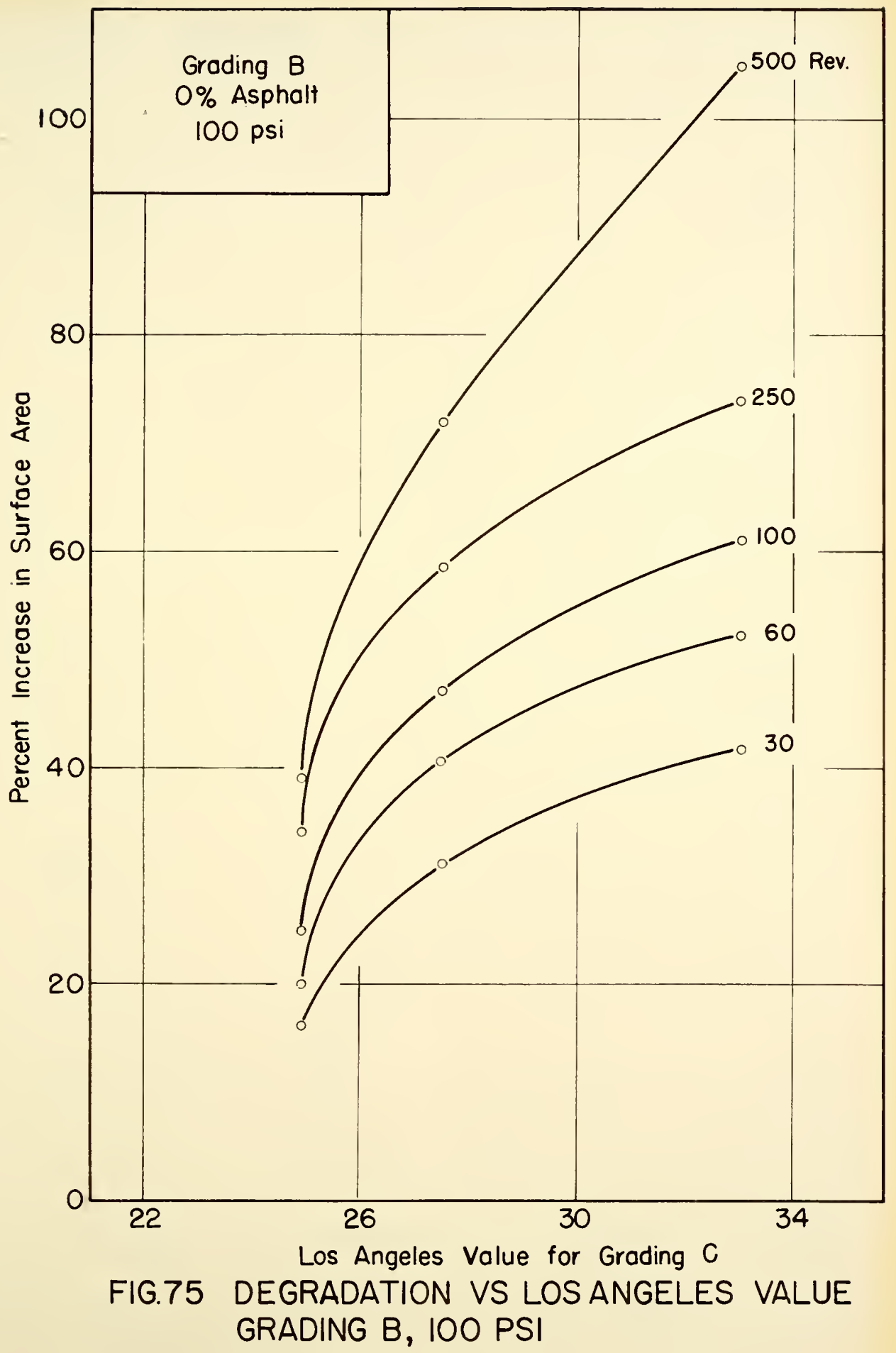




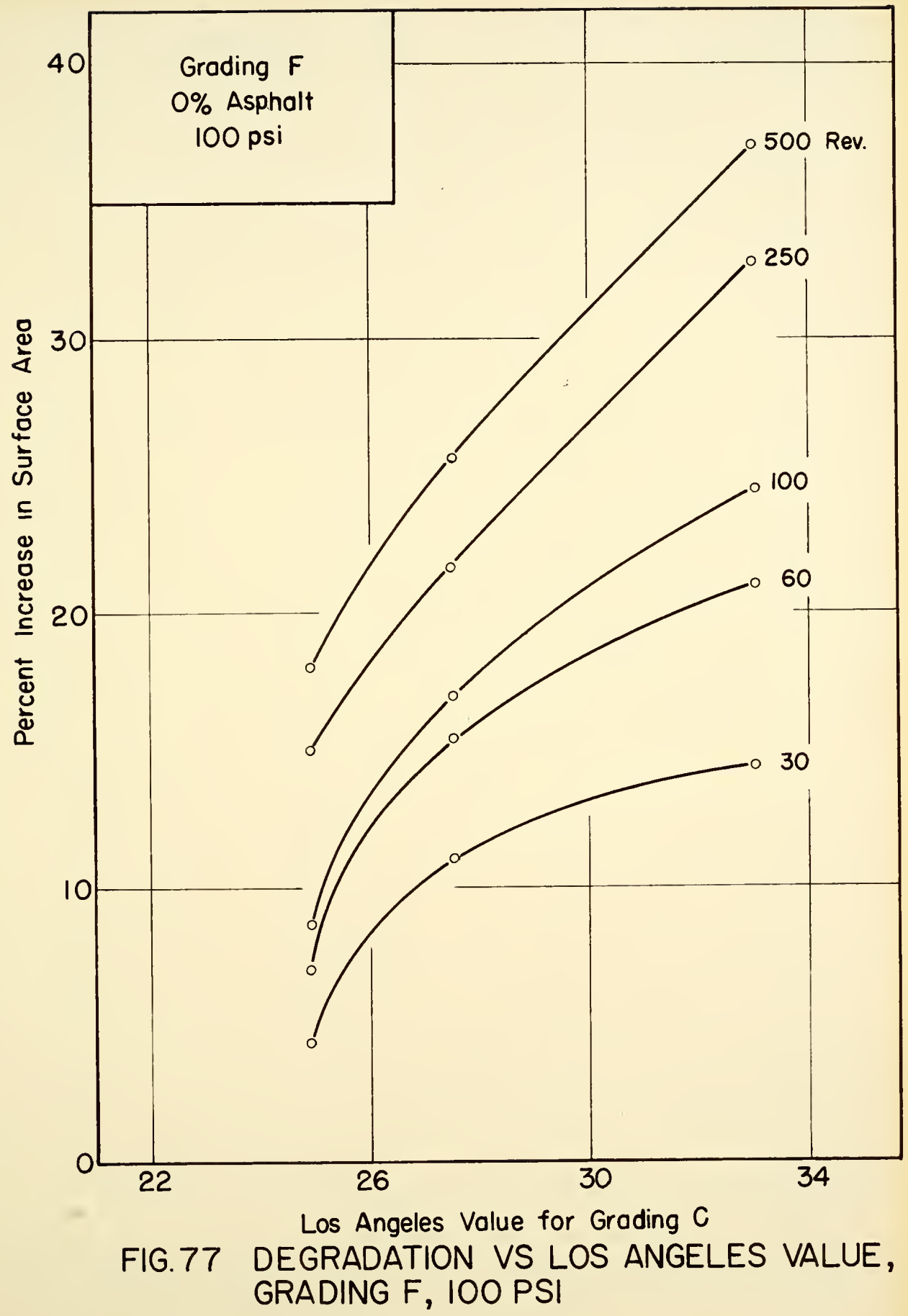




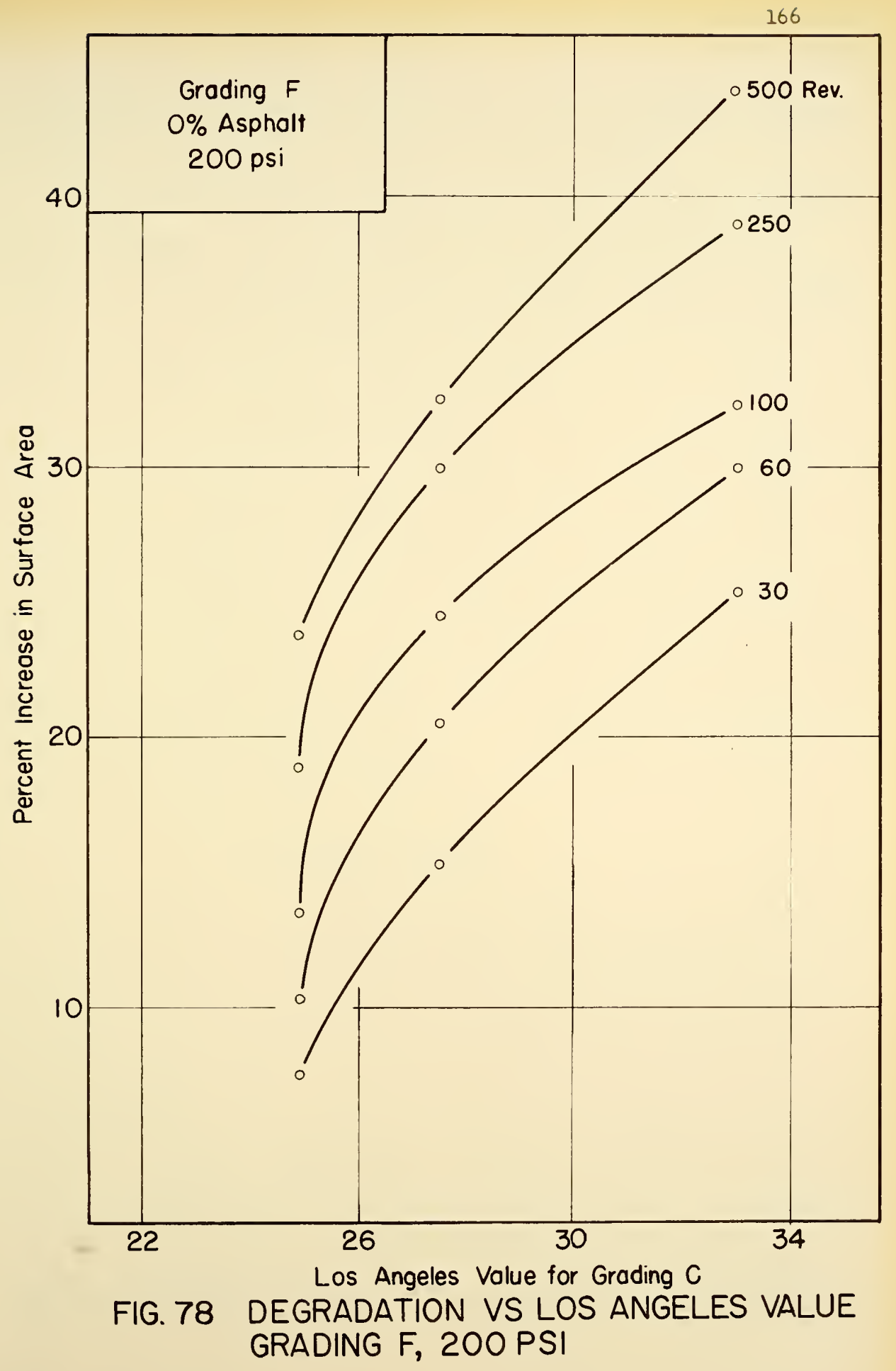


the degradation under equal compactive effort of that produced by the low Los Angeles value quartzite when tested in the open gradation.

It was mentioned before that degradation occurs due to two phenomena, wear and breakage. Wear was considered responsible for that portion of degradation which is caused by rotation and slippage of particles over each other, while breakage was considered to occur when the contact pressure exceeds the strength of the particle in a certain direction. Thus under traffic compaction the particles either break or rotation wears off their corners. In either case the result is production of particles of smaller sizes. These two actions, rotation and breakage will result in a denser packing, thus producing a mat whose particles have more contact points and less chance for rotation. This reduces the rate of degradation under further compaction. But in the Ios Angeles rattler test the particles do not enjoy this dense packing or cushioning effect which occurs in a road mat, and consequently the material is subjected to a more severe degradation condition than actually exists in the field.

\section{Petrographic Analys18}

Tables 19, 20, and 21 contain the summary of slide analysis of the aggregates used in this investigation. Figures 79,80 , and 81 show the thin sections of these aggregates*. A comparison of these results with degradation and Los Angeles values of the materials reveals that nature of grain boundaries, cementation, and percent of voids influence the resistance of materials to degradation. Good interlocking between the grains present in limestone, results in a low los Angeles value and low degradation. Loose interlocking, present in dolomite, results in a high Los Angeles 
TABLE 19

PETROGRAPHIC ANALYSIS OF H \& R DOLOMITE

Slide Analygis

Megascopic Identification: Dolomite, medium-grained, indistinct banding

\section{Mineralogy}

Bulk Minerals Volume (\&) Average Grain Size Range

Dolomite $>99 \quad .2 \mathrm{~mm} \quad .1-.4 \mathrm{~mm}$

Fine Pyrite 1

Composition and Nature of Matrix and Cementing Material: Smaller mesh of dolomite

Decomposition: Nil

Degree of Leaching: Minor

Secondary Minerals: Negligible, where present consist of

limonite and hematite

Secondary Cementation: Absent

Percent vold: $6.0 \%$

\section{Petrofabrice}

Nature of the Grain Boundaries: Loose interlocking

Fracturing and Cracking: Low

Particle Orientation: Random (sometimes Iineation due to deposition)

Banding: Indistinct

Presence of some replaced fossil fragments

Other Structures: Several pockets with concentration of very

fine-grained materials. Iow porosity in pockets. 
TABLE 20

\section{PETROGRAPHIC ANALYSIS OF BLOOMINGTON LIMESTONE}

\section{Slide Analysis}

Megascopic Identification: Calcite, medium-grained, indistinct banding

\section{Mineralogy}

Bulk Minerals

Calcite

Pyrite

Organics

Composition and Nature of Matrix and Cementing Materials:

Decomposition: $\mathrm{Nil}$

Fine-grained carbonate matrix

Degree of Leaching: Nil

Secondary Minerals: Total \% (vol.) $>1$

limonite, hematite

Secondary Cementation: Unobservable

Percent vold: .7\%

\section{Petrofabrics}

Nature of the Grain Boundaries: Cood interlocking Fracturing and Cracking: Not significant

Particle Orientation: Random

Banding: Indistinct banding. Lenses of fine particles

Other Structure: Marked change from very coarse mesh to very fine mesh.
Range

$.1-1 \mathrm{~mm}$

$.1-.3$ 
TABLE 21

\section{PETROGRAPHIC ANALYSIS OF BARABOO QUARTZITE}

\section{Slide Analysis}

Megascopic Identification: Hematitic, medium-grained quartzite, indistinct banding, numerous recemented fractures

\section{Mineralogr}

Bulk Minerals Volume (\%) Average Grain Size Range

Quartz $\quad$ S90 $_{90}^{.8 \mathrm{~mm}} \quad .01-1.0$

Pyrite

Composition and Nature of Matrix and Cementing Material:

Very fine-grained quartz and sericite (fibrous)

Decomposition and Leaching: Nil

Secondary Minerals: Hematite as coatings and finely disseminated grains, Sericite in seams and disseminated throughout

Percent void: $.5 \%$

\section{Petrofabrics}

Nature of the Grain Boundaries: Rock and grains are both highly fractured (cataclastic structure). All quartz grains display a prominent wavy extinction, indicating a highly stressed rock

Particle Orientation: Moderate lining along the long axis of the grains

Banding: Moderate banding depending on particle size

Other Structures: Recemented granulated matrix 


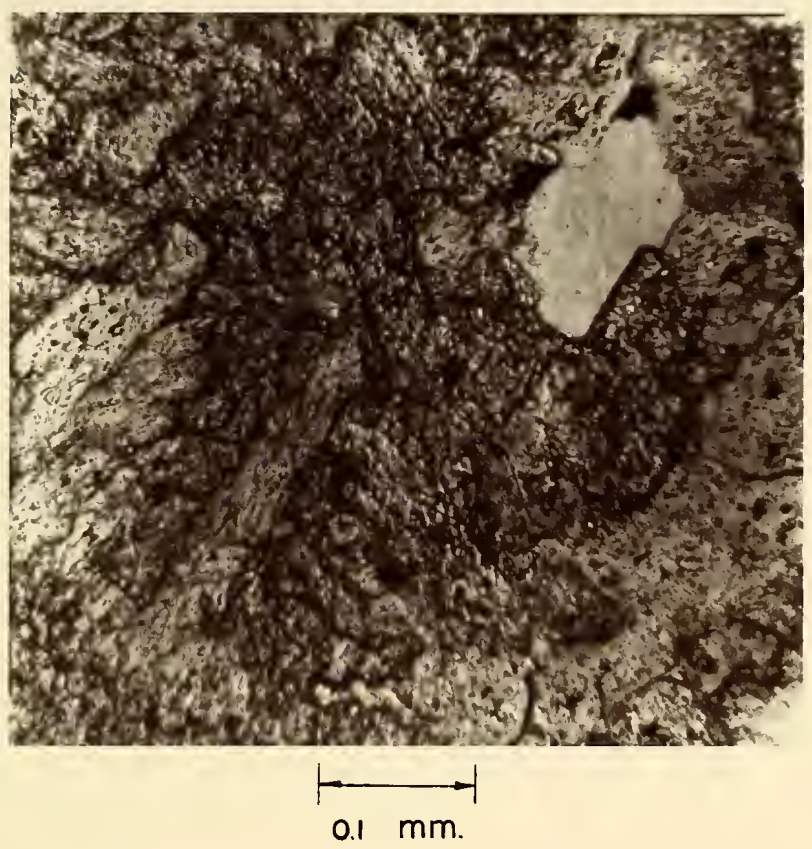

FIG.79 THIN SECTION OF H\&R DOLOMITE, ORDINARY LIGHT 


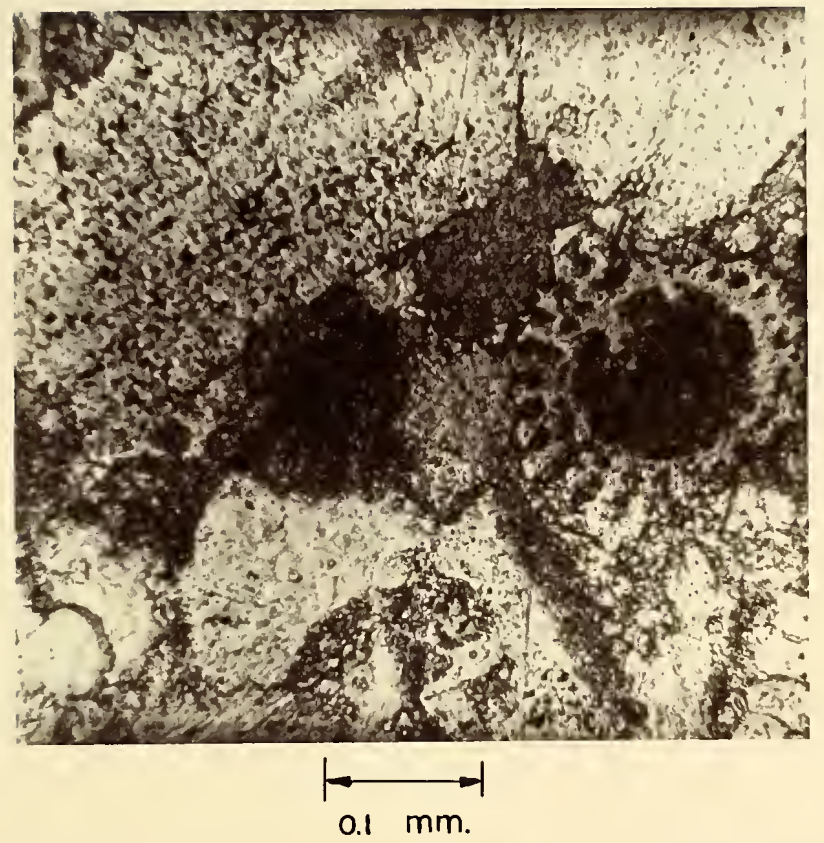

\section{FIG.80 THIN SECTION OF BLOOMINGTON LIMESTONE, ORDINARY LIGHT}




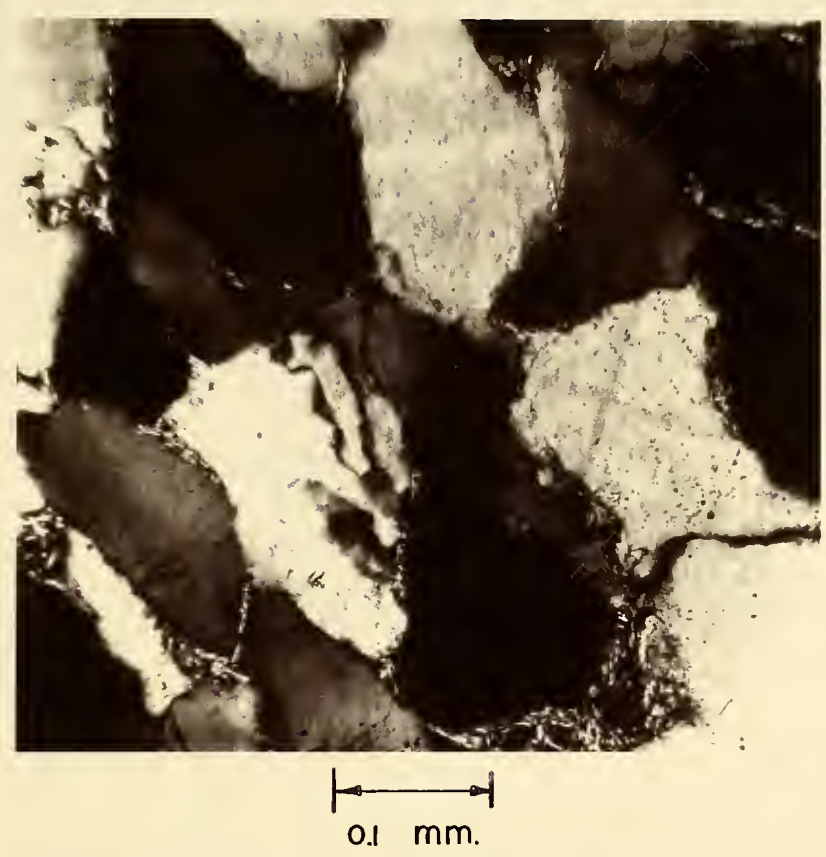

FIG.8I THIN SECTION OF BARABOO QUARTZITE, CROSSED NICOLS 
value and high degradation. In quartzite, strength is due to silica cementation and results in a comparatively strong and resistant rock. If the material had not been highly stressed, this strong cementation would have resulted in a very low Los Angeles value. But the directional weakness due to cracking and fracturing makes the material susceptible to impact breakage, which may be the reason for its high Los Angeles val ue as compared to the nature of its cementation. The results also show that degradation inereases as percent voids of the material increases.

\section{Relation Between Theory and Experiment}

The following formula is developed in the section on analysis of mechanism of degradation (Eq. (7)) for the degradation of one-sized aggregate:

$$
P_{1}=P_{0} e^{\beta\left(E_{0} / D_{0}-E_{i} / d_{i}\right)}
$$

Where $P_{1}=$ total percent of material smaller than size $d_{1}$

$$
P_{0}=100
$$

$E_{1}=$ energy per unit surface area of particles of size $d_{1}$

$E_{0}=$ energy per unit surface area of particles of size $D_{0}$, and $\beta=a$ constant

From the experimental results, the equation of the size distribution was found to be of a form

$$
P_{1}=P_{0} e^{-n \ln \left(D_{0} / d_{1}\right)}
$$

where $n$ is a factor depending on compactive effort and type of aggregate. Using the relationship $e^{-n}$ In $\left(D_{0} / d_{1}\right)=\left(D_{0} / d_{1}\right)^{-n}$ above equation becomes

$$
P_{1}=P_{0}\left(d_{1} / D_{0}\right)^{n}
$$


Eq. (3) is the same equation developed by Talbot and Richart. For the special case of $n=1 / 2$ we see that Eq. (3) yields a parabolic relationship not unlike that given by Fuller and Thompson to represent the gradation for maximum density.

Equating the theoretical and experimental results, we find

$$
e^{-\beta\left(E_{1} / d_{i}-E_{0} / D_{0}\right)}=e^{-n\left(\ln D_{0}-\ln d_{1}\right)}
$$

or

$$
\beta\left(E_{0} / D_{0}-E_{1} / d_{1}\right)=n\left[\ln \left(1 / D_{0}\right)-\ln \left(1 / d_{1}\right)\right]
$$

If $\mathrm{n}$ can be taken as a constant, as has been suggested by Charles (6) and other $(23)(48)$ a plot of Eq. (2) in $\log \log$ scale should generate a straight line. To examine the hypothesis, the curves shown in Figures 82, 83, and 84 were prepared. The resulting curves are shown to deviate considerably from a straight line in the range of coarse particle sizes. Evidently $n$ is not a constant but depends on breakage energy and particle size as is shown by the theoretical development. That 1s, considering $n=\beta \cdot \gamma$, Eq. (4) stipulates

$$
\left(E_{0} / D_{0}-E_{1} / d_{1}\right)=\ln \left(1 / D_{0}\right)^{\gamma}-\ln \left(1 / d_{1}\right)^{\gamma}
$$

which shows clearly that $\gamma_{1}$ a function of $E_{0}, E_{1}, D_{0}$, and $d_{1}$. Whereas $E_{0}$ and $D_{0}$ are constants for any size and type of aggregate $\left(E_{0}\right.$ and $\left.D_{0}\right), \gamma$ must be a function of breakage energy $E_{1}$ and particle size $d_{1}$. 


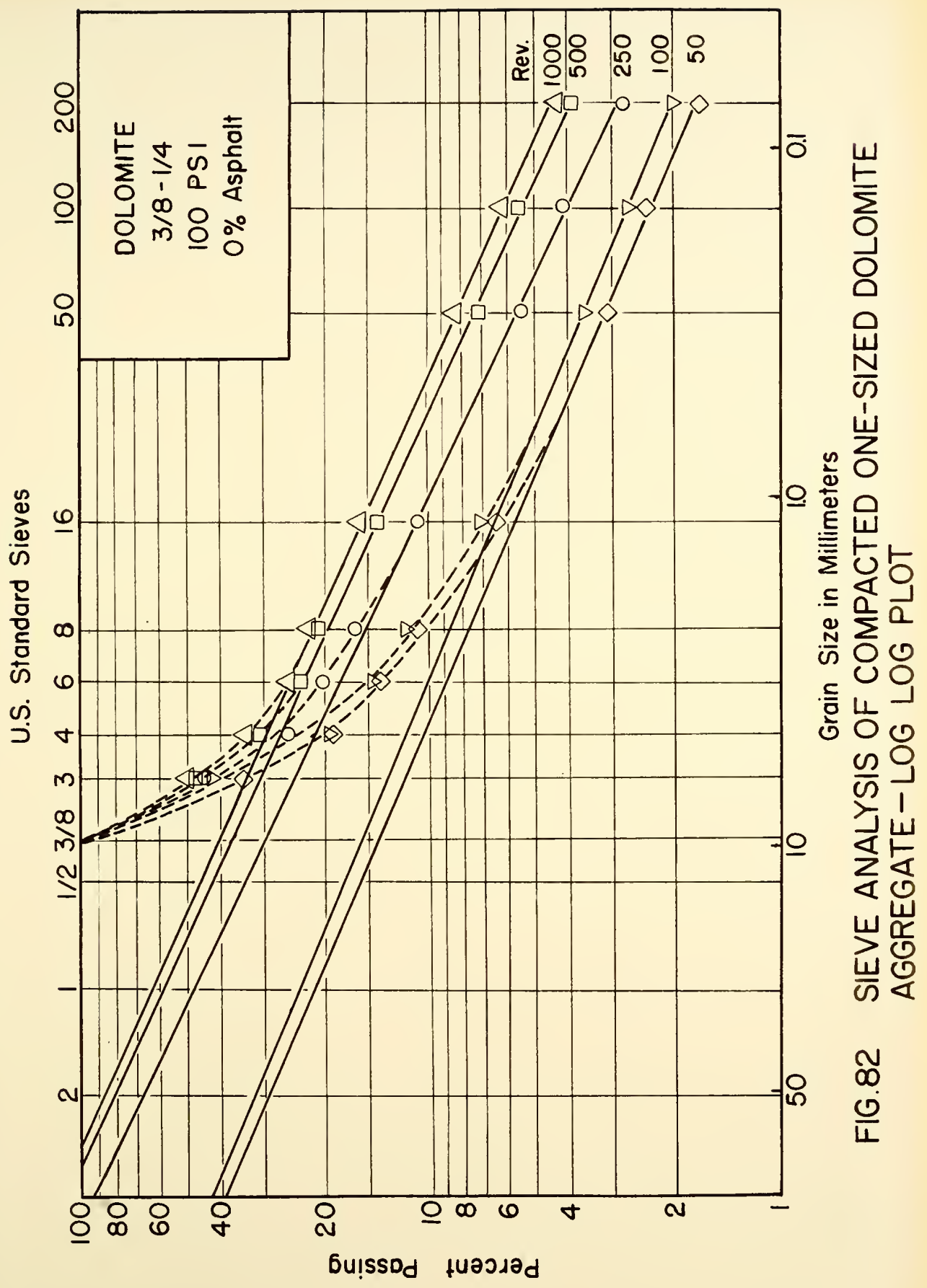




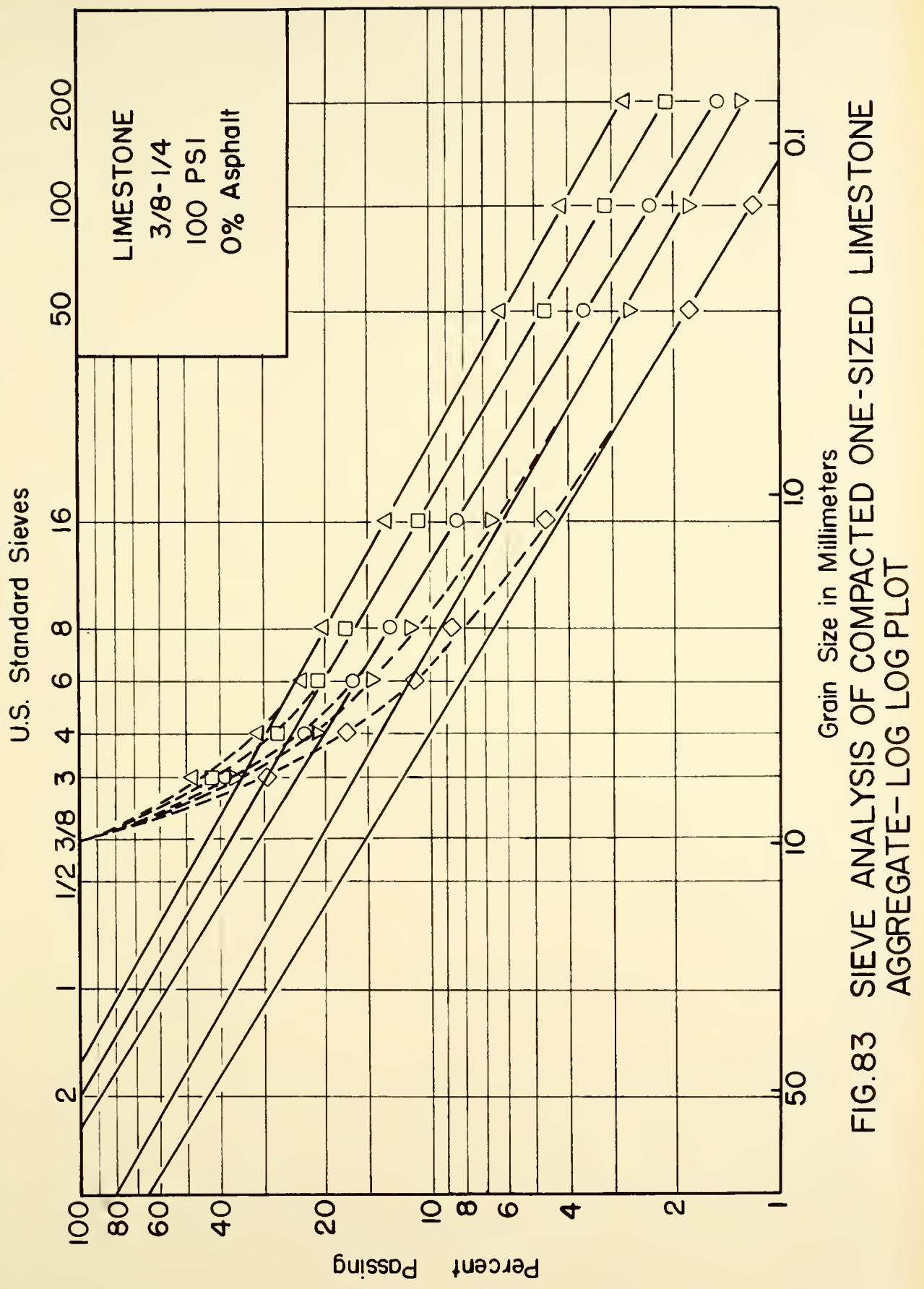




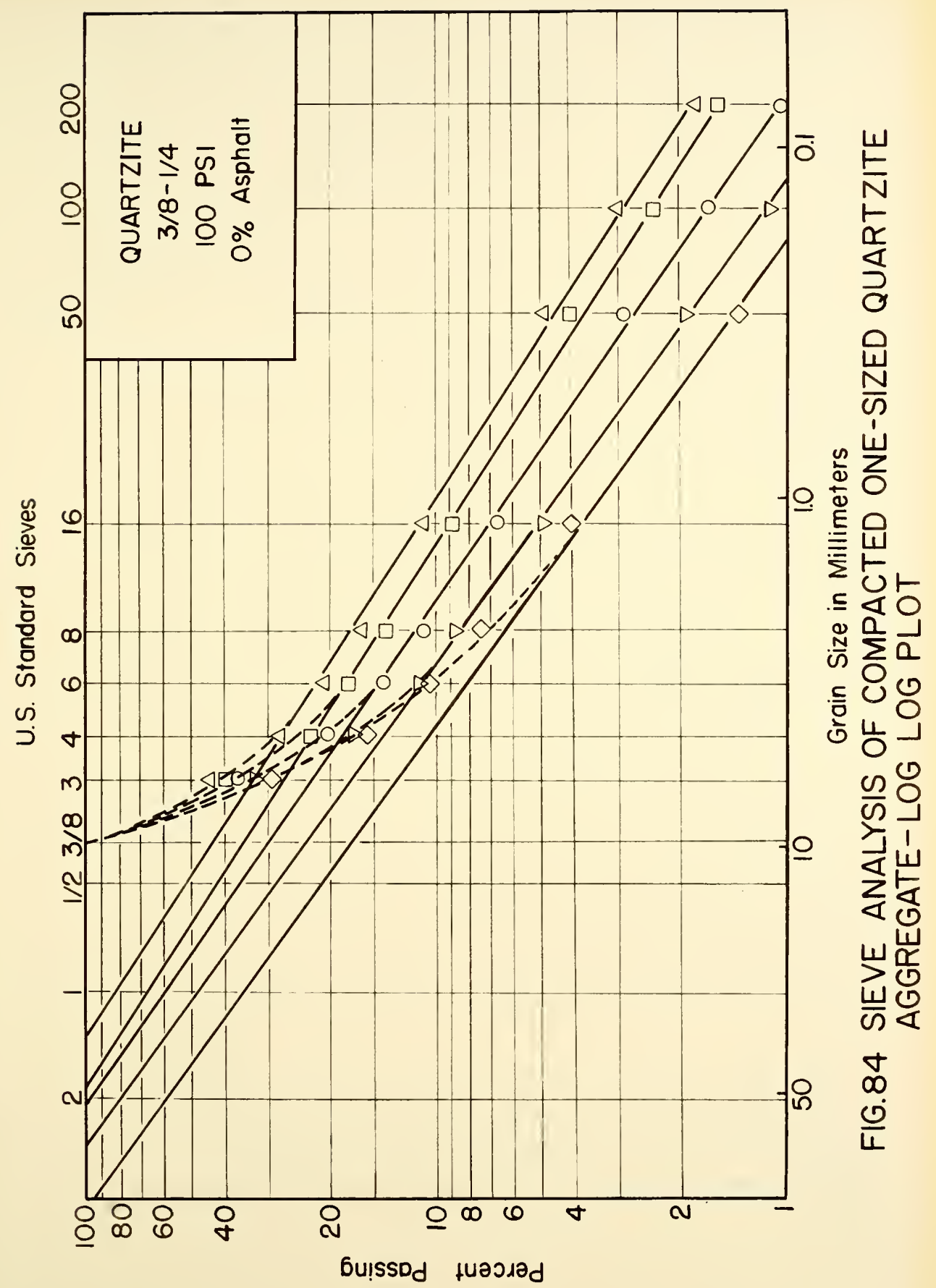


SUMMARY OF RESULTS

The following statements are presented as a resume of the findings resulting from this investigation.

1. Results of tests on one-sized aggregate indicated that the pattern of degradation when presented in the form of sieve analysis was constant, and the sieve analysis curves were generally smooth curves approaching a parabola in shape.

2. The pattern of degradation as represented by sieve analysis of one-sized aggregates was not affected by type or size of mineral aggregate, compactive effort, or method of compaction.

3. The magnitude of degradation of one-sized aggregates when measured on the basis of percent increase in surface area depended on (1) type of aggregate, (2) compactive effort, (3) method of compaction, and (4) original aggregate size. For specimens made of one-8ized pieces it was found that degradation increased as compactive effort increased. Degradation also increased as aggregate size became larger. Softer and weaker mineral aggregates produced more degradation under equal condition than harder and stronger materisls.

4. The results of tests on colored aggregate also indicated that combining different sizes of particles did not change the pattern of degradation of each fraction, but only affected the magnitude 
of degradation. The pattern of degradation as represented by sieve analysis was found to be independent of the presence of asphalt. It also was found that regardless of original gradation, amount of compactive effort, and presence or absence of asphalt, when the degradation product of each individual fraction was separated (made possible by a dyeing process) its sieve analysis followed a smooth curve similar in shape to those obtained from the separate testing of one-sized particles.

5. From the detailed study of factors affecting the magnitude of degradation, it was found that magnitude of degradation was directly related to the applied load and to its distribution in the mass.

6. Type of aggregate influenced the magnitude of degradation because different kinds of aggregate have variable resistance to breakage and wear. Thus, the softer and weaker the mineral aggregate the more was the degradation.

7. Compactive effort was found to have a pronounced effect on degradation. Compactive effort when changed by the magnitude of load was more effective on degradation than when changed by the number of repetitions of load. The change in magnitude of load had a more pronounced effect on the degradation of soft or weak materials than on hard or strong ones.

8. When compactive effort was changed by increasing the number of revolutions, most of the degradation occurred in the first hundred revolutions, after which the change in degradation became less as the number of revolutions was increased until this relationship 
became linear. This could be accounted for by the consideration that under the first few repetitions of load the loosely packed particles shifted around in order to produce a closer packing, resulting in the grinding off of corners of angular pleces and the production of fine material. Also, when the load was applied, the contact pressure increased and particles with internal fractures and weak planes were subject to immediate breakage. But as the number of repetitions increased, the movement and rotation of the particles decreased, contact points increased and contact pressure decreased thus causing a decrease in the rate of Increase of degradation.

9. The results of test on specimens with different original gradations showed that gradation of material had a very pronounced effect on degradation. It was found that the softest and weakest aggregate used in this investigation when compacted in a dense gradation produced much less degradation than the hardest and strongest aggregate when tested in an open gradation.

The change of degradation with change in gradation was thought to be related to contact pressures and the probability of rotation and slippage of particles. In a dense-graded mixture, due to the close packing of particles of different sizes, the number of contact points are numerous resulting in contact pressures of low magnitude and in less breakage of soft and weak part:eles.

10. No direct relationship could be established between asphalt content and degradation. Although it was found that depending on type of aggregate, compactive effort, and gradation of the mixture 
there was in general a certain asphalt content for which the degradation was minimum, no pattern for this dependency could be established.

11. It was found that rounded pieces of the same aggregate produced less degradation than angular one. This reduction due to shape of particles could be attributed to reduction in wear of corners.

12. A comparison of the amount of degradation produced in the gyratory machine with the Ios Angeles value of the aggregate showed that the Los Angeles test as performed under the standard method using open-graded aggregate corresponds to a high level of compactive effort. Even at the same grading, aggregate in this test does not have the confinement which exists in the field, and the test does not make provision for the effect of gradation on aggregate degradation.

13. From the petrographical examinations of the aggregates used it was found that the nature of the grain boundaries or cementing agent had great influence on degradation. The limestone material with good interlocking between grains had a low Los Angeles value and a comparatively low value of degradation, while for dolomite with its loose interlocking of grains the situation was reversed. Quartzite had the least degradation and the lowest Ios Angeles value chiefly because of its strong cementation by silica. It also was found that resistance to breakage increased as the porosity of the material decreased. 


\section{CONCLUSIONS}

The results obtained from this study appear to justify the following conclusions. It should be realized that these conclusions are specifically applicable only to the particular kinds of aggregate used in this study. Furthermore, it should be noted that all the tests were performed in the laboratory, and there exists no field correlation study to specifically evaluate the field behavior of the materials. Also, it has to be noted that all conclusions and recomendations deal with degradation characteristics of mineral aggregate. Protective measures suggested in this study are made only with respect to the reduction of aggregate degradation without considering their effects on other properties of mixtures.

1. Within the range of the materials and procedures used in this study, there appears to be a unique pattern for degradation of each aggregate fraction of a bituminous mixture. This pattern does not vary with kind of aggregate, compactive effort, method of compaction, presence of asphalt, or original gradation of the mixture.

2. The magnitude of degradation of a bituminous mixture, as measured by percent increase in aggregate surface area, depends on the following factors; kind of aggregate, gradation of the aggregate, compactive effort, and shape of particles. The effect of asphalt on the magnitude of degradation is dependent on other factors and cannot be considered as an independent variable. 
3. Kind of aggregate, when based on its Los Angeles value or 1ts petrographic analysis, has a dominant effect on degradation. Mineral aggregates with low Los Angeles values will produce less degradation than those with high Los Angeles values. Rocks with good interlocking or cementation between grains are more resistant to degradation than others.

4. Some aggregates having a Los Angeles loss greater than the minimum commonly specified may, from the standpoint of degradation, be satisfactory materials especially if used in dense gradings subjected to low compective effort.

5. Gradation of the mixture is the most important factor controlling degradation. As the gradation becomes more dense degradation decreases. The order of magnitude of this change is much greater than the order of magnitude of change of degradation due to other variables. Soft or ,weak materials with high Los Angeles values can produce much lees degradation than hard and strong materials if the former are used in dense-graded mixtures and the latter in open mixtures. Therefore, dense-graded mixtures offer the best use of local aggregates with high Los Angeles values.

6. Increase in compactive effort results in increase in degradation of the mixture regardless of the form of this incresse in effort, but degradation is more susceptible to change in magnitude of load than to change in repetition of load. The rate of change in degradation is high during the inftial part of the application of compactive effort, and thereafter becomes less as the compactive effort is increased. 
7. When the degradation of rounded particles is compared with that of angular particles of the same kind of aggregate, the rounded aggregate can be expected to produce less degradation because of a reduction of that portion of degradation which is due to wear. Use of rounded material will be helpful in reduction of degradation providing its use does not impair other properties of the mixtures. 


\section{SUGGESTIONS FOR FURTHER RESEARCH}

It is a well established fact that stability, durability, and flexibility are the primary properties of bituminous mixtures. All investigators share the opinion that these properties are subjected to considerable change during the life of pavements. It is also well accepted that most of the changes in these properties are due to traffic compaction and weathering. Traffic compaction, by applying compactive energy to the mat, changes these properties by further densification and reorientation of the structure of the pavement. Thls study has shown how an increase in compactive effort will cause a change in the gradation of the aggregate phase of mixtures, and has indicated which factors control this change. However there is a definite need for further investigation to analyze the effects of this change of gradation on the properties of bituminous mixtures, and to find out the effects of protective measures, suggested in this study, on these properties.

It is apparent that degradation occurs as mixtures densify under traffic compaction. The extent of this densification and its effect on the properties of the mixtures should also be investigated.

It is a well established fact that degradation of aggregates occurs due to the compactive energy applied. Therefore, it would be quite worthwhile if degradation were studied through the concepts of energy consumption and the measurement of energy required for a certain amount of degradation. This fundamental approach would lead to a better understanding of the mechanism of degradation and the factors affecting breakage energy. 
Efforts should also be made to correlate the results of this laboratory investigation with field performance of the mixtures. In such a correlation study, the inftial compaction, the densification due to traffic action, and the stability of the mixtures would have to be correlated with the magnitude of degradation obtained during different stages of the life of the pavement. 
LIST OF REFERENCES 


\section{LIST OF REFERENCES}

1. American Society for Testing Materials, "Book of Standards" Part 4, 1961.

2. Aughenbaugh, N. B., Johnson, R. B., and Yoder, E. J., "Available Information on Aggregate Degradation (A Iiterature Review), " Purdue University, April 1961, (unpublished).

3. Benson, J. R., "The Grading of Aggregates for Bituminous Construction," Special Technical Publication No. 83, American Society for Testing Materials, 1948.

4. Bond, F. C., "The Third Theory of Comminution," Transactions, American Institute of Mining Engineers, Vol. 193, 1952.

5. Brown, G. G. and Associates, "Unit Operations," John Wiley and Sons, Inc., 1950.

6. Charles, R. J., "Energy-Size Reduction Relationships in Comminution," Transactions, American Institute of Mining Engineers, Vol. 208, 1957.

7. Collet, F. R., Warnick, C. C., and Hoffman, D. S., "Prevention of Degradation of Basalt Aggregates Used in Highway-Base Construction," Proceeding8, Highway Research Board, Vol. 41, 1962.

8. Cook, F. C., "Report of the Road Research Board, "Department of Scientific and Industrial Research, London, England, 1935.

9. Croeser, H. M. W., "Bituminous Mixtures," Unpublished M. S. Thesis, University of Witwatersrand, Johannesburg, South Africa, 1944.

10. Day, H. I., "A Progress Report on Studies of Degrading Basalt Aggregate Bases," Proceedings, Highway Research Board, Vol. 41, 1962.

11. Ekse, Mo and Morris, H. C., "A Test for Production of Plastic Fines in the Process of Degradation of Mineral Aggregates," Special Technical Publication No. 277, American Society for Testing Materials, 1959.

12. Endersby, V. A., Griffith, R. I., and Sommer, M. J., "Adhesion Between Asphalts and Aggregates in the Presence of Water," Proceedings, The Association of Asphalt Paving Technologists, Vol. 16, 1947.

13. Endersby, V. A. and Vallerga, B. A., "Laboratory Compaction Methods and Their Effects on Mechanical Stability Tests for Asphaltic Pavements," Proceedings, The Association of Asphalt Paving Technologiats, Vol. 21, 1952. 
14. Erickson, L. F., "Degradation of Aggregates Used in Base Courses and Bituminous Surfacings," Circular 416, Highway Research Board, March 1960.

15. Erickson, L. F., "Degradation of Idaho Aggregates," Pacific Northwest Soils Conference, Moscow, Idaho, February 1958.

16. Faust, A. S., Wengel, L. A., Clump, C. W., Maus, L., and Anderson, L. B., "Principles of Unit Operations," John Wiley \& Sons, Inc., 1960.

17. Goetz, W. H., "Flexible Pavement Test Sections for Studying Pavement Design," Proceedings, Thirty-Seventh Annual Purdue Road School, 1952.

18. Goldbeck, A. T., "Discussion on the Los Angeles Abrasion Machine," Proceedings, American Society for Testing Materials, Vol. 35, Part II, 1935.

19. Coldbeck, A. T., "Mineral Aggregates for Railroad Ballast," Special Technical Publication No. 83. American Society for Testing Materials, 1948.

20. Coldbeck, A. T., "Report of Committee on Coarse Aggregates," Proceed1ngs, The Association of Asphalt Paving Technologists, Vol. 8, 1937.

21. Goldbeck, A. T., Gray, J. E., and Ludlow, L. I., Jr., "A Laboratory Service Test for Pavement Materials, "Proceedings, American Society for Testing Materials, पol. 34, Part II, 1934.

22. Gross, J., "Crushing and Grinding," Bulletin No. 402, U. S. Bureau of Mines, 1938.

23. Gross, J. and Zimmerlgy, S. R., "Crushing and Grinding," Transactions, American Institute of Mining Engineers, Vol. 87, 1930.

24. Havers, J. A. and Yoder, E. J., "A Study of Interactions of Selected Combinations of Subgrade and Base Course Subjected to Repeated Load1ng," Proceedings, Highway Research Board, Vol. 36, 1957.

25. Herrin, M. and Goetz, W. H., "Effect of Aggregate Shape on Stability of Bituminous Mixes," Proceedings, Highway Research Board, Vol. 33, 1954 .

26. Holmes, J. A., "A Contribution to the Study of Comminution - A Modified Form of Kick's Law," Transactions, Institute of Chemical Engineers, Vol. 35, 1957.

27. Idaho Department of Highways, "Standard Method of Test for Degradation of Aggregates," T-15-58, State of Idaho, Bo1se, Idaho, 1958.

28. Kimble, F. W. and Cibboney, W. B., "Control of Fleld Density of Bituminous Concrete with a Gyratory Compactor," Proceedings, The Association of Asphalt Paving Technologists, Vol. 30, 1961. 
29. Knight, B. H., "Influence of Aggregate Type on Stability of Asphalt Mixtures," Journal of Applied Chemistry, Vol. 3, No. 3, August 1953.

30. Laburn, R. J., "The Road Making Properties of Certain South African Stones," Unpublished M.S. Thesis, Part II, University of Witwatersrand, Johannesburg, South Africa, 1942.

31. Lang, F. C., "Influence of Quality of Aggregate on Strength of Concrete," Proceedings, American Society for Testing Materials, 1929.

32. Macnaughton, M. F., "Physical Changes in Aggregates in Bituminous Mixtures Under Compaction," Proceedings, The Association of Asphalt Paving Technologists, Vol. 8, January 1937.

33. Mather, B., "Shape, Surface Texture, and Coatings," Special Technical Publication No. 169, American Society for Testing Materials, 1955.

34. McGregor, D. J., "Directory of Crushed Limestone Producers in Indiana," Geological Survey, Directory No. 4, Indiana Department of Conservation, 1956.

35. McLaughlin, J. F., "Recent Developments in Aggregate Research," A paper to be presented at the IV World Meeting of the International Rosd Federation, Madrid, 1962.

36. McRae, J. L., "Compaction of Bituminous Concrete," Proceedings, The Association of Asphalt Paving Technologists, Vol. 26, 1957.

37. McRae, J. L. and Foster, C. R., "Theory and Application of a Gyratory Testing Machine for Hot-Mix Bituminous Pavement," Special Technical Publication No. 252, American Society for Testing Materials, 1959.

38. Miller, J. S., Discussion of Reference 4.

39. Minor, C. E., "Degradation of Mineral Aggregates," Special Technical Publication No. 277. American Society for Testing Materials, 1959.

40. Monismith, C. Lo and Vallerga, B. A., "Relationship between Density and Stability of Asphaltic Paving Mixtures," Proceedings, The Association of Asphalt Paving Technologists, Vol. 25, 1956.

41. Nevitt, H. G., "Compaction Fundamentals," Proceedings, The Association of Asphalt Paving Technologists, Vol. 26, 1957.

42. Page, L. W. and Cushman, A. S., "The United States Road Material Laboratory: Its Aims and Methods," Proceedings, Sixth Annual Meeting of the American Society for Testing Materials, Vol. 11i, 1903.

43. Pauls, J. T. and Carpenter, C. A., "Mineral Aggregates for Bituminous Constmuction," Special Technical Publication No. 83, American Society for Testing Materials, 1948. 
44. Philippi, O. A., "Molding Specimens of Bituminous Paving Mixtures," Proceedings, Highway Research Board, Vol. 31, 1952.

45. Piret, E. L., Kwong, J. M., Adams, J. T., and Johnson, J. F., "EnergyNew Surface Relationship in the Crushing of Sollds," Chemical Engineering Progress, Vol. 45, 1949.

46. Reagel, F. V., "How Good is Good Enough," Crushed Stone Journal, Vol. 35, No. 1, March 1960.

47. Rhodes, R. and Mielenz, R. C., "Petrograph1c and Mineralogic Characteristics of Aggregates," Special Technical Publication No. 83, American Society for Testing Materials, 1948.

48. Rothgery, L. J., "Los Angeles Rattler Test," Rock Products, Vol. 39, №. 12, December 1936.

49. Scott, L. E., "Secondary Minerals in Rock as a Cause of Pavement and Base Failure," Proceedings, Highway Research Board, Vol. 34, 1955.

50. Shelburne, T. E., "Crushing Resistance of Surface-Treatment Aggregates," Engineering Bulletin, Purdue University, Vol. 24, No. 5, September 1940.

51. Shelburne, T. E., "Surface Treatment Studies," Proceedings, The Association of Asphalt Paving Technologists, Vol. 11, 1940.

52. Shergold, F. A., "A Review of Available Information on the Significance of Roadstone Tests," Technical Paper No. 10, Road Research Laboratory, London, April 1948.

53. Shergold, F. A., "A Study of the Crushing and Wear of Surface-Dressing Chippings Under Rolling and Light Traffic," Research Note No. RN/2298/FAS, B.P. 397 Road Research Laboratory, London, 1954.

54. Shergold, F. A., "A Study of the Granulators Used in the Production of Roadmaking Aggregates," Technical Paper No. 44, Road Research Laboratory, London, October 1959.

55. Smith, V. R., "Application of the Triaxial Test to Bituminous Mixtures," Special Technical Publication No. 106, American Society for Testing Materials, 1950.

56. Sweet, H. S., "Physical and Chemical Tests of Mineral Aggregates and Their Significance," Special Technical Publication No. 83, American Society for Testing Materials, 1948.

57. Turner, R. S. and Wilson, J. D., "Degradation Study of Some Washington Aggregates, " Bulletin No. 232, Washington State, Institute of Technology, 1956.

58. Tyler, O. R., "Adhesion of Bituminous Films to Aggregates," Engineering Bulletin No. 5, Purdue University, Vol. 22, 1938. 
59. U. S. Army, Corps of Engineers, Waterways Experiment Station, Vicksburg, Miesissippi, "Development of the Gyratory Testing Machine and Procedures for Testing Htuminous Paving Mixtures," Technical Report No. 3-595, February 1962.

60. U. S. Arny, Corps of Engineers, Waterways Experiment Station, Vicksburg, Mississippi, "Proof-Test Section, Columbus Air Force Base," Technical Report No. 3-490, December 1958.

61. Vallerga, B. A., Seed, H. B., Monismith, C. L., and Cooper, R. S., "Effect of Shape, Size, and Surface Roughness of Aggregate Particles on the Strength of Granular Matertale, "Special Technical Publication No. 212, American Soclety for Testing Materials, 1957.

62. Wanenmacher, J. M., Twenhofel, W. H., and Rasch, G. O., "Paleozolc Strata of the Baraboo Area, Wisconsin," American Journal of Science, 5th Series, Vol. 28, No. 163, pp. 1-30, 1934.

63. Woods, K. B., "Distribution of Mineral Aggregates, " Special Technical Publication No. 83, American Soclety for Testing Materials, 1948.

64. Woods, K. B., "Highway Engineering Handbook," Section 16, "Distribution, Production, and Engineering Characteristics of Aggregates, " by McLaughlin, J. F., Woods, K. B., Mielenz, R. C., and Rockwood, N. C., McGraw-Hill, 1960.

65. Woolf, D. O., "Results of Physical Tests of Road Building Aggregates," Bulletin, Bureau of Public Roads, 1953. 
APPENDIX 


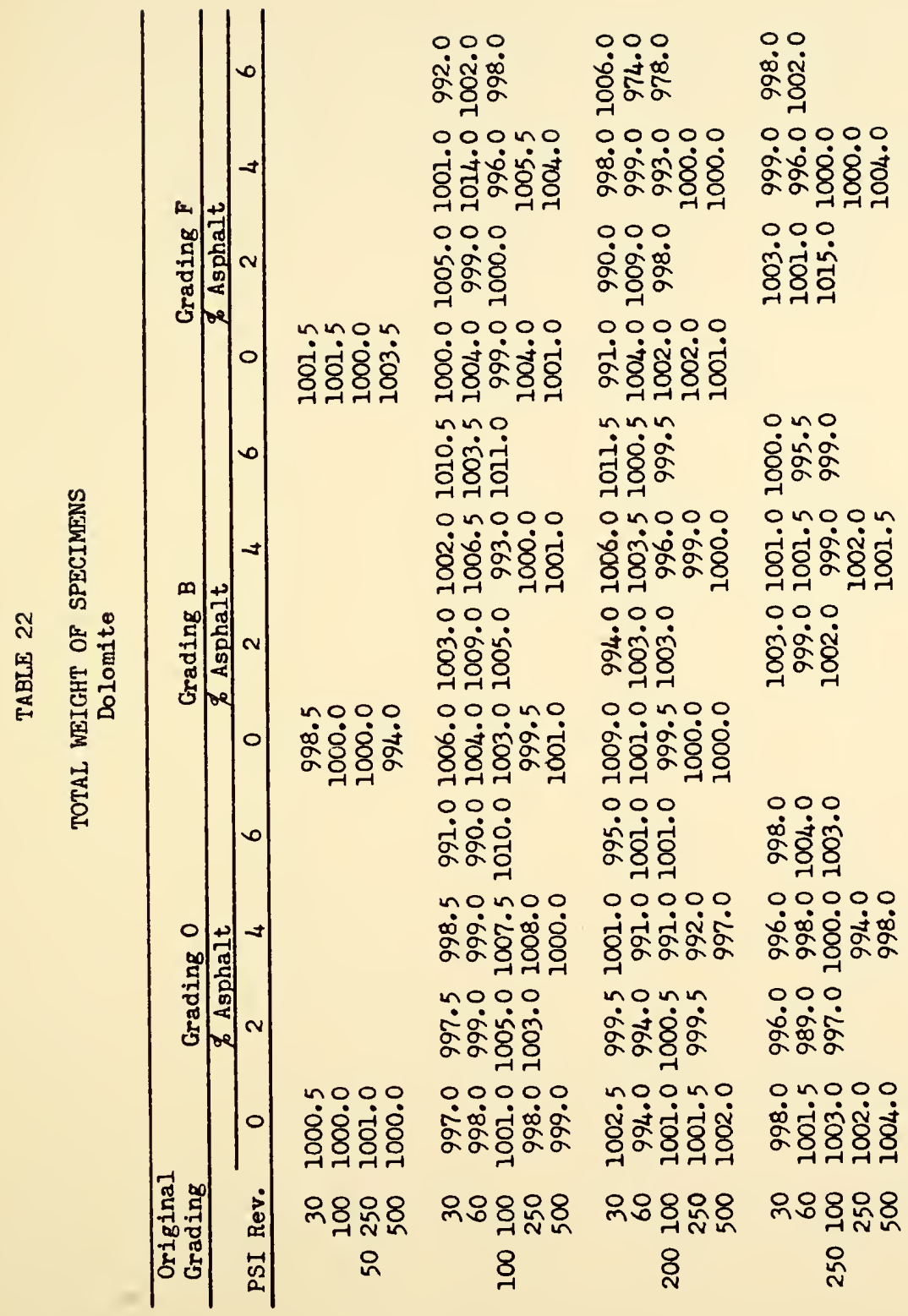




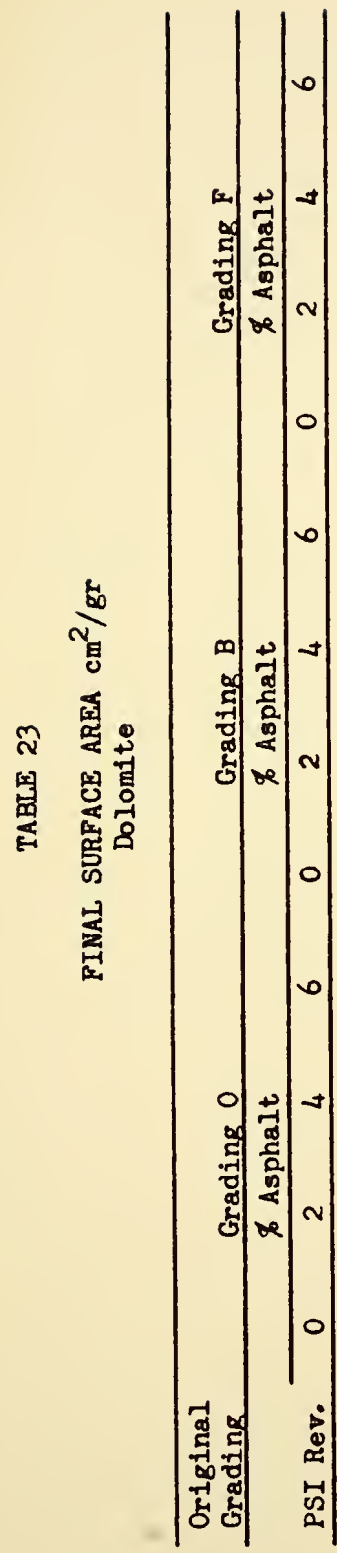

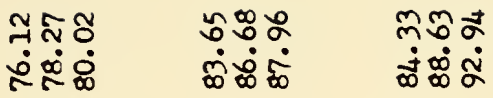

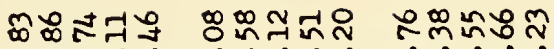

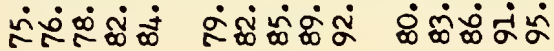

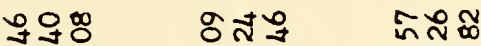

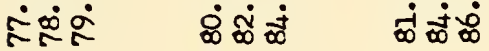

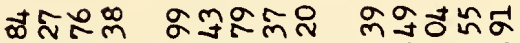

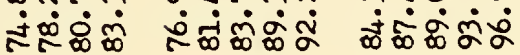

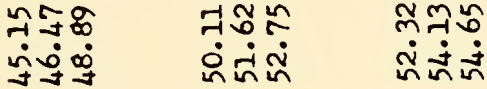

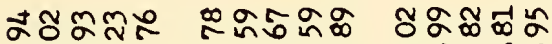

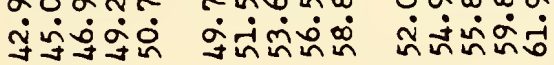

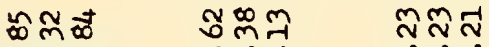

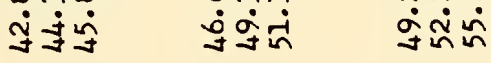

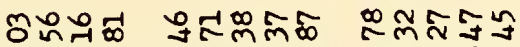

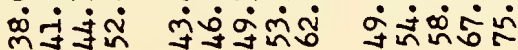

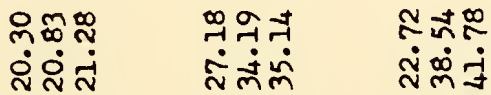

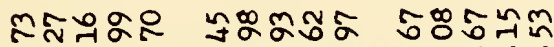

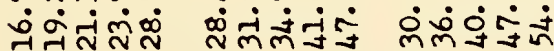

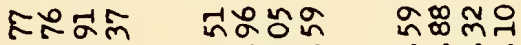
ن

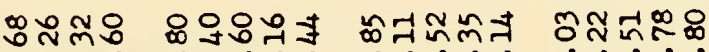

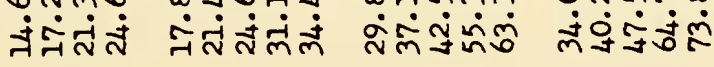

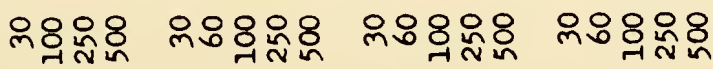

ㅇํ

\&

\&

in 


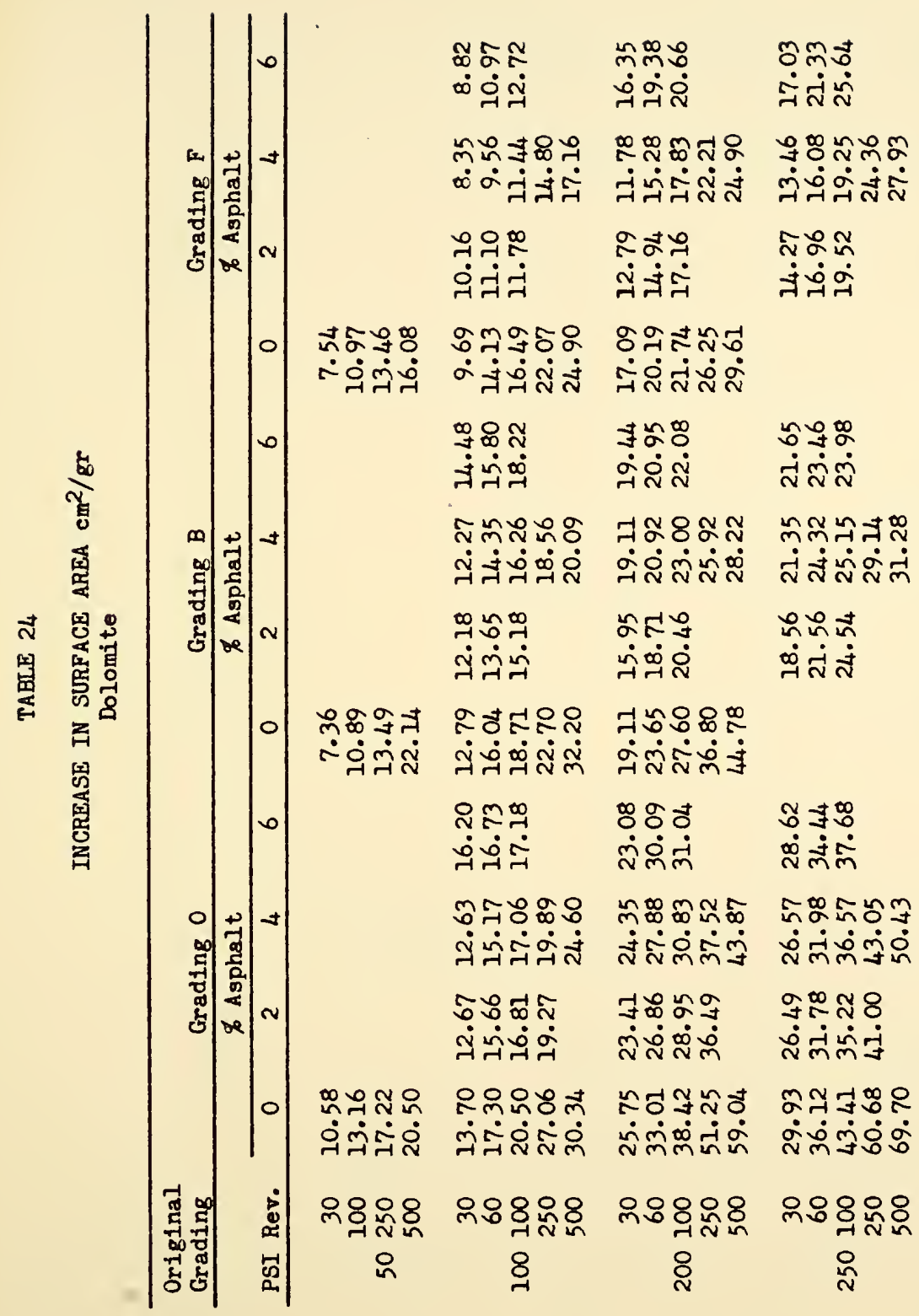




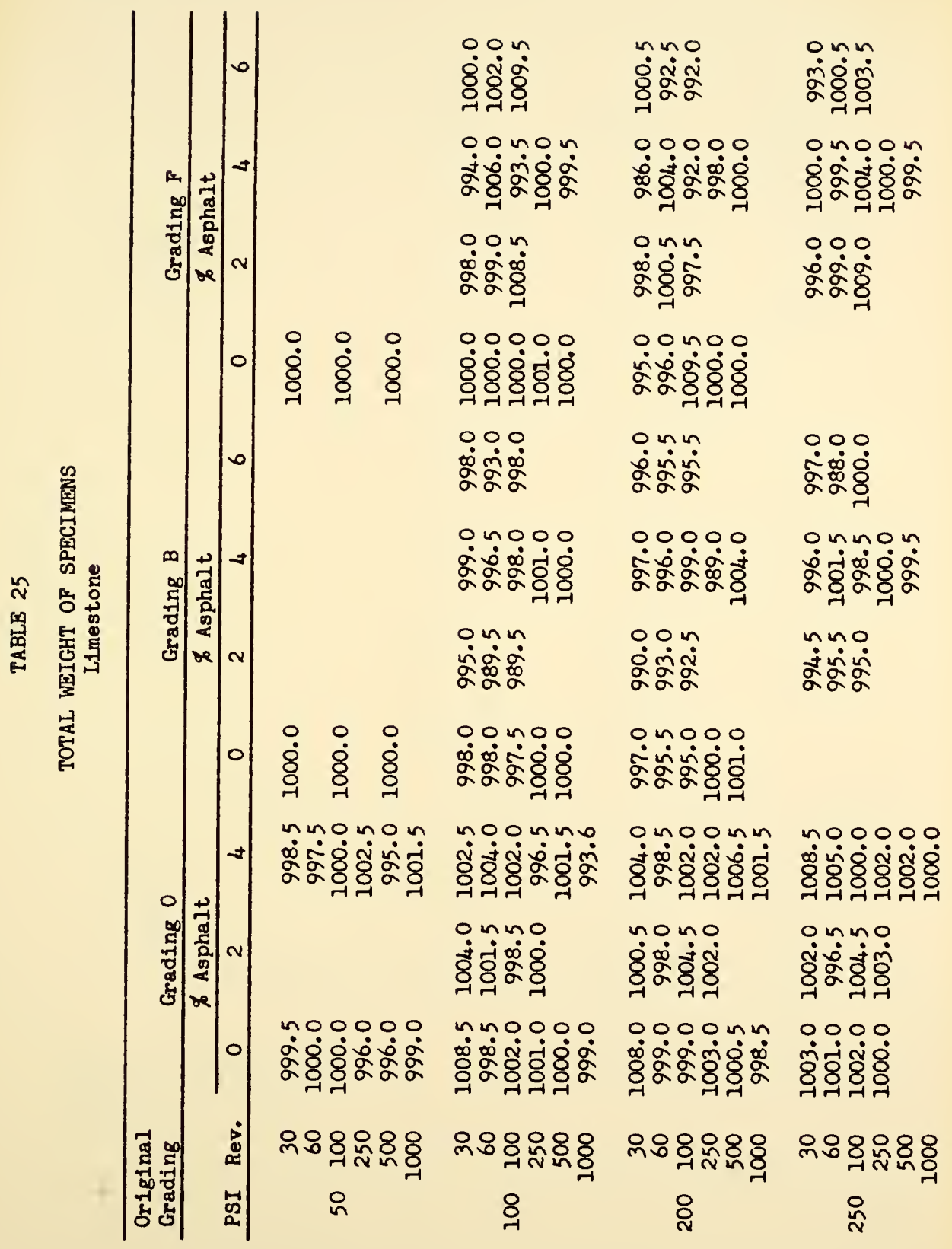




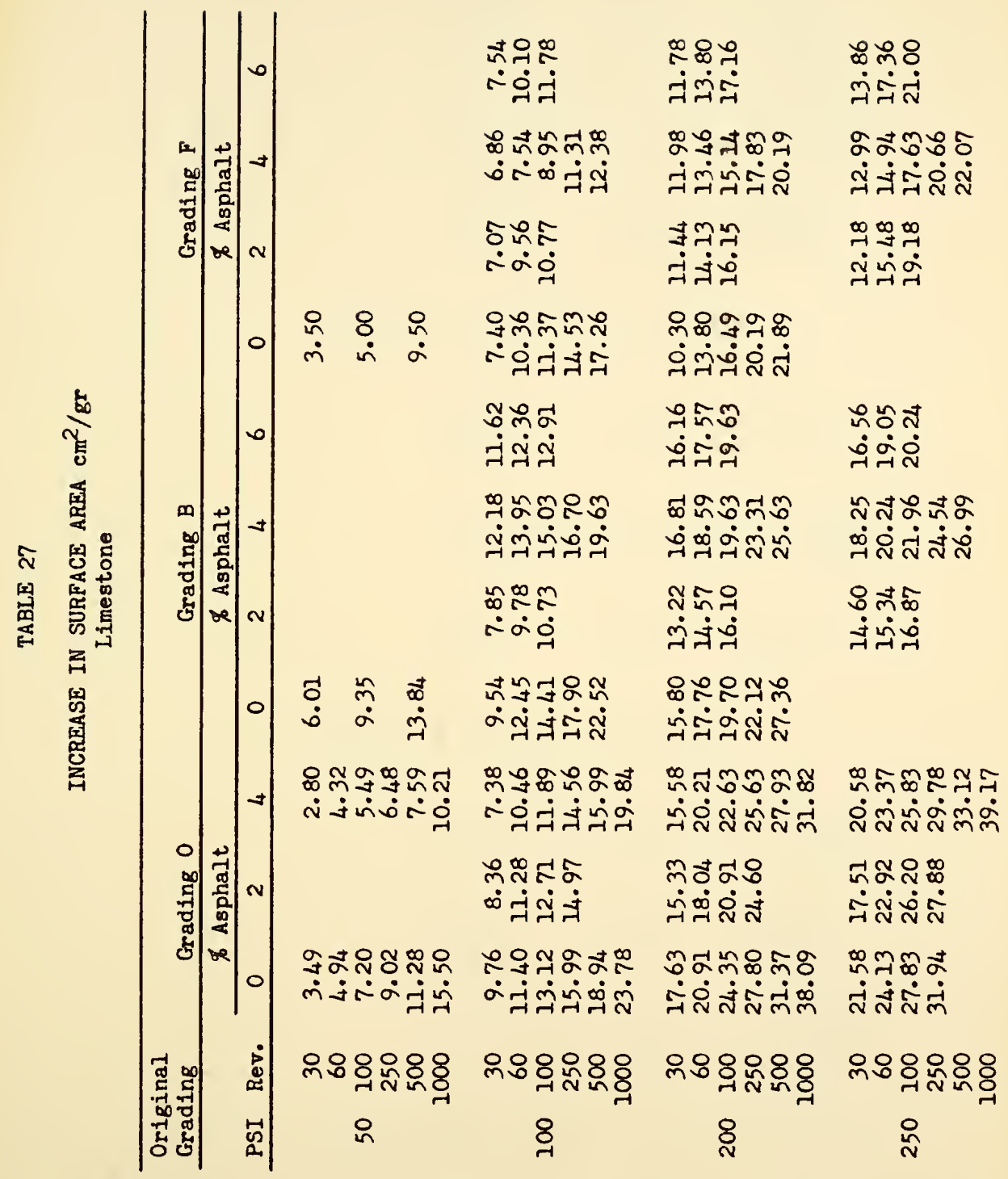




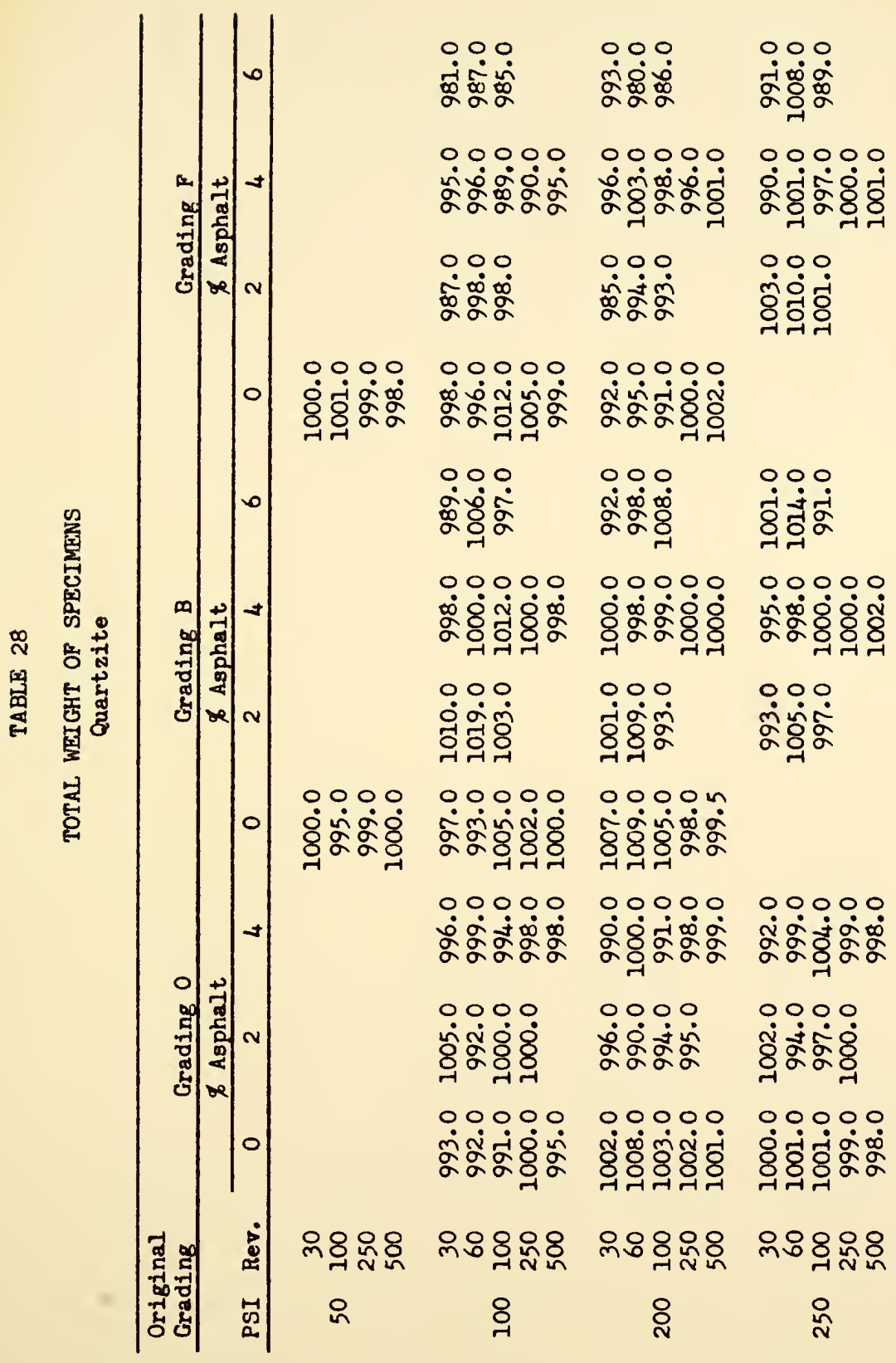




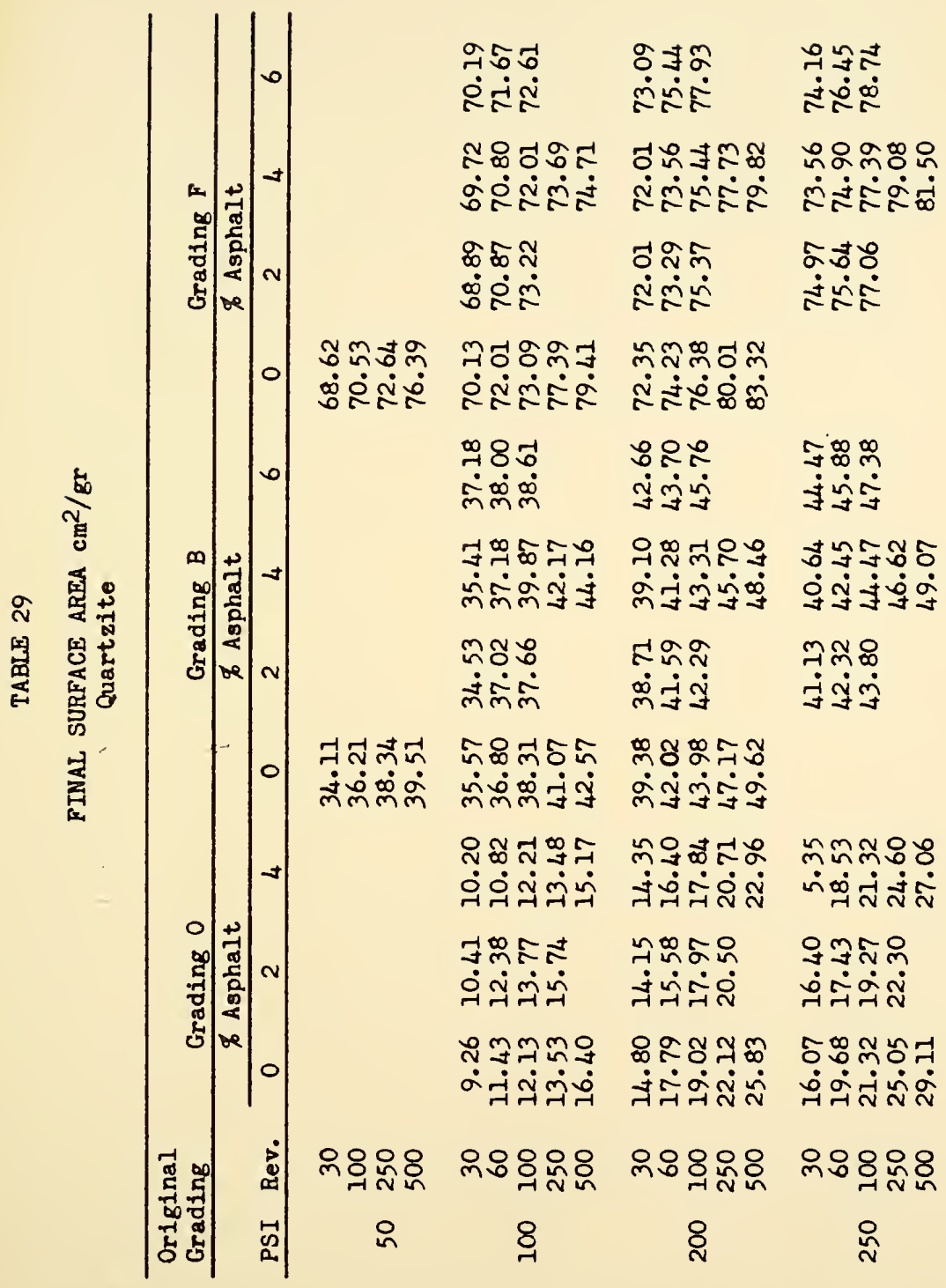




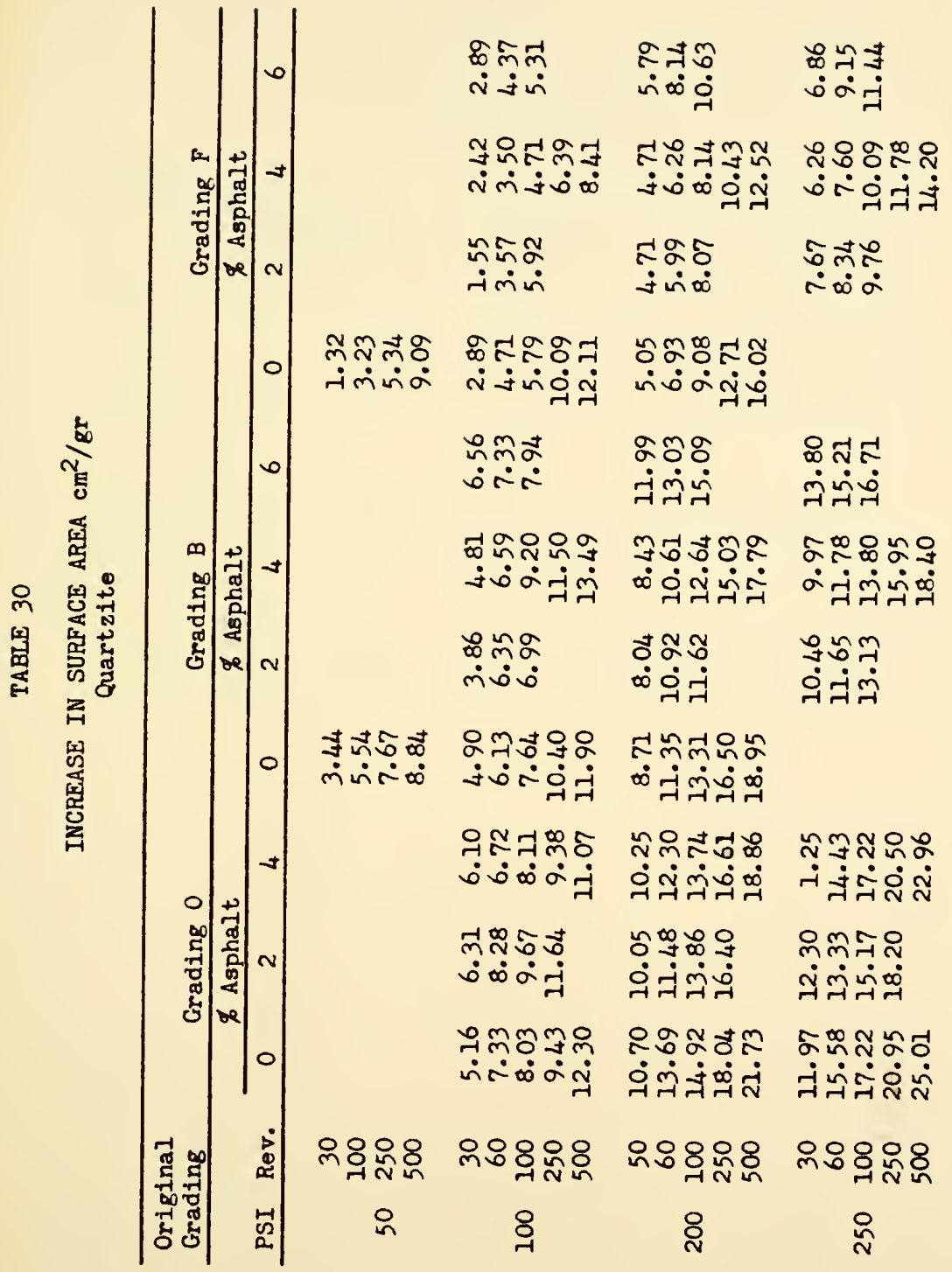


TABIE 31

TOTAL WEIGHT OF SPECIMENS

Rounded Quartzite

\begin{tabular}{|c|c|c|c|c|c|c|c|}
\hline \multicolumn{2}{|c|}{$\begin{array}{l}\text { Original } \\
\text { Grading }\end{array}$} & \multicolumn{2}{|c|}{ Grading 0} & \multicolumn{2}{|c|}{ Grading B } & \multicolumn{2}{|c|}{ Grading $F$} \\
\hline & & $\mathscr{B} \mathrm{A}$ & phalt & क A & phalt & $\not \mathrm{As}$ & phalt \\
\hline PSI & Rev. & 0 & 4 & 0 & 4 & 0 & 4 \\
\hline 100 & $\begin{array}{r}30 \\
100 \\
250\end{array}$ & $\begin{array}{r}1000.0 \\
999.5 \\
999.0\end{array}$ & $\begin{array}{l}1000.0 \\
1000.0 \\
1000.0\end{array}$ & $\begin{array}{r}999.0 \\
1001.0 \\
1000.5\end{array}$ & $\begin{array}{r}1000.0 \\
998.0 \\
999.5\end{array}$ & $\begin{array}{l}999.0 \\
998.0 \\
999.5\end{array}$ & $\begin{array}{r}995.0 \\
998.0 \\
1001.0\end{array}$ \\
\hline 200 & $\begin{array}{r}30 \\
100 \\
250\end{array}$ & $\begin{array}{l}1000.0 \\
1000.0 \\
1000.0\end{array}$ & $\begin{array}{r}999.5 \\
1000.0 \\
998.0\end{array}$ & $\begin{array}{r}1000.0 \\
1000.0 \\
998.0\end{array}$ & $\begin{array}{r}999.0 \\
999.0 \\
1001.0\end{array}$ & $\begin{array}{r}1000.5 \\
998.0 \\
1000.0\end{array}$ & $\begin{array}{l}999.5 \\
995.0 \\
999.0\end{array}$ \\
\hline 250 & $\begin{array}{r}30 \\
100 \\
250\end{array}$ & $\begin{array}{l}1001.0 \\
1000.5 \\
1002.0\end{array}$ & $\begin{array}{r}998.0 \\
1000.0 \\
1002.0\end{array}$ & $\begin{array}{r}999.0 \\
1000.0 \\
1000.0\end{array}$ & $\begin{array}{r}995.0 \\
1000.0 \\
1000.0\end{array}$ & $\begin{array}{r}1002.0 \\
995.0 \\
1000.0\end{array}$ & $\begin{array}{l}996.0 \\
997.0 \\
998.0\end{array}$ \\
\hline
\end{tabular}


TABLE 32

FINAL SURFACE AREA $\mathrm{cm}^{2} / \mathrm{gr}$ Rounded Quartzite

\begin{tabular}{|c|c|c|c|c|c|c|c|}
\hline \multicolumn{2}{|c|}{$\begin{array}{l}\text { Original } \\
\text { Grading }\end{array}$} & \multirow{2}{*}{\multicolumn{2}{|c|}{$\frac{\text { Grading } 0}{\not \text { Asphalt }}$}} & \multirow{2}{*}{\multicolumn{2}{|c|}{$\frac{\text { Grading B }}{\not \text { Asphalt }}$}} & \multirow{2}{*}{\multicolumn{2}{|c|}{$\frac{\text { Grading F }}{\text { \% Asphalt }}$}} \\
\hline \multirow[b]{2}{*}{ PSI } & \multirow[b]{2}{*}{ Rev. } & & & & & & \\
\hline & & 0 & 4 & 0 & 4 & 0 & 4 \\
\hline 100 & $\begin{array}{r}30 \\
100 \\
250\end{array}$ & $\begin{array}{l}6.88 \\
8.86 \\
9.76\end{array}$ & $\begin{array}{l}7.50 \\
8.61 \\
9.64\end{array}$ & $\begin{array}{l}32.88 \\
34.96 \\
36.50\end{array}$ & $\begin{array}{l}33.98 \\
35.73 \\
36.96\end{array}$ & $\begin{array}{l}67.97 \\
68.58 \\
70.13\end{array}$ & $\begin{array}{l}67.77 \\
69.45 \\
71.34\end{array}$ \\
\hline 200 & $\begin{array}{r}30 \\
100 \\
250\end{array}$ & $\begin{array}{r}8.77 \\
11.40 \\
12.79\end{array}$ & $\begin{array}{r}9.94 \\
11.21 \\
12.22\end{array}$ & $\begin{array}{l}34.41 \\
37.26 \\
39.26\end{array}$ & $\begin{array}{l}36.80 \\
37.88 \\
39.41\end{array}$ & $\begin{array}{l}69.05 \\
70.53 \\
72.48\end{array}$ & $\begin{array}{l}68.98 \\
71.00 \\
72.68\end{array}$ \\
\hline 250 & $\begin{array}{r}30 \\
100 \\
250\end{array}$ & $\begin{array}{r}9.35 \\
11.69 \\
13.57\end{array}$ & $\begin{array}{l}11.28 \\
12.92 \\
14.35\end{array}$ & $\begin{array}{l}34.75 \\
37.72 \\
39.56\end{array}$ & $\begin{array}{l}37.82 \\
39.10 \\
40.48\end{array}$ & $\begin{array}{l}69.25 \\
71.14 \\
73.09\end{array}$ & $\begin{array}{l}70.33 \\
71.47 \\
72.68\end{array}$ \\
\hline
\end{tabular}


TABLE 33

INCREASE IN SURFACE AREA $\mathrm{cm}^{2} / \mathrm{gr}$ Rounded Quartzite

\begin{tabular}{|c|c|c|c|c|c|c|c|}
\hline \multicolumn{2}{|c|}{$\begin{array}{l}\text { Original } \\
\text { Grading }\end{array}$} & \multirow{2}{*}{\multicolumn{2}{|c|}{$\frac{\text { Grading } 0}{\% \text { Asphalt }}$}} & \multicolumn{2}{|c|}{ Grading B } & \multicolumn{2}{|c|}{ Grading $\mathrm{F}$} \\
\hline \multirow[b]{2}{*}{ PSI } & \multirow[b]{2}{*}{ Rev. } & & & $\not \mathrm{As}$ & alt & $\not 6 \mathrm{As}$ & aIt \\
\hline & & 0 & 4 & 0 & 4 & 0 & 4 \\
\hline 100 & $\begin{array}{r}30 \\
100 \\
250\end{array}$ & $\begin{array}{l}2.78 \\
4.76 \\
5.66\end{array}$ & $\begin{array}{l}3.40 \\
4.51 \\
5.54\end{array}$ & $\begin{array}{l}2.21 \\
4.29 \\
5.83\end{array}$ & $\begin{array}{l}3.31 \\
5.06 \\
6.29\end{array}$ & $\begin{array}{l}0.67 \\
1.28 \\
2.83\end{array}$ & $\begin{array}{l}0.47 \\
2.15 \\
4.04\end{array}$ \\
\hline 200 & $\begin{array}{r}30 \\
100 \\
250\end{array}$ & $\begin{array}{l}4.67 \\
7.30 \\
8.69\end{array}$ & $\begin{array}{l}5.84 \\
7.11 \\
8.12\end{array}$ & $\begin{array}{l}3.74 \\
6.59 \\
8.59\end{array}$ & $\begin{array}{l}6.13 \\
7.21 \\
8.74\end{array}$ & $\begin{array}{l}1.75 \\
3.23 \\
5.18\end{array}$ & $\begin{array}{l}1.68 \\
3.70 \\
5.38\end{array}$ \\
\hline 250 & $\begin{array}{r}30 \\
100 \\
250\end{array}$ & $\begin{array}{l}5.25 \\
7.59 \\
9.47\end{array}$ & $\begin{array}{r}7.18 \\
8.82 \\
10.25\end{array}$ & $\begin{array}{l}4.08 \\
7.05 \\
8.89\end{array}$ & $\begin{array}{l}7.15 \\
8.43 \\
9.81\end{array}$ & $\begin{array}{l}1.95 \\
3.84 \\
5.79\end{array}$ & $\begin{array}{l}3.03 \\
4.17 \\
5.38\end{array}$ \\
\hline
\end{tabular}



